\title{
Evaluation of Atrium Smoke Exhaust \\ Make-up Air Velocity
}

\author{
By
}

\section{Jian Zhou}

\author{
A thesis submitted to \\ the Faculty of Graduate Studies and Research \\ in partial fulfillment of the requirements for the degree of
}

\section{Master of Applied Science}

\section{Department of Civil and Environmental Engineering Carleton University, Ottawa \\ November 2006}

\author{
The Master of Applied Science in Civil Engineering \\ is a joint program with the University of Ottawa, \\ administered by the Ottawa-Carleton Institute for Civil Engineering \\ (C) Copyright 2006, \\ Jian Zhou
}




$\begin{array}{ll}\begin{array}{l}\text { Library and } \\ \text { Archives Canada }\end{array} & \begin{array}{l}\text { Bibliothèque et } \\ \text { Archives Canada }\end{array} \\ \begin{array}{l}\text { Published Heritage } \\ \text { Branch }\end{array} & \begin{array}{l}\text { Direction du } \\ \text { Patrimoine de l'édition }\end{array} \\ \begin{array}{l}\text { 395 Wellington Street } \\ \text { Ottawa ON K1A ON4 }\end{array} & \begin{array}{l}\text { 395, rue Wellington } \\ \text { Ottawa ON K1A ON4 } \\ \text { Canada }\end{array}\end{array}$

Your file Votre référence ISBN: 978-0-494-23352-8 Our file Notre référence ISBN: 978-0-494-23352-8

NOTICE:

The author has granted a nonexclusive license allowing Library and Archives Canada to reproduce, publish, archive, preserve, conserve, communicate to the public by telecommunication or on the Internet, loan, distribute and sell theses worldwide, for commercial or noncommercial purposes, in microform, paper, electronic and/or any other formats.

The author retains copyright ownership and moral rights in this thesis. Neither the thesis nor substantial extracts from it may be printed or otherwise reproduced without the author's permission.
AVIS:

L'auteur a accordé une licence non exclusive permettant à la Bibliothèque et Archives Canada de reproduire, publier, archiver, sauvegarder, conserver, transmettre au public par télécommunication ou par l'Internet, prêter, distribuer et vendre des thèses partout dans le monde, à des fins commerciales ou autres, sur support microforme, papier, électronique et/ou autres formats.

L'auteur conserve la propriété du droit d'auteur et des droits moraux qui protège cette thèse. $\mathrm{Ni}$ la thèse ni des extraits substantiels de celle-ci ne doivent être imprimés ou autrement reproduits sans son autorisation.
In compliance with the Canadian

Privacy Act some supporting forms may have been removed from this thesis.

While these forms may be included in the document page count, their removal does not represent any loss of content from the thesis.
Conformément à la loi canadienne sur la protection de la vie privée, quelques formulaires secondaires ont été enlevés de cette thèse.

Bien que ces formulaires aient inclus dans la pagination, il n'y aura aucun contenu manquant.

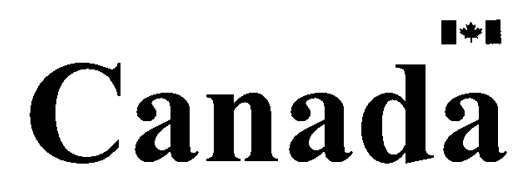




\begin{abstract}
Atria are becoming popular elements in commercial, office and residential buildings for providing attractive, environmentally controlled, naturally lit spaces. Smoke management systems often play an important role in extending the use of an atrium space or providing additional protection for occupants and property.
\end{abstract}

The rapid smoke spread through an atrium in case of fire is a major concern. Even if there are smoke barriers between the surrounding spaces and the atrium, the smoke layer may descent to a lower level, endangering occupants. Natural ventilation can be used to keep the smoke layer at high levels, but in some cases, such a system may not be effective and it is not frequently used in North America. Buildings with atrium are getting larger and they are being designed with mechanical smoke management systems.

In this study, a CFD model was used to evaluate the existing criterion for make-up air velocity and to determine if the $1 \mathrm{~m} / \mathrm{s}$ make-up air velocity limit is appropriate, or whether other values or methods are appropriate. For this, different size fires were simulated in various size atria equipped with smoke exhaust systems. The results of the analysis indicate that, the imposed velocity limit is not too restrictive. 


\section{Acknowledgements:}

I would like to take this opportunity to express my deep and sincere appreciation to my thesis supervisor Dr. George. Hadjisophocleous, for his guidance, advice, and suggestions. I am grateful to him for his great encouragement and support that made the work possible. I would also like to thank Chun, $\mathrm{L}$ and Robert, $\mathrm{K}$ who gave me a lot of help and had many discussions with me during my thesis work. 


\section{Table of Contents}

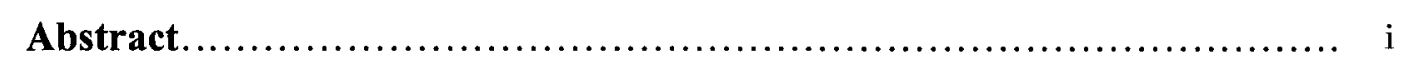

Acknowledgements............................................. ii

Table of Contents...................................................... ii

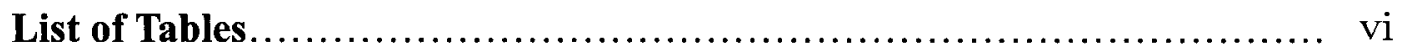

List of Figures...................................................... vii

List of Symbols................................................. xvii

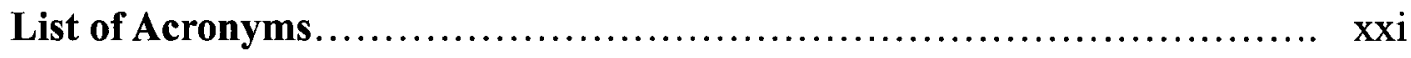

Chapter1-Introduction ........................................... 1

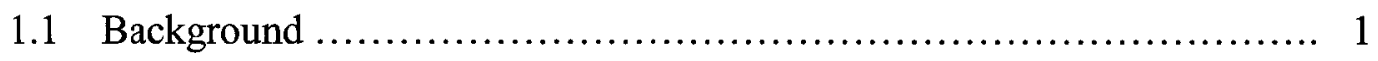

1.2 Objectives and Scope......................................... 4

1.2 .1 Objectives................................................ 5

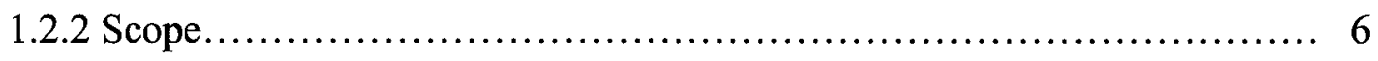

1.2.2.1 FDS Model Grid Sizes........................................ 6

1.2.2.2 Method of Fire Simulation and Fire Size....................... 7

1.2.2.3 Location of Entry Air Openings.............................. 7

1.2.2.4 Fire Location Relative to Wall Opening......................... 7

1.2.2.5 Height of Jet Plume Impact................................ 7

1.2.2.6 Velocity of Air Jet.......................................... 8

1.2.2.7 Atrium Height............................................... 8

1.3 Thesis Organization.......................................... 9 
Chapter 2 -Literature Review.

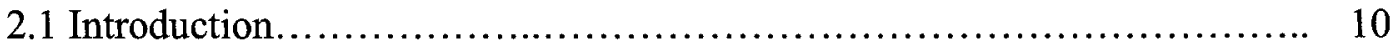

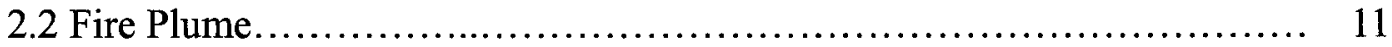

2.2.1 Effect of Wind on Flame......................................... 16

2.3 Smoke Layer Interface.......................................... 18

2.4 Smoke Management........................................... 23

2.4.1 Smoke Filling.................................................. 23

2.4.2 Natural Venting.................................................. 25

2.4.3 Mechanical Exhaust.............................................. 26

2.5 Make-Up Air.................................................... 28

2.5.1 Make-Up Air Velocity..................................... 28

Chapter 3 - Description of the Model............................. 33

3.1 CFD Modeling............................................... 33

3.2 Fire Dynamics Simulator........................................ 33

3.3 Atrium Geometry ............................................. 36

3.4 Boundary Conditions........................................... 38

Chapter 4 - Results of Numerical Simulations.......................... 39

4.1 Computational Grid............................................ 39

4.2 Results....................................................... 41

4.3 Impact of Wind on Flame......................................... 50

4.3 .1 Results.......................................................... 51

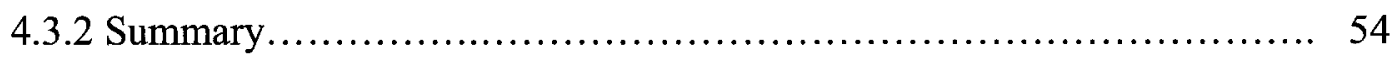


4.4 Impact of Opening Location..................................... 54

4.4 .1 Results..................................................... 56

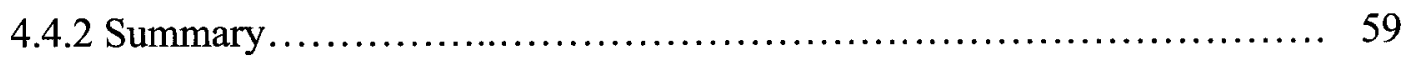

4.5 Model Validation............................................ 59

Chapter 5 - Impact of Make-Up Air Velocity .......................... 64

5.1 Results and Discussion.......................................... 66

5.1.1 Results for $10-\mathrm{m}$ Tall Atrium................................... 66

5.1.2 Results for $20-\mathrm{m}$ Tall Atrium.................................. 79

5.1 .3 Results for $30-m$ Tall Atrium................................... 88

5.1.3.1 Fire Location $5 \mathrm{~m}$ from the Opening.......................... 88

5.1.3.2 Fire Location $2.5 \mathrm{~m}$ from the Opening....................... 98

5.1.4 Results for 50-m Tall Atrium.................................... 106

5.1.4.1 Fire Location $5 \mathrm{~m}$ from the Opening......................... 106

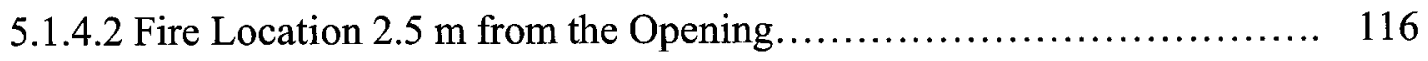

5.1 .5 Results for $60-\mathrm{m}$ Tall Atrium.................................... 126

5.1.5.1 Fire Location $5 \mathrm{~m}$ from the Opening.......................... 126

5.1.5.2 Fire Location $2.5 \mathrm{~m}$ from the Opening......................... 138

5.2 Summaries and Discussion of Results............................ 147

5.3 Summary....................................................... 156

Chapter 6 - Conclusions and Recommendations...................... 157

Chapter 7 - References .......................................... 159 


\section{List of Tables}

Table 3.1 Atria considered in this study.............................. 37

Table 4.1 FDS results of flame tilt angle compared with AGA and Thomas...... 52

Table 5.1 Parameters used for the simulations............................ 65

Table 5.2 Interface heights in $10-\mathrm{m}$ tall atrium........................... 78

Table 5.3 Interface heights in $20-\mathrm{m}$ tall atrium.......................... 87

Table 5.4 Interface heights in $30-\mathrm{m}$ tall atrium with fire $5 \mathrm{~m}$ from the opening... 97

Table 5.5 Interface heights in 30-m tall atrium with fire $2.5 \mathrm{~m}$ from the opening. 105

Table 5.6 Interface heights in 50-m tall atrium with fire $5 \mathrm{~m}$ from the opening... 115

Table 5.7 Interface heights in 50-m tall atrium with fire $2.5 \mathrm{~m}$ from the opening.. 125

Table 5.8 Interface heights in 60-m tall atrium with fire $5 \mathrm{~m}$ from the opening... 137

Table 5.9 Interface heights in 60-m tall atrium with fire $2.5 \mathrm{~m}$ from the opening.. 146

Table 5.10 The effect of make-up air velocity on interface height for the $10-\mathrm{m}$ tall atrium

Table 5.11 The effect of make-up air velocity on interface height for the $20-\mathrm{m}$ tall atrium.

Table 5.12 The effect of make-up air velocity on interface height for the $30-\mathrm{m}$ tall atrium (1).

Table 5.13 The effect of make-up air velocity on interface height for the $30-\mathrm{m}$ tall atrium (2).

Table 5.14 The effect of make-up air velocity on interface height for the $50-\mathrm{m}$ tall atrium (1).

Table 5.15 The effect of make-up air velocity on interface height for the 50-m tall 
$\operatorname{atrium}(2)$

Table 5.16 The effect of make-up air velocity on interface height for the $60-\mathrm{m}$ tall atrium (1)

Table 5.17 The effect of make-up air velocity on interface height for the $60-\mathrm{m}$ tall atrium (2) 155 


\section{List of Figures}

Figure 1.1 Intended operation of atrium smoke management with undisturbed plume

Figure 1.2 Impact of air jet disrupting the plume and exposing occupants to smoke.

Figure 2.1 Sketch of an axisymmetric plume

Figure 2.2 Flame inclination due to wind.

Figure 2.3 Clear height with steady fire.

Figure 2.4 Minimum smoke layer thickness.

Figure 2.5 Sketch of two zone model.

Figure 2.6 Natural venting in an atrium. 25

Figure 2.7 Mechanical smoke exhaust. 26

Figure 3.1 Schematic diagram of atrium 38

Figure 4.1 Coarse grid: $0.5 \mathrm{~m} \times 0.5 \mathrm{~m} \times 0.5 \mathrm{~m}$. 39

Figure 4.2 Medium grid: $0.25 \mathrm{~m} \times 0.25 \mathrm{~m} \times 0.25 \mathrm{~m}$ 40

Figure 4.3 Fine grid: $0.125 \mathrm{~m} \times 0.125 \mathrm{~m} \times 0.125 \mathrm{~m}$ 40

Figure 4.4 Locations of comparison points for grid sensitivity analysis. 41

Figure 4.5 Temperature profiles with height at the centerline of the plume (at

$$
\mathrm{X}=7.5, \mathrm{Y}=5.0) \text {. }
$$

Figure $4.6 \mathrm{CO}_{2}$ concentration profiles with height at the centerline of plume (at

$$
\mathrm{X}=7.5, \mathrm{Y}=5.0)
$$

Figure 4.7 $\mathrm{CO}$ concentration profiles with height at the centerline of plume (at 


$$
\mathrm{X}=7.5, \mathrm{Y}=5.0 \text { ) }
$$

Figure 4.8 Temperature profiles with height at $\mathrm{X}=2.5$ and $\mathrm{Y}=2.5 \ldots \ldots \ldots \ldots \ldots . . \ldots 4$

Figure 4.9 Temperature profiles with height at $X=2.5$ and $Y=7.5 \ldots \ldots \ldots \ldots \ldots .44$

Figure 4.10 Temperature profiles with height at $\mathrm{X}=7.5$ and $\mathrm{Y}=2.5 \ldots \ldots \ldots \ldots \ldots .45$

Figure 4.11 Temperature profiles with height at $\mathrm{X}=7.5$ and $\mathrm{Y}=7.5 \ldots \ldots \ldots \ldots .45$

Figure $4.12 \mathrm{CO}_{2}$ concentration profiles with height at $\mathrm{X}=2.5$ and $\mathrm{Y}=2.5 \ldots \ldots . .46$

Figure $4.13 \mathrm{CO}_{2}$ concentration profiles with height at $\mathrm{X}=2.5$ and $\mathrm{Y}=7.5 \ldots \ldots . .46$

Figure $4.14 \mathrm{CO}_{2}$ concentration profiles with height at $\mathrm{X}=7.5$ and $\mathrm{Y}=2.5 \ldots \ldots \ldots 47$

Figure $4.15 \mathrm{CO}_{2}$ concentration profiles with height at $\mathrm{X}=7.5$ and $\mathrm{Y}=7.5 \ldots \ldots .47$

Figure 4.16 CO concentration profiles with height at $\mathrm{X}=2.5$ and $\mathrm{Y}=2.5 \ldots \ldots \ldots .48$

Figure 4.17 CO concentration profiles with height at $X=2.5$ and $Y=7.5 \ldots \ldots \ldots .48$

Figure $4.18 \mathrm{CO}$ concentration profiles with height at $\mathrm{X}=7.5$ and $\mathrm{Y}=2.5 \ldots \ldots \ldots .49$

Figure $4.19 \mathrm{CO}$ concentration profiles with height at $\mathrm{X}=7.5$ and $\mathrm{Y}=7.5 \ldots \ldots \ldots .49$

Figure 4.20 Sketch of compartment for cross flow simulations............... 50

Figure 4.21 Sketch of flame inclination............................. 51

Figure 4.22 Flame tilt angle for the 0.5 -MW fire $\ldots \ldots \ldots \ldots \ldots \ldots \ldots \ldots \ldots \ldots . \ldots 2$

Figure 4.23 Flame tilt angle for the 1-MW fire........................... 53

Figure 4.24 Flame tilt angle for the $5-\mathrm{MW}$ fire........................ 53

Figure 4.25 Air supply opening at the bottom of the wall.................... 55

Figure 4.26 Air supply opening at the $2^{\text {nd }}$ piece of the wall................... 55

Figure 4.27 Air supply opening at the top of the wall..................... 56

Figure 4.28 Temperature contours on a vertical plane through the fire center, fire 
Figure 4.29 Temperature of make-up air for different opening locations. 58

Figure $4.30 \mathrm{CO}_{2}$ concentration of make-up air for different opening locations.... 59

Figure 4.31 Ceiling plan showing the exhaust inlets locations................ 60

Figure 4.32 The floor plan of the room................................. 61

Figure 4.33 Temperature rise in atrium.................................6. 62

Figure 5.1 Total and radiative HRR for the $2.5-\mathrm{MW}$ fire..................... 65

Figure 5.2 Temperature variations with time in $10-\mathrm{m}$ tall atrium............ 67

Figure 5.3 Temperature contours in 10-m tall atrium on a vertical plane through the fire center, fire size $=1 \mathrm{MW}$ 69

Figure 5.4 Temperature profiles in 10-m tall atrium with 1-MW fire. 70

Figure 5.5 $\mathrm{CO}_{2}$ Profiles in 10-m tall atrium with 1-MW fire. 70

Figure 5.6 Temperature contours in 10-m tall atrium on a vertical plane through the fire center, fire size $=2.5 \mathrm{MW}$

Figure 5.7 Temperature profiles in 10-m tall atrium with $2.5-\mathrm{MW}$ fire 73

Figure $5.8 \mathrm{CO}_{2}$ profiles in $10-\mathrm{m}$ tall atrium with $2.5-\mathrm{MW}$ fire. 73

Figure 5.9 Temperature contours in 10-m tall atrium on a vertical plane through the fire center, fire size $=5 \mathrm{MW}$ .75

Figure 5.10 Temperature profiles in 10-m tall atrium with 5-MW fire. 76

Figure 5.11 $\mathrm{CO}_{2}$ profiles in $10-\mathrm{m}$ tall atrium with 5-MW fire. 76

Figure 5.12 Temperature variations with time in $20-\mathrm{m}$ tall atrium. 79

Figure 5.13 Temperature contours in $20-\mathrm{m}$ tall atrium on a vertical plane through 
the fire center, fire size $=1 \mathrm{MW}$.

Figure 5.14 Temperature profiles in $20-\mathrm{m}$ tall atrium with 1-MW fire

Figure $5.15 \mathrm{CO}_{2}$ profiles in 20-m tall atrium with 1-MW fire.

Figure 5.16 Temperature contours in $20-\mathrm{m}$ tall atrium on a vertical plane through the fire center, fire size $=2.5 \mathrm{MW}$ 83

Figure 5.17 Temperature profiles in 20-m tall atrium with 2.5-MW fire. 84

Figure $5.18 \mathrm{CO}_{2}$ profiles in $20-\mathrm{m}$ tall atrium with $2.5-\mathrm{MW}$ fire. 84

Figure 5.19 Temperature contours $20-\mathrm{m}$ tall in atrium on a vertical plane through the fire center, fire size $=5 \mathrm{MW}$ 85

Figure 5.20 Temperature profiles in 20-m tall atrium with 5-MW fire. 86

Figure $5.21 \mathrm{CO}_{2}$ profiles in $20-\mathrm{m}$ tall atrium with 5-MW fire 86

Figure 5.22 Temperature variations with time in $30-\mathrm{m}$ tall atrium. 88

Figure 5.23 Temperature contours in $30-\mathrm{m}$ tall atrium on a vertical plane through the fire center, fire size $=1 \mathrm{MW}, 5 \mathrm{~m}$ from opening. 90

Figure 5.24 Temperature profiles in 30-m tall atrium with 1-MW fire, $5 \mathrm{~m}$ from opening. 91

Figure $5.25 \mathrm{CO}_{2}$ profiles in $30-\mathrm{m}$ tall atrium with 1-MW fire, $5 \mathrm{~m}$ from opening. 91

Figure 5.26 Temperature contours in $30-\mathrm{m}$ tall atrium on a vertical plane through the fire center, fire size $=2.5 \mathrm{MW}, 5 \mathrm{~m}$ from opening. 92

Figure 5.27 Temperature profiles in $30-\mathrm{m}$ tall atrium with $2.5-\mathrm{MW}$ fire, $5 \mathrm{~m}$ from opening 93 
Figure $5.28 \mathrm{CO}_{2}$ profiles in $30-\mathrm{m}$ tall atrium with $2.5-\mathrm{MW}$ fire, $5 \mathrm{~m}$ from

opening.

Figure 5.29 Temperature contours in $30-\mathrm{m}$ tall atrium on a vertical plane through

the fire center, fire size $=5 \mathrm{MW}, 5 \mathrm{~m}$ from opening

Figure 5.30 Temperature profiles in 30-m tall atrium with 5-MW fire, $5 \mathrm{~m}$ from opening. 96

Figure 5.31 $\mathrm{CO}_{2}$ profiles in 30-m tall atrium with 5-MW fire, $5 \mathrm{~m}$ from opening. 96

Figure 5.32 Temperature contours in 30-m tall atrium on a vertical plane through the fire center, fire size $=1 \mathrm{MW}, 2.5 \mathrm{~m}$ from opening. 99

Figure 5.33 Temperature profiles in 30-m tall atrium with 1-MW fire, $2.5 \mathrm{~m}$ from opening. 100

Figure $5.34 \mathrm{CO}_{2}$ profiles in $30-\mathrm{m}$ tall atrium with $1-\mathrm{MW}$ fire, $2.5 \mathrm{~m}$ from opening 100

Figure 5.35 Temperature contours in 30-m tall atrium on a vertical plane through the fire center, fire size $=2.5 \mathrm{MW}, 2.5 \mathrm{~m}$ from opening 101

Figure 5.36 Temperature profiles in 30-m tall atrium with $2.5-\mathrm{MW}$ fire, $2.5 \mathrm{~m}$ from opening. 102

Figure $5.37 \mathrm{CO}_{2}$ profiles in $30-\mathrm{m}$ tall atrium with $2.5-\mathrm{MW}$ fire, $2.5 \mathrm{~m}$ from opening. 102

Figure 5.38 Temperature contours in $30-\mathrm{m}$ tall atrium on a vertical plane through the fire center, fire size $=5 \mathrm{MW}, 2.5 \mathrm{~m}$ from opening 103 
Figure 5.39 Temperature profiles inn 30-m tall atrium with 5-MW fire, $2.5 \mathrm{~m}$ from opening. 104

Figure $5.40 \mathrm{CO}_{2}$ profiles in $30-\mathrm{m}$ tall atrium with $5-\mathrm{MW}$ fire, $2.5 \mathrm{~m}$ from opening 104

Figure 5.41 Temperature variations with time in $50-\mathrm{m}$ tall atrium. 106

Figure 5.42 Temperature contours in $50-\mathrm{m}$ tall atrium on a vertical plane through the fire center, fire size $=1 \mathrm{MW}, 5 \mathrm{~m}$ from opening 108

Figure 5.43 Temperature profiles in 50-m tall atrium with 1-MW fire, $5 \mathrm{~m}$ from opening. 109

Figure 5.44 $\mathrm{CO}_{2}$ profiles in 50-m high atrium with 1-MW fire, $5 \mathrm{~m}$ from opening. 109

Figure 5.45 Temperature contours in 50-m tall atrium on a vertical plane through the fire center, fire size $=2.5 \mathrm{MW}, 5 \mathrm{~m}$ from opening.

Figure 5.46 Temperature profiles in 50-m tall atrium with $2.5-\mathrm{MW}$ fire, $5 \mathrm{~m}$ from opening

Figure $5.47 \mathrm{CO}_{2}$ profiles in $50-\mathrm{m}$ tall atrium with $2.5-\mathrm{MW}$ fire, $5 \mathrm{~m}$ from opening.

Figure 5.48 Temperature contours in $50-\mathrm{m}$ tall atrium on a vertical plane through the fire center, fire size $=5 \mathrm{MW}, 5 \mathrm{~m}$ from opening.

Figure 5.49 Temperature profiles in 50-m tall atrium with 5-MW fire, $5 \mathrm{~m}$ from opening 
Figure $5.50 \mathrm{CO}_{2}$ profiles in $50-\mathrm{m}$ tall atrium with $5-\mathrm{MW}$ fire, $5 \mathrm{~m}$ from

opening.

Figure 5.51 Temperature contours in 50-m tall atrium on a vertical plane through

the fire center, fire size $=1 \mathrm{MW}, 2.5 \mathrm{~m}$ from opening.

Figure 5.52 Temperature profiles in 50-m tall atrium with 1-MW fire, $2.5 \mathrm{~m}$ from

opening.

Figure $5.53 \mathrm{CO}_{2}$ profiles in 50-m tall atrium with 1-MW fire, $2.5 \mathrm{~m}$ from

opening.

Figure 5.54 Temperature contours in 50-m tall atrium on a vertical plane through the fire center, fire size $=2.5 \mathrm{MW}, 2.5 \mathrm{~m}$ from opening

Figure 5.55 Temperature profiles in 50-m tall atrium with $2.5-\mathrm{MW}$ fire, $2.5 \mathrm{~m}$ from

opening.

Figure 5.56 $\mathrm{CO}_{2}$ profiles in $50-\mathrm{m}$ tall atrium with $2.5-\mathrm{MW}$ fire, $2.5 \mathrm{~m}$ from opening.

Figure 5.57 Temperature contours in 50-m tall atrium on a vertical plane through the fire center, fire size $=5 \mathrm{MW}, 2.5 \mathrm{~m}$ from opening.

Figure 5.58 Temperature profiles in 50-m tall atrium with 5-MW fire, $2.5 \mathrm{~m}$ from opening.

Figure $5.59 \mathrm{CO}_{2}$ profiles in $50-\mathrm{m}$ tall atrium with $5-\mathrm{MW}$ fire, $2.5 \mathrm{~m}$ from opening.

Figure 5.60 Temperature variations with time in $60-\mathrm{m}$ tall atrium. 126 
Figure 5.61 Temperature contours in $60-\mathrm{m}$ tall atrium on a vertical plane through the fire center, fire size $=1 \mathrm{MW}, 5 \mathrm{~m}$ from opening.

Figure 5.62 Temperature profiles in 60-m tall atrium with 1-MW fire, $5 \mathrm{~m}$ from opening.

Figure $5.63 \mathrm{CO}_{2}$ profiles in $60-\mathrm{m}$ tall atrium with $1-\mathrm{MW}$ fire, $5 \mathrm{~m}$ from opening.

Figure 5.64 Temperature contours in $60-\mathrm{m}$ tall atrium on a vertical plane through the fire center, fire size $=2.5 \mathrm{MW}, 5 \mathrm{~m}$ from opening.

Figure 5.65 Temperature profiles in 60-m tall atrium with $2.5-\mathrm{MW}$ fire, $5 \mathrm{~m}$ from opening.

Figure 5.66 $\mathrm{CO}_{2}$ profiles in $60-\mathrm{m}$ tall atrium with $2.5-\mathrm{MW}$ fire, $5 \mathrm{~m}$ from opening

Figure 5.67 Temperature contours in $60-\mathrm{m}$ tall atrium on a vertical plane through the fire center, fire size $=5 \mathrm{MW}, 5 \mathrm{~m}$ from opening

Figure 5.68 Temperature profiles in 60-m tall atrium with 5-MW fire, $5 \mathrm{~m}$ from opening.

Figure $5.69 \mathrm{CO}_{2}$ profiles in $60-\mathrm{m}$ tall atrium with 5-MW fire, $5 \mathrm{~m}$ from opening

Figure 5.70 Temperature contours in $60-\mathrm{m}$ tall atrium on a vertical plane through the fire center, fire size $=1 \mathrm{MW}, 2.5 \mathrm{~m}$ from opening

Figure 5.71 Temperature profiles in 60-m tall atrium with 1-MW fire, $2.5 \mathrm{~m}$ from opening. 
Figure $5.72 \mathrm{CO}_{2}$ profiles in $60-\mathrm{m}$ tall atrium with $1-\mathrm{MW}$ fire, $2.5 \mathrm{~m}$ from

$$
\text { opening...... }
$$

Figure 5.73 Temperature contours in $60-\mathrm{m}$ tall atrium on a vertical plane through

$$
\text { the fire center, fire size }=2.5 \mathrm{MW}, 2.5 \mathrm{~m} \text { from opening. }
$$

Figure 5.74 Temperature profiles in $60-\mathrm{m}$ tall atrium with $2.5-\mathrm{MW}$ fire, $2.5 \mathrm{~m}$ from opening

Figure $5.75 \mathrm{CO}_{2}$ profiles in $60-\mathrm{m}$ tall atrium with $2.5-\mathrm{MW}$ fire, $2.5 \mathrm{~m}$ from opening 142

Figure 5.76 Temperature contours in $60-\mathrm{m}$ tall atrium on a vertical plane through the fire center, fire size $=5 \mathrm{MW}, 2.5 \mathrm{~m}$ from opening 143

Figure 5.77 Temperature profiles in 60-m tall atrium with 5-MW fire, $2.5 \mathrm{~m}$ from opening.

Figure $5.78 \mathrm{CO}_{2}$ profiles in $60-\mathrm{m}$ tall atrium with $5-\mathrm{MW}$ fire, $2.5 \mathrm{~m}$ from opening.

Figure 5.79 Normalized interface height of the $10-\mathrm{m}$ tall atrium. 148

Figure 5.80 Normalized interface height of the $20-\mathrm{m}$ tall atrium. 149

Figure 5.81 Normalized interface height of $30-\mathrm{m}$ tall atrium with fire $5 \mathrm{~m}$ from the opening. 150

Figure 5.82 Normalized interface height of $30-\mathrm{m}$ tall atrium with fire $2.5 \mathrm{~m}$ from the opening.

Figure 5.83 Normalized interface height of $50-\mathrm{m}$ tall atrium with fire $5 \mathrm{~m}$ from the opening 
Figure 5.84 Normalized interface height of 50-m tall atrium with fire $2.5 \mathrm{~m}$ from the opening ...................................................... 153

Figure 5.85 Normalized interface height of $60-\mathrm{m}$ tall atrium with fire $5 \mathrm{~m}$ from the opening........................................................ 154

Figure 5.86 Normalized interface height of $60-\mathrm{m}$ tall atrium with fire $2.5 \mathrm{~m}$ from

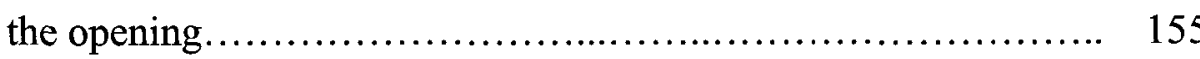




\section{List of Symbols}

A

Av

C

$\mathrm{C}_{\mathrm{n}}$

D

$D$

$D_{i}$

F

g

$\mathrm{H}$

Ho

$\mathrm{Hv}$

$h$

$h_{i}$

$k$

$\dot{m}_{i}^{\prime \prime \prime}$

$\mathrm{m}^{\prime \prime}$

$\mathrm{m}_{\mathrm{e}}$

$\mathrm{m}_{\mathrm{p}}$

$m_{p p}$

$m_{p, \text { corner (in) }}$

$m_{p, \text { corner(out) }}$
Floor area, $\mathrm{m}^{2}$

Area of venting, $\mathrm{m}^{2}$

Vent coefficient 0.6

Interpolation constant typically in the range of 0.15 to 0.2

Diameter of fire, $m$

Material diffusivity

Diffusion of $i$ th species

Fuel

Acceleration due to gravity $\left(9.8 \mathrm{~m} / \mathrm{s}^{2}\right)$

The atrium height, $\mathrm{m}$

Height of opening, $\mathrm{m}$

The flame height, $\mathrm{m}$

Enthalpy

Enthalpy of $i$ th species

Thermal conductivity

Production rate of $i_{\text {th species per unit volume }}$

Mass flow rate per area, $\mathrm{g} /\left(\mathrm{s} \mathrm{m}^{2}\right)$

Mass flow rate of exhaust smoke, $\mathrm{kg} / \mathrm{s}$

Upward mass flow rate of plume, $\mathrm{kg} / \mathrm{s}$

Plume mass flow rate, $\mathrm{kg} / \mathrm{s}$

Mass flow rate of an inside corner plume, $\mathrm{kg} / \mathrm{s}$

Mass flow rate of an exterior corner plume, $\mathrm{kg} / \mathrm{s}$

xviii 


\begin{tabular}{|c|c|}
\hline$m_{p, \text { wall }}$ & Mass flow rate of a wall plume, $\mathrm{kg} / \mathrm{s}$ \\
\hline $\mathrm{m}_{\mathrm{v}}$ & Mass flow rate through vent, $\mathrm{kg} / \mathrm{s}$ \\
\hline$m_{p}(Z)$ & Theoretical flow rate at the interface height $\mathrm{Z}$ predicted by FDS, $\mathrm{kg} / \mathrm{s}$ \\
\hline$M_{O}$ & Oxygen molecular weight \\
\hline$M_{F}$ & Fuel molecular weight \\
\hline $\mathrm{O}$ & Oxygen \\
\hline$P_{s}$ & Pressure of smoke layer at the ceiling, $\mathrm{kPa}$ \\
\hline$P_{o}$ & Outside pressure, $\mathrm{kPa}$ \\
\hline Q & Total heat release rate, $\mathrm{kW}$ \\
\hline$Q_{c}$ & Convective heat release rate, $\mathrm{kW}(0.6 \sim 0.7 \mathrm{Q})$ \\
\hline$Q_{r}$ & Radiative heat release rate, $\mathrm{kW}$ \\
\hline$q_{r}$ & Radiative heat flux vector \\
\hline$T_{a}$ & Ambient temperature, $\mathrm{K}$ \\
\hline $\mathrm{T}_{\mathrm{b}}$ & The temperature near the bottom of the compartment, $\mathrm{K}$ \\
\hline $\mathrm{T}_{\max }$ & The maximum temperature of the compartment, $\mathrm{K}$ \\
\hline $\mathrm{T}_{\mathrm{o}}$ & Centerline temperature, $\mathrm{K}$ \\
\hline $\mathrm{t}$ & Time from ignition, $\mathrm{s}$ \\
\hline $\mathrm{u}$ & Wind velocity, $\mathrm{m} / \mathrm{s}$ \\
\hline $\mathbf{u}=(\mathbf{u}, \mathrm{v}, \mathrm{w})$ & Velocity vector \\
\hline$V_{\text {in }}$ & Make-up air velocity, $\mathrm{m} / \mathrm{s}$ \\
\hline$V_{e}$ & Exhaust velocity, $\mathrm{m} / \mathrm{s}$ \\
\hline$v_{O}$ & stoichiometric coefficients \\
\hline
\end{tabular}




\begin{tabular}{|c|c|}
\hline$v_{F}$ & Fuel stoichiometric coefficients \\
\hline W & The width of opening, $\mathrm{m}$ \\
\hline $\mathrm{X}$ & $\mathrm{X}$ component \\
\hline $\mathrm{Y}$ & Y component \\
\hline$Y$ & Mass fraction \\
\hline$Y_{i}$ & Mass fraction of $i$ th species \\
\hline$Y_{O}^{\infty}$ & Ambient oxygen mass fraction \\
\hline$Y_{F}^{I}$ & Fuel mass fraction in the fuel stream \\
\hline Z & Interface height above the fuel, $\mathrm{m}$ \\
\hline$Z_{1}$ & Mean flame height, $\mathrm{m}$ \\
\hline$Z_{o}$ & Virtual origin height, $\mathrm{m}$ \\
\hline$\rho_{\alpha}$ & Air density, $\mathrm{kg} / \mathrm{m}^{3}$ \\
\hline$\rho$ & Gas density, $\mathrm{kg} / \mathrm{m}^{3}$ \\
\hline$\rho_{\mathrm{g}}$ & Density of hot gases, $\mathrm{kg} / \mathrm{m}^{3}$ \\
\hline$\beta$ & The flame tilt angle \\
\hline
\end{tabular}




\section{List of Acronyms}

AGA American Gas Association

CFD Computational Fluid Dynamics

FDS Fire Dynamics Simulator

HRRPUA Heat Release Rate Per Unit Area Feature of FDS

HVAC Heating, Ventilating and Air-Conditioning

NFPA Nation Fire Protection Association

SFPE $\quad$ Safety Fire Protection Engineering 


\section{Chapter 1}

\section{Introduction}

\subsection{Background}

In North America, the atrium has become a commonplace for providing an attractive and comfortable environment in buildings such as luxurious hotels, multi-level shopping centers and prestigious commercial buildings. Most atria have a large undivided space, designed for creating visual and spatial appeal. One of the concerns associated with atria is fire safety; when a fire occurs in an atrium, smoke can fill the atrium and the connected floors rapidly.

An atrium within a building is a large open space created by an opening or series of openings in floor assemblies, thus connecting two or more floors of the building. The roof of the atrium is closed, and the sides may be opened to all floors, to some of the floors or closed to all or some of the floors by fire-resistant construction. There may be two or more atria within a single building, all interconnected at the ground floor or on a number of floors.

By interconnecting floor spaces, an atrium violates the concept of floor-to-floor compartmentation, which is intended to limit the spread of fire and smoke from the floor of fire origin to other floors of the building. With a fire on the floor of an atrium or in any space open to it, smoke can fill the atrium and connected floor spaces. 
Protecting the occupants of a building from the adverse effects of smoke in the event of a fire is a primary objective of any fire protection system design. Building codes introduce special requirements for atrium spaces in buildings, such as:

$>$ Installing automatic sprinklers throughout the building.

$>$ Limiting combustible materials on the floor of an atrium.

$>$ Providing tenable conditions in egress routes by installing mechanical exhaust systems.

Design requirements for smoke exhaust systems are provided by NFPA 92B [1] and Klote and Milke (1992) [2]. The intended operation of atrium smoke management systems depends on the formation of a plume above the fire to take the smoke upward as illustrated in Figure 1.1. Current design requirements set a maximum make-up air velocity of $1 \mathrm{~m} / \mathrm{s}$ to prevent distuption of the plume. This is contained in the ASHRAE/SFPE publication, Principles of Smoke Management [3] and the National Fire Protection Association (NFPA) publication, Guide for Smoke Management Systems in Malls, Atria, and Other Large Spaces, NFPA 92B [1]. Figure 1.2 illustrates a high make-up air velocity causing plume disruption, filling much of the atrium with smoke, and exposing occupants to smoke.

According to NFPA 92B [1], the $1 \mathrm{~m} / \mathrm{s}$ criterion is based on limited research into the effect of wind on flames. The work is cited in the SFPE Handbook of Fire Protection Engineering [4] [5]. Many designers have stated that meeting the $1 \mathrm{~m} / \mathrm{s}$ requirement is 
often costly and presents a hardship. For example: when the atrium is $50-\mathrm{m}$ tall and the fire size is $1 \mathrm{MW}$, the mass flow rate of the smoke exhaust should be $288.91 \mathrm{~kg} / \mathrm{s}$. With a make-up air velocity of $1 \mathrm{~m} / \mathrm{s}$, the area of the opening providing this air should be $347 \mathrm{~m}^{2}$. If this opening is put at ground level, and assuming a height of the opening of $3 \mathrm{~m}$, the length of the opening should be $115 \mathrm{~m}$. For many buildings such opening may not be possible. There is, therefore a need to investigate this criterion to determine whether is too conservative.

This project investigated the impact of make-up air velocity on the fire plume and the interface height through the use of CFD models, and studied the mechanisms involved.

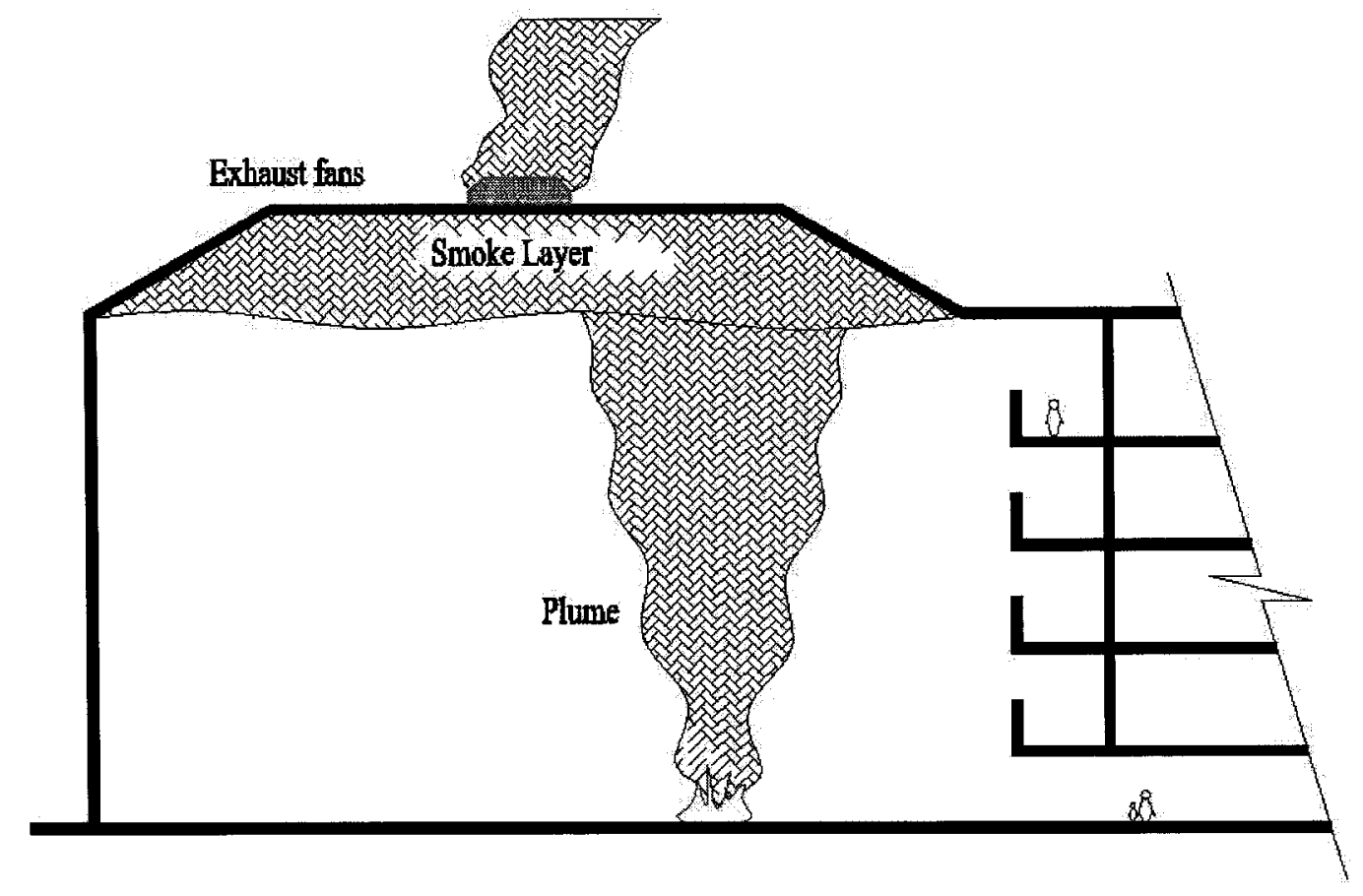

Figure 1.1 Intended operation of atrium smoke management with undisturbed plume 


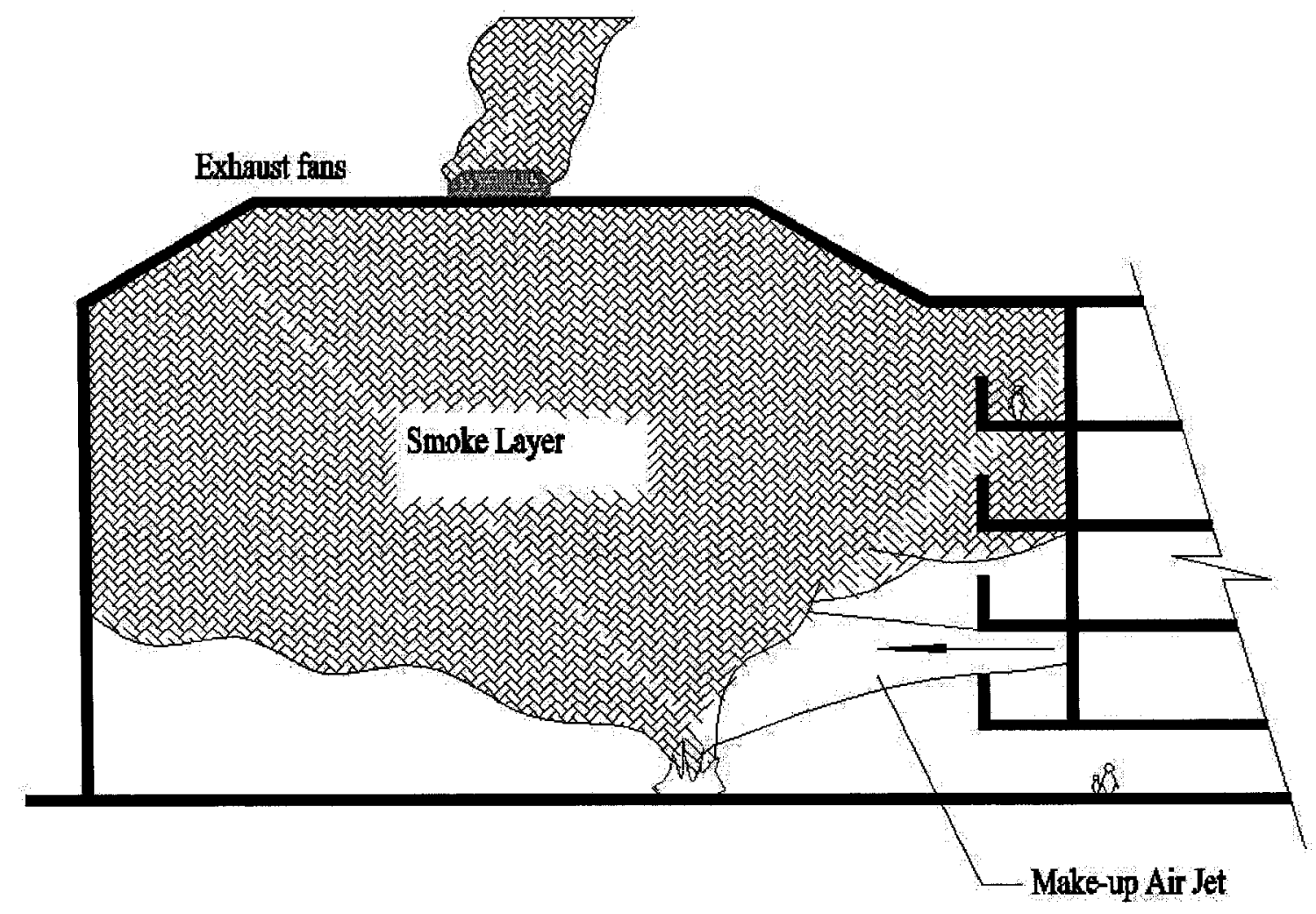

Figure 1.2 Impact of air jet disrupting the plume and exposing occupants to smoke

\subsection{Objectives and Scope}

The approach described in codes is based on maintaining the smoke layer interface at a specified distance above the highest walking surface in an atrium. The associated smoke exhaust capacity required to provide a large clear height could be substantial. Further, designers are also concerned about providing the necessary make-up air, especially given the requirement of a maximum velocity for the make-up air of $1 \mathrm{~m} / \mathrm{s}$. In tall atria, because of the substantial clear height, air being entrained into the plume dilutes and decreases the hazard posed by smoke. Consequently, the high capacity exhaust fans may be removing smoke that poses relatively little threat to building occupants, indicating a design, which is not cost-effective. 
The effectiveness of an atrium smoke management system may be affected by obstructions in the smoke plume (Hansell and Morgan [6]) or the presence of a preexisting stratification layer in the atrium (Hinckley [7]). In the former case, smoke may be directed to adjacent spaces or mixed with the air within the zone in which tenable conditions are required. In the latter case, smoke produced by the fire may not reach the ceiling where it could be exhausted by a smoke management system. Also, in this case, smoke buildup could occur at a height at which it can migrate into the communicating spaces.

Under some conditions, another phenomenon called plugholing in which air from the lower layer can mix with the smoke in the upper layer as it is being exhausted by the smoke management system may exist, which may impact on the effectiveness of a smoke management system. This reduces the clear height in the atrium and may expose people to smoke and toxic gases.

\subsubsection{Objectives}

In this study, a computational fluid dynamics (CFD) model was used to evaluate the impact of make-up air velocity on the effectiveness of an atrium smoke exhaust system to determine whether the current restriction of $1 \mathrm{~m} / \mathrm{s}$ is justified. Comparisons of results of different fire scenarios are presented in order to explain the mechanisms of smoke flow in atria when an air jet impacts the smoke plume. 


\subsubsection{Scope}

The project involved computer modeling using the Fire Dynamics Simulator (FDS) [8], [9]. Simulations were conducted to determine the effect of air jet interaction on smoke plumes and the performance of atrium smoke exhaust systems where there is such interaction. The following simulation parameters were considered:

$>$ Grid sizes

$>$ Method of fire simulation and fire size

$>$ Location of opening

$>$ Fire location relative to opening

Height of jet-plume impact

Velocity of air jet

Atrium height

\subsubsection{FDS Model Grid Sizes}

The Fire Dynamics Simulator (FDS) [8], [9] developed by NIST is the computer model that was used for this study. In order to establish a grid that ensured a grid independent solution, simulations using different grid sizes were conducted to find the most effective grid size. Guidance on this was provided by Hadjisophocleous and McCartney [10]. 


\subsubsection{Method of Fire Simulation and Fire Size}

In this study, the fire was modeled using the mixture fraction model of FDS [9]. The fire size ranged from 1 to $5 \mathrm{MW}$, which covers most of the expected fires in atria.

\subsubsection{Location of Entry Air Openings}

The openings providing make-up air to the atrium can be located on any side of the atrium. It was found in Souza and Milke [11] that the most severe case is the case of the openings located on one side of the atrium, as the flow of air towards the fire comes from one direction. This is the location used in this study.

\subsubsection{Fire Location Relative to Wall Opening}

The fire can be located anywhere in the atrium, however the probability that the fire plume is disrupted by the make-up air increases as the fire moves closer to the opening. The following locations were used for these simulations: fire at $2.5 \mathrm{~m}, 3.5 \mathrm{~m}$, and $5.0 \mathrm{~m}$ from the opening.

\subsubsection{Height of Jet Plume Impact}

The higher the location of the opening is from the fire elevation the more likely the plume will be disrupted as the buoyancy forces and plume momentum decrease with height. Simulations were done to study the impact of the opening on the plume. 


\subsubsection{Velocity of Air Jet}

The velocity of the intake air is the main parameter of the investigation. As stated earlier, a velocity of less than $1 \mathrm{~m} / \mathrm{s}$ is currently required. The proposed simulations consider velocities ranging from 0.5 to $1.5 \mathrm{~m} / \mathrm{s}$. For a given atrium height, the required velocity values were obtained by changing the area of the make-up air openings.

\subsubsection{Atrium Height}

Atrium height is one of the most important parameters affecting the smoke exhaust flow rate. This can be seen in correlations of the mass flow rate at the plume in which the height of the plume is raised to the power of $5 / 3$, while the fire size is raised to the power of $1 / 3$. The higher the smoke layer the larger the amount of make-up air required. For this study, atrium heights ranging from $10 \mathrm{~m}$ to $60 \mathrm{~m}$ were considered. The floor area of the atrium had to be increased with an increase in height to accommodate the increased diameter of the plume with height, which for example at $60 \mathrm{~m}$ is expected to be between $17 \mathrm{~m}$ and $30 \mathrm{~m}$. 


\subsection{Thesis Organization}

The organization of the remaining chapters is briefly outlined as follows:

Chapter 2 contains a comprehensive review of previous research related to fire models, smoke management and fire plumes.

$>$ Chapter 3 provides a description of the computational model used in the study, including selection of fire modeling, computational grid size, airflow model and heat transfer.

$>$ Chapter 4 discusses the results of the grid sensitivity analysis that was conducted and presents the impact of fire geometry on the fire plume. A comparison of predicted results with experimental data is also presented in this chapter.

Chapter 5 presents the results of simulations performed to study the impact of different air flow locations on the fire plume and compares the predicted results of hot gas temperature, $\mathrm{CO}_{2}$ concentration and smoke obscuration for different make-up air velocities in an effort to investigate whether the criterion that the make-up air velocity may not exceed $1 \mathrm{~m} / \mathrm{s}$ is appropriate.

Finally, Chapter 6 provides a brief summary of this thesis, and presents the main conclusions and recommendations. 


\section{Chapter 2}

\section{Literature Review}

\subsection{Introduction}

There are a number of investigations on smoke management in atria that focus on smoke filling, natural venting and mechanical exhaust issues. This chapter will review existing models and previous work addressing the problem of smoke management systems and smoke plumes.

NFPA 92B [1] provides a definition for smoke as follows: "smoke consists of the airborne solid and liquid particulates and gases evolved when a material undergoes pyrolysis or combustion, together with the quantity of air that is entrained or mixed into the mass". When smoke moves through a building, air mixes into the smoke gas reducing the temperature and the concentration of combustion products.

Generally, smoke is recognized as the major killer in a fire because it often migrates quickly to building locations remote from the fire space, exposing occupants to toxic gases, heat and thermal radiation, and reduced visibility [3]. The reduction in visibility is a major threat in atrium fires as it affects occupants who are not located in the fire area and can cause disorientation. 


\subsection{Fire Plume}

Practically all fires go through an initial stage where a buoyant gas stream rises above a localized area undergoing combustion into the surrounding space of essentially uncontaminated air. This stage begins at ignition, continues through a possible smoldering interval, into a flaming interval and may end when the surrounding space flashes over. The buoyant flow, including any flames, is referred to as a fire plume.

Heskestead [12] discussed how volatiles driven off from the combustible material, by heat fed back from the fire, mix with the surrounding air and form a "diffusion flame". Surrounding the flame and extending upward is a boundary which confines the entire buoyant flow of combustion products and entrained air. Due to the density difference, the hotter and less dense mass rises upwards. As the hot gases rise, cold air is entrained into the plume. As listed below, Klote and Milke [3] recognized five types of plumes:

\section{Axisymmetric Plume}

The buoyant axisymmetric plume is the most commonly used plume in fire safety engineering. An axis of symmetry is assumed to exist along the vertical centerline of the plume, and air is entrained horizontally from all directions along the height. The equation describing the rate of upward mass flow of the plume is written in Eq 2-1. 


$$
\mathrm{m}_{\mathrm{p}}=0.07 \mathrm{Q}_{\mathrm{c}}{ }^{1 / 3} \mathrm{Z}^{5 / 3}+0.0018 \mathrm{Q}_{\mathrm{c}} \quad \text { for } \mathrm{Z} \geq \mathrm{Z}_{1} \quad \mathrm{Eq} 2-1
$$

Where:

$\mathrm{m}_{\mathrm{p}}=$ Upward mass flow rate of plume, $\mathrm{kg} / \mathrm{s}$

$\mathrm{Q}_{\mathrm{c}} \quad=$ Convective heat release rate, $\mathrm{kW}(0.6 \sim 0.7 \mathrm{Q})$

$\mathrm{Q} \quad=$ Heat release rate, $\mathrm{kW}$

$\mathrm{Z} \quad=$ Height above fuel, $\mathrm{m}$

$\mathrm{Z}_{1} \quad=$ Mean flame height, $\mathrm{m}\left(\mathrm{Z}_{1}=0.166 \mathrm{Q}_{\mathrm{c}}{ }^{2 / 5}\right)$

\section{Wall Plume}

When the fire source is located very close to a wall, air is mainly entrained along the side opposite to the wall. Air entrainment into the plume is thereby cut in half. According to Zukoski [13], the plume mass flow rate can be calculated to be half of the plume mass flow of a fire with twice the heat release rate. The simple Zukoski plume mass flow equation is:

$$
m_{p, \text { wall }}=\frac{1}{2} 0.07\left(2 Q_{c}\right)^{1 / 3} Z^{5 / 3}
$$

Where:

$m_{p, \text { wall }}=$ Mass flow rate of a wall plume, $\mathrm{kg} / \mathrm{s}$

$Q_{c} \quad=$ Convective heat release rate, $\mathrm{kW}$

$\mathrm{Z} \quad=$ Height above fuel, $\mathrm{m}$ 


\section{Corner Plume}

When the fire source is placed near an inside corner, air entrainment into the plume is cut to one quarter. In other words, the entrainment rate can be approximated as one quarter of that of an axisymmetric plume. Similarly, the plume mass flow is roughly one quarter of the flow with four times the heat release rate. Zukoski's [13] plume mass flow equation is:

$$
m_{p, \text { corner }(\text { in })}=\frac{1}{4} 0.07\left(4 Q_{c}\right)^{1 / 3} Z^{5 / 3}
$$

Where:

$$
\begin{array}{ll}
m_{p, \text { corner }(\text { in })} & =\text { Mass flow rate of an inside corner plume, } \mathrm{kg} / \mathrm{s} \\
Q_{c} & =\text { Convective heat release rate, } \mathrm{kW} \\
\mathrm{Z} & =\text { Height above fuel, } \mathrm{m}
\end{array}
$$

When the fire source is at an exterior corner, the plume mass flow is three quarter of the flow with four-thirds times the heat release rate. The plume mass flow equation shows in Eq 2-4.

$$
m_{p, \text { corner }(\text { out })}=\frac{3}{4} 0.07\left(\frac{4}{3} Q_{c}\right)^{1 / 3} Z^{5 / 3}
$$

Where:

$$
\begin{array}{ll}
m_{p, \text { corner(out })} & =\text { Mass flow rate of an exterior corner plume, } \mathrm{kg} / \mathrm{s} \\
Q_{c} & =\text { Convective heat release rate, } \mathrm{kW} \\
\mathrm{Z} & =\text { Height above fuel, } \mathrm{m}
\end{array}
$$




\section{Balcony Spill Plume}

A balcony spill plume refers to the vertical plume generated from a horizontally moving smoke layer under a balcony when it reaches the end of the balcony. A balcony spill plume originates from a fire when the smoke flows under a balcony and spills into the atrium [3].

\section{Window Plume}

A window plume is established when smoke moves out from the room of origin and enters into the adjacent atrium through an opening. NFPA 92B [1] identifies the window plume after flashover, and for ventilation controlled conditions.

The type of plume that is considered for this study is the axisymmetric plume, as it is the one most commonly used for atrium applications. Figure 2.1 shows the axisymmetric plume.

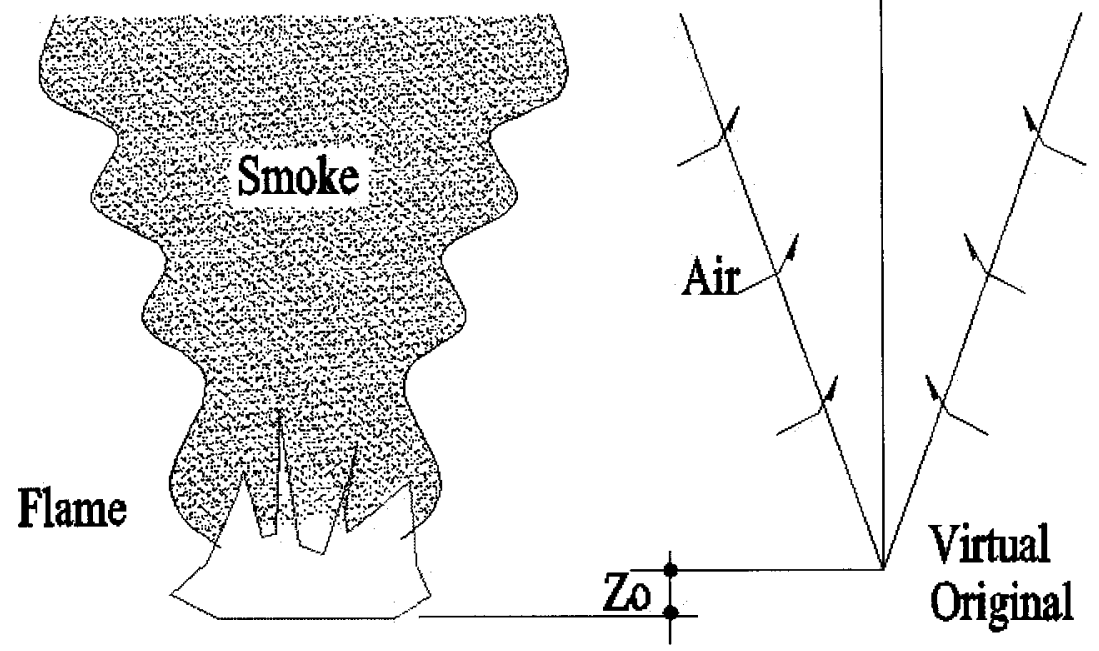

Figure 2.1 Sketch of an axisymmetric plume 
Several correlations for the mass flow rate, maximum temperature and flame height of an axisymmetric plume have been developed and they are useful in characterizing the fire plume.

Research conducted by Heskestad [14] on plumes and the plume correlations developed became the basis of many codes and standards in North America. These equations are used in this study. For atrium applications, the virtual origin can be neglected because the height of the interface is much greater than the virtual origin height (Zo: as shown in Figure 2.1).

Maximum Temperature: When a fire occurs in an atrium, the temperature of the plume varies with height. The centerline temperature is the greatest temperature of the plume [14] at any height. The simplified equation of maximum temperature at the centerline is shown below:

$$
\mathrm{T}_{\mathrm{o}}=25 \frac{\mathrm{Q}_{\mathrm{c}}{ }^{2 / 3}}{\mathrm{Z}^{5 / 3}}+\mathrm{T}_{\mathrm{a}}
$$

Where:

$\mathrm{T}_{\mathrm{o}} \quad=$ Centerline temperature, $\mathrm{K}$

$\mathrm{T}_{\mathrm{a}} \quad=$ Ambient temperature, $\mathrm{K}$

$\mathrm{Q}_{\mathrm{c}} \quad=$ Convective heat release rate, $\mathrm{kW}$

$\mathrm{Z} \quad=$ Interface height above the fuel, $\mathrm{m}$ 
Flame Height: The flame height of a fire depends on the fire geometry, ambient conditions, and convective heat. Calculation of the mean flame height can be computed using:

$$
\mathrm{Z}_{1}=0.166 \mathrm{Q}_{\mathrm{c}}^{2 / 5}
$$

Where:

$\mathrm{Z}_{1} \quad=$ Mean flame height, $\mathrm{m}$

$\mathrm{Q}_{\mathrm{c}} \quad=$ Convective heat release rate, $\mathrm{kW}$

Mass Flow Rate: The mass flow rate of an axisymmetric plume is given below:

$$
\mathrm{m}_{\mathrm{p}}=0.07 \mathrm{Q}_{\mathrm{c}}^{1 / 3} \mathrm{Z}^{5 / 3}+0.0018 \mathrm{Q}_{\mathrm{c}} \quad \text { for } \mathrm{Z} \geq \mathrm{Z}_{1} \quad \mathrm{Eq} 2-7
$$

And when the height $\mathrm{Z}$ is lower than the flame height, the following equation is used:

$$
m_{p}=0.032 Q_{c}^{3 / 5} Z \quad \text { for } \mathrm{Z}<\mathrm{Z}_{1} \quad \mathrm{Eq} 2-8
$$

Where:

$\mathrm{m}_{\mathrm{p}} \quad=$ Mass flow rate of plume entering the hot layer, $\mathrm{kg} / \mathrm{s}$

$\mathrm{Q}_{\mathrm{c}} \quad=$ Convective heat release rate, $\mathrm{kW}(0.6 \sim 0.7 \mathrm{Q})$

$\mathrm{Q} \quad=$ Total heat release rate, $\mathrm{kW}$

$\mathrm{Z} \quad=$ Interface height above the fuel, $\mathrm{m}$

$\mathrm{Z}_{\mathrm{l}} \quad=$ Mean flame height, $\mathrm{m}$

\subsubsection{Effect of Wind on Flame}

Several investigators have studied the impact of wind on flame. Figure 2.2 illustrates a general schematic of the windblown flame. 


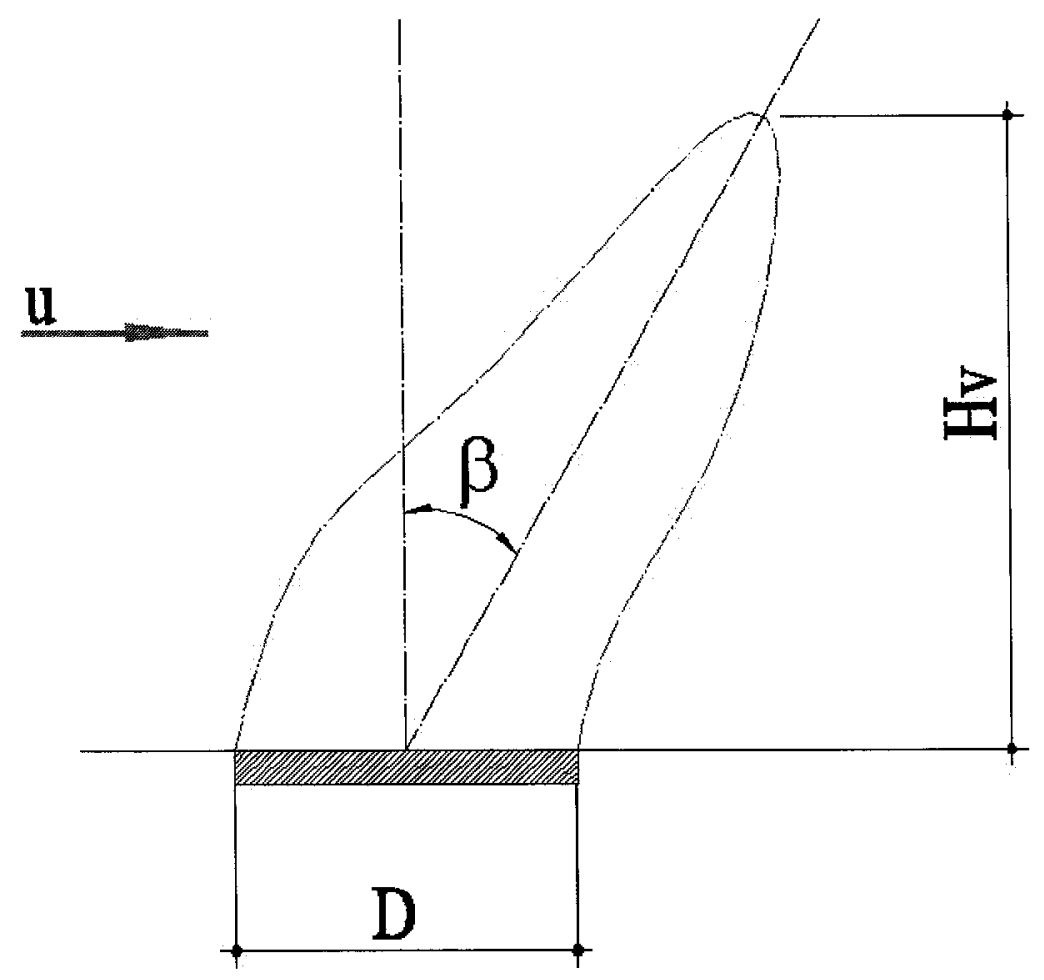

Figure 2.2 Flame inclination due to wind

Thomas [15] developed the following correlation for the flame tilt angle $\beta$, based on the data from wood cribs:

$$
\cos \beta=0.7\left[\frac{u}{\left(g m^{\prime \prime} D / \rho \alpha\right)^{1 / 3}}\right]^{-0.49}
$$

Where:

$\mathrm{u} \quad=$ Wind velocity, $\mathrm{m} / \mathrm{s}$

$\mathrm{m}^{\prime \prime}=$ Mass flow rate per area, $\mathrm{g} /\left(\mathrm{s} \mathrm{m}^{2}\right)$

$\mathrm{D} \quad=$ Diameter of fire, $\mathrm{m}$

$\rho_{\alpha} \quad=$ Density of ambient air, $\mathrm{g} / \mathrm{m}^{3}$

$\mathrm{g}=$ Acceleration due to gravity $\left(9.8 \mathrm{~m} / \mathrm{s}^{2}\right)$

Hv = Height of flame, $m$ 
Based on measured values, the American Gas Association (AGA) [16] proposed the following correlation to determine the flame tilt angle $\beta$ :

$\cos \beta=\left[\begin{array}{ll}=1 & \text { for } U^{*} \leq 1 \\ \longrightarrow=\left(\frac{1}{U^{*}}\right)^{1 / 2} & \text { for } U^{*} \geqslant 1\end{array}\right.$ Eq 2-10

Where:

$$
U^{*}=\frac{u}{\left(g m^{\prime \prime} D / \rho_{\alpha}\right)^{1 / 3}}
$$

$\mathrm{u}=$ Wind velocity, $\mathrm{m} / \mathrm{s}$

$\mathrm{m}^{\prime \prime}=$ Mass flow rate per area, $\mathrm{g} /\left(\mathrm{s} \mathrm{m}^{2}\right)$

D $\quad$ Diameter of fire, $m$

$\rho_{\alpha}=$ Density of ambient air, $\mathrm{g} / \mathrm{m}^{3}$

\subsection{Smoke Layer Interface}

The object of an atrium smoke exhaust system is to maintain a specified clear height. Figure 2.3 illustrates a mechanical smoke exhaust system in operation, which maintains the smoke layer height above the highest level where occupants may be present. 


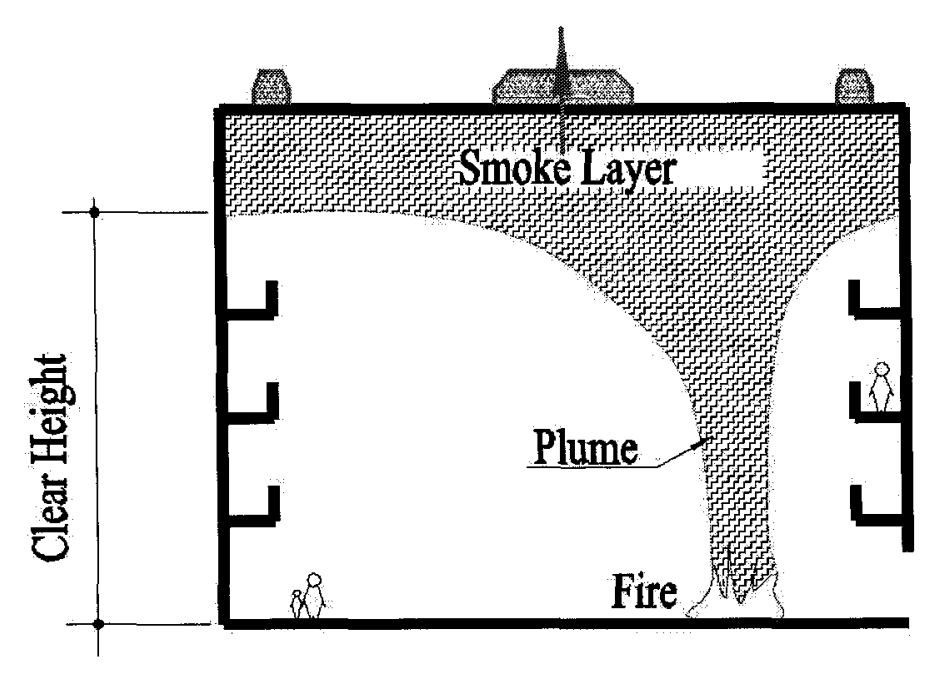

Figure 2.3 Clear height with steady fire

The natural filling of smoke in the atrium without exhaust of floor area $A\left(\mathrm{~m}^{2}\right)$ and height $\mathrm{H}(\mathrm{m})$ without an opening in the upper layer by considering only mass transfer is given by Chow [17]:

$$
\frac{d}{d t}\left[\rho_{\alpha} A(H-Z)\right]=m_{p p}
$$

Where:

$m_{p p} \quad=$ Plume mass flow rate, $\mathrm{kg} / \mathrm{s}$
$\mathrm{A}=$ Floor area, $\mathrm{m}^{2}$
$\mathrm{H} \quad=$ The atrium height, $\mathrm{m}$
$\mathbf{t} \quad=$ Time from ignition, $\mathrm{s}$
$\rho_{\alpha} \quad=$ Air density, $\mathrm{kg} / \mathrm{m}^{3}$
$\mathrm{Z} \quad=$ The interface height above the fuel, $\mathrm{m}$ 
The mass flow of an axisymmetric plume at the height of the smoke layer from a point fire source placed on the floor away from walls is given by Eq 2-7. The clear height is from the top of the fuel to the interface between the clear space and the smoke layer. The atrium walls and ceilings are thought of as being adiabatic or as having negligible heat transfer.

Following the derivation by Chow, the location of the smoke layer interface is given by Wong [18]:

$$
\frac{Z}{H}=\left(0.0018 Q^{1 / 3} t+1\right)^{-(3 / 2)}
$$

Where:

$\mathrm{Z} \quad=$ Height of smoke layer above the fuel, $\mathrm{m}$

$\mathrm{H}=$ Atrium height, $\mathrm{m}$

$\mathrm{Q}=$ Heat release rate, $\mathrm{kW}$

$\mathrm{t} \quad=$ Time from the fire start, $\mathrm{s}$

Empirical correlations have been developed by Heskestad to determine the position of the smoke layer interface as a function of time for steady fires. These correlations, included in NFPA 92B [1], are based on experimental data in large spaces.

The correlations provide conservative estimates of the smoke layer interface height The position of the smoke layer interface for steady fires can be estimated using the following equation. 


$$
\frac{Z}{H}=1.11-0.28 \ln \left[\frac{t \mathrm{Q}^{1 / 3} H^{-4 / 3}}{\left(\frac{A}{H^{2}}\right)}\right]
$$

Where,

$\mathrm{Z} \quad=$ Height of smoke layer above the fire, $\mathrm{m}$

$\mathrm{H}=$ Ceiling height above the fire, $\mathrm{m}$

$\mathrm{t} \quad=$ Time, $\mathrm{s}$

$\mathrm{Q}=$ Heat release rate from steady fire, $\mathrm{kW}$

A = Cross-sectional area of the atrium, $\mathrm{m}^{2}$

In this study, an upper limit for $\mathrm{Z} / \mathrm{H}$ of 0.8 was chosen, which relates to the highest achievable smoke level to ensure that the thickness of the ceiling jet is covered.

Figure 2.4 shows the maximum achievable smoke layer height in an atrium.

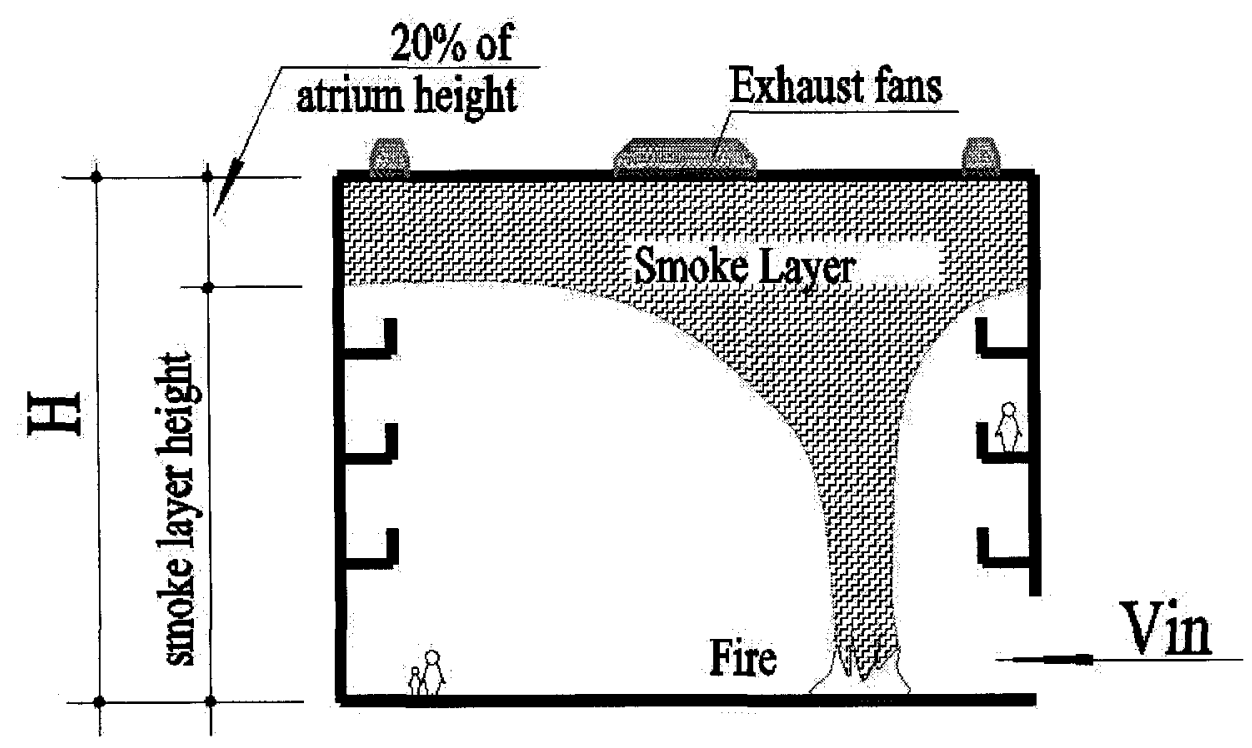

Figure 2.4 Minimum smoke layer thickness 
Cooper et al. [19] developed a method for defining the height of the interface between the hot and cold zones produced by a fire based on a limited number of point temperature measurements over the height of a compartment. They assumed that the interface is at the height where the temperature, $T_{n}$ is given by:

$$
T_{n}=C_{n}\left(T_{\max }-T_{b}\right)+T_{b}
$$

Where:

$\mathrm{T}_{\max }=$ The maximum temperature of the compartment, $\mathrm{K}$.

$\mathrm{T}_{\mathrm{b}} \quad=$ The temperature near the bottom of the compartment, $\mathrm{K}$

$\mathrm{C}_{\mathrm{n}} \quad=$ Interpolation constant typically in the range of 0.15 to 0.2 .

A similar equation can also be used to determine the interface height based on $\mathrm{CO}_{2}$ concentration.

Lougheed [20], [21] pointed out that the value of $C_{n}$ equal to 0.2 gives a smoke interface height near the bottom of the transition zone while $C_{n}$ equal to 0.8 gives a smoke interface height near the top of the transition zone. For CFD modeling, the value of $C_{n}$ between 0.5 and 0.6 is recommended [10].

In this study, a clear height is defined using Equation 2-16 with $C_{n}$ set at 0.6 . Both temperature and $\mathrm{CO}_{2}$ concentrations were used in Equation 2-16, so two interface heights are defined, one based on temperature and the other on $\mathrm{CO}_{2}$. As there is a variation between the temperature and $\mathrm{CO}_{2}$ profiles at different locations, the interface heights were computed at each location based on both temperature and $\mathrm{CO}_{2}$ 
concentration values, and their average value was used to represent the atrium interface height.

\subsection{Smoke Management}

In general, smoke management systems are intended to restrict the smoke layer to the upper portion of the atrium or to limit the spread of smoke to areas outside the atrium. Most atria smoke management systems are designed with the goal of not exposing occupants to smoke during evacuation. As sprinklers may not be effective in suppressing fires in large spaces, smoke management systems play an important role in fire safety of atria. The following approaches of smoke management in atria are used: 1) smoke filling, 2) natural venting, and 3) mechanical exhaust. [3]

\subsubsection{Smoke Filling}

Smoke filling applies only to very large volume spaces where the filling time is larger than the time for evacuation, including the time it takes to become aware of the fire and to prepare for movement to an exit. Smoke filling calculations can be done by a zone model or empirical smoke filling equations.

Using a zone model is a common approach for smoke management design calculations Bukowski [22] and Jones [23]. Zone models divide the space into two layers with uniform properties: an upper hot layer and a lower layer of cool gas. As 
shown in Figure 2.5 the smoke interface is considered to be the height at the bottom of the hot layer.

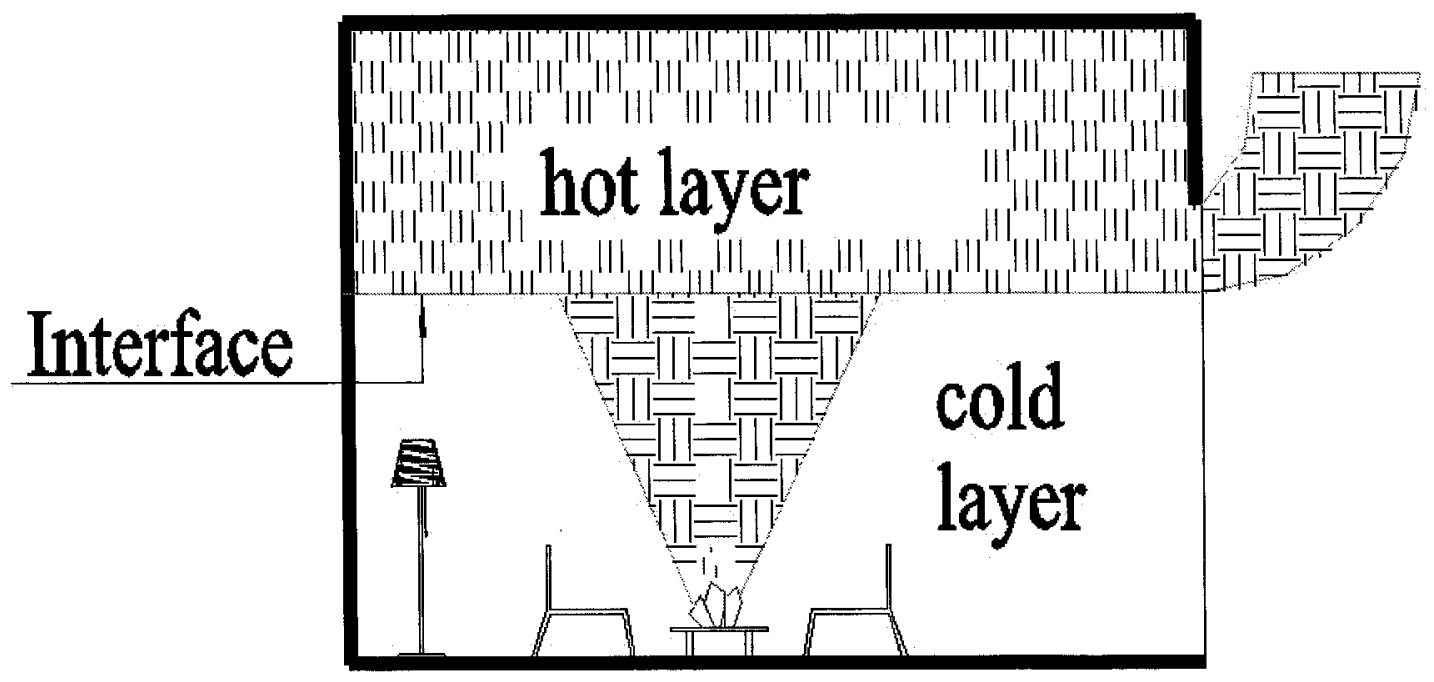

Figure 2.5 Sketch of two zone model

The empirical filling equations are based on smoke filling tests that were done by various researchers, such as Nowler [24], Mulholland et al. [25], Cooper et al. [26] and Hagglund et al. [27]. Their work showed that, in real fires, there is a transition zone between the lower cool layer and the upper hot layer. They assumed that the first indication of smoke could be thought of as the bottom of the transition zone. From their research, they developed the empirical equations for steady fires Equation 2-15. When a plume has no contact with the walls of an atrium of a constant cross-sectional area with respect to height. Wall contact reduces entrainment of air. Calculations of smoke filling in NFPA 92B [1] also use Equation 2-15. 


\subsubsection{Natural Venting}

In many countries, natural venting is very popular for atrium exhaust. Figure 2.6

illustrates smoke exhaust with natural venting.

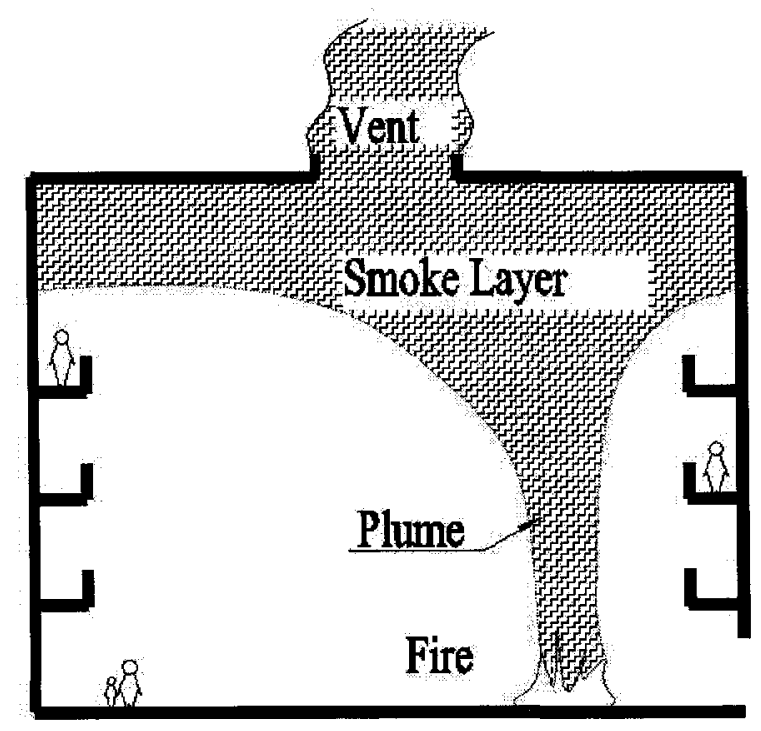

Figure 2.6 Natural venting in an atrium

Klote and Milke [3] state that the buoyancy of hot smoke forces smoke out of open vents at or near the top of the atria. For steady flow, the mass flow of air from the top vents equals the mass flow of air entering below the smoke layer. Klote's equation for mass flow is:

$$
m_{v}=C A_{v}\left[2 \rho_{g}\left(P_{s}-P_{o}\right)\right]^{1 / 2} \quad \text { Eq } 2-17
$$

Where:

$\mathrm{m}_{\mathrm{v}} \quad=$ Mass flow rate through vent, $\mathrm{kg} / \mathrm{s}$

$\mathrm{C} \quad=$ Vent coefficient 0.6

$\rho_{\mathrm{g}} \quad=$ Density of hot gases, $\mathrm{kg} / \mathrm{m}^{3}$

$A_{\mathrm{V}} \quad=$ Area of venting, $\mathrm{m}^{2}$

$P_{s} \quad=$ Pressure of smoke layer at the ceiling, $\mathrm{kPa}$ 
$P_{o} \quad=$ Outside pressure, $\mathrm{kPa}$

\subsubsection{Mechanical Exhaust}

Mechanical exhaust systems use either a dedicated exhaust system or the exhaust fans of the HVAC system. Figure 2.7 illustrates the mechanical exhaust system in an atrium.

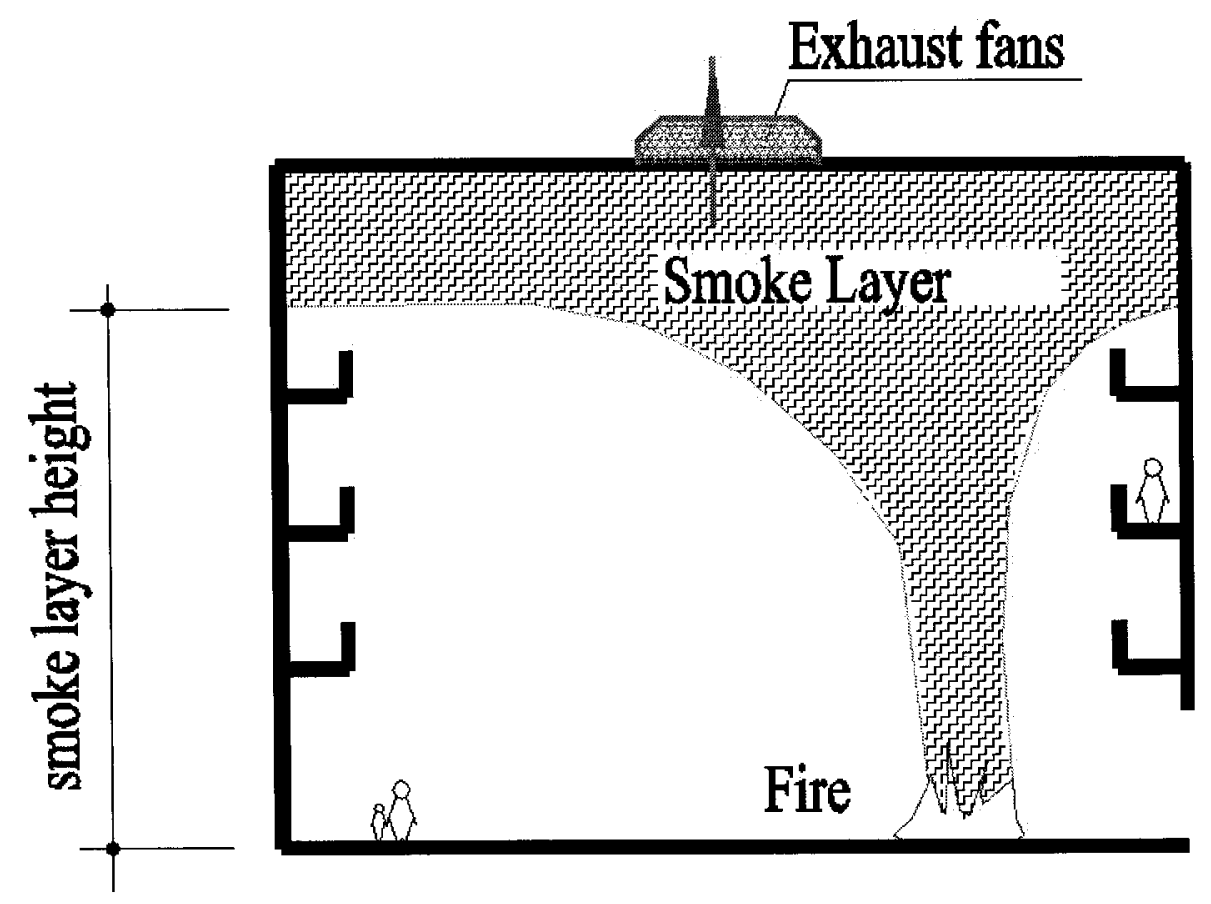

Figure 2.7 Mechanical smoke exhaust

In some cases, smoke exhaust is done in conjunction with pressurization of non-smoke zones and results in sufficient pressure differences to prevent smoke from entering these zones. In real fires, due to window breakage or due to the presence of another large opening to the outside from the smoke zone, the pressure differences can decrease significantly. 
Klote and Milke [3] present a method of analysis of a mechanical exhaust system that is based on the following simplifying assumptions:

$>$ The only mass flow into the smoke layer is the fire plume.

$>$ The only mass flow from the smoke layer is the smoke exhaust.

The exhaust is removing only smoke and not any air from below the smoke layer.

The smoke layer height is constant.

The flows into and out of the smoke layer are at equilibrium.

Heat transfer between the smoke layer and the surroundings has reached steady state.

According to theses assumptions, we can write:

$$
\mathrm{m}_{\mathrm{p}}=\mathrm{m}_{\mathrm{e}}
$$

$\mathrm{m}_{\mathrm{p}}=$ Mass flow rate of plume entering the hot layer computed in Eq 2-7, $\mathrm{kg} / \mathrm{s}$

$\mathrm{m}_{\mathrm{e}}=$ Mass flow rate of exhaust smoke, $\mathrm{kg} / \mathrm{s}$

The equation for calculating the exhaust flow rate used in Klote is Eq 2-7. Obviously, an atrium smoke ventilation system removes smoke from the atrium limiting the accumulation of heat and smoke within the atrium and arresting the descent of the smoke layer.

Hadjisophocleous and Fu [28] considered the interface height in an atrium with $9 \mathrm{~m} \times 6 \mathrm{~m} \times 5 \mathrm{~m}$ height. The heat release rate ranged from $15 \mathrm{~kW}$ to $600 \mathrm{~kW}$. The measured exhaust rate ranged from 1.94 to $5.13 \mathrm{~kg} / \mathrm{s}$. The experimental interface 
height between the smoke and cold layer was defined as the position with the maximum temperature gradient or concentration gradient. A comparison was given between the interface height from the experimental data and the prediction of a two-zone model. The experimental data showed that for small to medium heat release rates, both the temperature profiles and concentration of $\mathrm{CO}_{2}$ profiles yield similar interface heights. For the larger fire sizes, the concentration of $\mathrm{CO}_{2}$ profiles gave higher interface heights. They also reported that the predicted concentration of $\mathrm{CO}_{2}$ was considerably higher than the experimental data. On the contrary, temperature was found to be in better agreement to the experimental data for the large heat release rate fires.

\subsection{Make-Up Air}

For an atrium smoke management system that involves the venting of smoke from the hot upper layer, a make-up air supply must be provided. Once the exhaust rate for the smoke control system is identified, the atrium design must be capable of providing make-up air to the space so the atrium does not become a vacuum.

\subsubsection{Make-Up Air Velocity}

The amount of make-up air necessary for an atrium smoke control system is not typically identified in building codes. Make-up air should be introduced into the atrium below the smoke interface level. Several researchers have tried to determine if there are adverse effects from using high make-up air supply velocities. 
Heskestad [12] and Mudan and Croce [29] suggest that velocities above $1 \mathrm{~m} / \mathrm{s}$ alter the symmetric smoke plume, which results in an increase in the amount of air entrained into the plume.

NFPA 92B [1] specifically states that the supply velocity of make-up air at the perimeter of the atrium must be limited to sufficiently low values so as not to deflect the fire plume significantly, which would increase the air entrainment rate, or disturb the smoke interface. A maximum make-up supply velocity of about $1 \mathrm{~m} / \mathrm{s}$ is recommended, based on flame deflection data. Where maintaining a smoke layer height is not a design goal, plume disruption due to supply velocity might not be detrimental.

The same mass flow rate of air as the air exhausted from the top of the atrium needs to be supplied to the atrium below the smoke layer. This supply needed to accommodate the exhaust may be provided naturally through openings or leakage paths or by using supply fans. Milke and Klote and Milke [3] point out that fan-powered make-up air is often sized at $90 \%$ to $97 \%$ of the exhaust airflow rate.

Natural supply is one of the approaches used to introduce air through doors or windows, which can open upon the activation of the exhaust system. An atrium with direct access to the exterior may use natural supply by automatically opening doors or 
windows in the exterior walls and allowing the atrium exhaust system to draw in outside air.

An atrium with little or no access to the building exterior will require mechanical systems to provide make-up air. This method may be difficult, due to the constraint of maintaining the $1 \mathrm{~m} / \mathrm{s}$ maximum velocity. For a large atrium, this method could not supply air effectively.

In recent years, designers of large buildings considered natural supply combined with a mechanical exhaust system. In this method, as Klote and Milke [3] pointed out, the make-up air supplied to the atrium should be:

Uncontaminated

Introduced below the smoke layer

Introduced at a low velocity

Supplied at a rate less than the required exhaust rate

Yi et al. [30], using a zone model; studied the impact of different positions of make up air supply on the performance of a mechanical exhaust system. Three scenarios with different relative positions for providing make-up air during mechanical exhaust were considered: smoke layer interface is above, within and below the air inlet. The predictions by the zone model agreed well with the experimental findings. They state that when the position of the air supply is lower than the smoke layer, a minimum 
smoke layer interface height could be maintained for a given fire size and extraction rate. When the air supply is above the smoke layer interface, make-up air would enter the smoke layer directly and mix with the smoke. Smoke temperature would be reduced significantly and a safe steady height of smoke layer could not be attained for this situation. When the air inlet is at the interface height, the average temperature rise of the smoke layer would be lower than the case with the air inlet located below the smoke layer.

Souza and Milke [11] used FDS 3.0 to study a $30 \mathrm{~m}$ atrium with a $3 \mathrm{MW}$ fire to determine whether there are adverse effects to increasing the make-up air supply velocity beyond the $1 \mathrm{~m} / \mathrm{s}$. They have simulated both symmetric and asymmetric intake vent configurations at air supply velocities of $0.5 \mathrm{~m} / \mathrm{s}, 1.0 \mathrm{~m} / \mathrm{s}, 1.5 \mathrm{~m} / \mathrm{s}$, and 3.0 $\mathrm{m} / \mathrm{s}$. They have concluded that, for symmetric vent placement, with the fire located in the center of the floor, the smoke interface height was not affected when the air velocity is at $1 \mathrm{~m} / \mathrm{s}$ and $1.5 \mathrm{~m} / \mathrm{s}$.

The research demonstrated that if a symmetric supply vent configuration around the expected design fire in an atrium is provided, a velocity below $1 \mathrm{~m} / \mathrm{s}$ can reduce significantly the smoke layer thickness. For the asymmetric test case, a velocity below $2 \mathrm{~m} / \mathrm{s}$ could not provide adverse affects. However, a velocity of over $2 \mathrm{~m} / \mathrm{s}$ deflects the plume. 
This study did not investigate the impact of make-up velocity when the fire is not located at the center of the atrium. 


\section{Chapter 3}

\section{Description of the Model}

\subsection{CFD Modeling}

In a wide range of fire protection engineering applications, CFD (Computational Fluid Dynamics) models are used to simulate smoke movement. A CFD model divides a space into a large number of control volumes and solves the governing equations for each control volume. The basic principles of mass, momentum, and energy conservation are incorporated in CFD models.

\subsection{Fire Dynamics Simulator}

The FDS (Fire Dynamics Simulator) [9] is used extensively for fire applications. FDS can model fires in a single compartment, multi-compartments, as well as, atria and warehouses.

For most applications, FDS uses a Large Eddy Simulation (LES) approach. This approach, which is the default model, does not require a very fine grid to capture the mixing reaction during a fire. It is also possible to perform a Direct Numerical Simulation (DNS) in FDS if the numerical grid is fine enough.

The LES refers to the description of turbulent mixing of the gaseous fuel and combustion products with the local atmosphere surrounding the fire. The eddies that account for most of the mixing are large enough to be calculated with reasonable 
accuracy from the equations of fluid dynamics. The conservation equations describing the transport of mass, momentum, and energy are the following [31]:

Conservation of Mass:

$$
\frac{\partial \rho}{\partial t}+\rho \nabla \mathbf{u}=0 \quad \text { Eq 3-1 }
$$

Conservation of Momentum:

$$
\frac{\partial}{\partial t}\left(\rho Y_{i}\right)+\nabla \cdot \rho Y_{i} \mathbf{u}=\nabla \cdot \rho D_{i} \nabla Y_{i}+\dot{m}_{i}^{\prime \prime \prime} \quad \text { Eq 3-2 }
$$

Conservation of Energy

$$
\frac{\partial}{\partial t}(\rho h)+\nabla \cdot \rho h \mathbf{u}=\frac{D p}{D t}-\nabla \cdot q_{r}+\nabla \cdot k \nabla T+\sum_{i} \nabla \cdot h_{i} \rho D_{i} \nabla Y_{i} \quad \text { Eq 3-3 }
$$

Where,

$$
\begin{array}{ll}
\mathbf{u}=(\mathrm{u}, \mathrm{v}, \mathrm{w}) & =\text { Velocity vector } \\
h & =\text { Enthalpy } \\
h_{i} & =\text { Enthalpy of } i \text { th species } \\
Y_{i} & =\text { Mass fraction of } i \text { th species } \\
D_{i} & =\text { Diffusion of } i \text { th species } \\
\dot{m}_{i}^{\prime \prime \prime} & =\text { Production rate of } i \text { th species per unit volume } \\
q_{r} & =\text { Radiative heat flux vector } \\
k & =\text { Thermal conductivity }
\end{array}
$$


In LES the diffusion of fuel and oxygen is computed using a mixture fraction combustion model. The mixture fraction model assumes that the combustion is controlled by the mixing of fuel and oxygen. All chemical reactions occur intensely fast so that fuel and oxygen never exist at one location at the same time. Due to this assumption, it is possible to represent all species relevant to the combustion process by one parameter. This parameter is the mixture fraction $Z(x, t)$, which depends on the space $\mathbf{x}$ and time $t$. For a given value of $Z$ the relation of the mass fraction of different species is always the same. Each of the species can be described as a function of $\mathrm{Z}$. The mixture fraction $\mathrm{Z}$ can be used to represent the local concentration of fuel or oxygen. The mixture fraction $\mathrm{Z}$ is defined as: [31]

$$
Z=\frac{s Y_{F}-\left(Y_{O}-Y_{O}^{\infty}\right)}{s Y_{F}^{I}+Y_{O}^{\infty}} \quad ; \quad s=\frac{v_{O} M_{O}}{v_{F} M_{F}} \quad \text { Eq }-3-4
$$

Where,

$$
\begin{array}{ll}
\mathrm{F} & =\text { Fuel } \\
\mathrm{O} & =\text { Oxygen } \\
Y & =\text { Mass fraction } \\
Y_{O}^{\infty} & =\text { Ambient oxygen mass fraction } \\
Y_{F}^{I} & =\text { Fuel mass fraction in the fuel stream } \\
M_{O} & =\text { Oxygen molecular weight } \\
M_{F} & =\text { Fuel molecular weight } \\
v_{O} & =\text { Oxygen stoichiometric coefficients } \\
v_{F} & =\text { Fuel stoichiometric coefficients }
\end{array}
$$


The mixture fraction $\mathrm{Z}$ satisfies the conservation law [9]:

$$
\frac{\partial \rho Z}{\partial t}+\nabla \cdot \rho \mathbf{u} Z=\nabla \cdot \rho D \nabla Z \quad \text { Eq } 3-5
$$

Where,

$\rho \quad=$ Gas density, $\mathrm{kg} / \mathrm{m}^{3}$

D $\quad$ Material diffusivity

$\mathbf{u}=(\mathrm{u}, \mathrm{v}, \mathrm{w}) \quad=$ Velocity vector

Eq 3-5 is a linear combination of the fuel and oxygen mass conservation equation. It assumes that the reaction that consumes fuel and oxygen occurs so fast that fuel and oxygen cannot coexist.

\subsection{Atrium Geometry}

This study considered a rectangular atrium with the fire at the ground floor. The characteristics of the atrium and the fires considered are the following:

The atrium has a square cross sectional area with widths ranging from $10 \mathrm{~m}$ to 40 $\mathrm{m}$ and heights from $10 \mathrm{~m}$ to $60 \mathrm{~m}$.

$>$ The atrium has an opening on one side for make-up air, with an area that is variable to provide the necessary make-up air velocity of $0.5 \mathrm{~m} / \mathrm{s}, 1 \mathrm{~m} / \mathrm{s}, 1.25 \mathrm{~m} / \mathrm{s}$, and $1.5 \mathrm{~m} / \mathrm{s}$.

Fire is located at ground floor level.

Fire heat release rates considered are: $1 \mathrm{MW}, 2.5 \mathrm{MW}$ and $5 \mathrm{MW}$.

The location of fire: 
a) For the atria with widths of $10 \mathrm{~m}$ or $15 \mathrm{~m}$, the fire was located at $0.25 \mathrm{~L}$ (L: the width of atrium) from the wall opening.

b) For the atria with widths of $20 \mathrm{~m}, 30 \mathrm{~m}$ and $40 \mathrm{~m}$ : the fire was located at $5 \mathrm{~m}$ or $2.5 \mathrm{~m}$ from the opening.

There are exhaust fans located at the top of the ceiling, which provide the necessary smoke exhaust. Smoke exhaust openings were uniformly distributed over the entire area of the ceiling to minimize the effect of the ceiling jet. The fan exhaust flow rate was computed using Eq 2-7.

Table 3.1 provides a list of all models considered for this study and their corresponding values and Figure 3.1 shows a schematic diagram of the atrium.

Table 3.1 Atria considered in this study

\begin{tabular}{|c|c|c|c|c|c|}
\hline Name of atrium & Atrium 10 & Atrium 20 & Atrium 30 & Atrium 50 & Atrium 60 \\
\hline $\begin{array}{l}\text { Atrium dimensions } \\
(\mathrm{W} \times \mathrm{L} \times \mathrm{H}),(\mathrm{m})\end{array}$ & $10 \times 10 \times 10$ & $15 \times 15 \times 20$ & $20 \times 20 \times 30$ & $30 \times 30 \times 50$ & $40 \times 40 \times 60$ \\
\hline $\begin{array}{l}\text { Fire distance from } \\
\text { opening, (m) }\end{array}$ & 2.5 & 3.75 & 5.0 and 2.5 & 5.0 and 2.5 & 5.0 and 2.5 \\
\hline $\begin{array}{l}\text { Smoke layer height } \\
\text { above the floor }(\mathrm{m})\end{array}$ & 8 & 16 & 24 & 40 & 48 \\
\hline Fire HRR (MW) & & & $1,2.5$, and 5 & & \\
\hline Opening Area & \multicolumn{5}{|c|}{ Variable to yicld required velocity } \\
\hline Opening location & \multicolumn{5}{|c|}{ On one wall starting at ground level } \\
\hline $\begin{array}{l}\text { Velocity of entry air } \\
\qquad(\mathrm{m} / \mathrm{s})\end{array}$ & \multicolumn{5}{|c|}{$0.5,1.0,1.25$, and 1.5} \\
\hline Exhaust fans & \multicolumn{5}{|c|}{ Computed using Eq 2-7 } \\
\hline
\end{tabular}




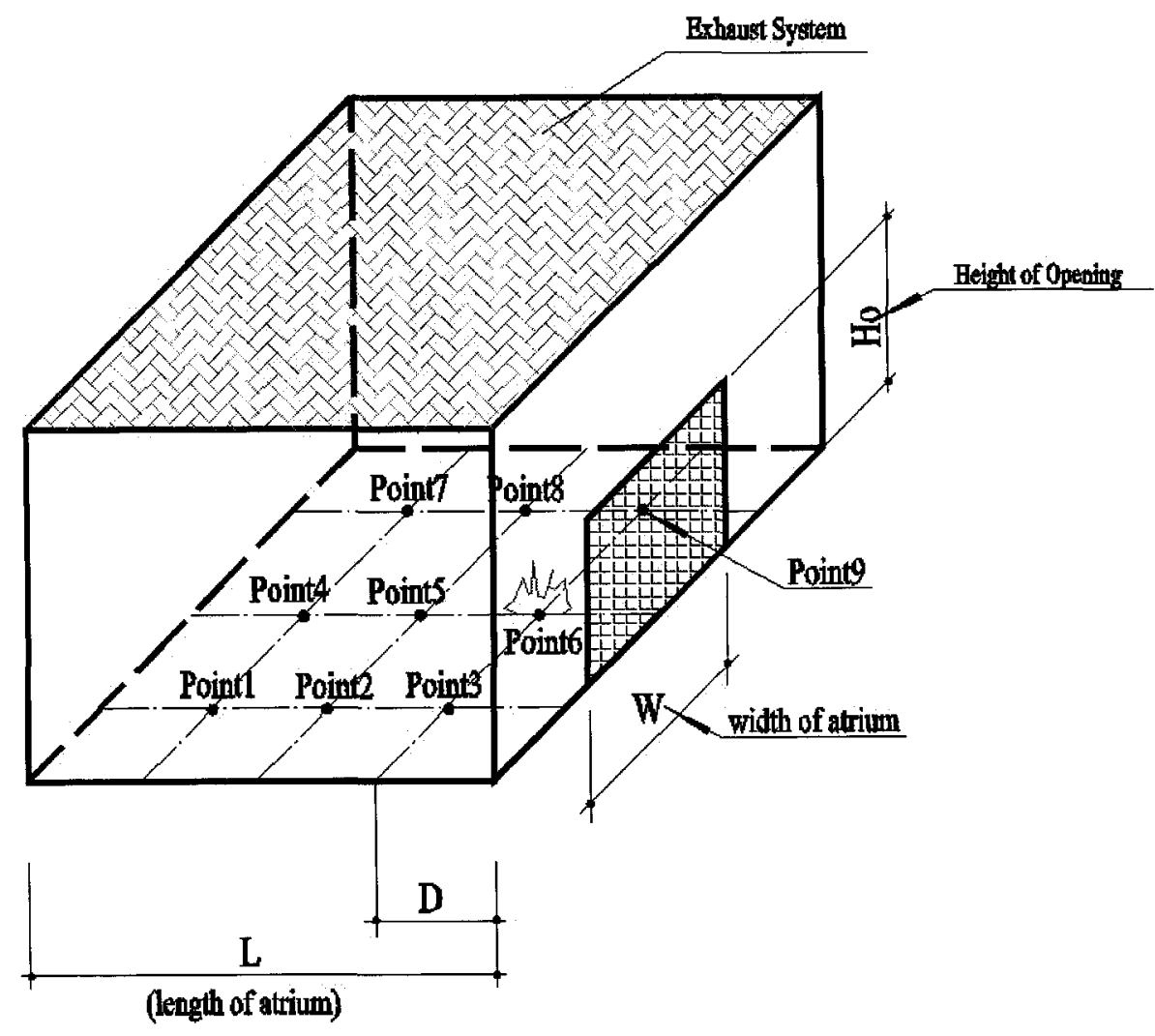

Figure 3.1 Schematic diagram of atrium

\subsection{Boundary Conditions}

The following boundary conditions were used in the simulation:

Solid wall: The walls of the atrium were modeled as solid walls covered with gypsum boards.

$>$ Floor: The floor was modeled as $200 \mathrm{~mm}$ thick concrete.

$>$ Ceiling vent: A constant mass flow rate was defined throughout the ceiling area based on the mass flow rate required to maintain the interface height at $0.8 \mathrm{H}$, where $\mathrm{H}$ is the height of the atrium.

$>$ Wall openings: The make-up air opening on the wall was assumed to be a passive opening. 


\section{Chapter 4}

\section{Results of Numerical Simulations}

\subsection{Computational Grid}

A number of preliminary simulations were performed in order to determine the optimum size of the grid, which will yield acceptable results. An atrium with a size of $10 \times 10 \times 10 \mathrm{~m}$ was considered for these tests. The atrium had a $3 \times 3 \mathrm{~m}$ opening in one wall, and the exhaust flow rate was set at $4.88 \mathrm{~m}^{3} / \mathrm{s}$. The inlet area was $9 \mathrm{~m}^{2}$ resulting an inlet air velocity of $0.5 \mathrm{~m} / \mathrm{s}$. The fire had a heat release rate of $1 \mathrm{MW}$. Three different grids were employed for the entire space of the atrium with sizes of $0.5 \mathrm{~m}, 0.25 \mathrm{~m}$, and $0.125 \mathrm{~m}$ as shown in Figure 4.1, Figure 4.2, and Figure 4.3.

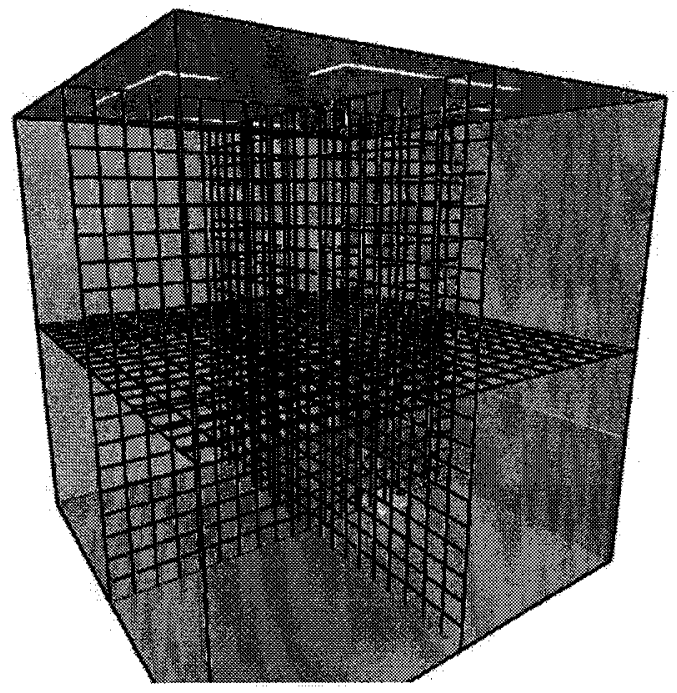

Figure 4.1 Coarse grid: $0.5 \mathrm{~m} \times 0.5 \mathrm{~m} \times 0.5 \mathrm{~m}$ 


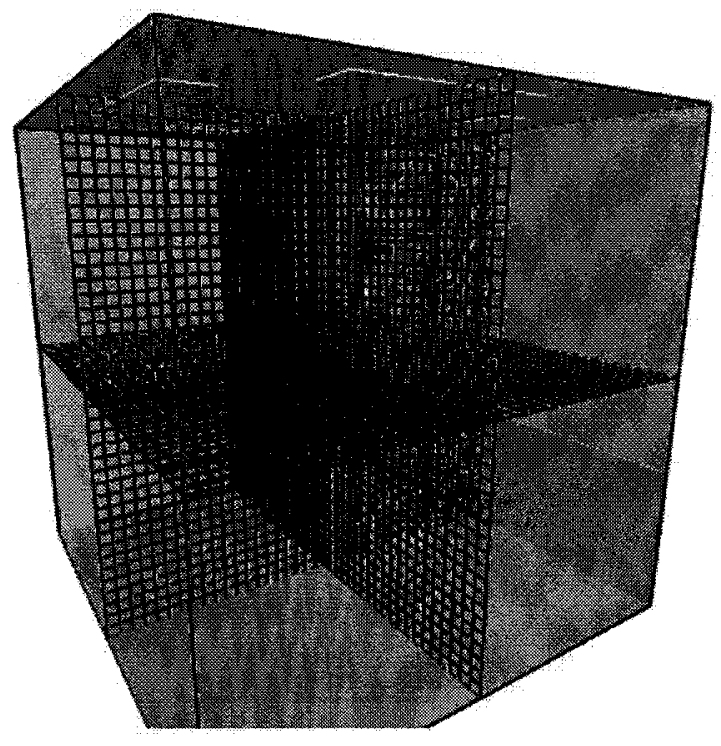

Figure 4.2 Medium grid: $0.25 \mathrm{~m}$ x $0.25 \mathrm{~m}$ x $0.25 \mathrm{~m}$

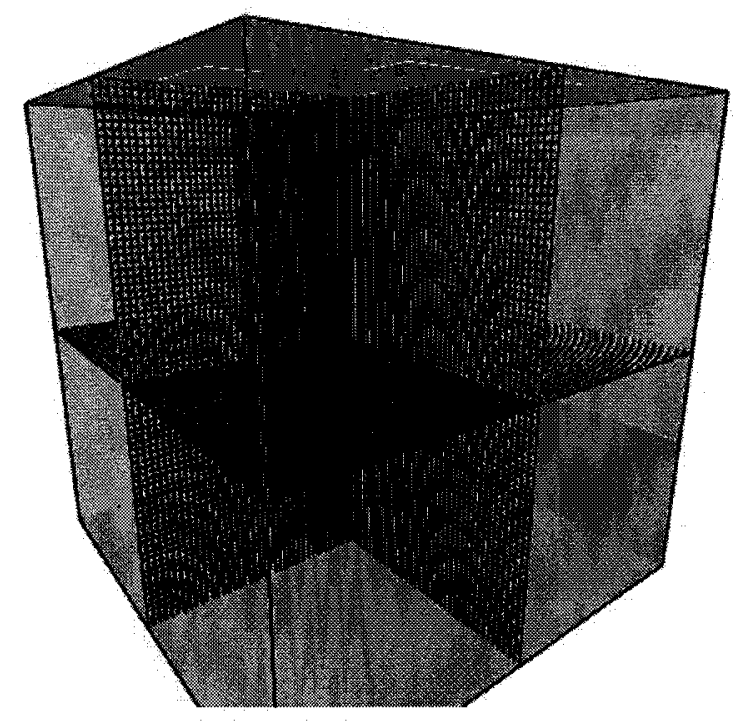

Figure 4.3 Fine grid: $0.125 \mathrm{~m} \times 0.125 \mathrm{~m} \times 0.125 \mathrm{~m}$ 


\subsection{Results}

To determine the best grid size that should be used for the simulation, preliminary runs were performed using the three different grids. Temperature, concentration of $\mathrm{CO}$, and concentration of $\mathrm{CO}_{2}$ profiles at the quarter points of the atrium and at the centerline of the fire as shown in Figure 4.4 are compared at various heights.

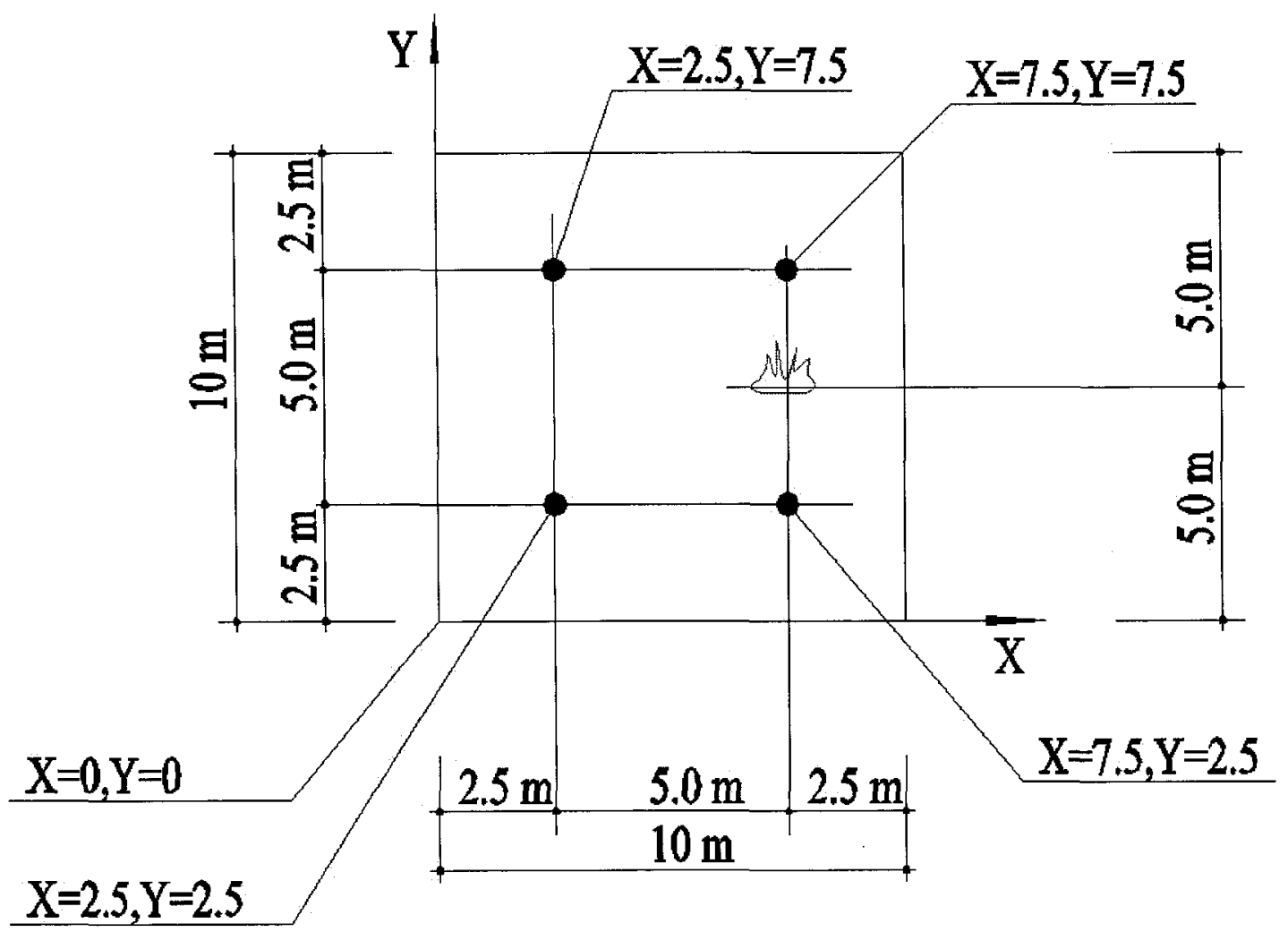

Figure 4.4 Locations of comparison points for grid sensitivity analysis

Figure 4.5 shows the temperature profiles with height at the centerline of the plume (at $\mathrm{X}=7.5, \mathrm{Y}=5.0$ ). The temperature predicted on the three different grids vary significantly at lower heights. The maximum temperature on the fine grid is about 3 times higher than that on the coarse grid. This is due to the mixture fraction combustion model that was used for simulating the fire. In the mixture fraction model 
it is assumed that the reaction takes place on an infinitely thin flame sheet where both the fuel and oxygen concentrations go to zero. So, a fine grid captures the flame sheet better than a coarse grid and provides a more accurate flame temperature. This temperature difference between the results of the different grids decreases with height. Temperatures at heights over $7.5 \mathrm{~m}$ are very close.

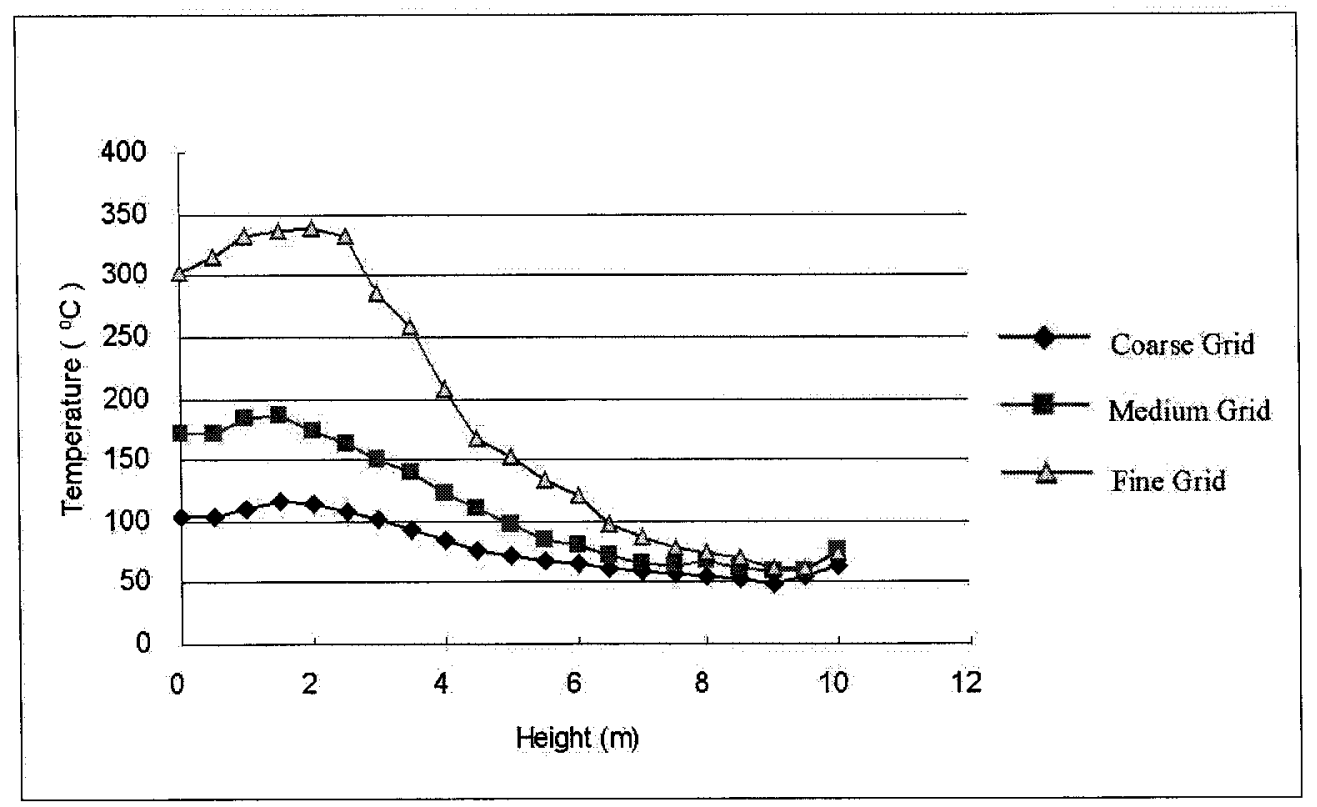

Figure 4.5 Temperature profiles with height at the centerline of the plume (at

$$
\mathrm{X}=7.5, \mathrm{Y}=5.0 \text { ) }
$$

Figure 4.6 shows the $\mathrm{CO}_{2}$ concentration profiles with height at the centerline of the plume and Figure 4.7 illustrates the plume centerline $\mathrm{CO}$ concentration profile with height. As with the temperature profiles, there is a large difference of the concentration of the three different grids at heights below $6 \mathrm{~m}$. Above this height, the concentrations are very close to each other. 


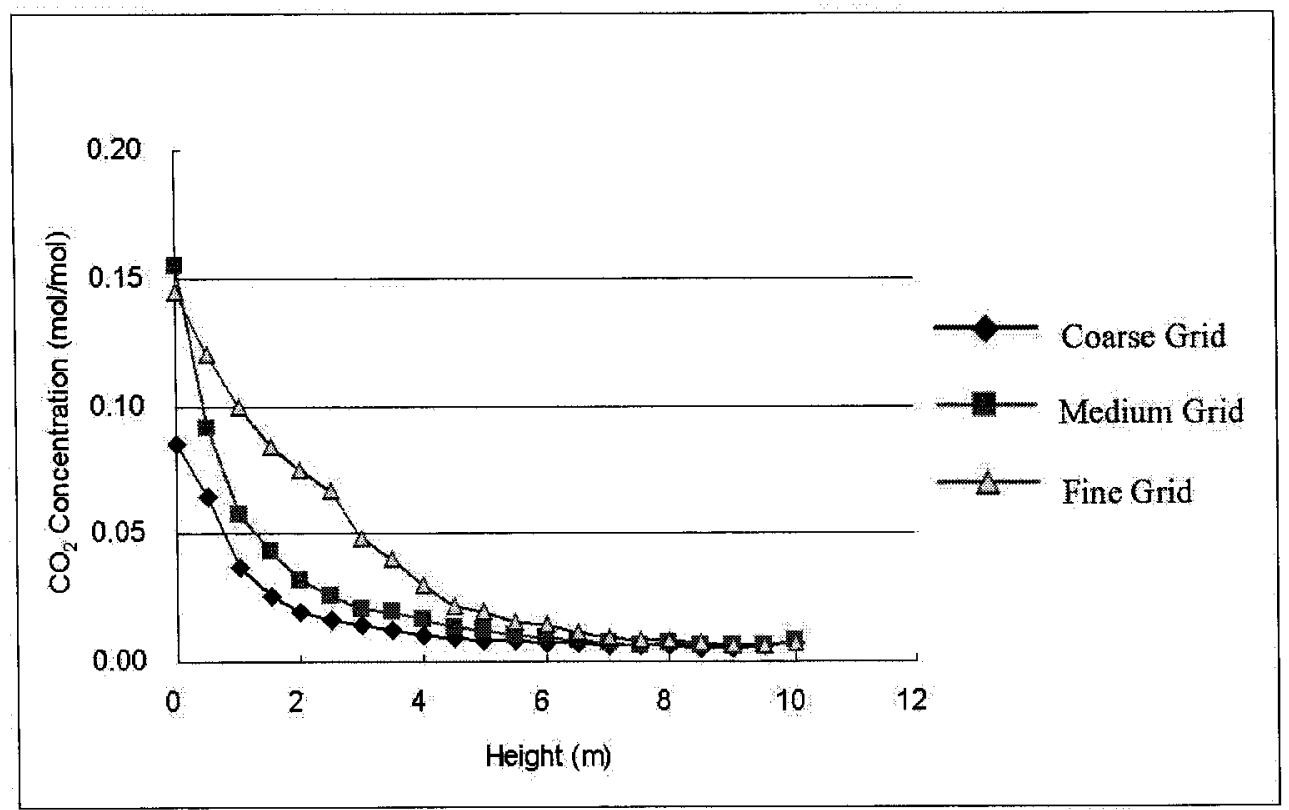

Figure $4.6 \mathrm{CO}_{2}$ concentration profiles with height at the centerline of plume (at $\mathrm{X}=7.5, \mathrm{Y}=5.0)$

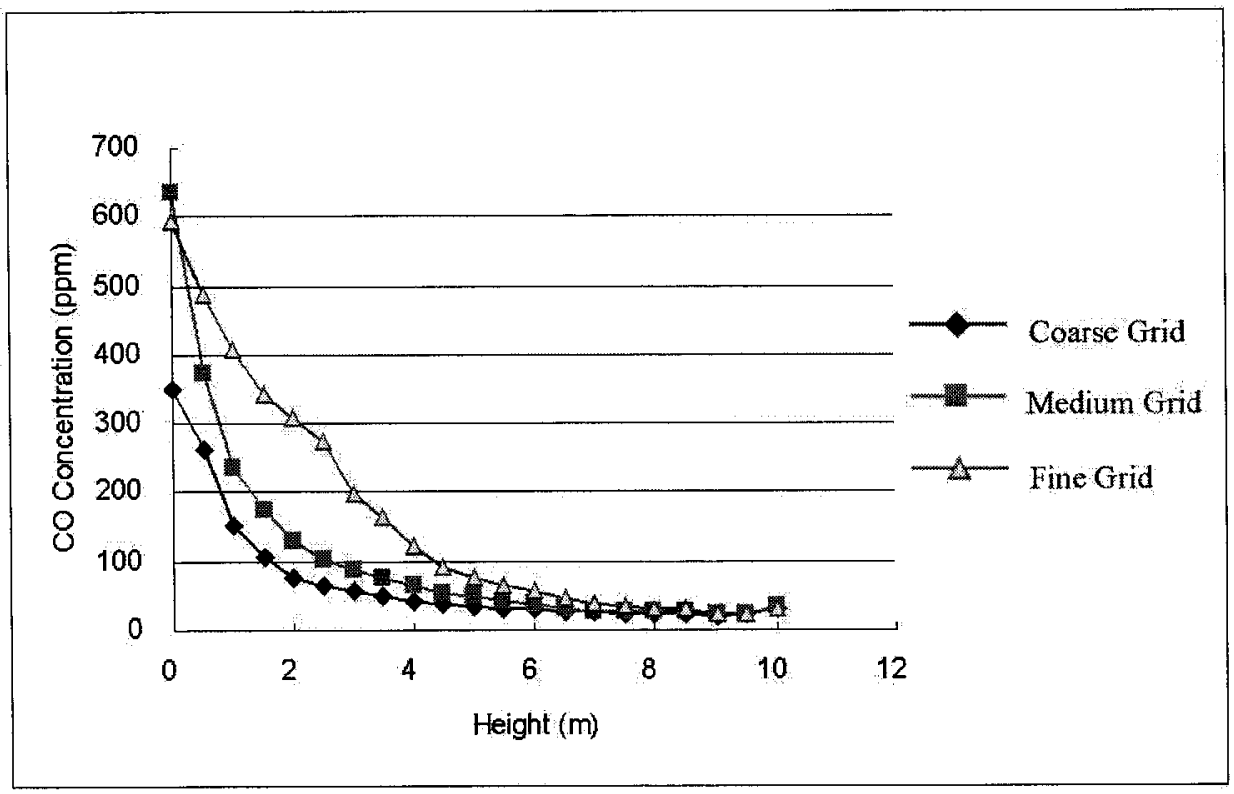

Figure $4.7 \mathrm{CO}$ concentration profiles with height at the centerline of plume (at

$$
\mathrm{X}=7.5, \mathrm{Y}=5.0)
$$


Figures 4.8 to 4.11 show the temperature profiles for the three different grids at the quarter points of the atrium. The results indicate that the medium and fine grid sizes produce very similar profiles. The $\mathrm{CO}$ and $\mathrm{CO}_{2}$ concentration profiles shown in Figures 4.12 to 4.19 also show that the predictions of the medium and fine grids are similar.

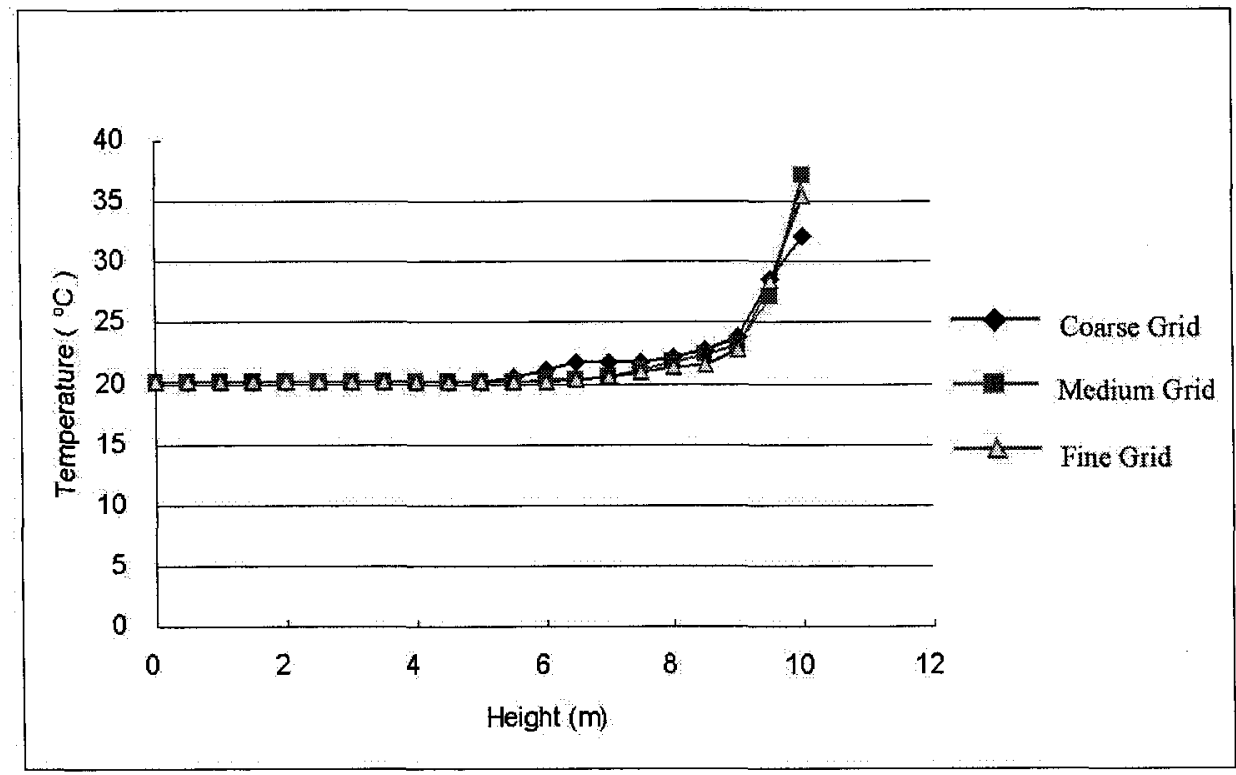

Figure 4.8 Temperature profiles with height at $X=2.5$ and $Y=2.5$

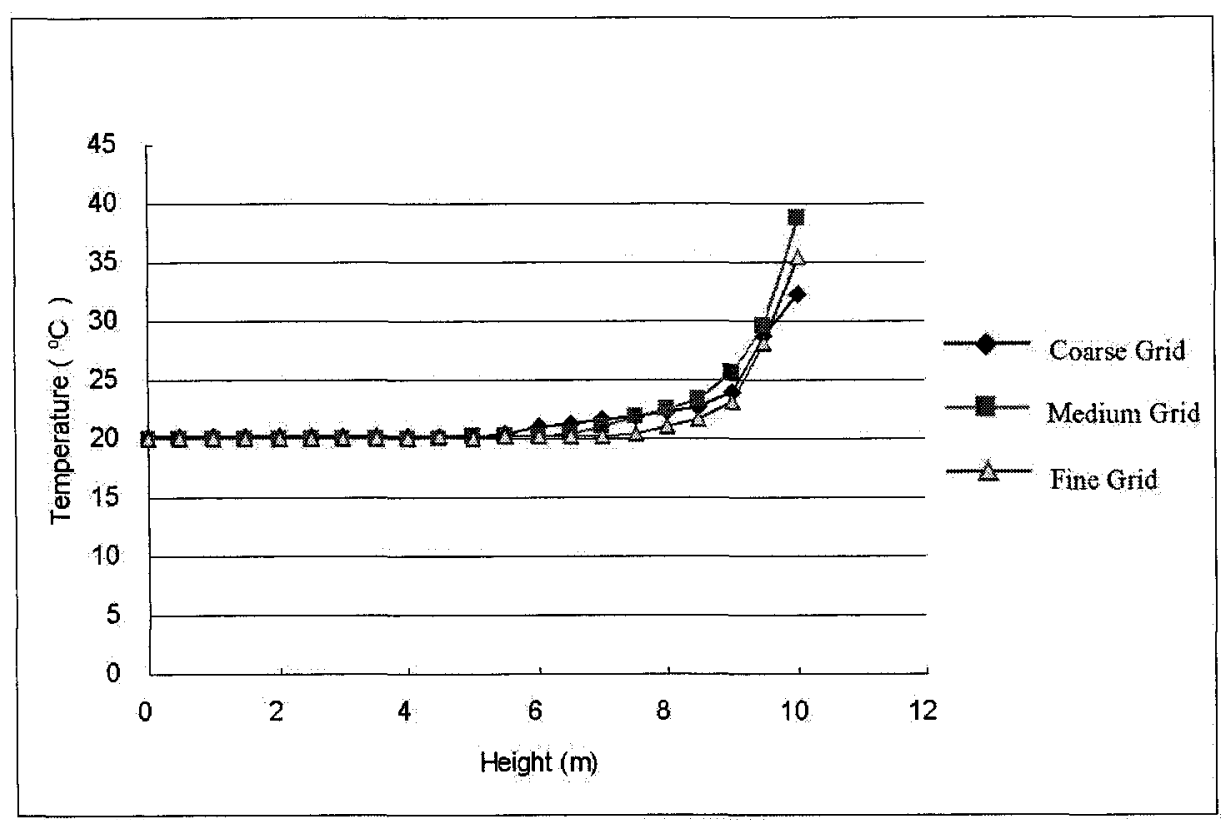

Figure 4.9 Temperature profiles with height at $\mathrm{X}=2.5$ and $\mathrm{Y}=7.5$ 


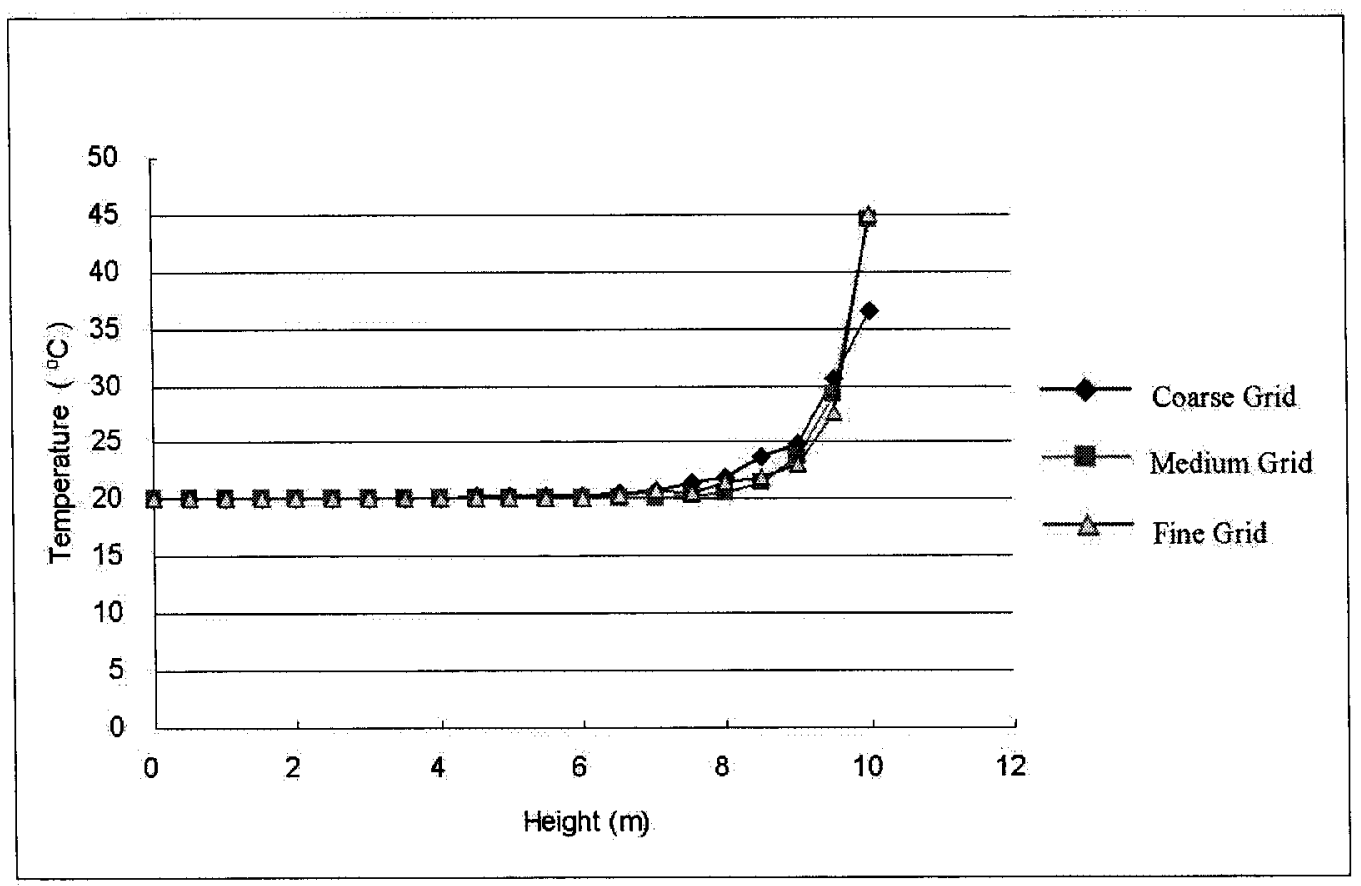

Figure 4.10 Temperature profiles with height at $\mathrm{X}=7.5$ and $\mathrm{Y}=2.5$

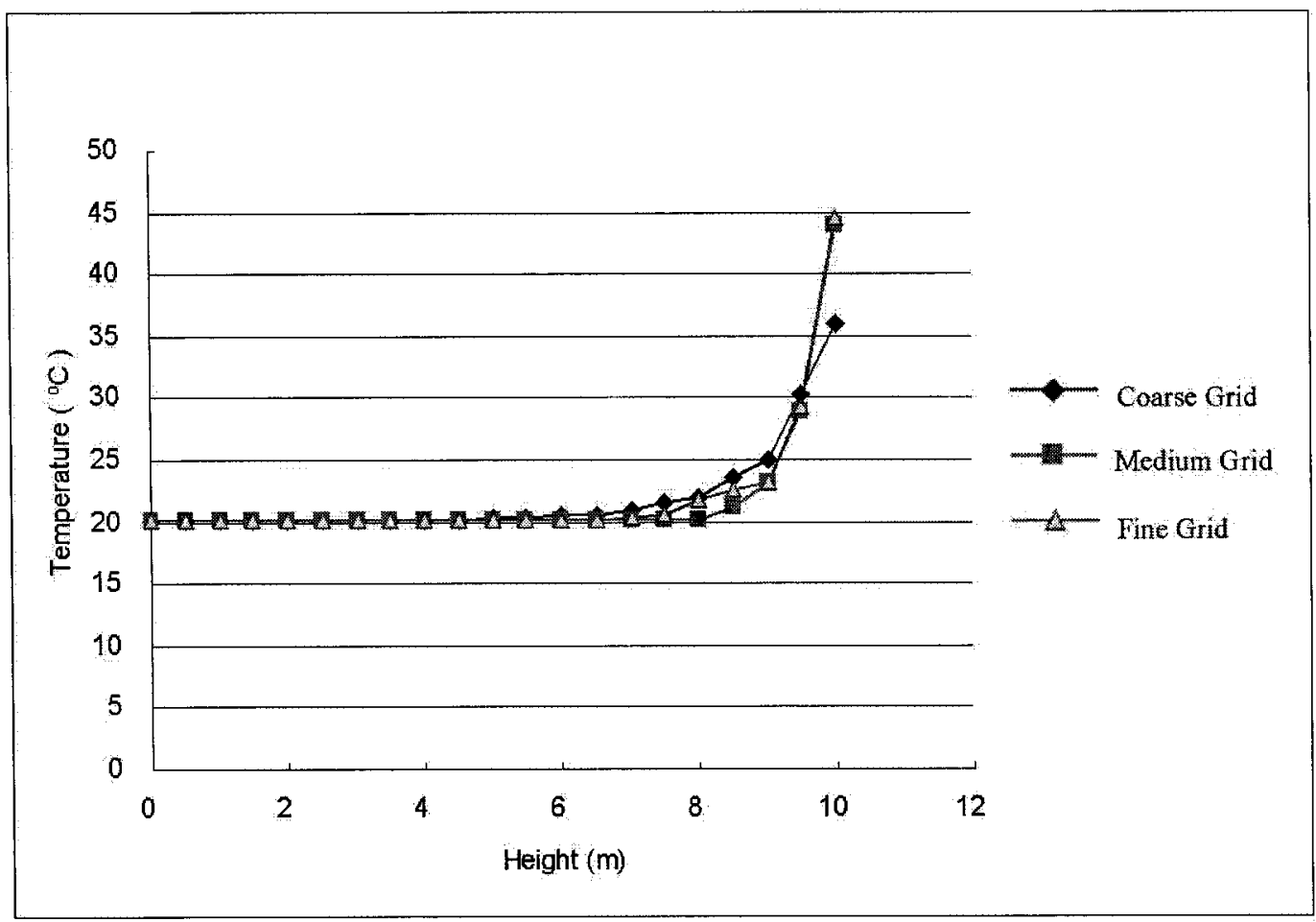

Figure 4.11 Temperature profiles with height at $\mathrm{X}=7.5$ and $\mathrm{Y}=7.5$ 
The profiles of $\mathrm{CO}_{2}$ and $\mathrm{CO}$ concentration are shown in Figures 4.12-4.19.

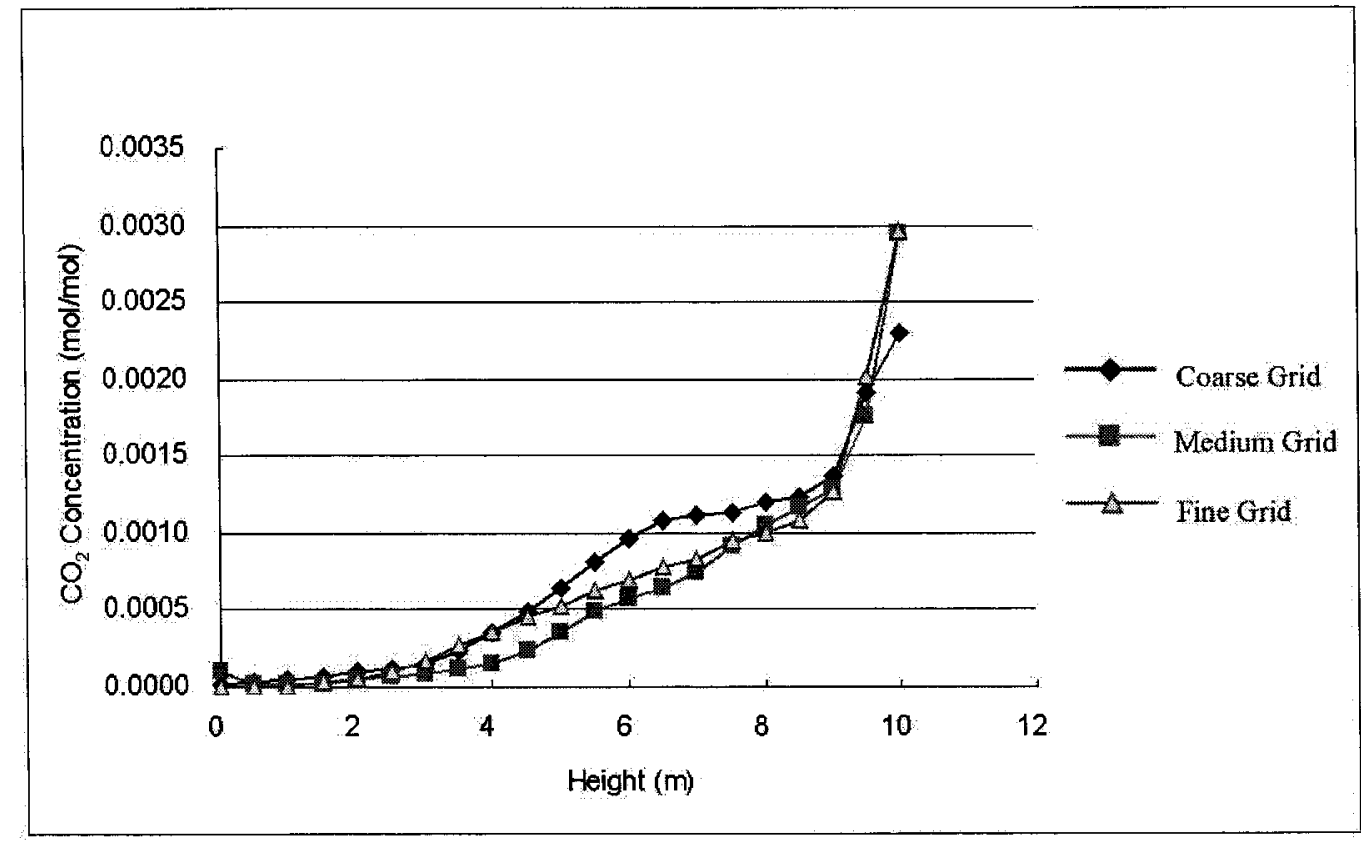

Figure $4.12 \mathrm{CO}_{2}$ concentration profiles with height at $\mathrm{X}=2.5$ and $\mathrm{Y}=2.5$

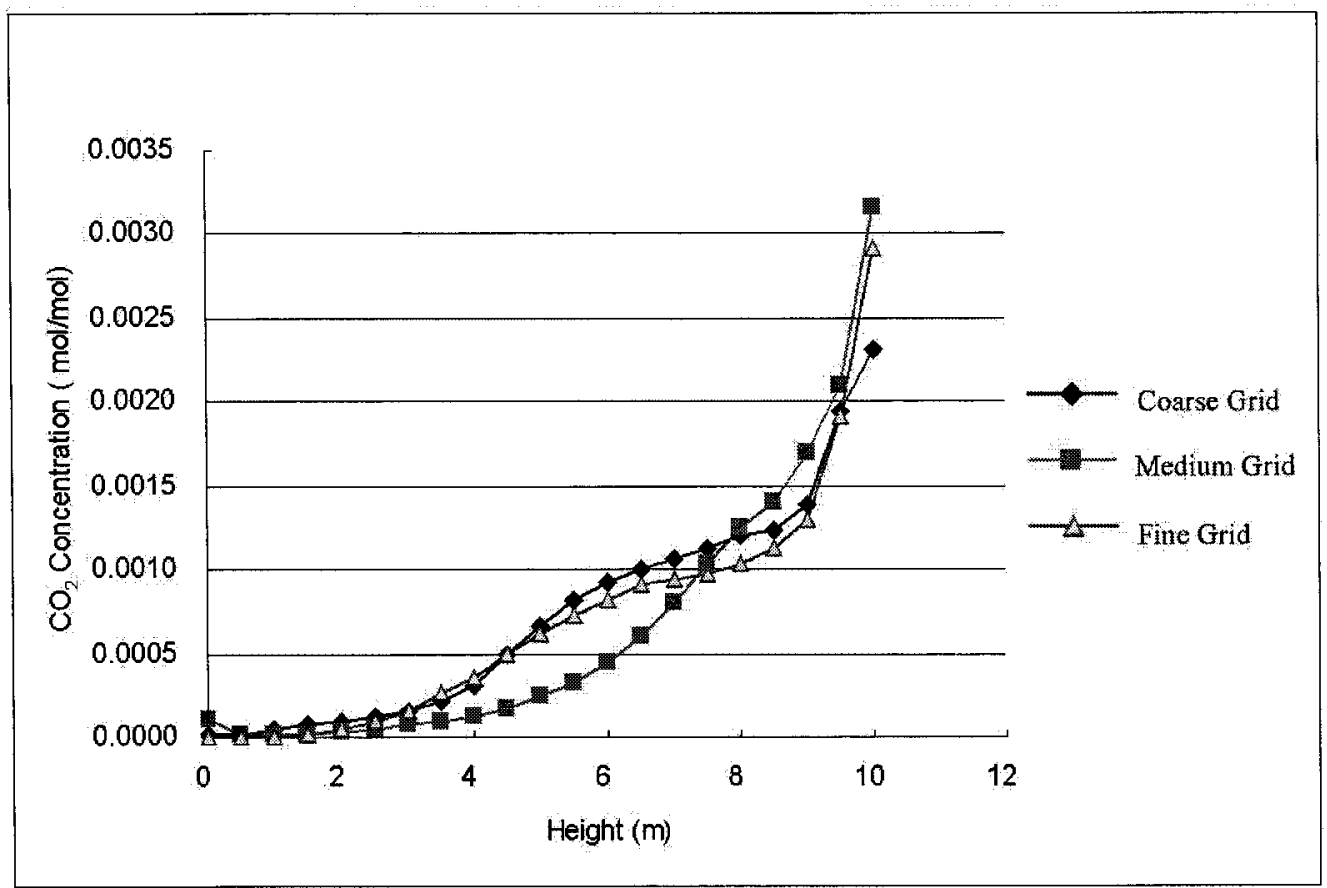

Figure $4.13 \mathrm{CO}_{2}$ concentration profiles with height at $\mathrm{X}=2.5$ and $\mathrm{Y}=7.5$ 


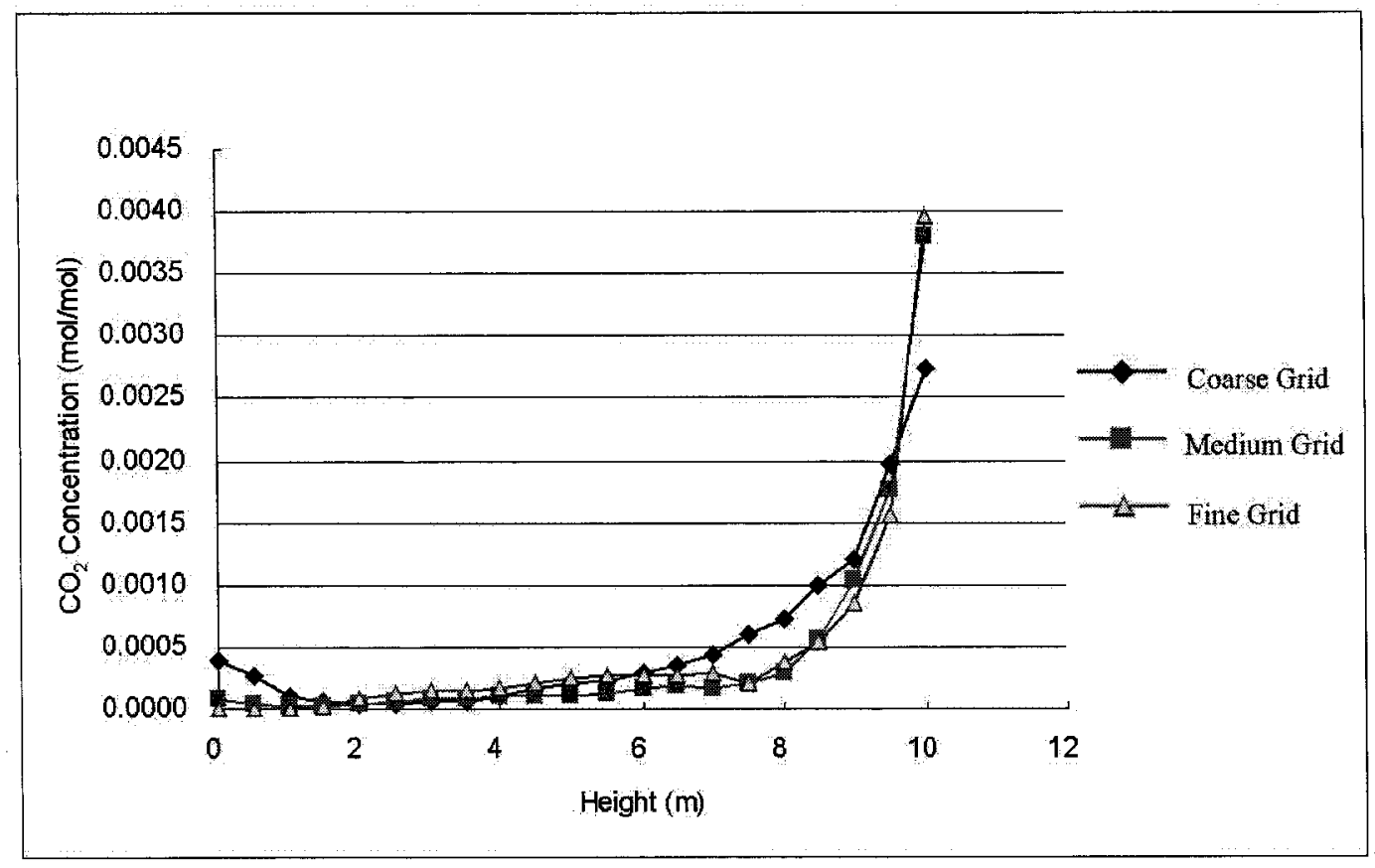

Figure $4.14 \mathrm{CO}_{2}$ concentration profiles with height at $\mathrm{X}=7.5$ and $\mathrm{Y}=2.5$

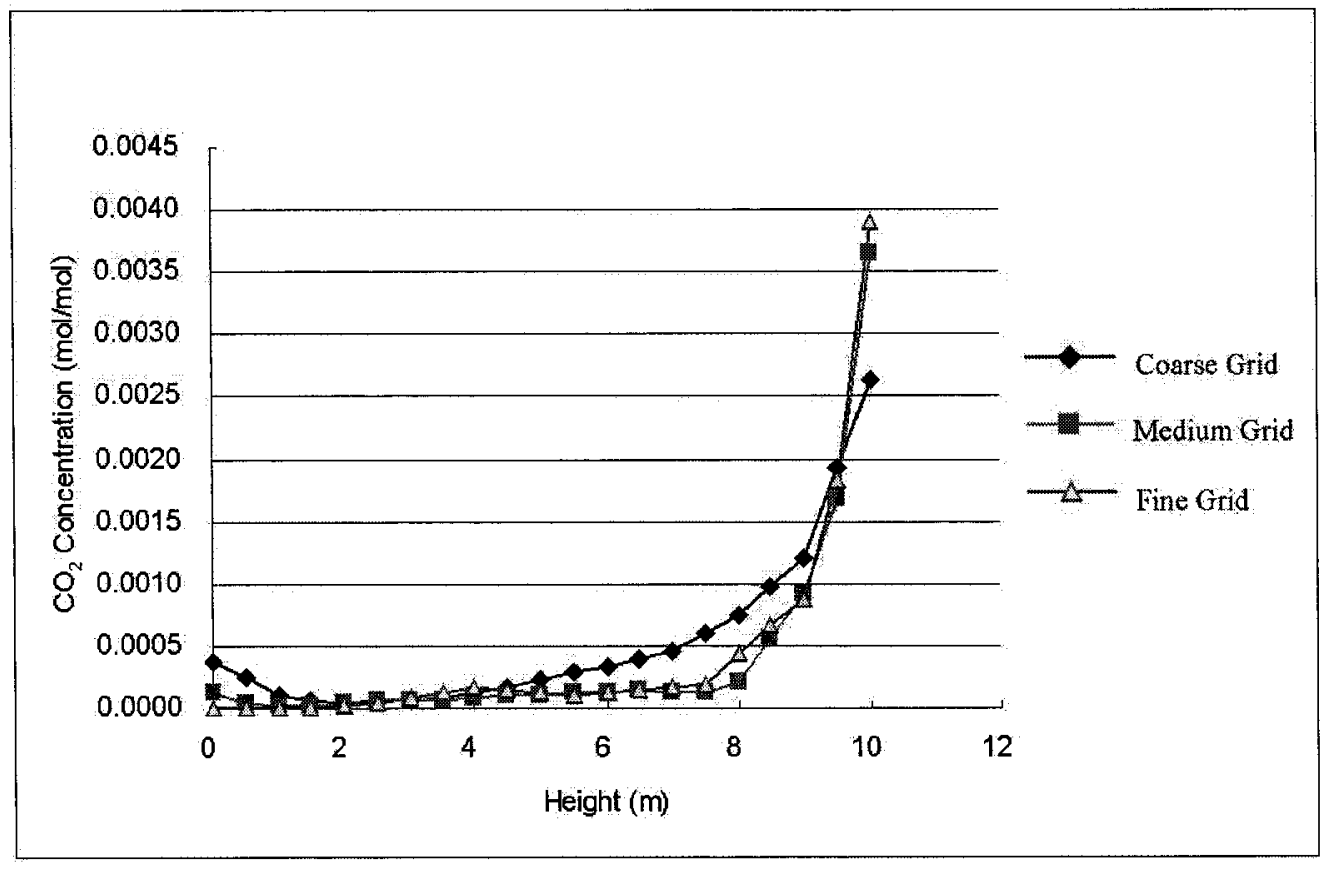

Figure $4.15 \mathrm{CO}_{2}$ concentration profiles with height at $\mathrm{X}=7.5$ and $\mathrm{Y}=7.5$ 


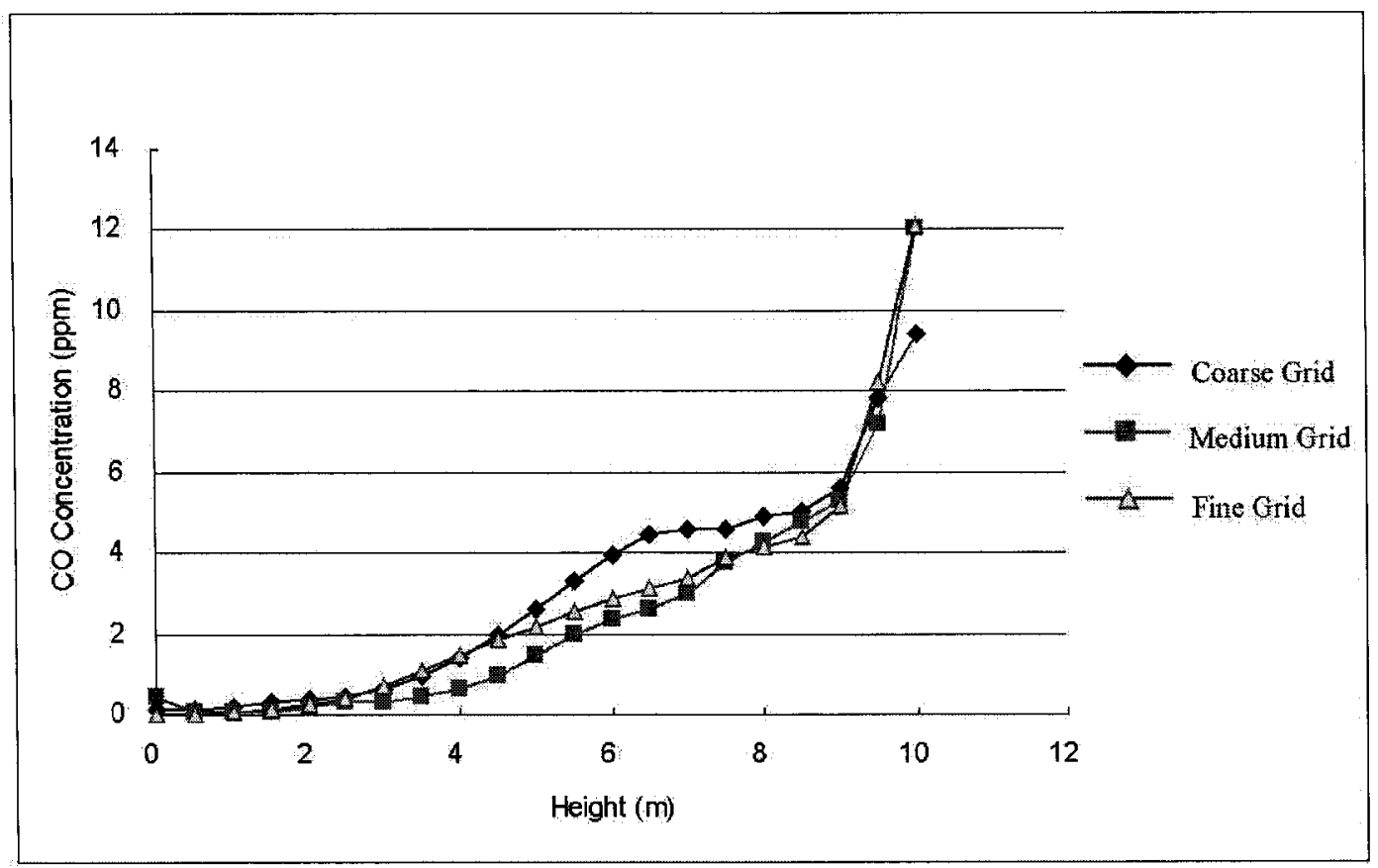

Figure 4.16 CO concentration profiles with height at $\mathrm{X}=2.5$ and $\mathrm{Y}=2.5$

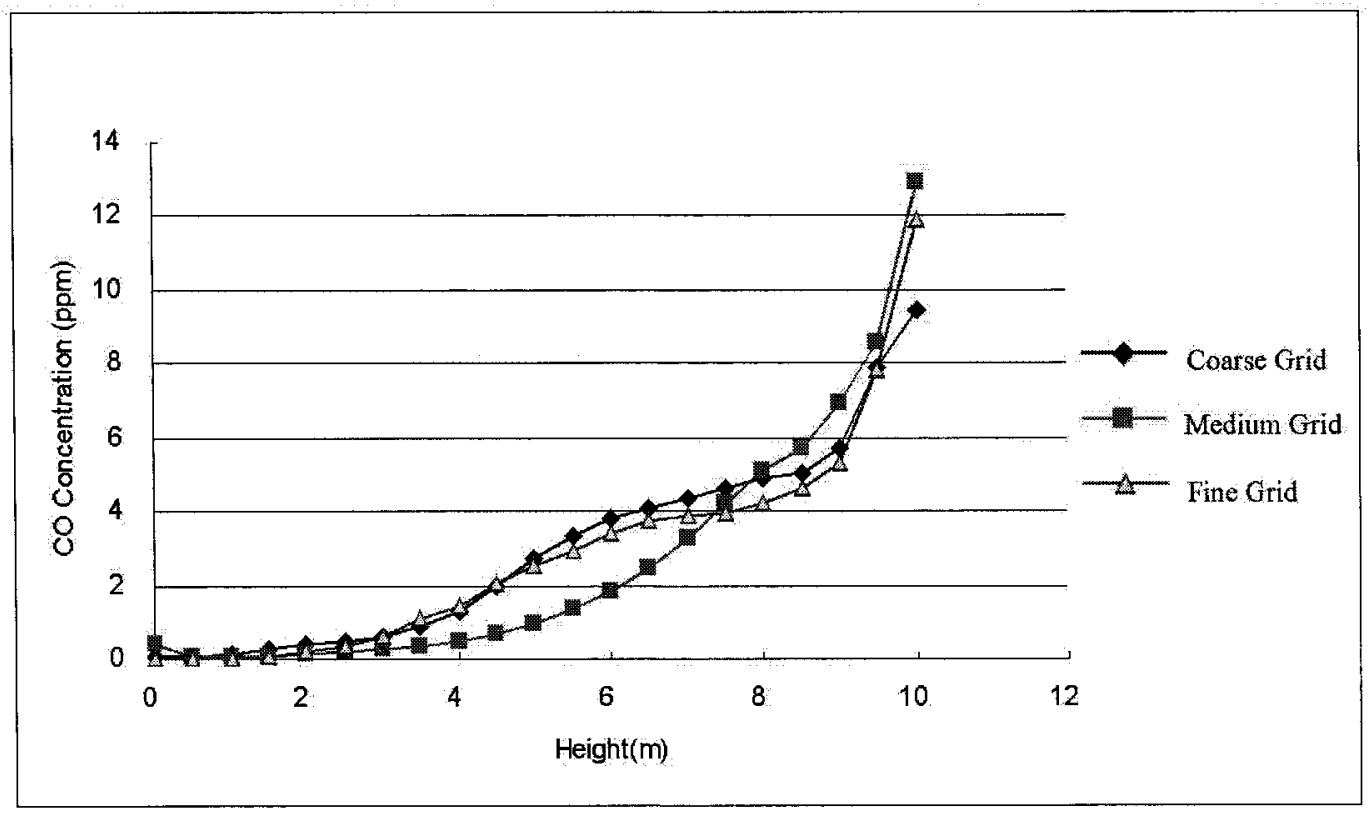

Figure 4.17 CO concentration profiles with height at $\mathrm{X}=2.5$ and $\mathrm{Y}=7.5$ 


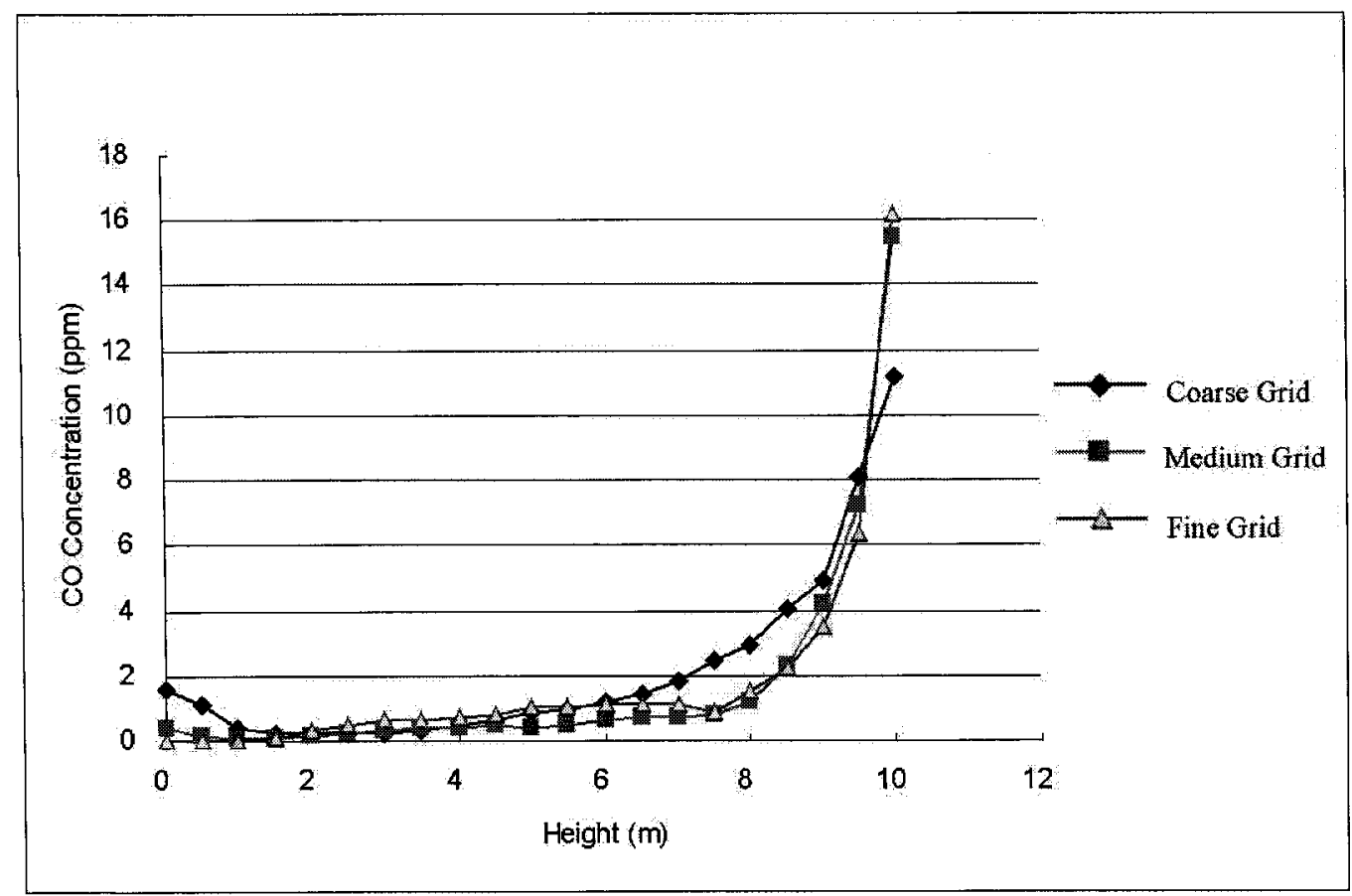

Figure 4.18 CO concentration profiles with height at $X=7.5$ and $Y=2.5$

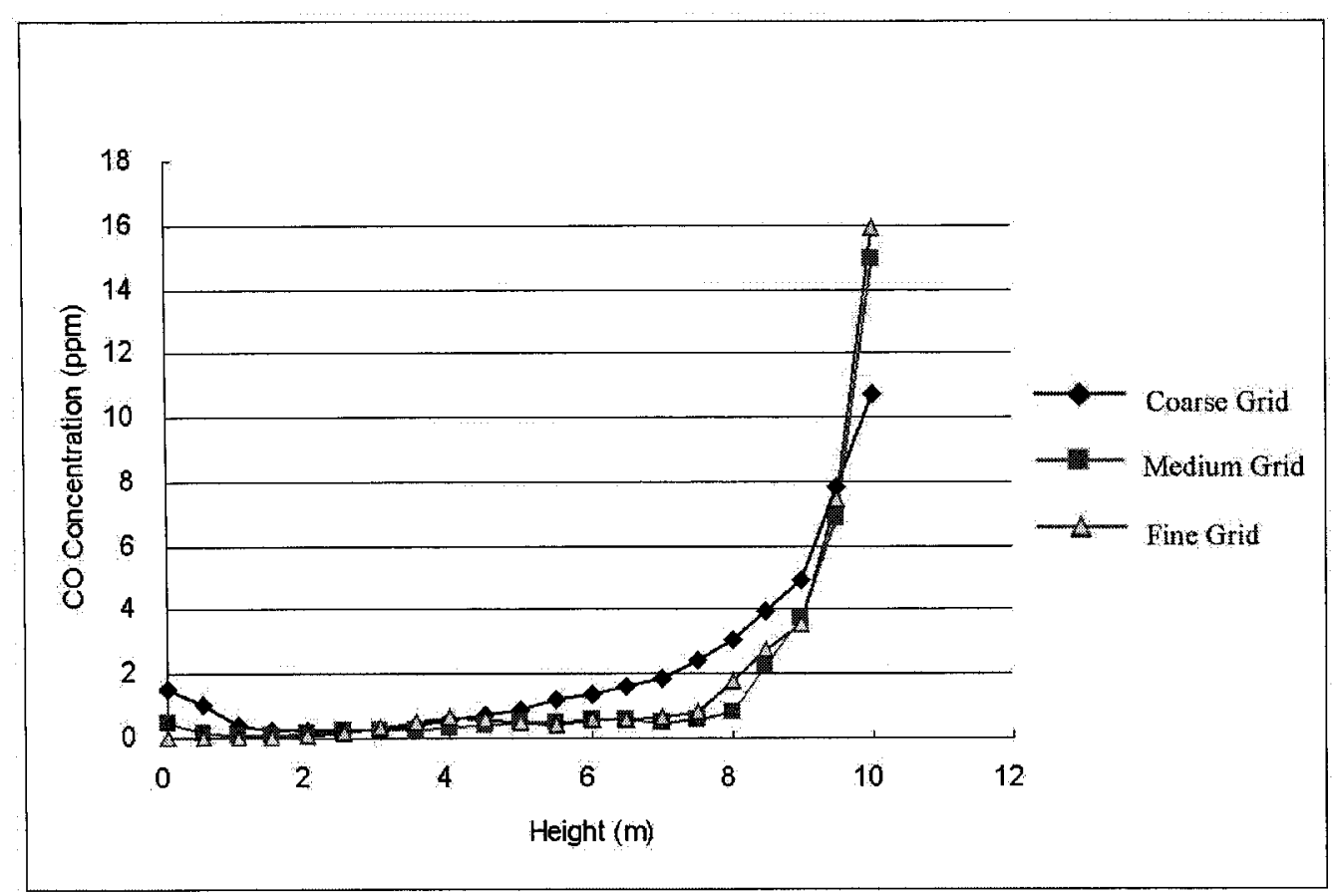

Figure 4.19 CO concentration profiles with height at $\mathrm{X}=7.5$ and $\mathrm{Y}=7.5$

The results of these runs show that FDS is sensitive to grid size, especially in the region near the fire. The profiles show that a $0.5 \mathrm{~m}$ grid produce results that are very 
different from those of the fine grids. The results produced by the $0.25 \mathrm{~m}$ grid and the $0.125 \mathrm{~m}$ grid do not differ significantly especially outside the fire area. From this, it was decided to use the $0.25 \mathrm{~m}$ grid size as the optimum grid for this study.

\subsection{Impact of Wind on Flame}

This section describes a number of simulations done to investigate the effect of a cross flow on the fire plume. For these runs, a compartment 30 meters in length, 10 meters in width and 6 meters in height was used. The wall and ceiling of the compartment were made with gypsum board and the floor was $200 \mathrm{~mm}$ thick concrete. The $10 \mathrm{~m}(\mathrm{~W}) \times 6 \mathrm{~m}(\mathrm{H})$ sides of the compartment were open. At one of the openings, a constant velocity flow is specified, while the other side is defined as a passive opening. Figure 4.20 shows a sketch of the compartment as well as the location of the fire that is placed $7.5 \mathrm{~m}$ from the left opening at the center of the compartment. Figure 4.21 is a sketch showing the definition of the inclination angle $\beta$.

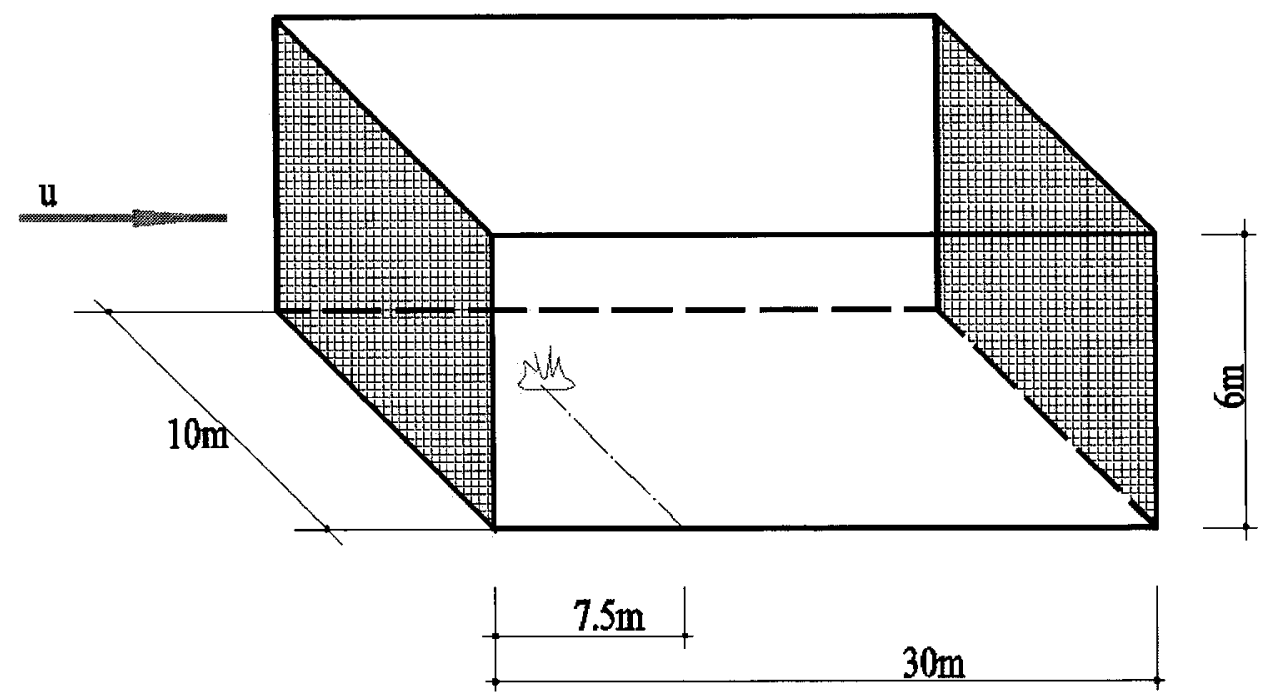

Figure 4.20 Sketch of compartment for cross flow simulations 


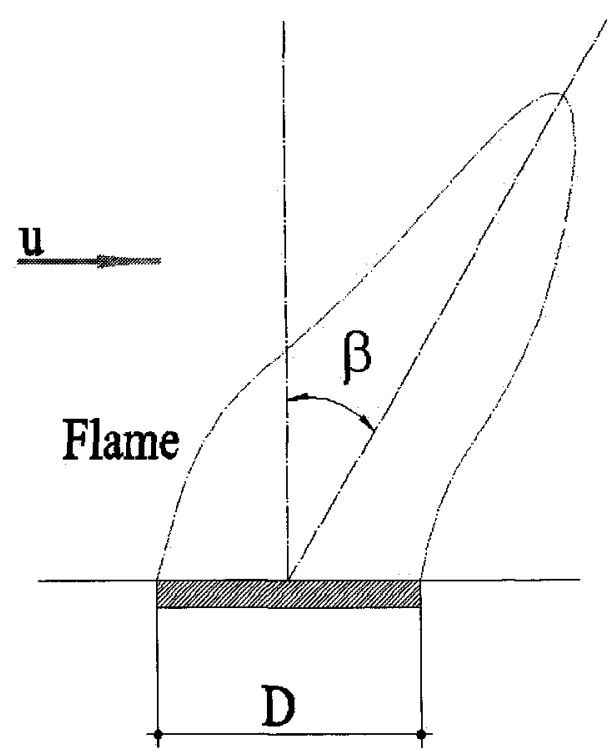

Figure 4.21 Sketch of flame inclination

The velocity of entry air was given the following values: $0.5 \mathrm{~m} / \mathrm{s}, 1.0 \mathrm{~m} / \mathrm{s}, 1.5 \mathrm{~m} / \mathrm{s}$, and $2 \mathrm{~m} / \mathrm{s}$. The fire size was: $0.5 \mathrm{MW}, 1 \mathrm{MW}$, and $5 \mathrm{MW}$. The mesh used had 120 cells in the $\mathrm{X}$ direction, 40 cells in the $\mathrm{Y}$ direction and 24 cells in the $\mathrm{Z}$ direction.

\subsubsection{Results}

FDS was used to perform the simulations to determine the impact of the airflow velocity on the flames. The flame tilt angle defined as shown in Figure 4.21 was determined for each simulation.

The results obtained from FDS are shown in Table 4.1. They are compared with calculations employing the Thomas [15] and American Gas Association (AGA) methods [16]. 
Table 4.1 FDS results of flame tilt angle compared with AGA and Thomas

\begin{tabular}{|c|c|c|c|c|c|c|c|c|c|}
\hline \multirow{2}{*}{$(\mathrm{m} / \mathrm{s})$} & \multicolumn{3}{|c|}{$0.5 \mathrm{MW}$} & \multicolumn{3}{c|}{$1 \mathrm{MW}$} & \multicolumn{3}{c|}{$5 \mathrm{MW}$} \\
\cline { 2 - 10 } & FDS & Thomas & AGA & FDS & Thomas & AGA & FDS & Thomas & AGA \\
\hline 0.5 & $16.3^{\circ}$ & $32.5^{\circ}$ & $0.00^{\circ}$ & $16.3^{\circ}$ & $19.2^{\circ}$ & $0.00^{\circ}$ & $7.1^{\circ}$ & $0.00^{\circ}$ & $0.00^{\circ}$ \\
\hline 1.0 & $39^{\circ}$ & $53.5^{\circ}$ & $32.2^{\circ}$ & $35^{\circ}$ & $48.3^{\circ}$ & $18.10^{\circ}$ & $26.6^{\circ}$ & $29.8^{\circ}$ & $0.00^{\circ}$ \\
\hline 1.5 & $45^{\circ}$ & $60.8^{\circ}$ & $46.3^{\circ}$ & $39^{\circ}$ & $56.9^{\circ}$ & $39.11^{\circ}$ & $33.7^{\circ}$ & $44.7^{\circ}$ & $18.2^{\circ}$ \\
\hline 2.0 & $59^{\circ}$ & $64.9^{\circ}$ & $53.2^{\circ}$ & $56^{\circ}$ & $61.7^{\circ}$ & $47.8^{\circ}$ & $39.8^{\circ}$ & $51.9^{\circ}$ & $28.5^{\circ}$ \\
\hline
\end{tabular}

Figures 4.22 to 4.24 show a comparison of the tilt angle obtained from these methods.

All results demonstrate that an increase of the airflow velocity cause an increase of the tilt angle.

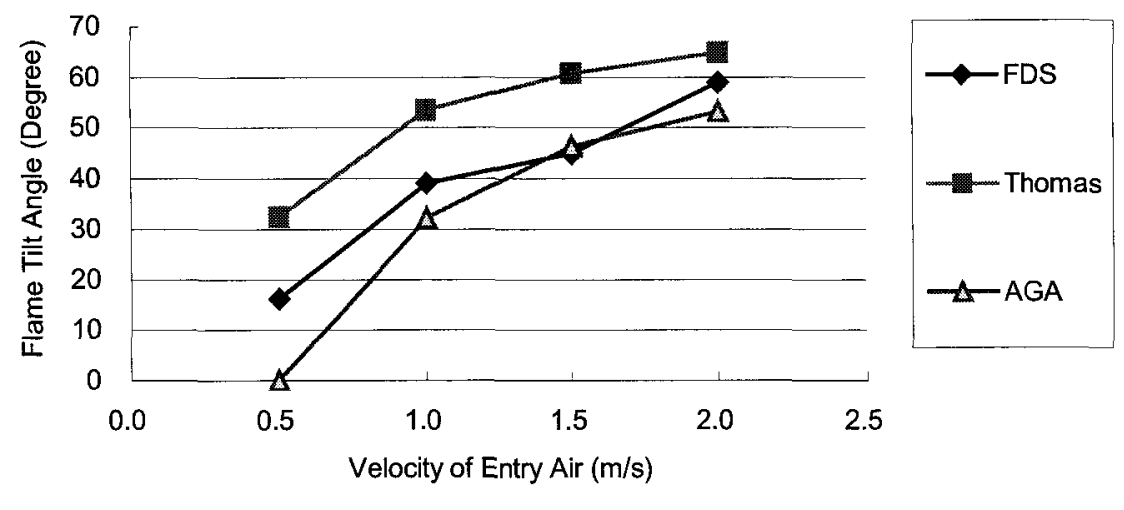

Figure 4.22 Flame tilt angle for the 0.5-MW fire 


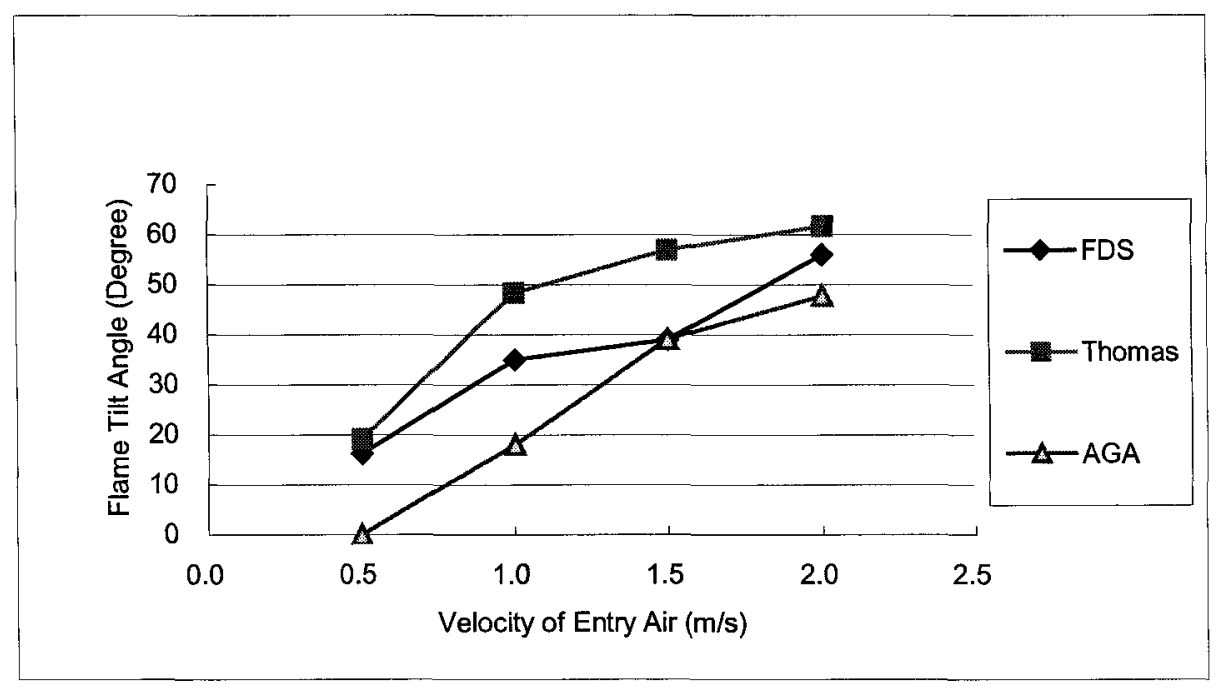

Figure 4.23 Flame tilt angle for the 1-MW fire

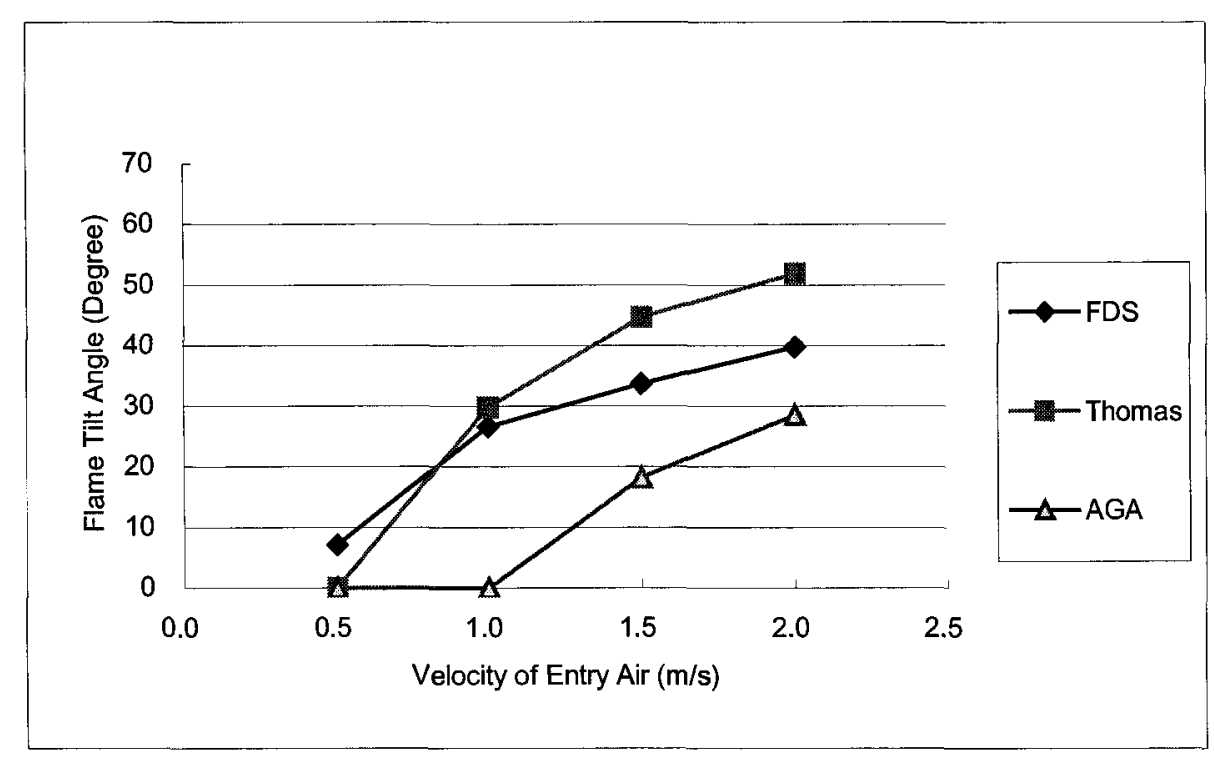

Figure 4.24 Flame tilt angle for the 5-MW fire

As we can see, for the $0.5-\mathrm{MW}$ fire, the results of the three methods are very close. FDS results are close to those obtained using the AGA calculation. For the 1-MW medium fire, the results of FDS are very close to those of Thomas but different from the AGA results. The results of FDS for the 5-MW fire compare better with the results of Thomas. 


\subsubsection{Summary}

The results of these simulations show that FDS is capable of modeling the impact of wind speed on the flames. The results demonstrate that air velocity impacts the flames of small size fires considerably more than the plumes of large fires. The results show even velocities of $1.0 \mathrm{~m} / \mathrm{s}$ cause the flame to tilt for all fire sizes simulated. Higher velocities cause significantly higher flame tilts with tilt angles larger than $45^{\circ}$.

\subsection{Impact of Opening Location}

A number of simulations have been conducted to determine the impact of the height of the opening for make-up air on the fire plume. For these simulations, an atrium was considered with dimensions of 10 meters in length, 10 meters in width and 10 meters in height. To reduce ceiling effects, the atrium was assumed to have no ceiling. A fire of $1 \mathrm{MW}$ was located 2.5 meters from the air supply opening. An opening $5 \mathrm{~m}$ wide and $3.33 \mathrm{~m}$ high was placed on one wall of the atrium at three different heights supplying the specified make-up air.

The make-up air velocity for all simulations was set to $1 \mathrm{~m} / \mathrm{s}$. The exhaust velocity was set to $0.195 \mathrm{~m} / \mathrm{s}$ that corresponds to an exhaust flow rate of $20.85 \mathrm{~kg} / \mathrm{s}$. This flow rate has been computed from equation 2-7 with a heat release rate of $1 \mathrm{MW}$ and a interface height of $8 \mathrm{~m}$. 
Figure 4.25 shows the opening at the bottom of the wall. In Figure 4.26 the bottom of the opening is $3.33 \mathrm{~m}$ above the floor, and in Figure 4.27 the bottom of the opening is $6.66 \mathrm{~m}$ above the floor. In the Figures, Vin is the make-up velocity and Ve is the exhaust velocity.

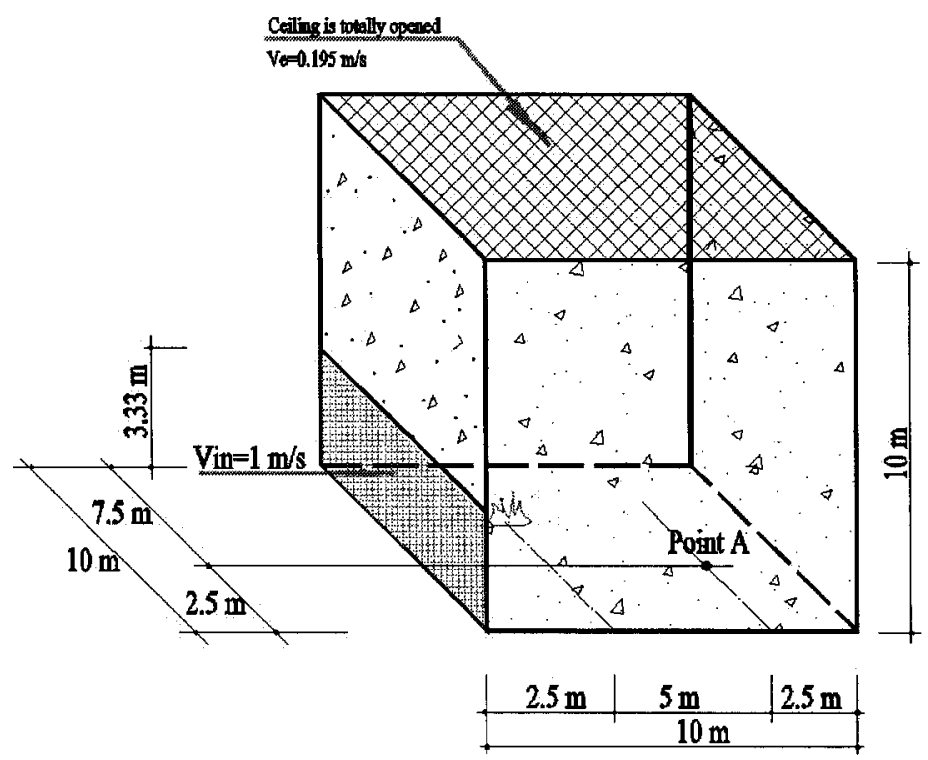

Figure 4.25 Air supply opening at the bottom of the wall

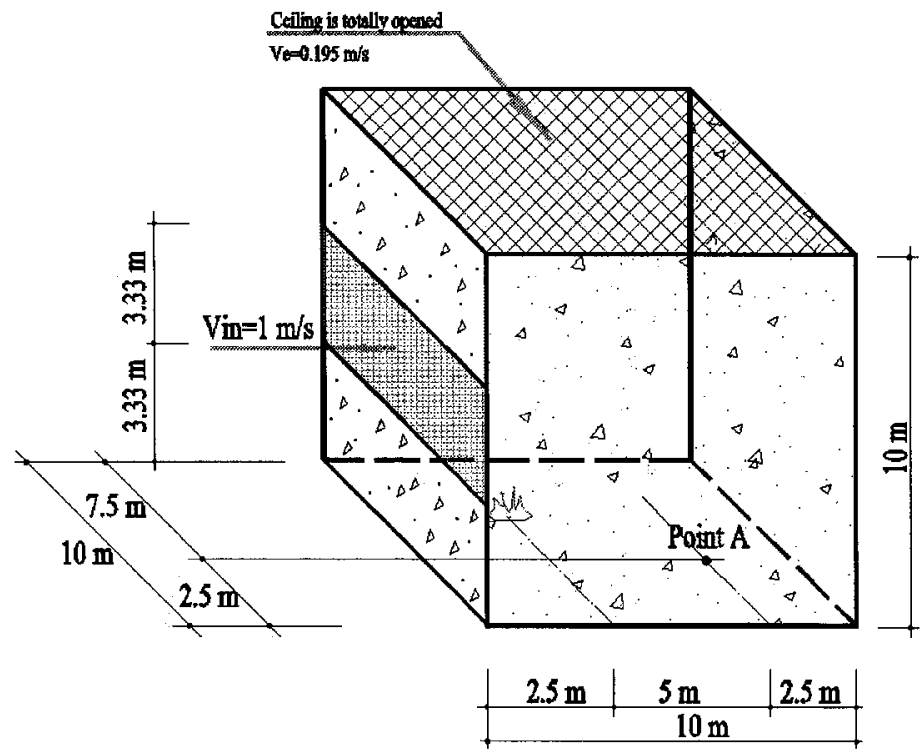

Figure 4.26 Air supply opening at the $2^{\text {nd }}$ piece of the wall 


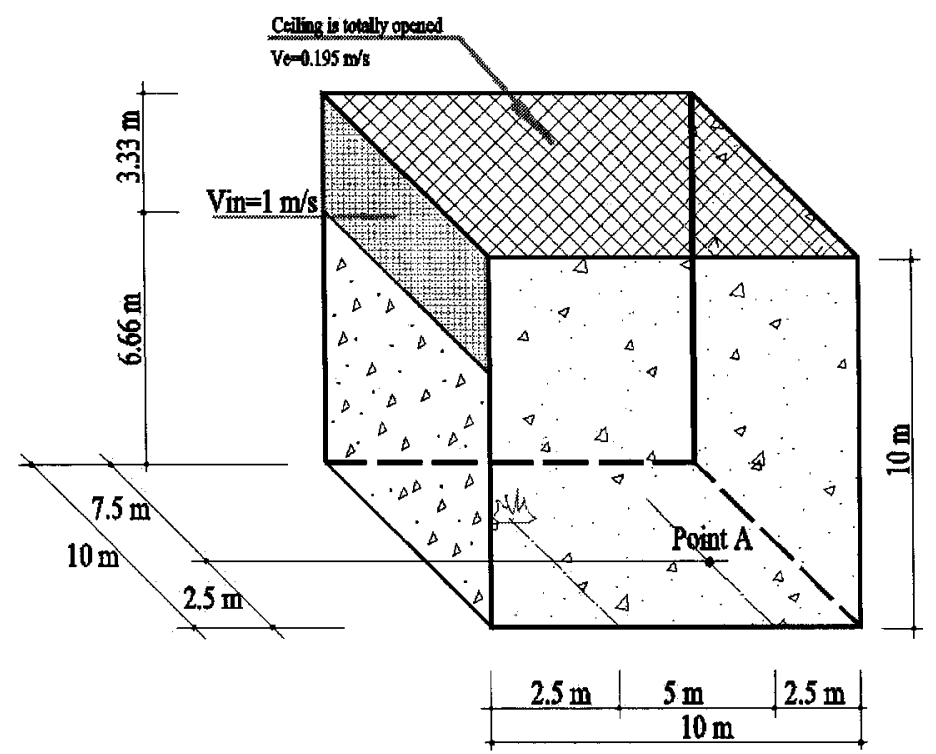

Figure 4.27 Air supply opening at the top of the wall

\subsubsection{Results}

Three simulations have been performed using FDS. Figure 4.28 shows the plume shape for the different opening locations. From Figure 4.28 (a), it can be seen that the flame tilt angle is about $10^{\circ}$ when the opening is at the bottom. The incoming air affects only the base of the flame and causes a small flame tilt however it does not affect the smoke plume much. Figure 4.28 (b) shows that when the opening is at 3.33 $\mathrm{m}$ from the floor, the incoming air disrupts the fire plume causing mixing with the surrounding air, bringing smoke to the lower part of the atrium. When the opening is at the top, the impact of the incoming air on the plume appears to be minimal. 


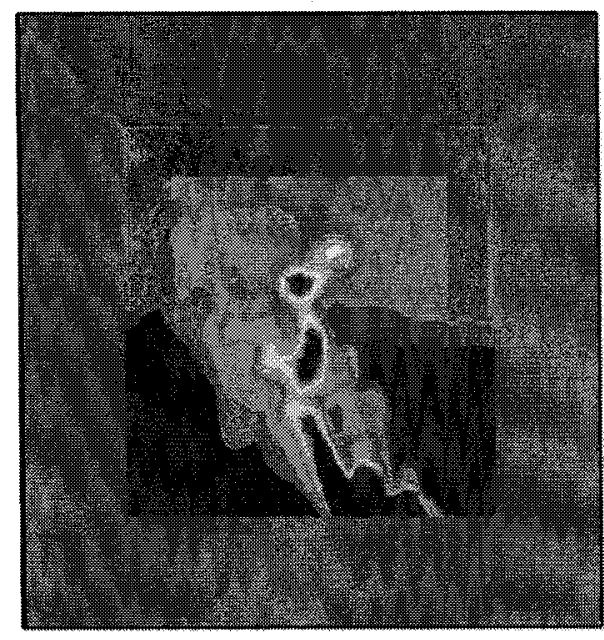

a) Opening at the ground level

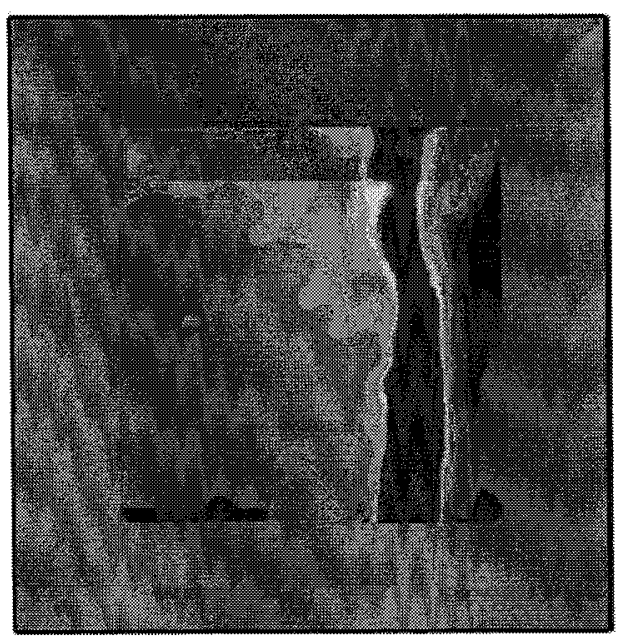

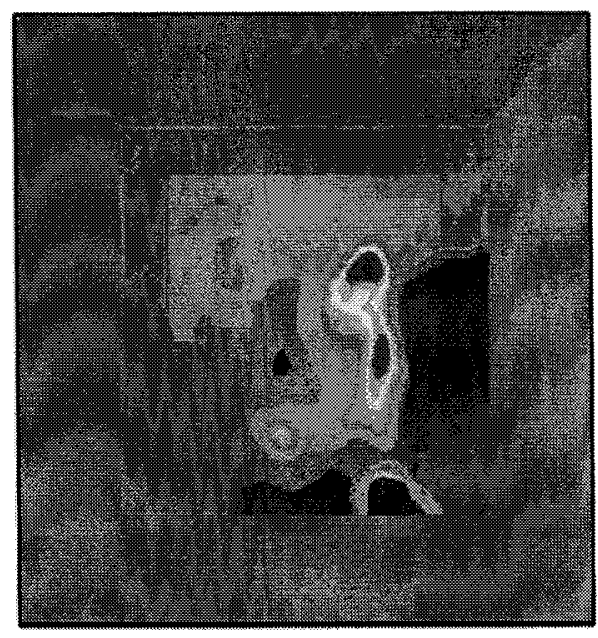

Plot3d temp c 96.5 89.0 81.5 74.0 66.5 59.0 b) Opening at $3.33 \mathrm{~m}$

c) Opening at $6.66 \mathrm{~m}$

Figure 4.28 Temperature contours on a vertical plane through the fire center, fire size

$$
=1 \mathrm{MW} \text {, for different opening locations }
$$

The impact of opening location is also demonstrated in Figure 4.29 and Figure 4.30 that show temperature and $\mathrm{CO}_{2}$ profiles respectively in the atrium for the three 
different opening locations. These profiles are at the quarter point of the atrium, Point A in Figures 4.25.

As it can be seen from these figures, the opening at the bottom of the atrium causes the least disruption to the temperature and $\mathrm{CO}_{2}$ profiles. The worst case is with the opening at $3.33 \mathrm{~m}$ from the floor. Placing the opening at the top of the atrium also causes a lot of mixing in the atrium even at the lower levels, as demonstrated by the temperature and $\mathrm{CO}_{2}$ profiles.

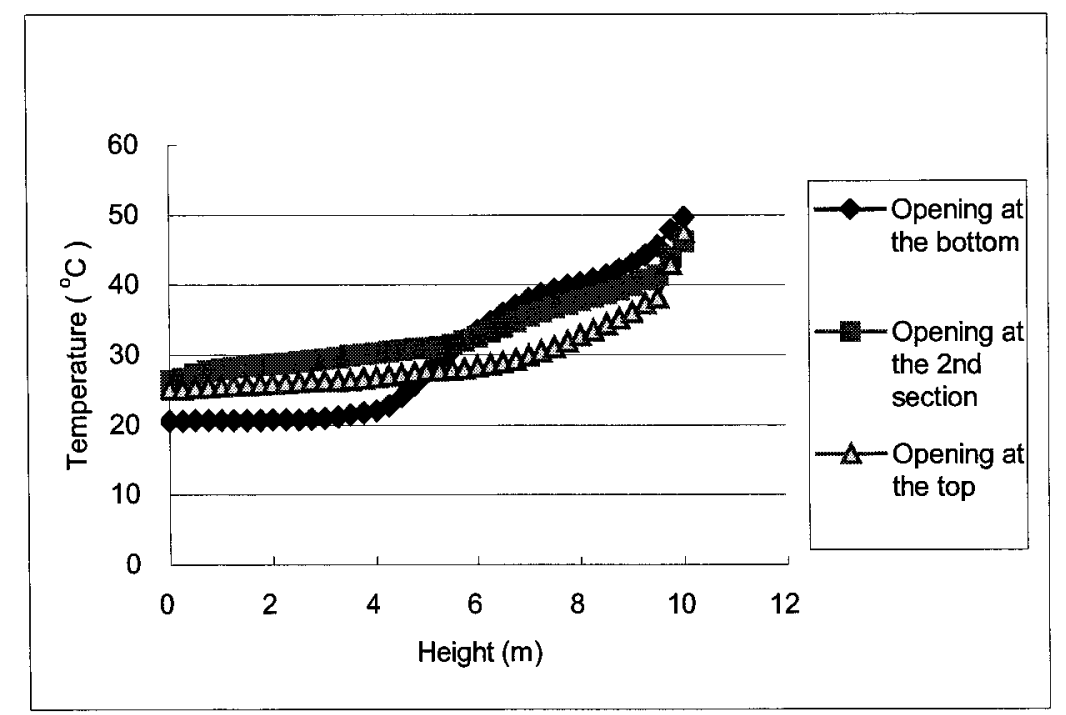

Figure 4.29 Temperature of make-up air for different opening locations 


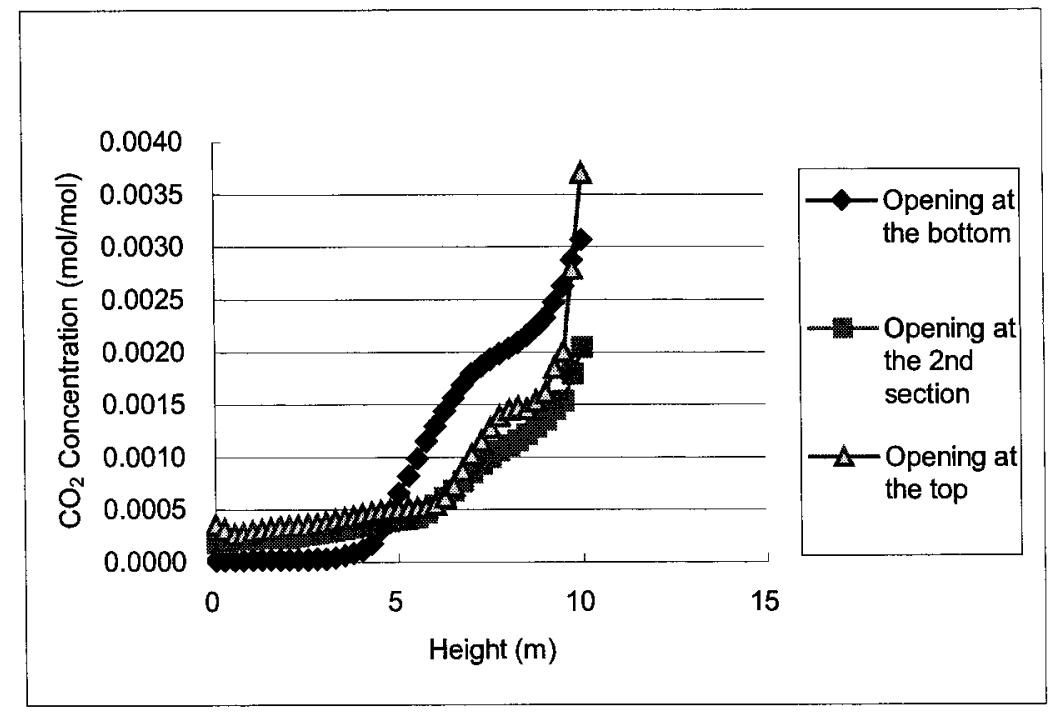

Figure $4.30 \mathrm{CO}_{2}$ concentration of make-up air for different opening locations

\subsubsection{Summary}

The results of these simulations demonstrated that the best location for the make-up air opening is near the ground. Placing these openings at higher elevation causes significant mixing at the lower layer of the atrium.

\subsection{Model Validation}

To determine the ability of FDS to predict the conditions in an atrium with mechanical exhaust, the model was used to simulate an experiment performed at the National Research Council of Canada (NRC) [32]. This experiment was done in a $9 \mathrm{~m} \mathrm{x} 6 \mathrm{mx}$ $5 \mathrm{~m}$ compartment that was equipped with mechanical exhaust. Thirty-two exhaust vents located at the ceiling were used to remove smoke as shown in Figure 4.31. 


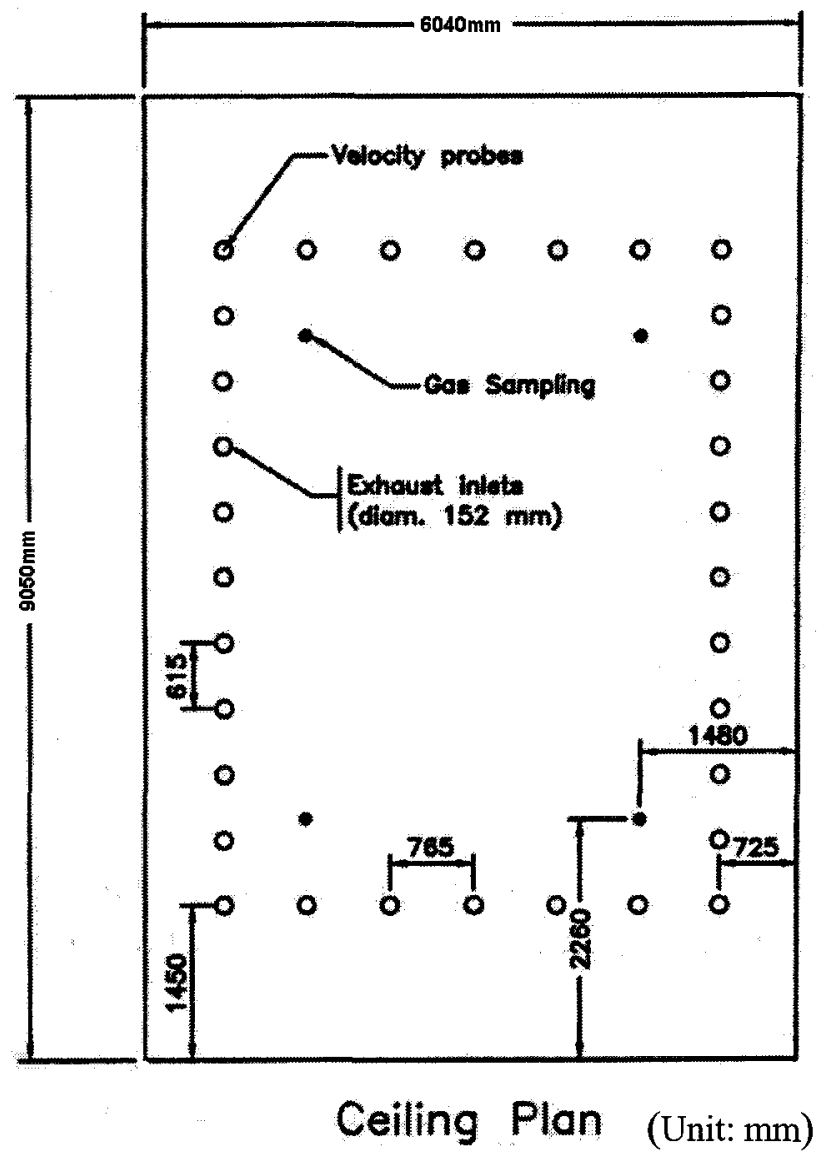

Figure 4.31 Ceiling plan showing the exhaust inlets locations.

Fresh air to the compartment was supplied through openings on the floor as shown in Figure 4.32 . 


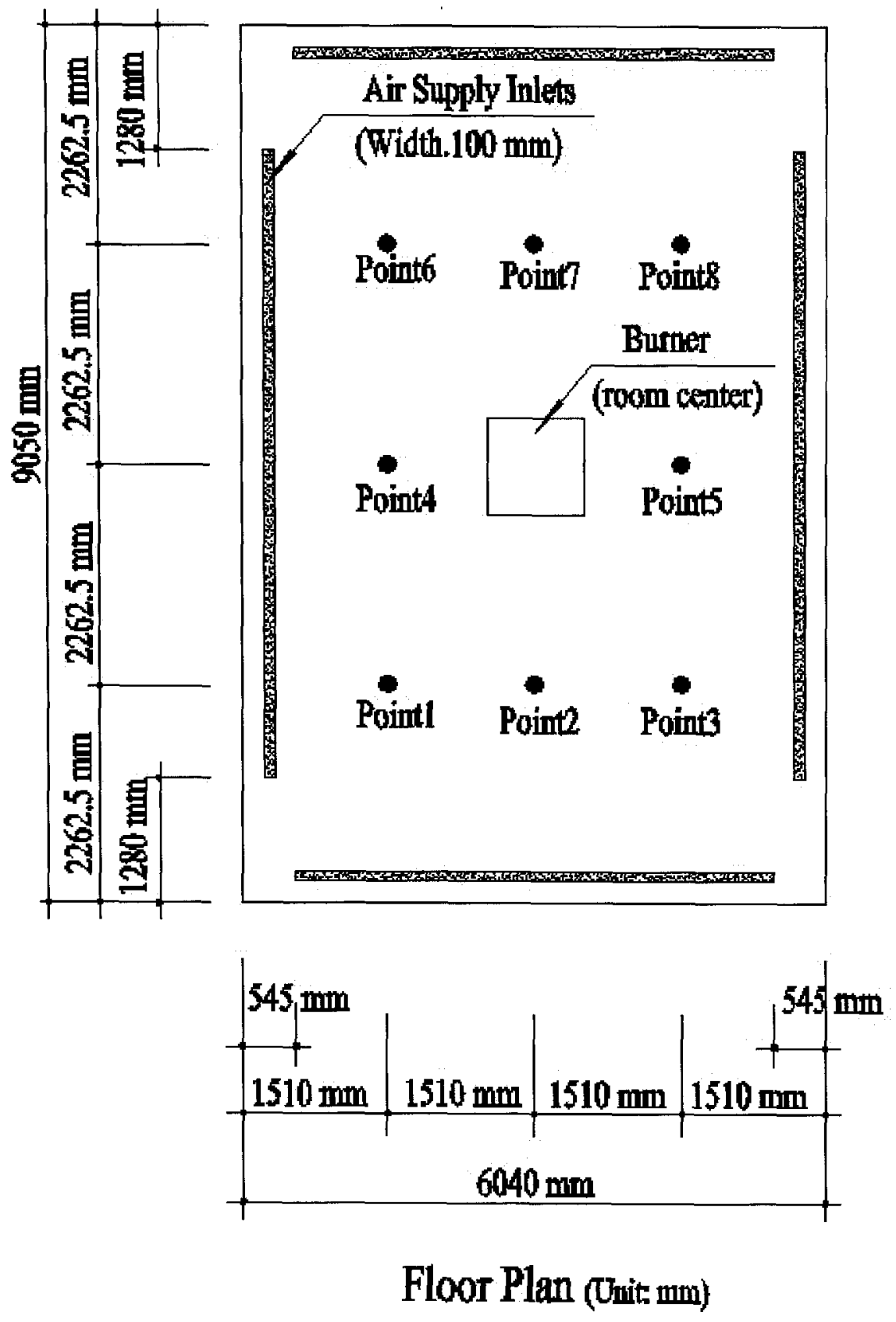

Figure 4.32 The floor plan of the room 
The exhaust system was served by a fan with a nominal capacity of $5.4 \mathrm{~m}^{3} / \mathrm{s}$. A square propane burner with an area of $1 \mathrm{~m}^{2}$ was used for the fire source. The burner was capable of simulating fires up to $600 \mathrm{~kW}$. The fire size of the test simulated was $250 \mathrm{~kW}$.

The temperature profile is the average temperature of the Point $1,2,3,4,5,6,7$ and 8 that shown in Figure 4.32 is compared to the experimental temperature profile in Figure 4.33.

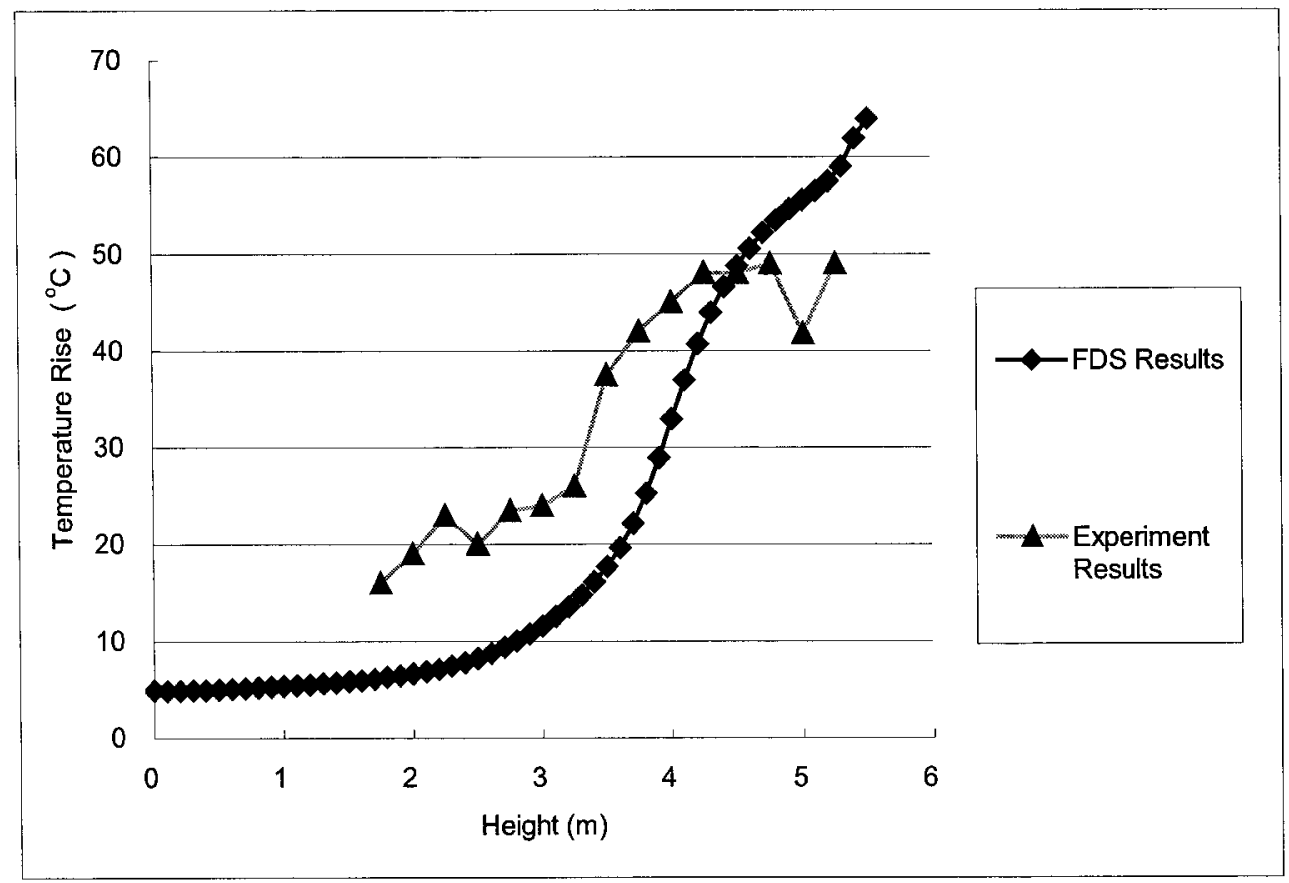

Figure 4.33 Temperature rise in atrium

The figure shows that FDS does a relatively good job in predicting the temperature profile in the atrium. The predicted temperature continues to rise up to the ceiling, while the experiment shows a more uniform temperature in the upper layer. Using the 
approach discussed in Chapter 2, the predicted hot layer height is $4.5 \mathrm{~m}$ and the experimental is $3.7 \mathrm{~m}$. The predicted average temperature of the hot layer is $54^{\circ} \mathrm{C}$, while the experimental is $45^{\circ} \mathrm{C}$. 


\section{Chapter 5}

\section{Impact of Make-Up Air Velocity}

This chapter presents the work done to determine the impact of the make-up air velocity on the conditions in the atrium and especially on the height of the smoke layer, and to investigate whether the $1 \mathrm{~m} / \mathrm{s}$ limitation imposed by NFPA 92B [1] is reasonable.

The study considered different make-up air velocities ranging from $0.5 \mathrm{~m} / \mathrm{s}$ to $1.5 \mathrm{~m} / \mathrm{s}$, three fire sizes $1 \mathrm{MW}, 2.5 \mathrm{MW}$ and $5 \mathrm{MW}$ at different locations from the opening and five different atrium sizes. Figure 3.1 shows a sketch of the atrium considered. The make-up air opening is placed on one wall of the atrium at ground level and the fire was located in front of the opening at different distances. The parameters considered for these simulations are shown in Table 5.1.

Fire was modeled using the heat release rate per unit area feature of FDS (HRRPUA). The area of the fire was varied to keep the HRRPUA at $1 \mathrm{MW} / \mathrm{m}^{2}$. The openings for make-up air for all simulations were placed at ground level. The size of the openings was varied to achieve the required make-up air velocity. The mass flow rate was calculated using the correlations in NFPA 92B such that the smoke layer height is maintained at $0.8 \mathrm{H}$, where $\mathrm{H}$ is the height of the atrium. This flow rate was used as a boundary condition in FDS at the ceiling level. To minimize the impact of the exhaust characteristics on the conditions in the atrium, the whole ceiling area was 
used to exhaust smoke. For all simulations, the convective heat release rate was assumed to the $65 \%$ of the total heat release rate. This is confirmed in Figure 5.1, which shows the total and radiative heat release rate for the $2.5-\mathrm{MW}$ fire.

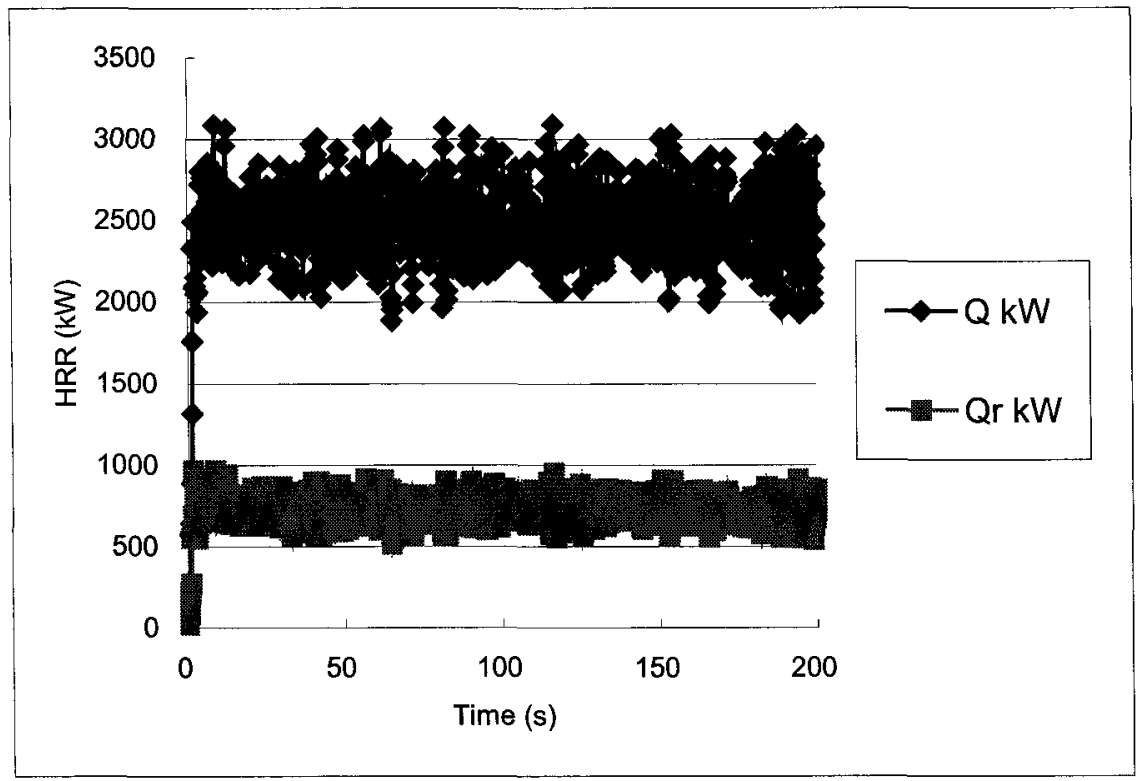

Figure 5.1 Total and radiative HRR for the 2.5-MW fire

Table 5.1 Parameters used for the simulations

\begin{tabular}{|c|c|c|c|c|c|}
\hline Atrium name & Atrium 10 & Atrium 20 & Atrium 30 & Atrium 50 & Atrium 60 \\
\hline $\begin{array}{l}\text { Atrium dimensions } \\
(\mathrm{W} \times \mathrm{L} \times \mathrm{H}),(\mathrm{m})\end{array}$ & $10 \times 10 \times 10$ & $15 \times 15 \times 20$ & $20 \times 20 \times 30$ & $30 \times 30 \times 50$ & $40 \times 40 \times 60$ \\
\hline Atrium surfaces & \multicolumn{5}{|c|}{ The walls are covered with gypsum board, and the floor is $0.2 \mathrm{~m}$ thick concrete. } \\
\hline $\begin{array}{c}\text { Fire Distance from } \\
\text { opening, (m) }\end{array}$ & 2.5 & 3.75 & 5.0 and 2.5 & 5.0 and 2.5 & 5.0 and 2.5 \\
\hline $\begin{array}{l}\text { Smoke layer height } \\
\text { above the floor }(\mathrm{m})\end{array}$ & 8 & 16 & 24 & 40 & 48 \\
\hline Fire HRR (MW) & \multicolumn{5}{|c|}{$1,2.5$, and 5} \\
\hline Opening Area & \multicolumn{5}{|c|}{ Depends on make-up air velocity } \\
\hline Opening location & \multicolumn{5}{|c|}{ Opening on one wall at ground level. } \\
\hline $\begin{array}{c}\text { Velocity of entry air } \\
\qquad(\mathrm{m} / \mathrm{s})\end{array}$ & \multicolumn{5}{|c|}{$0.5, \quad 1.0,1.25$, and 1.5} \\
\hline Exhaust fans & \multicolumn{5}{|c|}{ Fixed to provide necessary smoke layer height based on NFPA 92B correlation. } \\
\hline
\end{tabular}


To consider all parameters shown in Table 5.1, 96 simulations were performed. The results of these simulations are presented in the following sections.

\subsection{Results and Discussion}

\subsubsection{Results for 10-m Tall Atrium}

The fire for the $10-\mathrm{m}$ tall atrium simulations was placed $2.5 \mathrm{~m}$ from the opening. Simulations were done for the three fire sizes and four different make-up air velocities.

The mass flow rate of the exhaust for the 1-MW fire simulations was set to $20.85 \mathrm{~kg} / \mathrm{s}$, and the area of the make-up air openings was set to $35.36 \mathrm{~m}^{2}, 17.67 \mathrm{~m}^{2}, 14.13 \mathrm{~m}^{2}$ and $11.79 \mathrm{~m}^{2}$, in order to obtain the four velocities. Figure 5.2 depicts temperature variation with time at the quarter point of the atrium and three different heights. The figure clearly show that steady state conditions in the atrium occurred at about $100 \mathrm{~s}$. Based on this, the simulation time for all simulation for this atrium size was set to 200 s. 


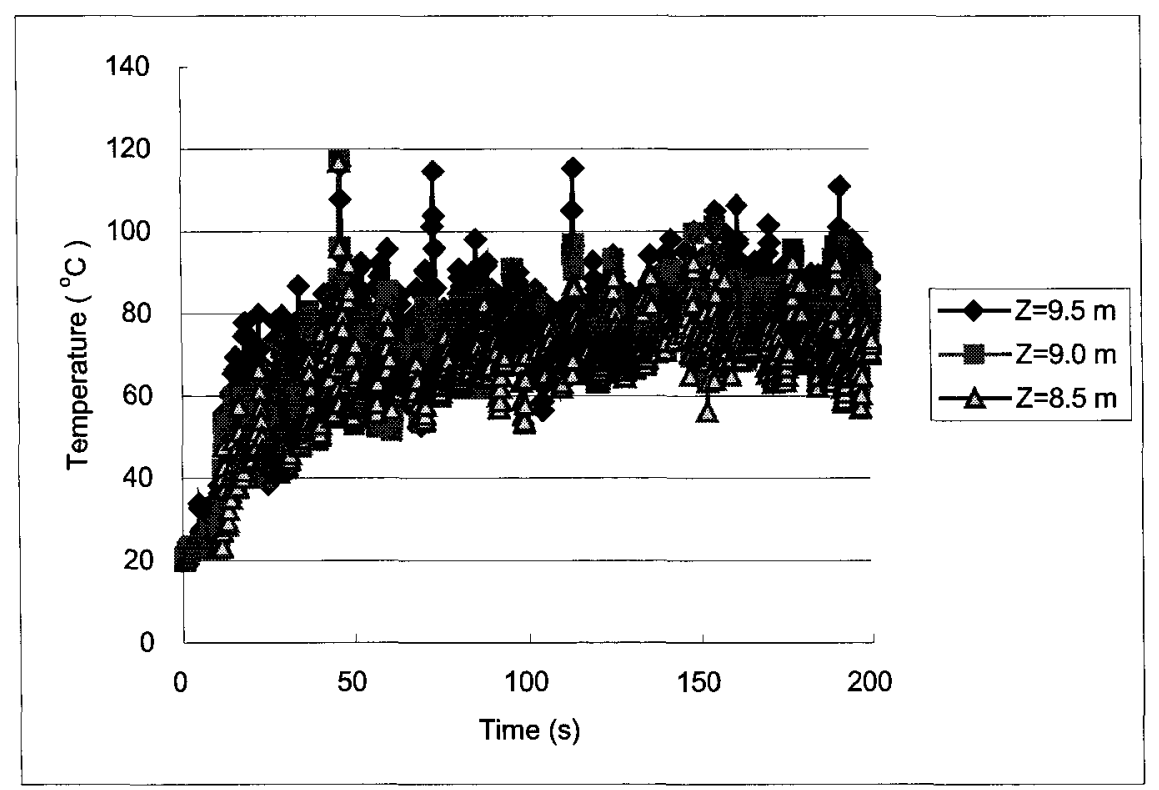

Figure 5.2 Temperature variations with time in $10-\mathrm{m}$ tall atrium

Figure 5.3 shows the temperature distributions at $200 \mathrm{~s}$ on a vertical plane passing through the fire centerline and the centre of the opening for the 1-MW fire and the four different make-up air velocities: $0.5 \mathrm{~m} / \mathrm{s}, 1.0 \mathrm{~m} / \mathrm{s}, 1.25 \mathrm{~m} / \mathrm{s}$ and $1.5 \mathrm{~m} / \mathrm{s}$.

As shown in Figure 5.3 (a), when the make-up air velocity is $0.5 \mathrm{~m} / \mathrm{s}$, the plume is not affected by the incoming air. It rises vertically to the ceiling and the hot layer is maintained at the design level.

Figure 5.3 (b) shows that the make-up air velocity of $1 \mathrm{~m} / \mathrm{s}$ causes the plume to tilt by about $10^{\circ}$, and the volume of the plume is much larger as there is more mixing with the surrounding air. This additional entrainment decrease the height of the hot layer interface. Increasing the make-up air velocity to $1.25 \mathrm{~m} / \mathrm{s}$ cause more disturbance to the plume and the hot layer to decrease further. This effect is shown in Figure 5.3 (c). 
Figure 5.3 (d) shows that the $1.5 \mathrm{~m} / \mathrm{s}$ make-up air velocity results in a plume tilt of about $45^{\circ}$ and causes a smoke mixing with the air in the lower layer.

In summary, the results of the simulations for the 1-MW fire in the 10-m tall atrium shown graphically in Figure 5.3 clearly shows the impact of the make-up air velocity on the plume and the hot layer height. Even the $1.0 \mathrm{~m} / \mathrm{s}$ make-up air velocity causes the plume to tilt and the hot layer to descend. This effect increases with increased velocity.

The locations in the atrium for calculating the interface height were shown in Figure 3.1. To further analyze the results of these simulations, temperature and $\mathrm{CO}_{2}$ concentrations at Point 7, shown in Figure 3.1 are considered. 


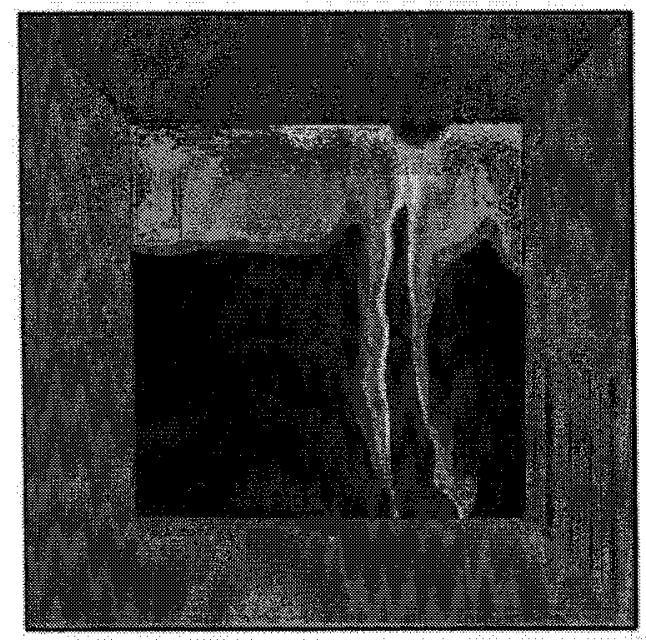

(a) Make-up air velocity $=0.5 \mathrm{~m} / \mathrm{s}$

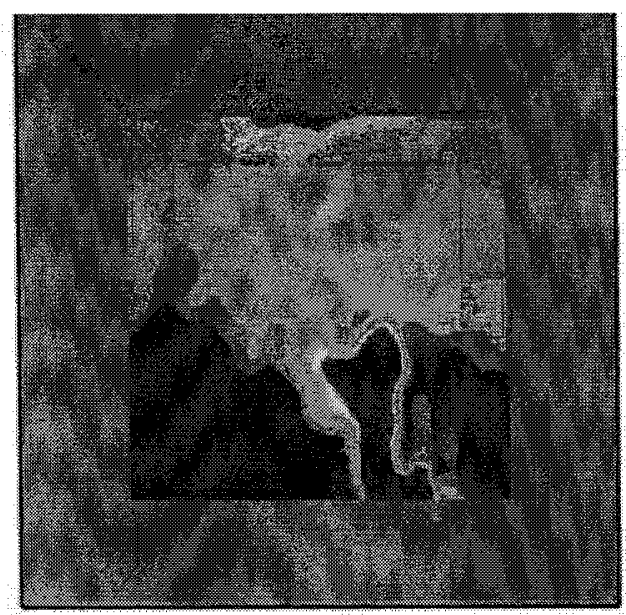

(c) Make-up air velocity $=1.25 \mathrm{~m} / \mathrm{s}$

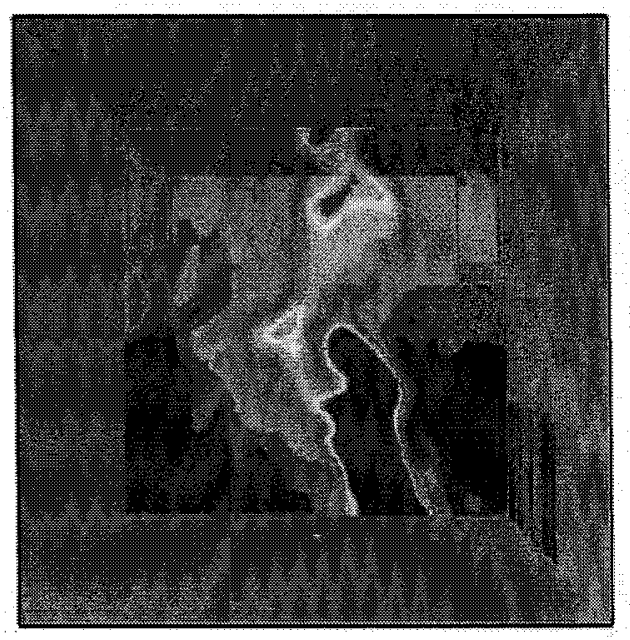

Plot3d

temp

c

85.0

78.5

72.0

65.5

59.0

52.5

(b) Make-up air velocity $=1.0 \mathrm{~m} / \mathrm{s}$

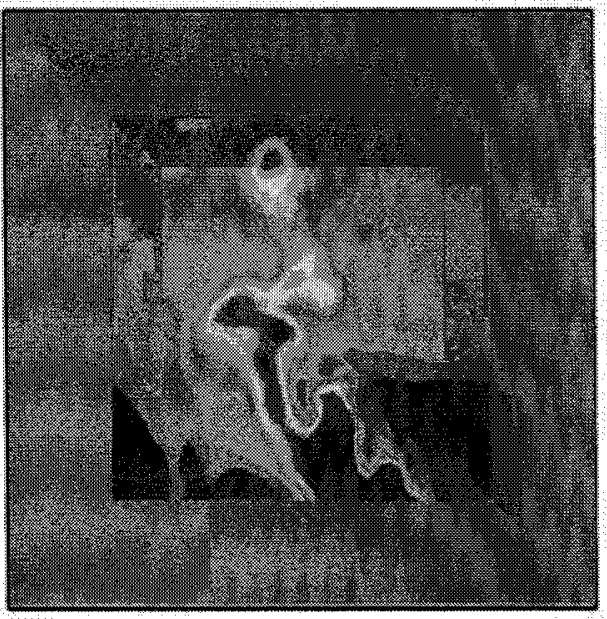

39.5

33.0

26.5

20.0

Figure 5.3 Temperature contours in 10-m tall atrium on a vertical plane through the

fire center, fire size $=1 \mathrm{MW}$

Figure 5.4 shows the temperature profiles with different make-up air velocities at

Point 7 and Figure 5.5 illustrates the $\mathrm{CO}_{2}$ profiles at the same location. The profiles are obtained by averaging the predictions over a $50 \mathrm{~s}$ period, from $150 \mathrm{~s}$ to $200 \mathrm{~s}$. Both the temperature and $\mathrm{CO}_{2}$ profiles show that increasing the make-up air velocity from $0.5 \mathrm{~m} / \mathrm{s}$ to $1.0 \mathrm{~m} / \mathrm{s}$ increases the thickness of the transition zone between the 
lower and the upper layer, a trend that is also observed with the $1.25 \mathrm{~m} / \mathrm{s}$ velocity. An important observation is the increased temperature of the lower layer for the $1.5 \mathrm{~m} / \mathrm{s}$ simulation, which is a result of the mixing of smoke with air in the lower layer.

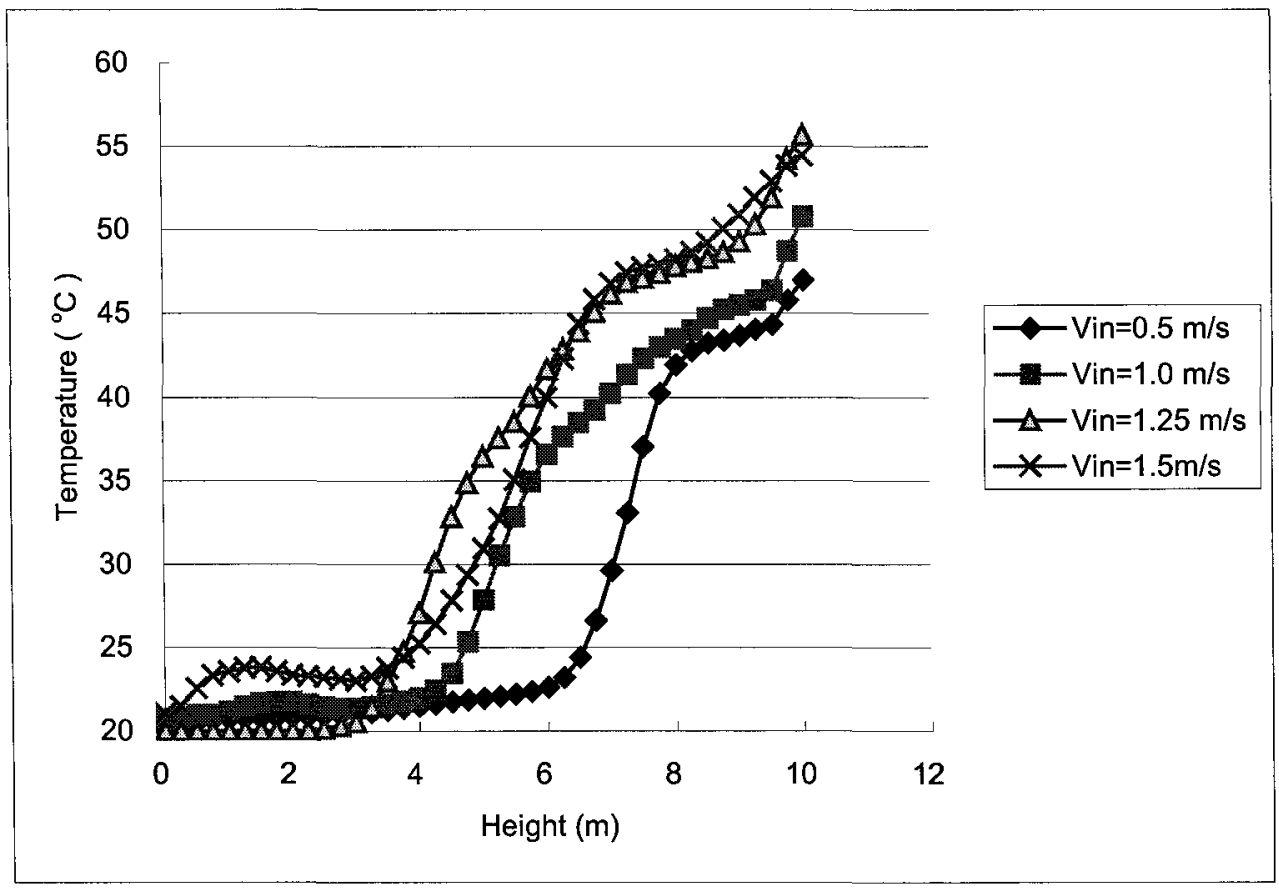

Figure 5.4 Temperature profiles in 10-m tall atrium with 1- MW fire

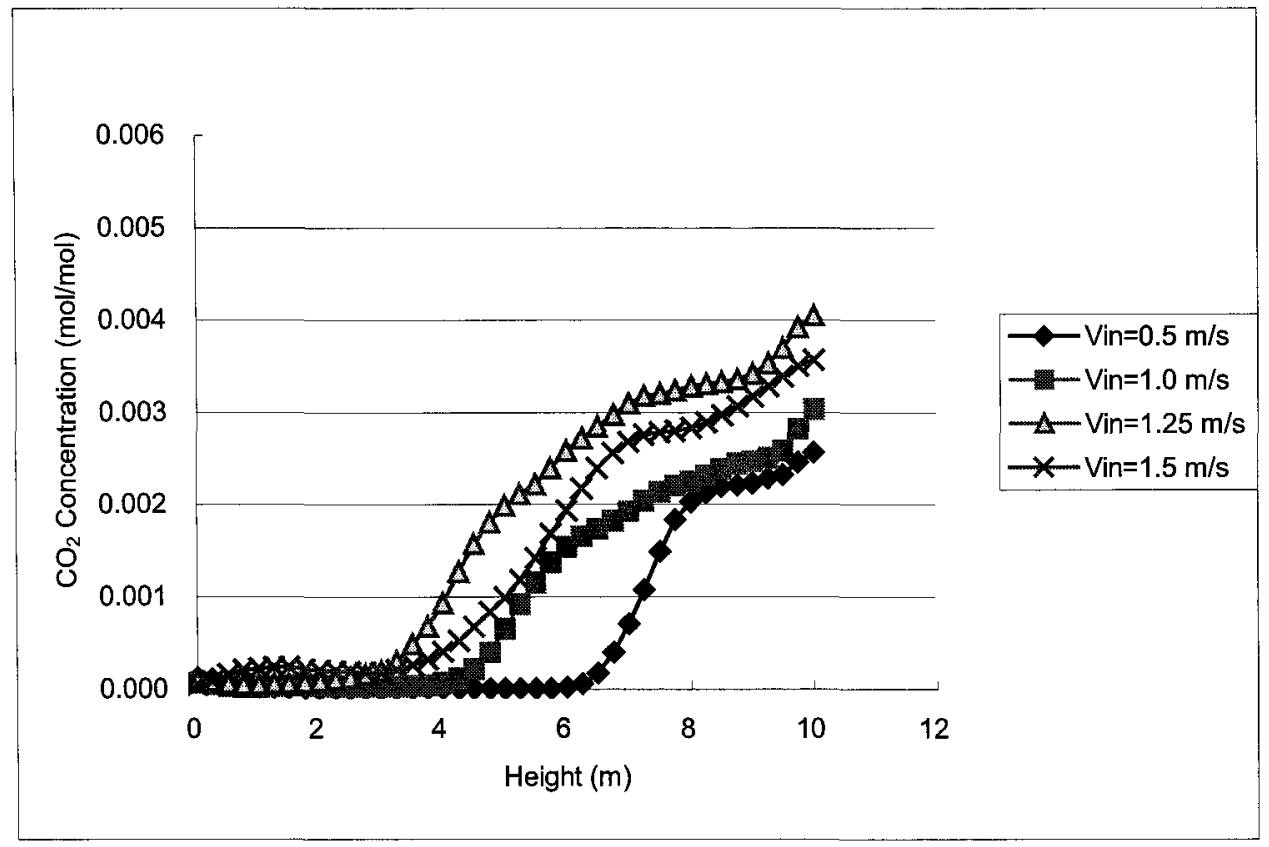

Figure $5.5 \mathrm{CO}_{2}$ profiles in $10-\mathrm{m}$ tall atrium with 1 - MW fire 
The mass flow rate for the $2.5-\mathrm{MW}$ fire was set to $29.64 \mathrm{~kg} / \mathrm{s}$. The four opening areas to achieve the require make-up air velocities were: $50.22 \mathrm{~m}^{2}, 25.11 \mathrm{~m}^{2}, 20.1 \mathrm{~m}^{2}$ and $16.74 \mathrm{~m}^{2}$. The results of the simulations for the $2.5-\mathrm{MW}$ fire size are similar to those of the 1-MW fire however the effect is not as severe. This can be seen in the contours of these simulations at $200 \mathrm{~s}$ shown in Figure 5.6 for the four make-up air velocities.

Figure 5.6 (a) shows the temperature contours for the $0.5 \mathrm{~m} / \mathrm{s}$ make-up air velocity. Although the make-up air does not affect the lower part of the plume it causes some disturbance at the middle parts mainly because of the height of the opening that extends to $6 \mathrm{~m}$, in order to accommodate the large opening area required to achieve the $0.5 \mathrm{~m} / \mathrm{s}$ velocity. This disturbance however does not seem to affect the height of the hot layer which is maintained at the design level.

Increasing the velocity to $1.0 \mathrm{~m} / \mathrm{s}$, Figure $5.6(\mathrm{~b})$, does not seem to affect much the plume or the hot layer. The velocities of $1.25 \mathrm{~m} / \mathrm{s}$ and $1.5 \mathrm{~m} / \mathrm{s}$ cause the hot layer height to decrease as they generate more entrainment into the plume, as shown in Figure $5.6(c)$ and (d). 


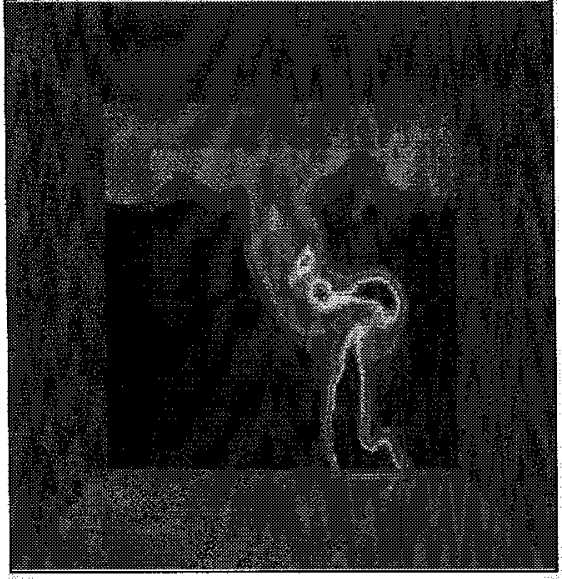

(a) Make-up air velocity $=0.5 \mathrm{~m} / \mathrm{s}$

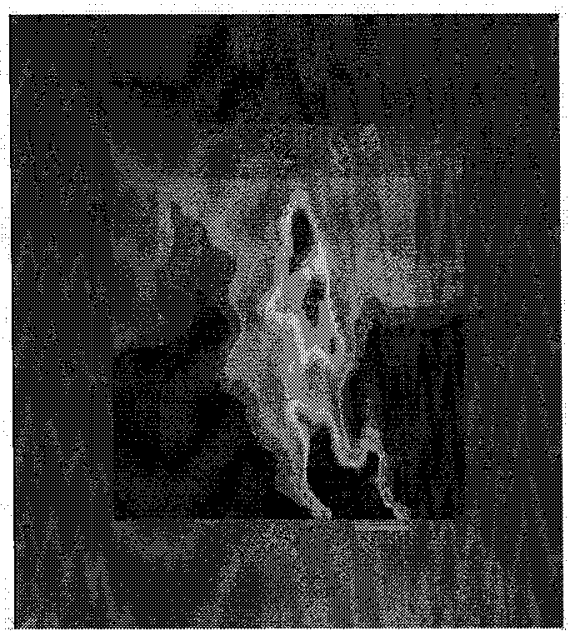

(c) Make-up air velocity $=1.25 \mathrm{~m} / \mathrm{s}$
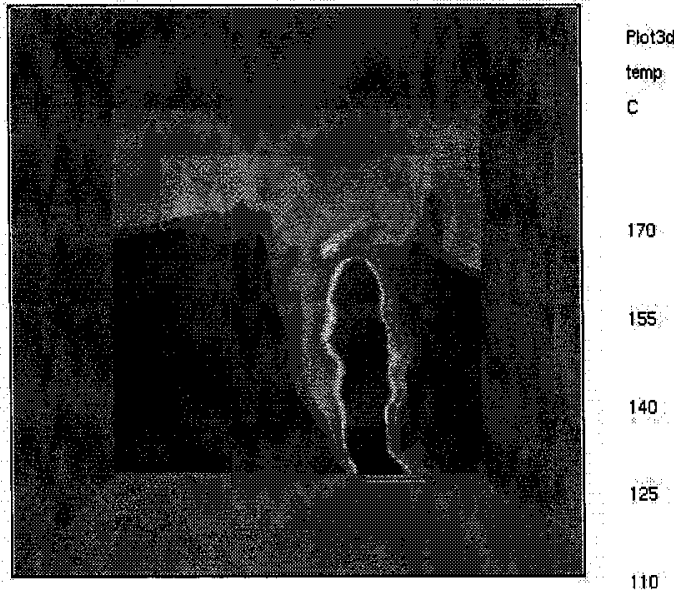

(b) Make-up air velocity $=1.0 \mathrm{~m} / \mathrm{s}$

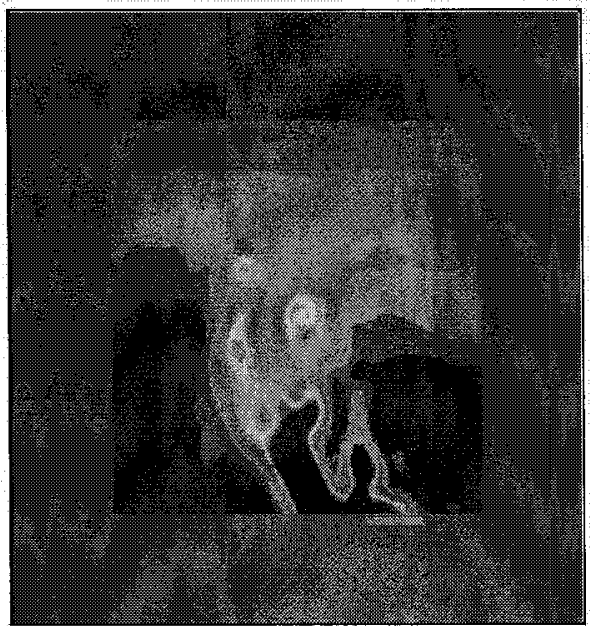

95.0

800

650

50.

350

$20: 0$

Figure 5.6 Temperature contours in 10-m tall atrium on a vertical plane through the fire center, fire size $=2.5 \mathrm{MW}$

Figures 5.7 and 5.8 show the temperature and $\mathrm{CO}_{2}$ profiles at Point 7 . The figures show that the interface height is above $8 \mathrm{~m}$ when the make-up air velocity is $0.5 \mathrm{~m} / \mathrm{s}$ and $1.0 \mathrm{~m} / \mathrm{s}$. The make-up air velocity of $1.25 \mathrm{~m} / \mathrm{s}$ and $1.5 \mathrm{~m} / \mathrm{s}$ cause the interface height to drop to around $7 \mathrm{~m}$. 


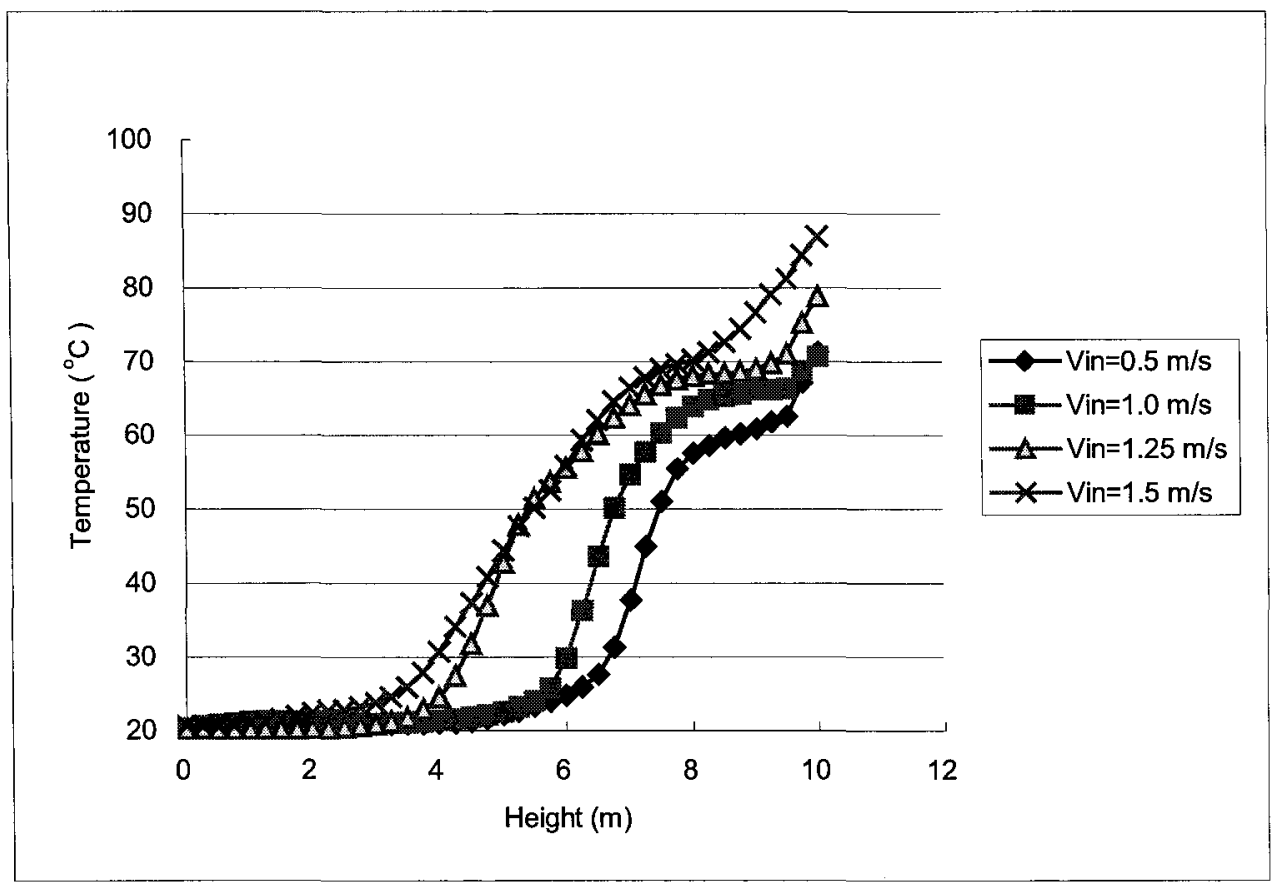

Figure 5.7 Temperature profiles in 10-m tall atrium with 2.5-MW fire

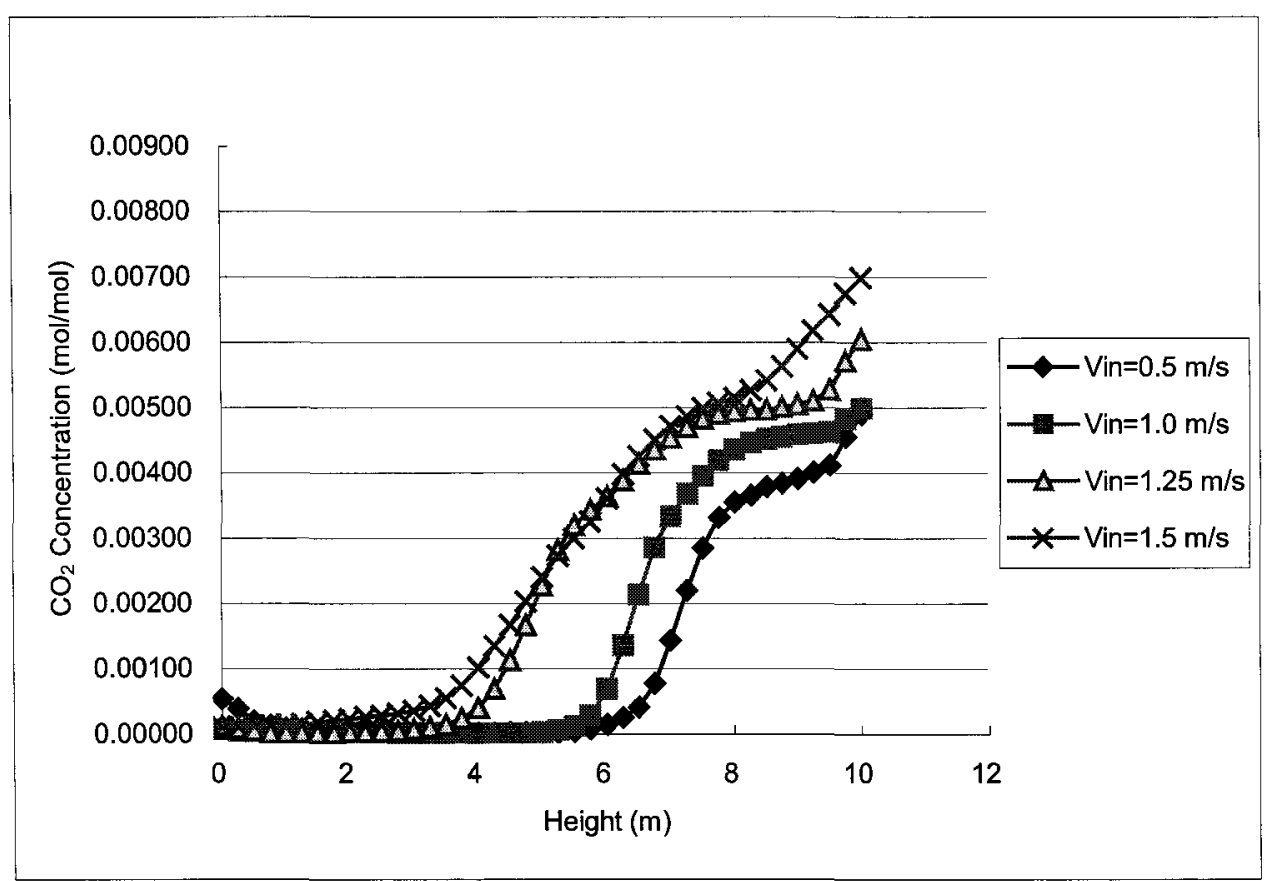

Figure $5.8 \mathrm{CO}_{2}$ profiles in $10-\mathrm{m}$ tall atrium with $2.5-\mathrm{MW}$ fire 
For the 5-MW fire, the exhaust flow rate was $39.5 \mathrm{~kg} / \mathrm{s}$ and the areas of the openings were $66.99 \mathrm{~m}^{2}, 33.50 \mathrm{~m}^{2}, 26.79 \mathrm{~m}^{2}$ and $22.32 \mathrm{~m}^{2}$. Figure 5.9 shows the temperature contours for this fire size at $200 \mathrm{~s}$.

Figure 5.9 (a) shows the fire plume with a $0.5 \mathrm{~m} / \mathrm{s}$ make-up air velocity. The plume rises unaffected straight to the ceiling and the hot layer remains high. Figure 5.9 (b) that depicts the temperature contours with a make-up air velocity of $1.0 \mathrm{~m} / \mathrm{s}$ shows that this velocity does not affect the plume nor the interface height significantly. The make-up air velocities of $1.25 \mathrm{~m} / \mathrm{s}$ and $1.5 \mathrm{~m} / \mathrm{s}$ cause some disturbance to the plume and a drop of the interface height as it can be seen in Figures 5.9 (c) and (d). 


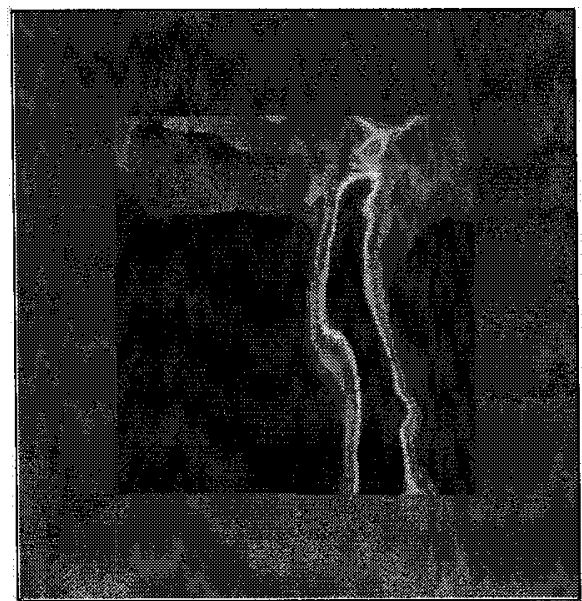

(a) Make-up air velocity $=0.5 \mathrm{~m} / \mathrm{s}$

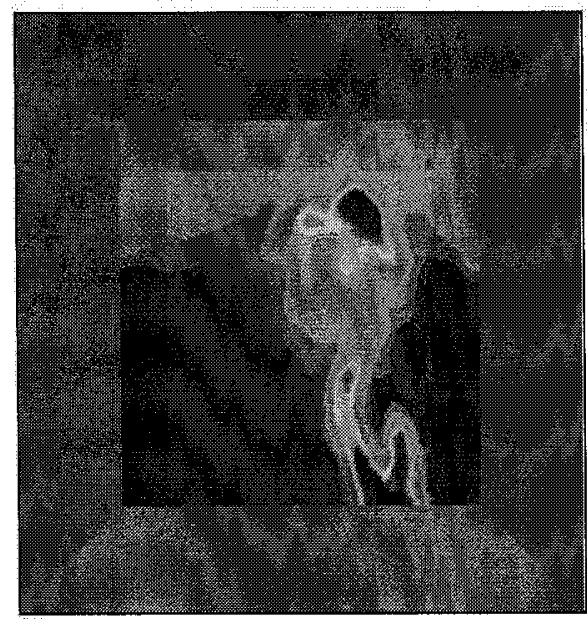

(c) Make-up air velocity $=1.25 \mathrm{~m} / \mathrm{s}$

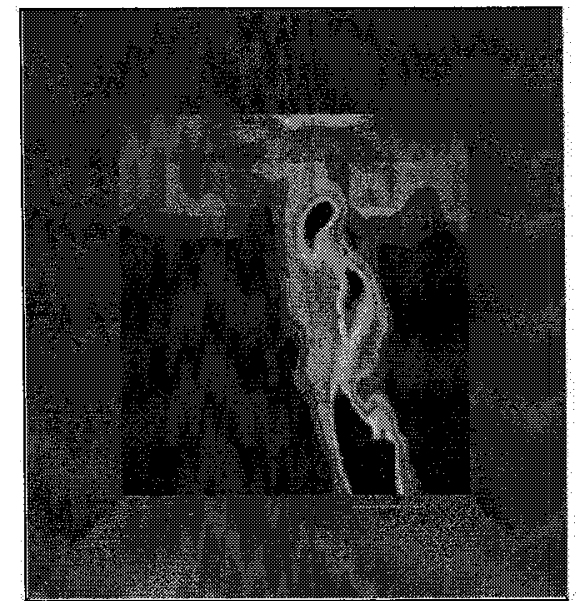

Plot3id

temp

C

270
245
220
195
170

145

(b) Make-up air velocity $=1.0 \mathrm{~m} / \mathrm{s}$

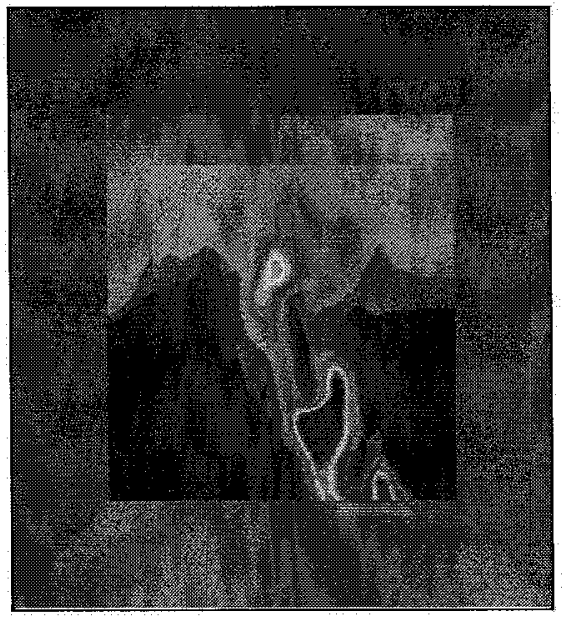

120

95.0

70.0

450

20.0

(d) Make-up air velocity $=1.5 \mathrm{~m} / \mathrm{s}$

Figure 5.9 Temperature contours in $10-\mathrm{m}$ tall atrium on a vertical plane through the

fire center, fire size $=5 \mathrm{MW}$

Figures 5.10 and 5.11 show the temperature and $\mathrm{CO}_{2}$ profiles at Point 7 for the four make-up air velocities. Both temperature and $\mathrm{CO}_{2}$ profiles show that the profiles are affected by the increased make-up air velocity, however the interface height does not decrease much. 


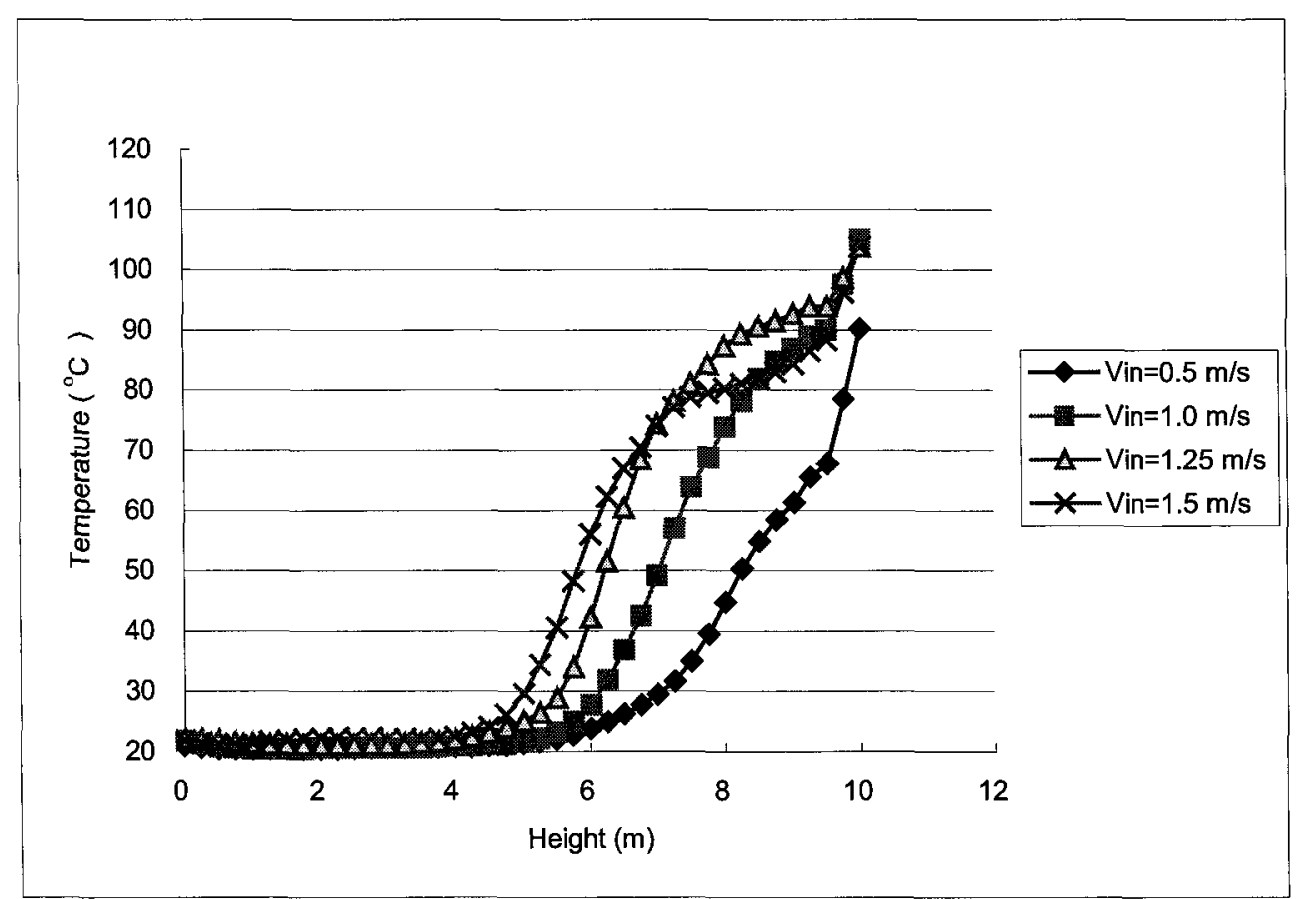

Figure 5.10 Temperature profiles in 10-m tall atrium with 5-MW fire

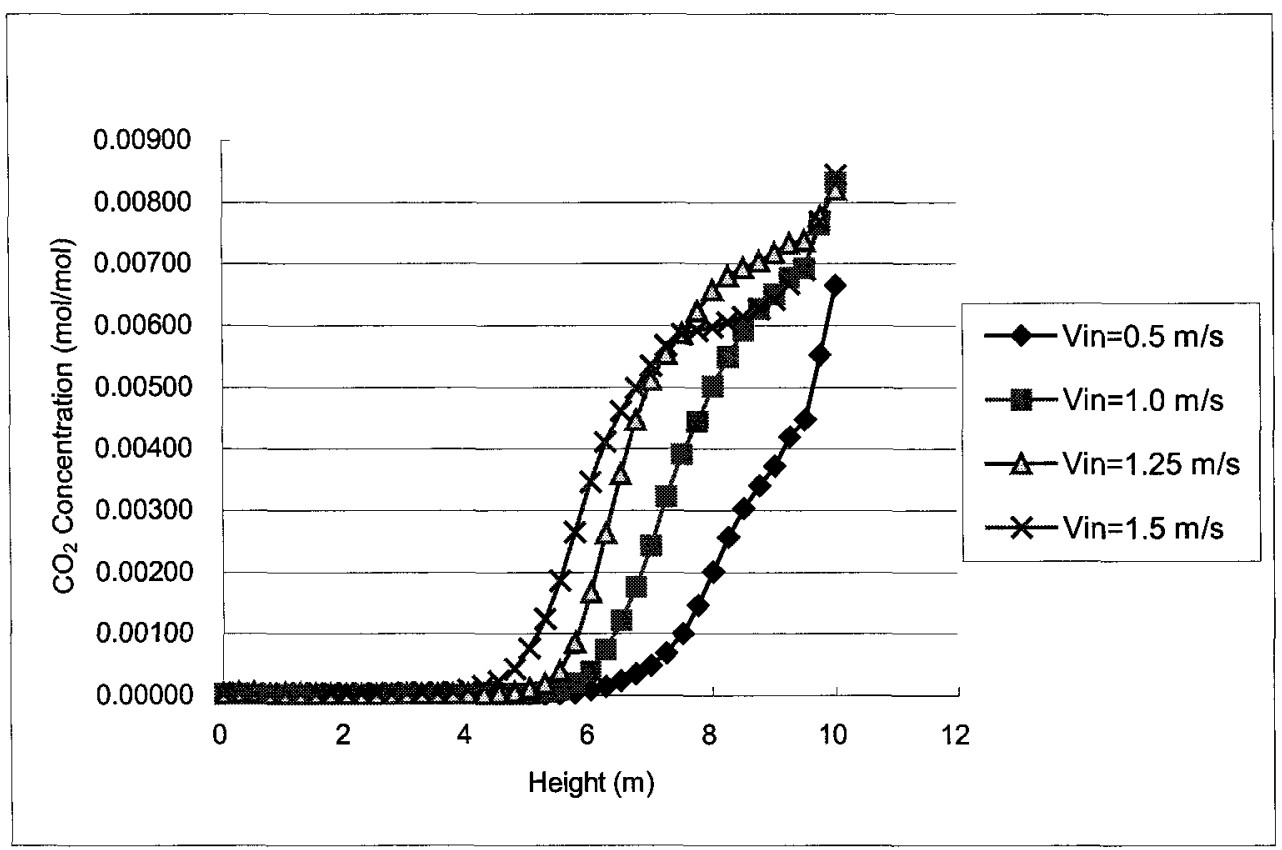

Figure 5.11 $\mathrm{CO}_{2}$ profiles in 10-m tall atrium with 5-MW fire

The interface heights for the $10-\mathrm{m}$ tall atrium are summarized in Table 5.2. The values shown on this table are time-averaged values over the $150 \mathrm{~s}-200 \mathrm{~s}$ period of the 
simulation. The average values shown in the last column are average values of Points 1 to 9 . The table shows that for all heat release rates, the predicted interface height is close to $8 \mathrm{~m}$, the value used in equation 2.7 , to compute the exhaust flow rates. The values indicate that as the strength of the fire increase, the impact of the make-up air velocity on interface height decrease. For all fire sizes, however velocities of $1.25 \mathrm{~m} / \mathrm{s}$ and $1.5 \mathrm{~m} / \mathrm{s}$ cause significant reduction of the interface height. As seen in the table, the lowest interface height corresponds to the 1-MW fire with a velocity of $1.5 \mathrm{~m} / \mathrm{s}$. 
Table 5.2 Interface heights in $10-\mathrm{m}$ tall atrium

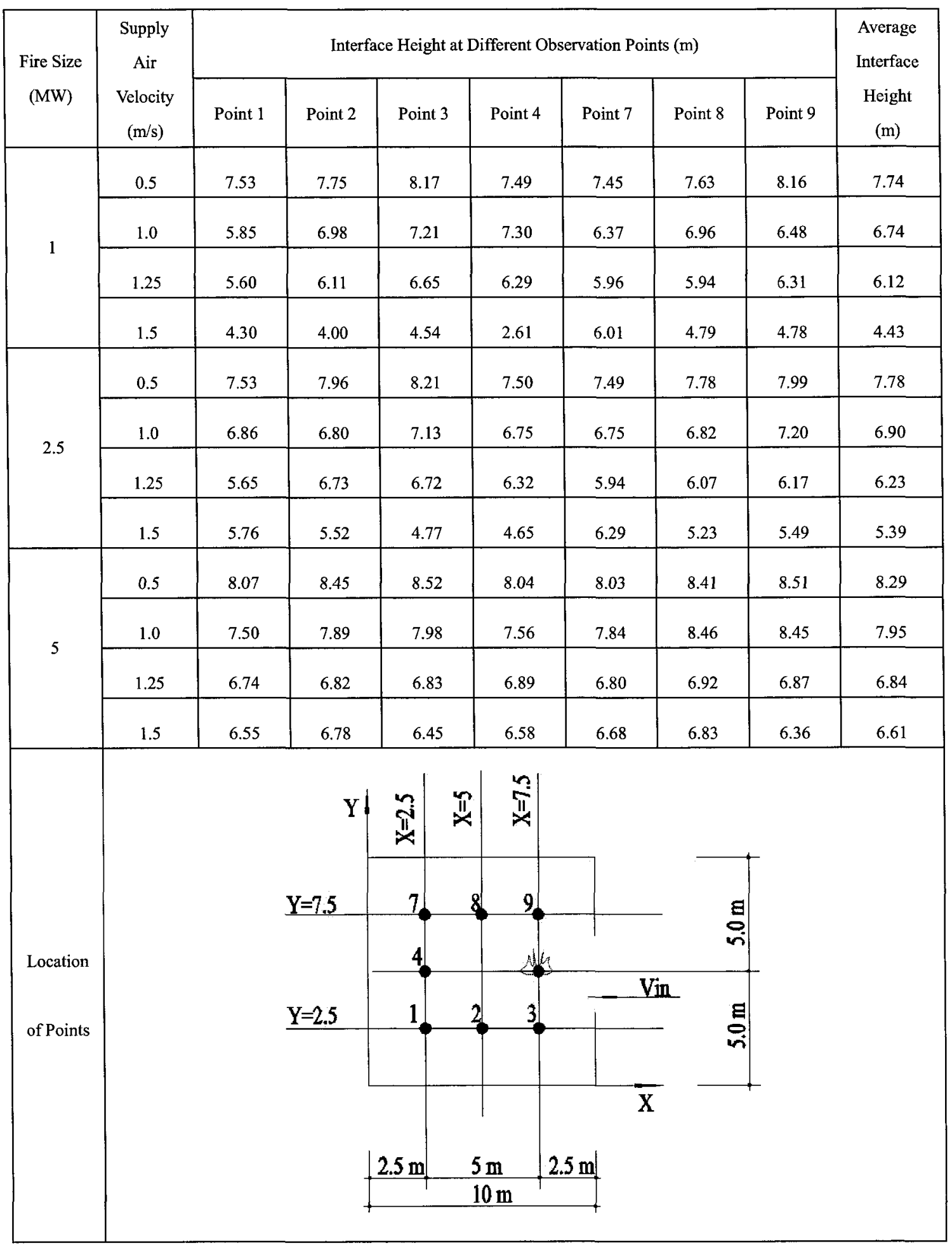




\subsubsection{Results for 20-m Tall Atrium}

The fire for the $20-\mathrm{m}$ tall atrium simulations was placed at $3.75 \mathrm{~m}$ from the opening.

Simulations were done for the three fire sizes and four different make-up air velocities.

The mass flow rate of the exhaust for the 1-MW fire simulations was set to $63.65 \mathrm{~kg} / \mathrm{s}$, and the area of the make-up air openings was set to $107.92 \mathrm{~m}^{2}, 53.96 \mathrm{~m}^{2}, 43.14 \mathrm{~m}^{2}$ and $35.97 \mathrm{~m}^{2}$, in order to obtain the four velocities. Figure 5.12 which depicts temperature variations with time for the 1-MW fire case at the quarter point of the atrium and different heights shows that steady state conditions were reached at $150 \mathrm{~s}$ for this atrium.

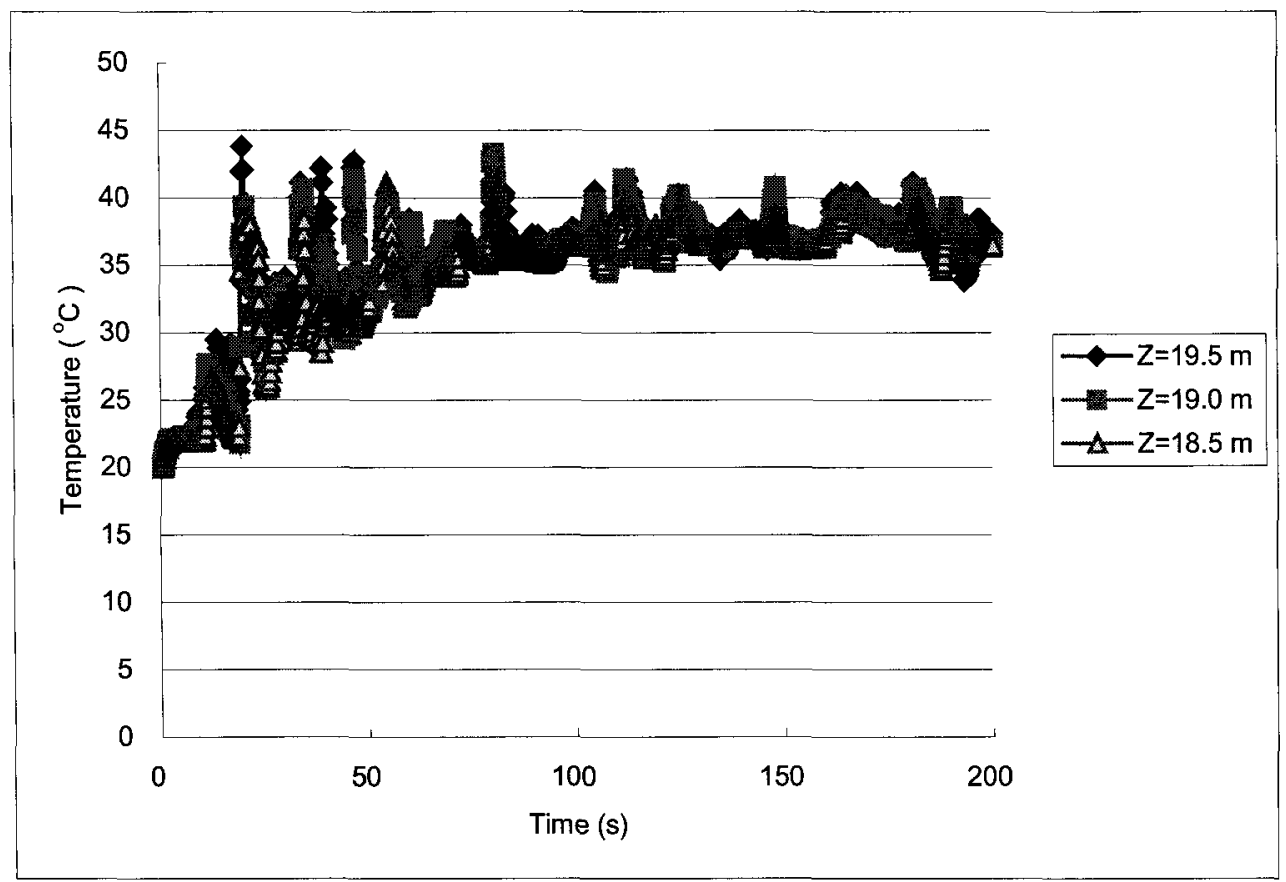

Figure 5.12 Temperature variations with time in 20 -m tall atrium 
Figure 5.13 shows the temperature distributions at $200 \mathrm{~s}$ on a vertical plane passing through the fire centerline and the center of the opening for the 1-MW fire and the four different make-up air velocities: $0.5 \mathrm{~m} / \mathrm{s}, 1.0 \mathrm{~m} / \mathrm{s}, 1.25 \mathrm{~m} / \mathrm{s}$ and $1.5 \mathrm{~m} / \mathrm{s}$. As shown in the figure, when the make-up air velocity reaches $1.0 \mathrm{~m} / \mathrm{s}$ the plume starts to tilt. This effect increases with increased velocity. When the make-up air velocity rises to $1.5 \mathrm{~m} / \mathrm{s}$, the entry airflow causes the plume to tilt by over $45^{\circ}$.

Figure 5.14 shows the temperature profiles with different make-up air velocities at Point 7 and Figure 5.15 depicts the $\mathrm{CO}_{2}$ profiles at the same location. These figures also show that the increased make-up air velocity cause a decrease of the interface height. 

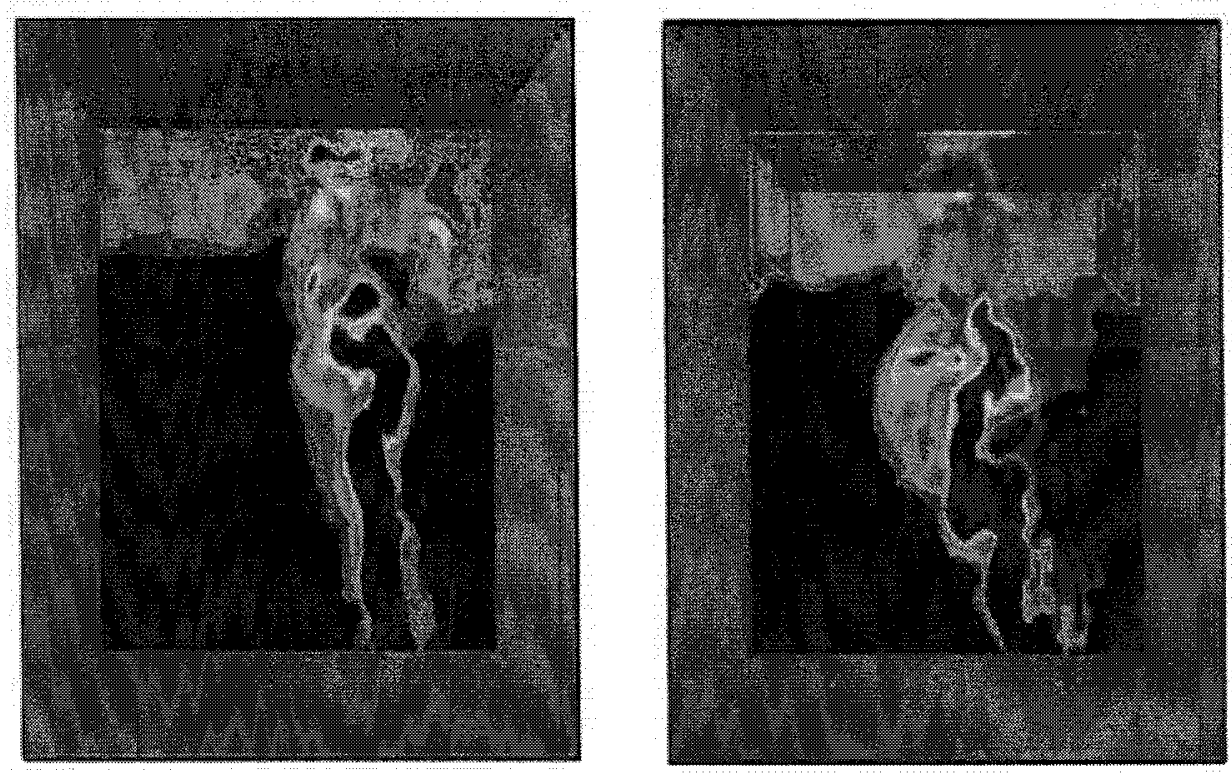

\begin{tabular}{l} 
Plot3d \\
temp \\
45.0 \\
42.5 \\
40.0 \\
37.5 \\
35.0 \\
32.5 \\
30.0 \\
27.5 \\
25.0 \\
22.5 \\
20.0 \\
\hline
\end{tabular}

(a) Make-up air velocity $=0.5 \mathrm{~m} / \mathrm{s}$

(b) Make-up air velocity $=1.0 \mathrm{~m} / \mathrm{s}$
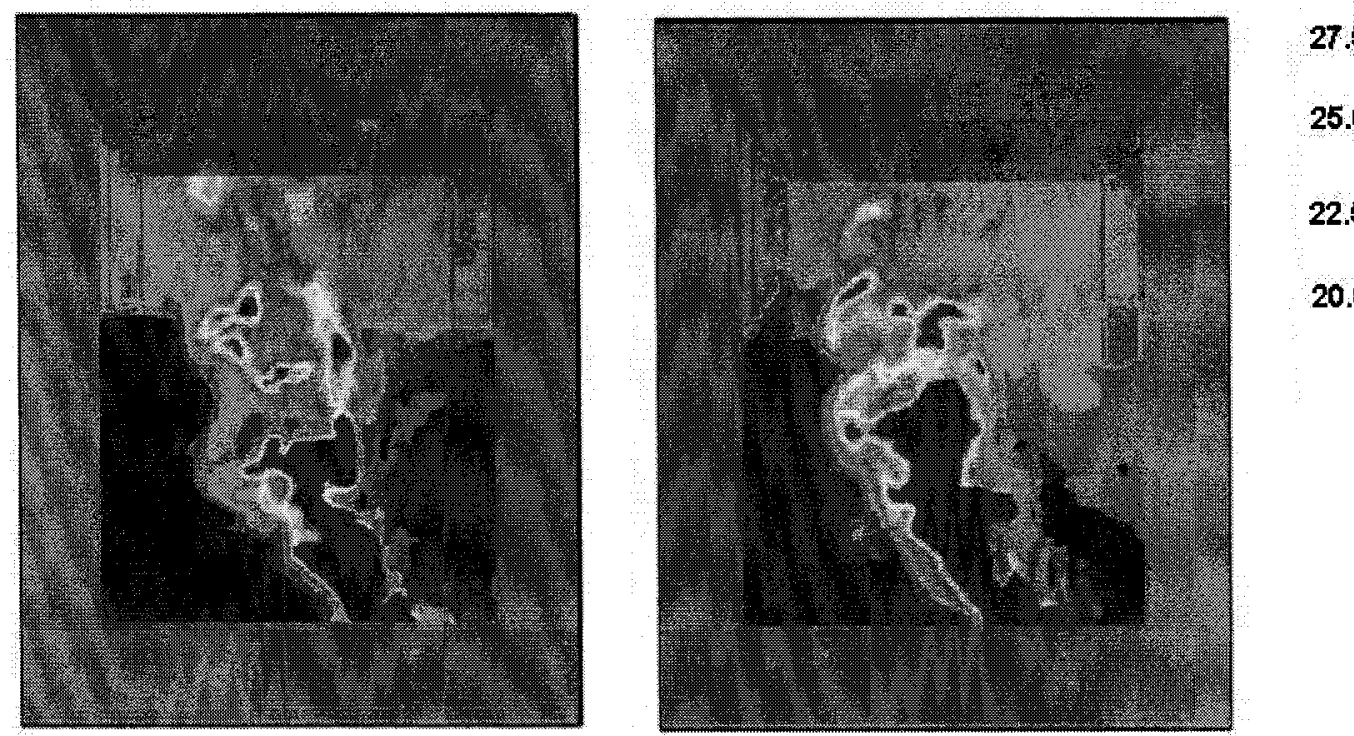

(c) Make-up air velocity $=1.25 \mathrm{~m} / \mathrm{s}$

(d) Make-up air velocity $=1.5 \mathrm{~m} / \mathrm{s}$

Figure 5.13 Temperature contours in $20-\mathrm{m}$ tall atrium on a vertical plane through the fire center, fire size $=1 \mathrm{MW}$ 


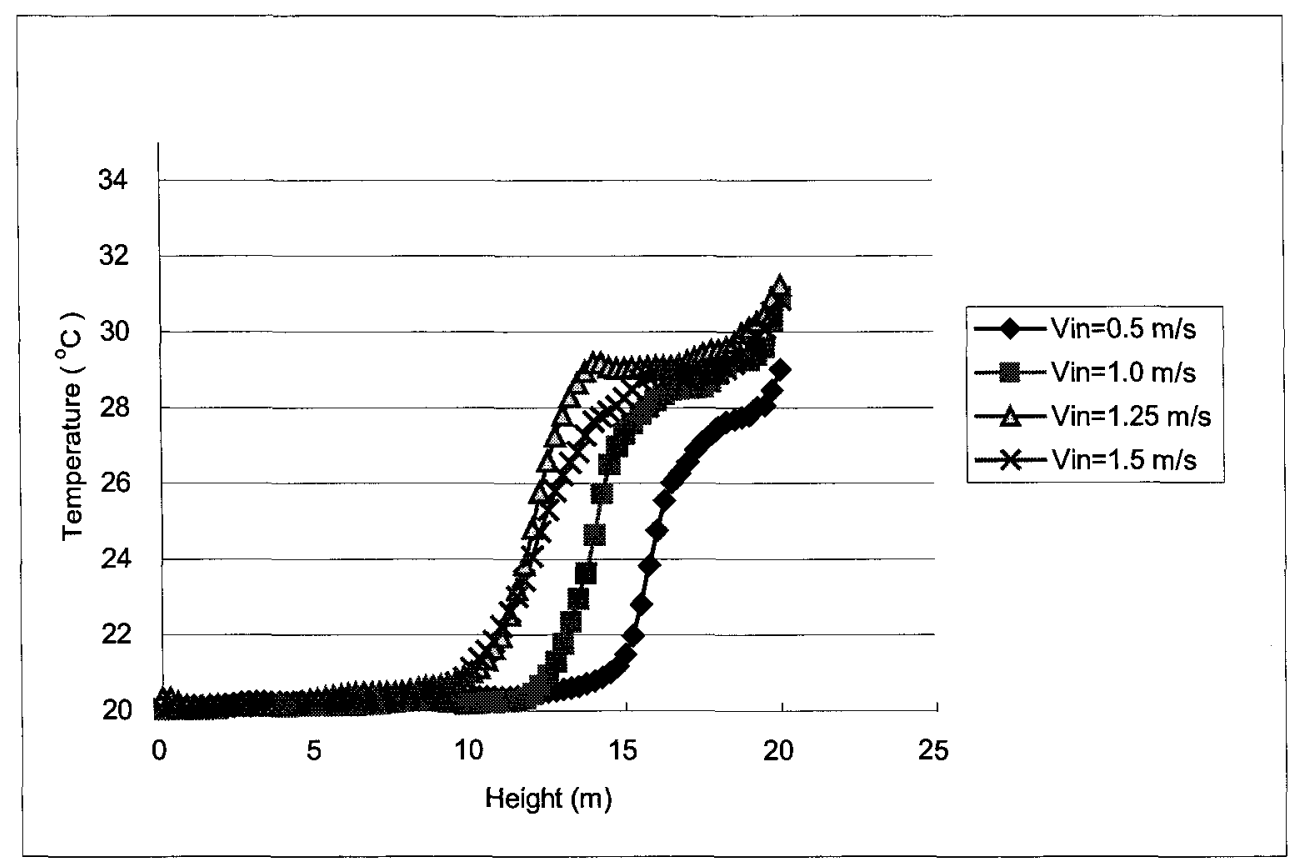

Figure 5.14 Temperature profiles in 20-m tall atrium with 1-MW fire

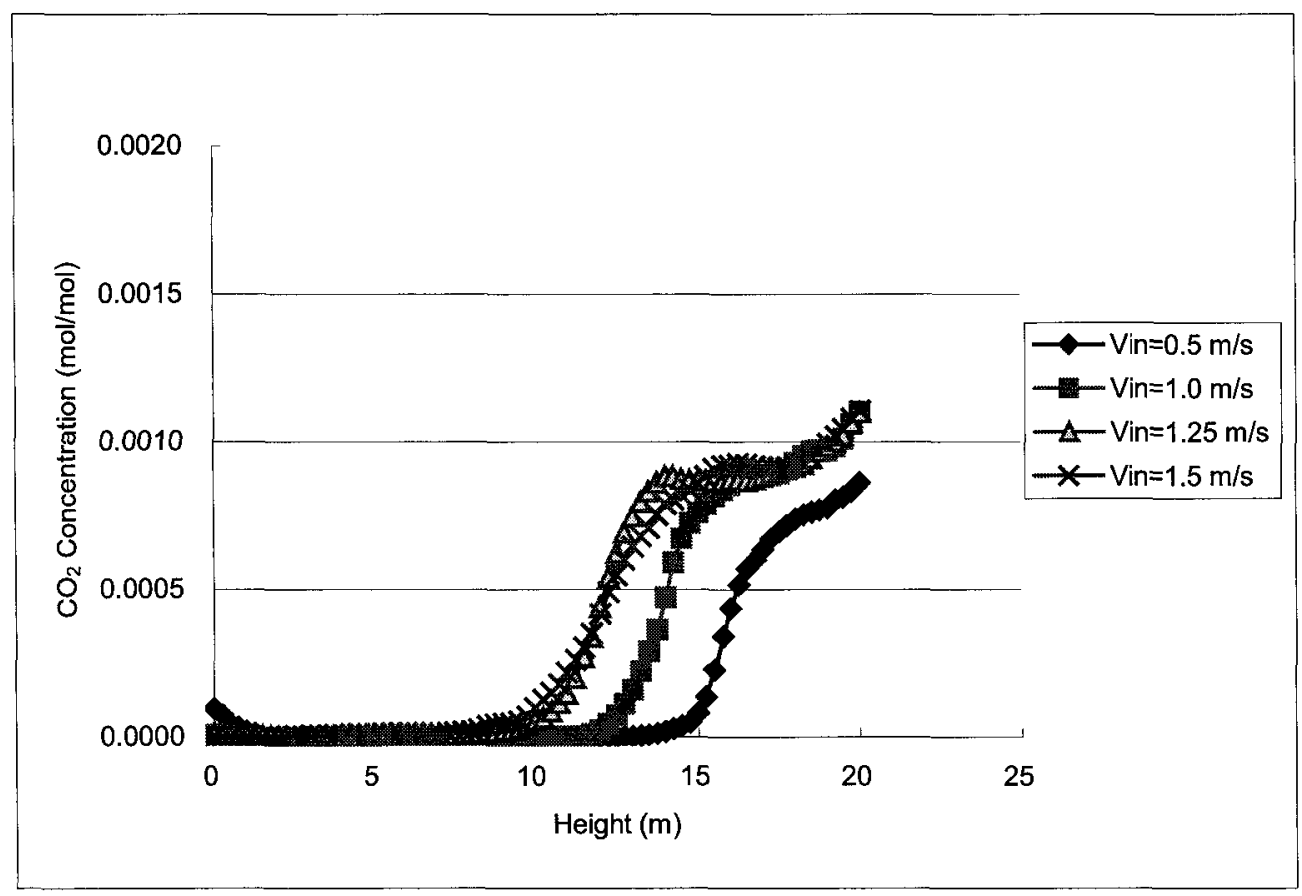

Figure $5.15 \mathrm{CO}_{2}$ profiles in $20-\mathrm{m}$ tall atrium with $1-\mathrm{MW}$ fire

The mass flow rate of the exhaust for the $2.5-\mathrm{MW}$ fire was set to $87.73 \mathrm{~kg} / \mathrm{s}$, and the area of the make-up air openings was set to $148.7 \mathrm{~m}^{2}, 74.35 \mathrm{~m}^{2}, 59.48 \mathrm{~m}^{2}$ and 49.56 
$\mathrm{m}^{2}$. The results of the simulations for the 2.5-MW fire size are different than those of the 1-MW fire in that the fire plume does not tilt so much. This can be seen in the contours of these simulations at $200 \mathrm{~s}$ shown in Figure 5.16 for the four make-up air velocities. Figures 5.17 and 5.18 which show the temperature and $\mathrm{CO}_{2}$ profiles at Point 7 indicate that the interface height is also not affected as much as with the 1MW fire.
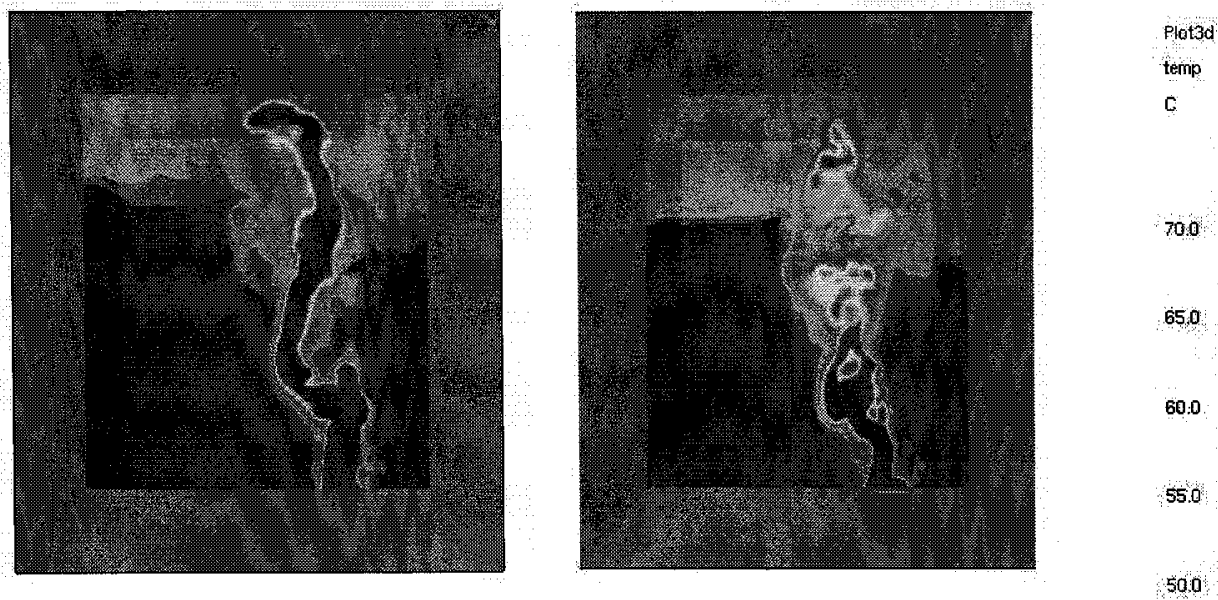

(a) Make-up air velocity $=0.5 \mathrm{~m} / \mathrm{s}$

(b) Make-up air velocity $=1.0 \mathrm{~m} / \mathrm{s}$
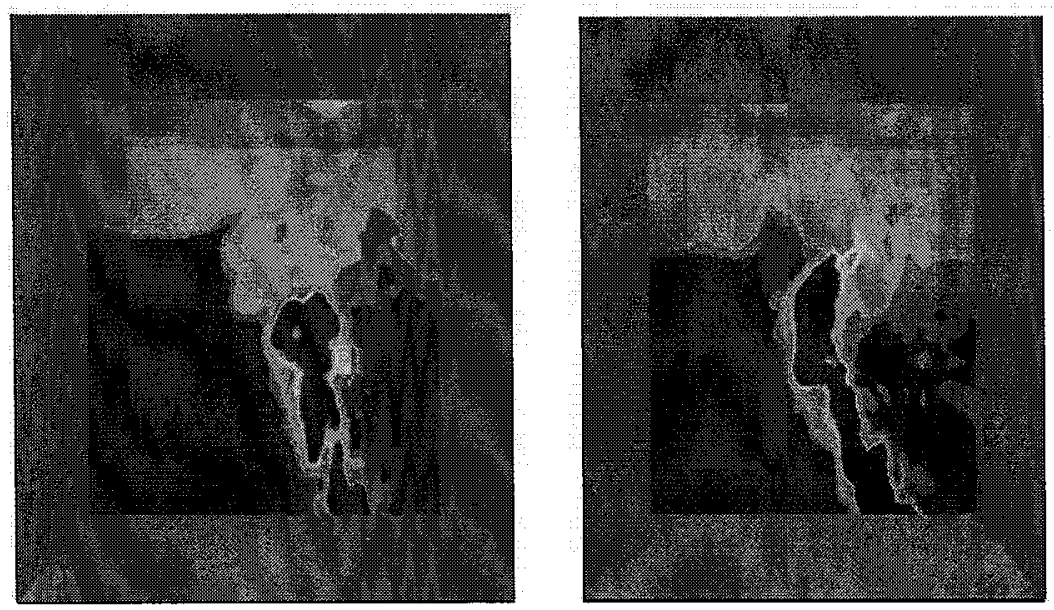

(c) Make-up air velocity $=1.25 \mathrm{~m} / \mathrm{s}$

(d) Make-up air velocity $=1.5 \mathrm{~m} / \mathrm{s}$

Figure 5.16 Temperature contours in $20-\mathrm{m}$ tall atrium on a vertical plane through the fire center, fire size $=2.5 \mathrm{MW}$ 


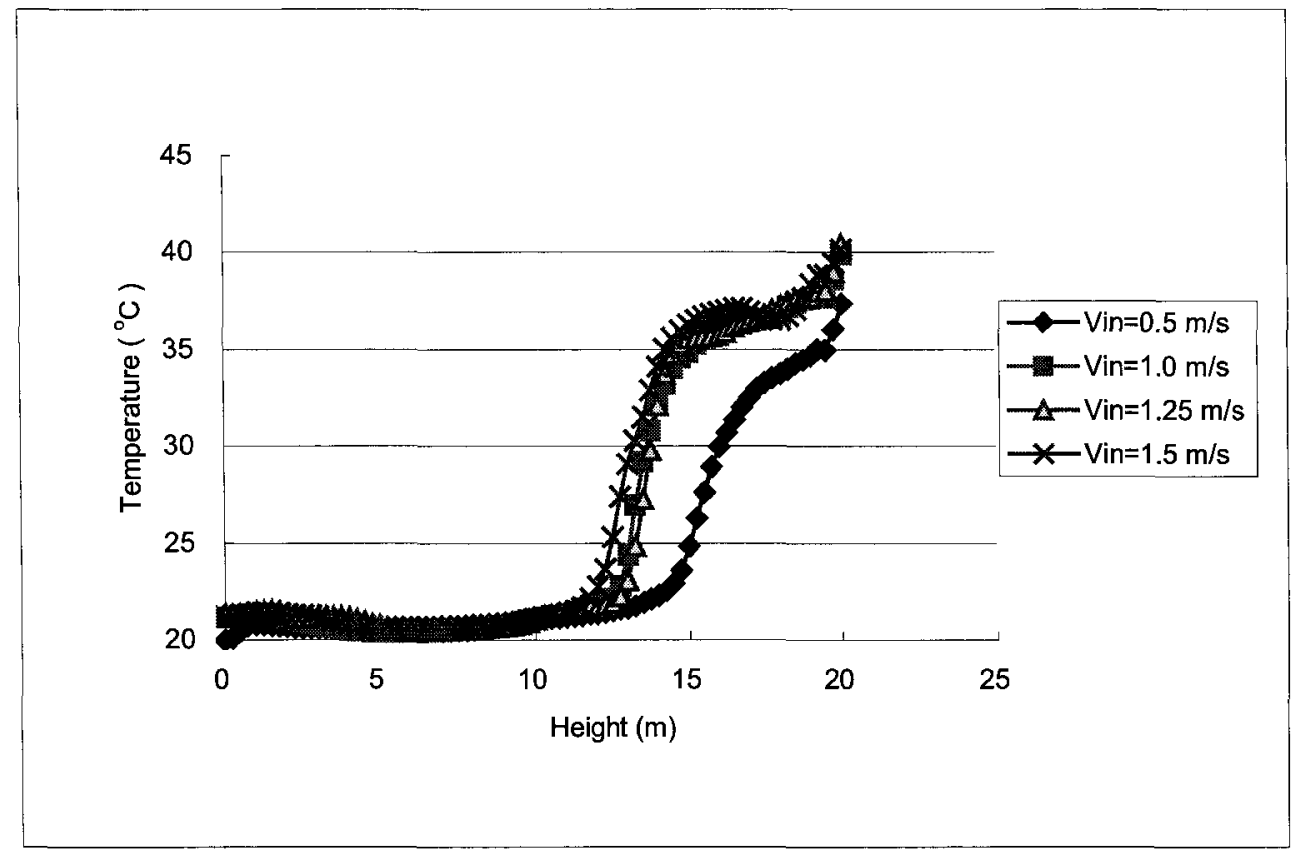

Figure 5.17 Temperature profiles in 20-m tall atrium with 2.5-MW fire

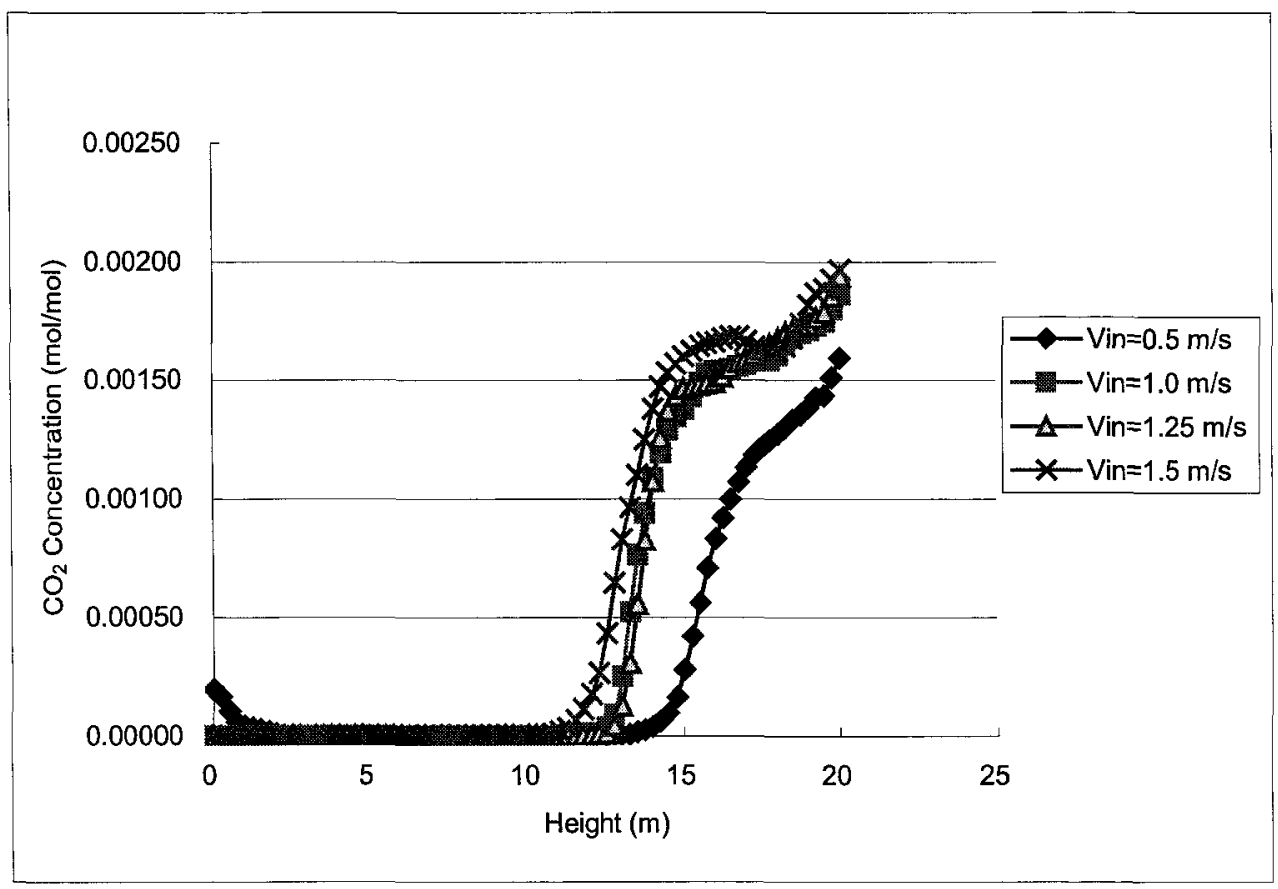

Figure $5.18 \mathrm{CO}_{2}$ profiles in $20-\mathrm{m}$ tall atrium with $2.5-\mathrm{MW}$ fire

The mass flow rate of the exhaust for the $5-\mathrm{MW}$ fire was $112.69 \mathrm{~kg} / \mathrm{s}$, and the areas of the make-up air openings were: $190.97 \mathrm{~m}^{2}, 95.48 \mathrm{~m}^{2}, 76.38 \mathrm{~m}^{2}$ and $63.65 \mathrm{~m}^{2}$. The impact of the make-up air velocity on the fire plume for these simulations decreases 
even more. This can be clearly seen in Figure 5.19 that shows the temperature contours at $200 \mathrm{~s}$ in the atrium. The figure shows that the fire plume is not affected significantly by the increased velocity. Figures 5.20 and 5.21 that depict the temperature and $\mathrm{CO}_{2}$ concentration profiles at Point 7 show that the impact of the make-up air velocity on the profiles however is quite large, especially between the profiles of the $0.5 \mathrm{~m} / \mathrm{s}$ and $1.0 \mathrm{~m} / \mathrm{s}$.
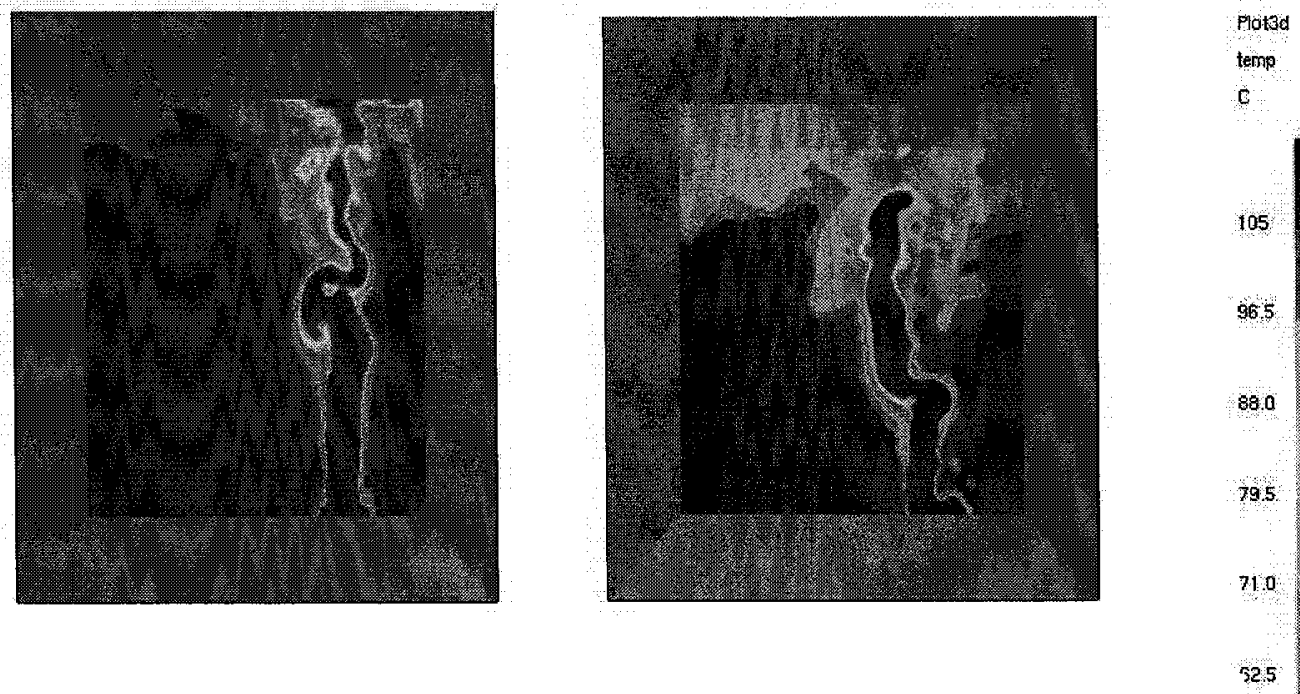

(a) Make-up air velocity $=0.5 \mathrm{~m} / \mathrm{s}$

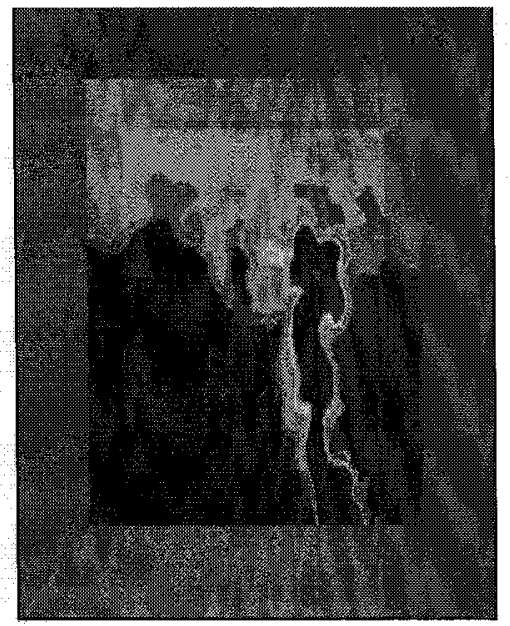

(b) Make-up air velocity $=1.0 \mathrm{~m} / \mathrm{s}$

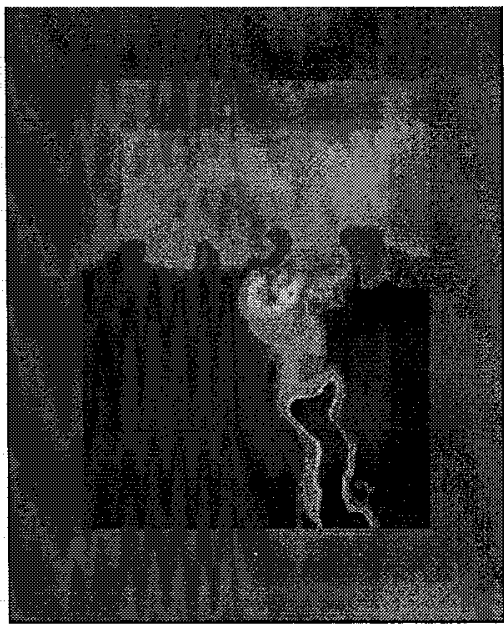

(c) Make-up air velocity $=1.25 \mathrm{~m} / \mathrm{s}$

(d) Make-up air velocity $=1.5 \mathrm{~m} / \mathrm{s}$

Figure 5.19 Temperature contours in 20-m tall atrium on a vertical plane through the fire center, fire size $=5 \mathrm{MW}$ 


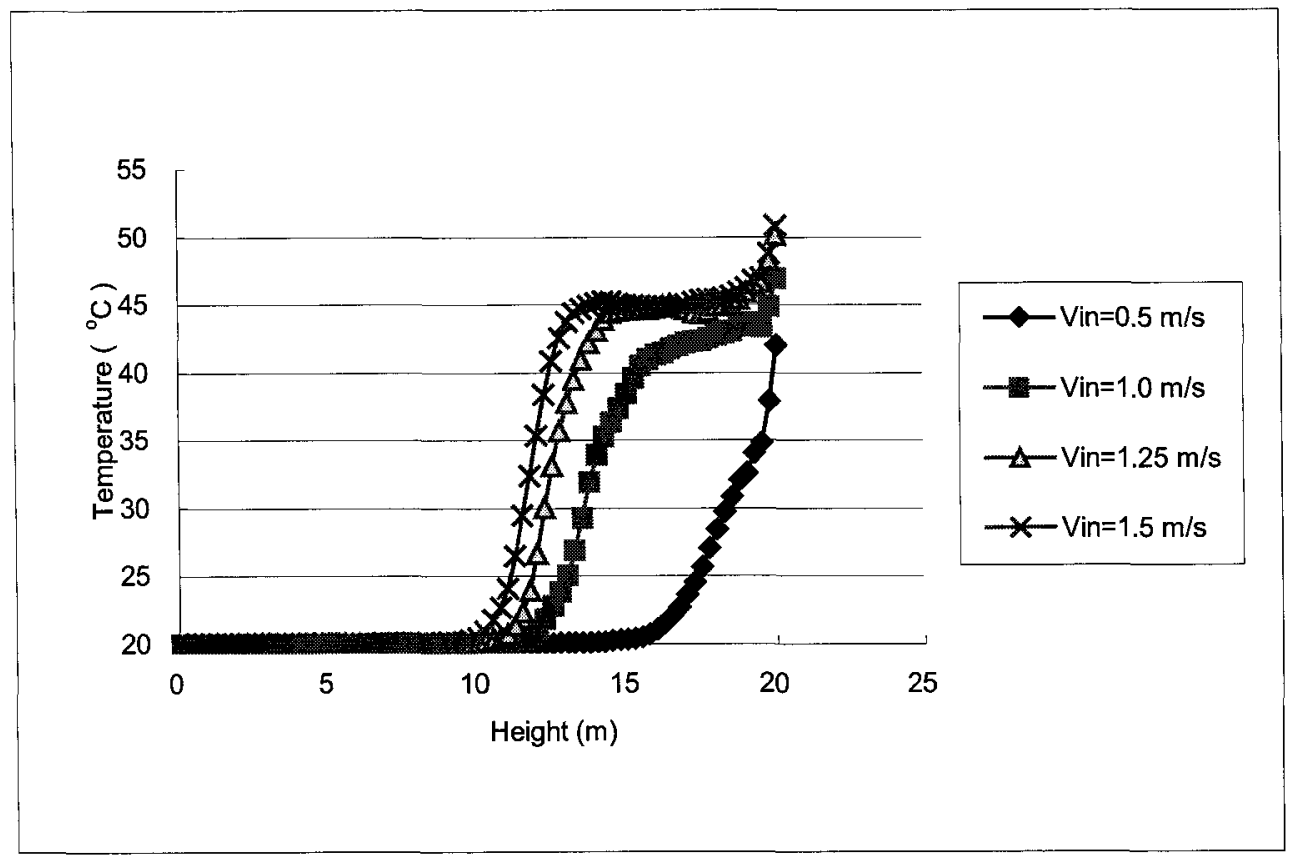

Figure 5.20 Temperature profiles in $20-\mathrm{m}$ tall atrium with 5-MW fire

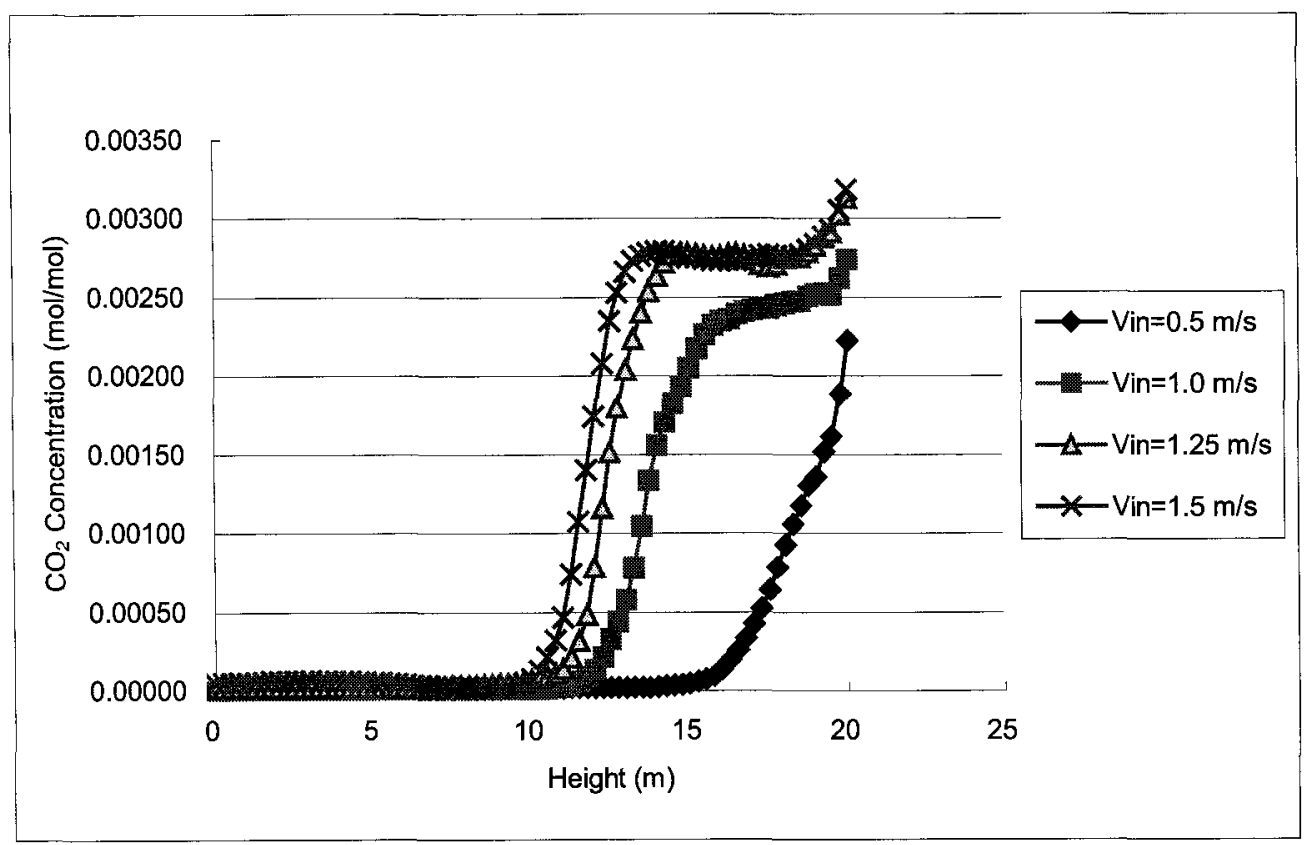

Figure 5.21 $\mathrm{CO}_{2}$ profiles in 20-m tall atrium with 5-MW fire

The interface heights for the $20-\mathrm{m}$ tall atrium are summarized in Table 5.3. The table shows that the largest decrease of the interface height due to the increased make-up 
air velocity occurs with the 1-MW fire. As the fire size increases, the impact of the make-up air velocity on interface height decreases.

Table 5.3 Interface heights in $20-\mathrm{m}$ tall atrium

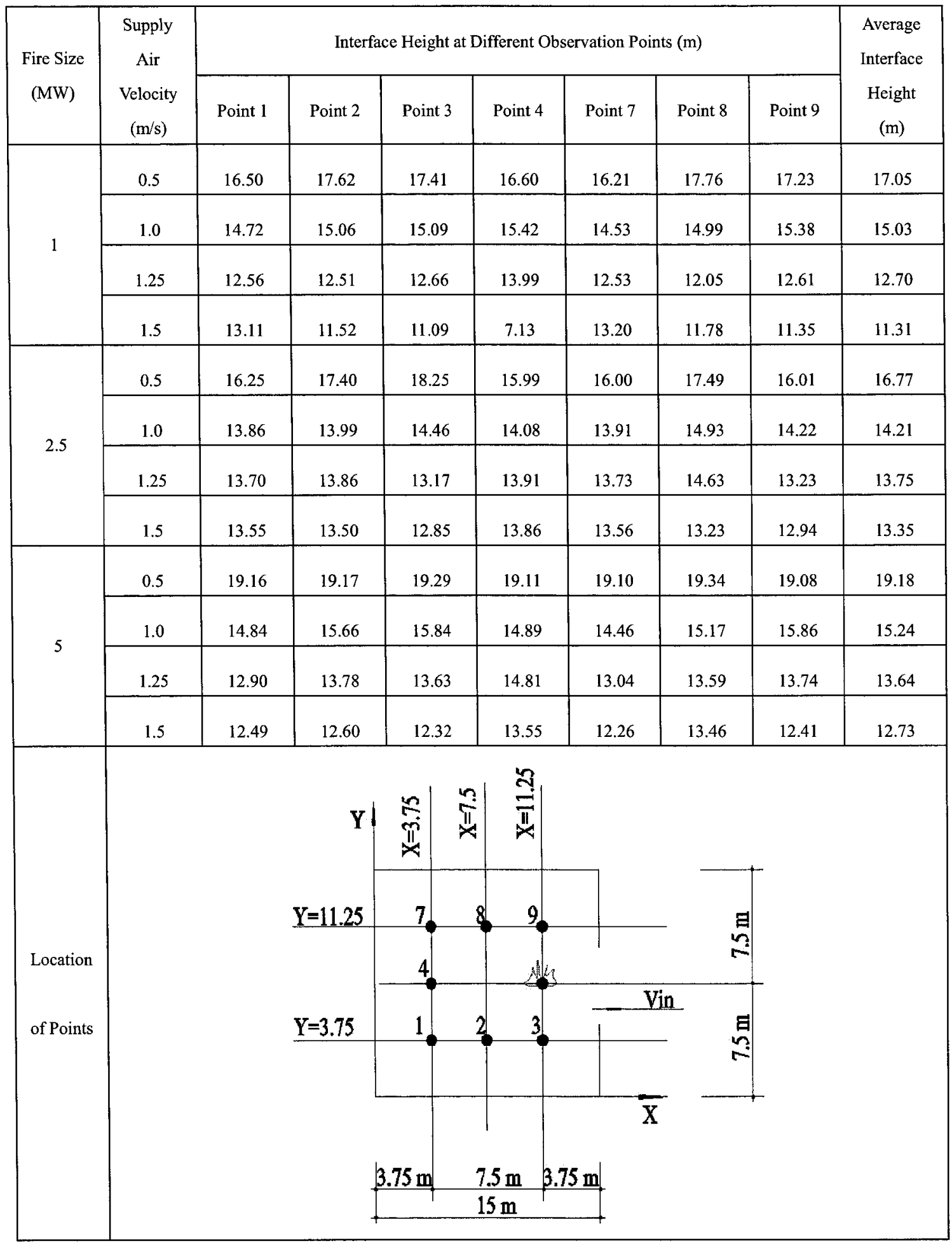




\subsubsection{Results for 30-m Tall Atrium}

Simulations for the $30-\mathrm{m}$ high atrium considered two different fire locations: $5 \mathrm{~m}$ and $2.5 \mathrm{~m}$ from the opening. Figure 5.22 which depicts temperature variation with time for the 1-MW fire at the quarter point of the atrium and different heights shows that steady state conditions were reached at about $200 \mathrm{~s}$ for this atrium. For this reason, all simulation for the $30-\mathrm{m}$ tall atrium were done up to $300 \mathrm{~s}$.

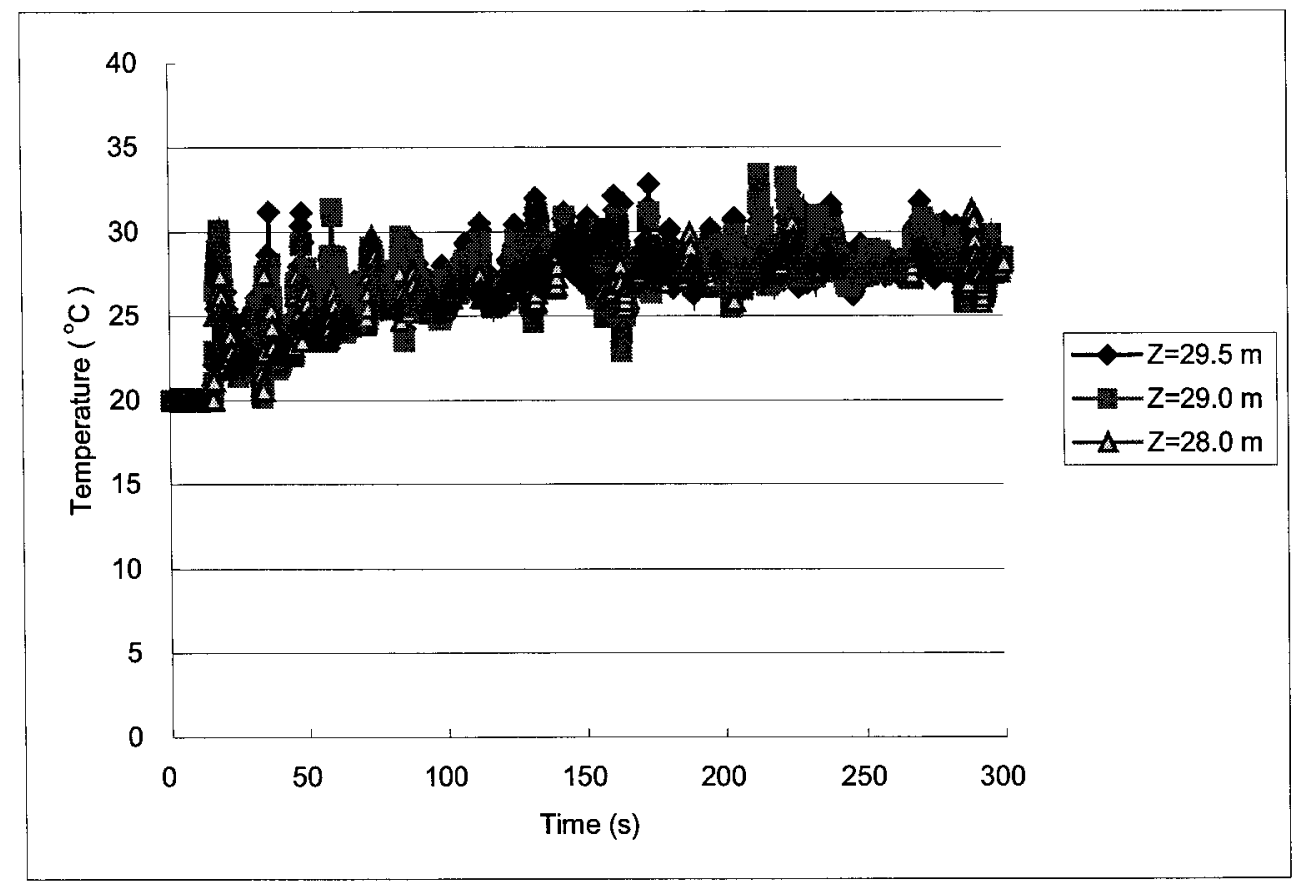

Figure 5.22 Temperature variations with time in $30-\mathrm{m}$ tall atrium

\subsubsection{Fire Location $5 \mathrm{~m}$ from the Opening}

The fire for these simulations was placed $5 \mathrm{~m}$ from the opening. Simulations were done for the three fire sizes and the four different make-up air velocities.

The mass flow rate of the exhaust for the 1-MW fire simulations was set to 123.98 $\mathrm{kg} / \mathrm{s}$, and the areas of the make-up air openings were: $210.12 \mathrm{~m}^{2}, 105.06 \mathrm{~m}^{2}, 84.05 \mathrm{~m}^{2}$ 
and $70.04 \mathrm{~m}^{2}$. Figure 5.23 shows the temperature distributions at $300 \mathrm{~s}$ on a vertical plane passing through the fire centerline and the center of the opening for the 1-MW fire and the four different make-up air velocities. The temperature rise of the hot layer for these simulations is much lower than for the smaller atria. This can clearly be seen also in Figure 5.24 that shows the temperature profiles at Point 7 of the atrium. As the figure shows, the maximum temperature rise is less than $5^{\circ} \mathrm{C}$. Despite the fact that the increase of the make-up air velocity affects the fire plume, as shown in Figure 5.23, its effect on the temperature and the $\mathrm{CO}_{2}$ profiles shown in Figures 5.24 and 5.25 is small.

The mass flow rate of the exhaust for the $2.5-\mathrm{MW}$ fire was set to $169.61 \mathrm{~kg} / \mathrm{s}$, and the areas of the make-up air openings were: $287.4 \mathrm{~m}^{2}, 143.76 \mathrm{~m}^{2}, 114.96 \mathrm{~m}^{2}$ and $95.8 \mathrm{~m}^{2}$. The results of the 2.5-MW fire shown in Figures 5.26, 5.27 and 5.28 show that the maximum temperature rise is 7 to $8{ }^{\circ} \mathrm{C}$. The temperature contours for these runs at $300 \mathrm{~s}$, which depicted in Figure 5.26, show that although the increase velocity of the make-up air affect the fire plume this effect is not as pronounced as for the 1-MW fire case. This can also be seen in Figures 5.27 and 5.28 that illustrate temperature and $\mathrm{CO}_{2}$ profiles at Point 7 in the atrium. These figures show that there is a change in the profiles from the $0.5 \mathrm{~m} / \mathrm{s}$ to the $1.0 \mathrm{~m} / \mathrm{s}$ velocities, however the higher velocities do not alter the profiles very much. 


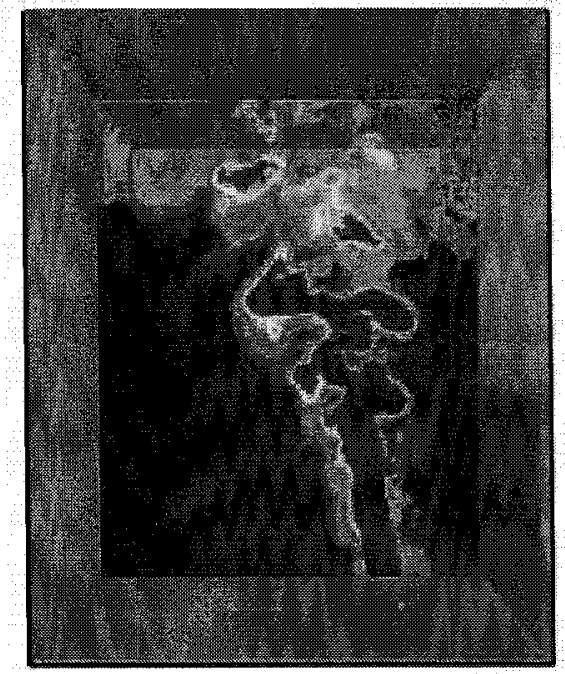

(a) Make-up air velocity $=0.5 \mathrm{~m} / \mathrm{s}$

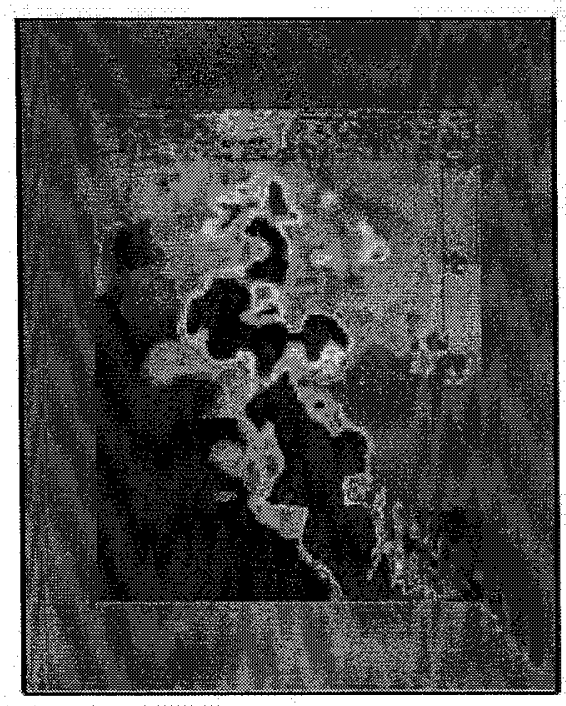

(c) Make-up air velocity $=1.25 \mathrm{~m} / \mathrm{s}$

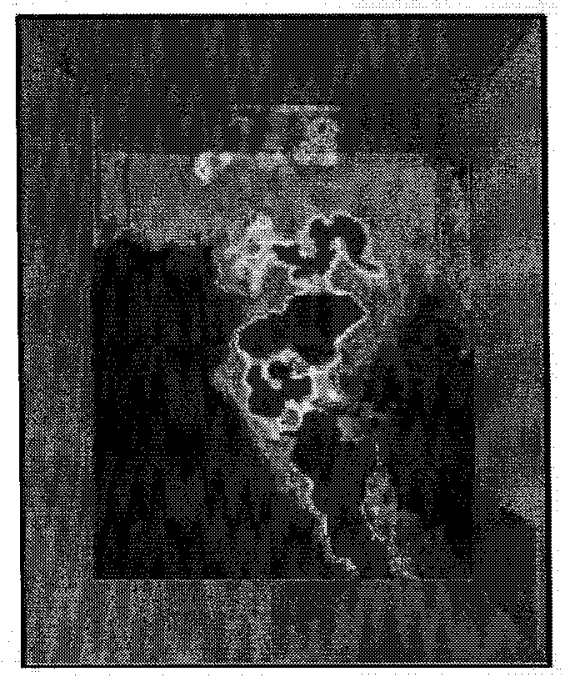

Plot3d

temp

$c$

30.0

29.0

28.0

27.0

26.0

(b) Make-up air velocity $=1.0 \mathrm{~m} / \mathrm{s}$

25.0

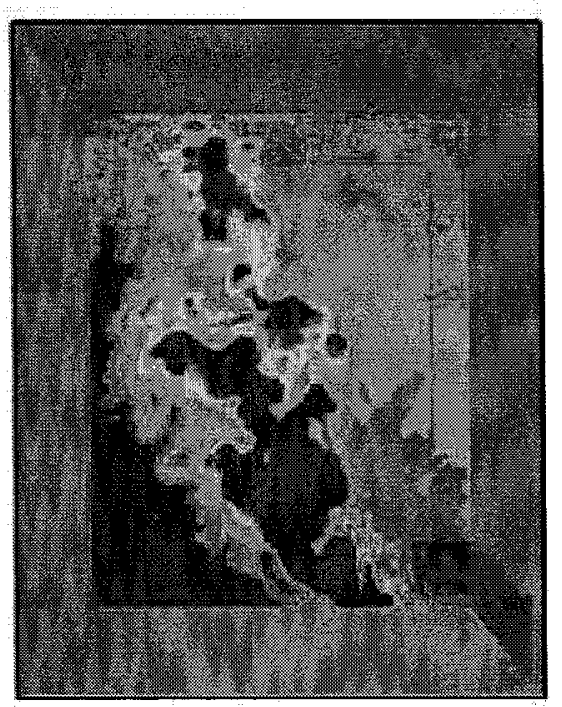

24.0

23.0

22.0

21.0

20.0

Figure 5.23 Temperature contours in $30-\mathrm{m}$ tall atrium on a vertical plane through the fire center, fire size $=1 \mathrm{MW}, 5.0 \mathrm{~m}$ from opening 


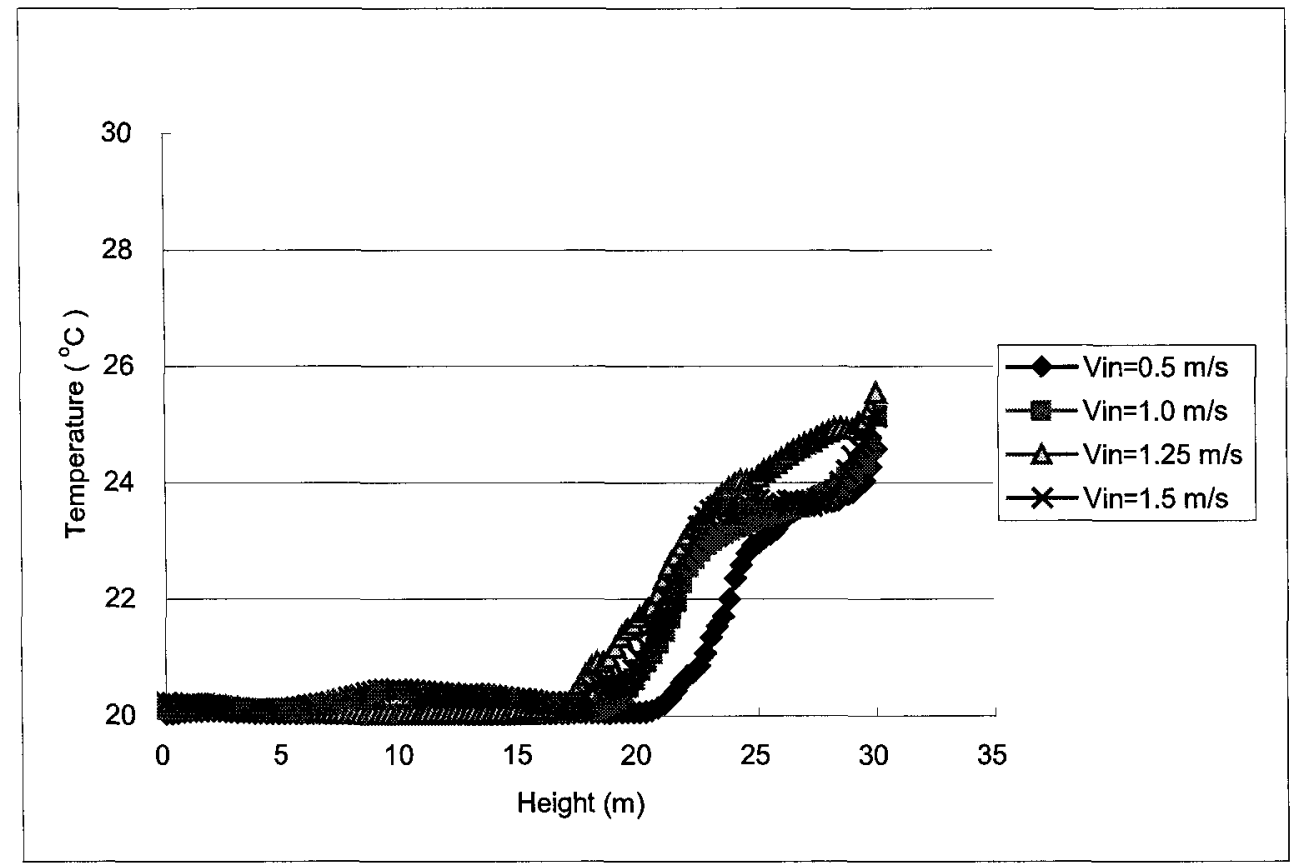

Figure 5.24 Temperature profiles in 30-m tall atrium with 1-MW fire, $5 \mathrm{~m}$ from opening

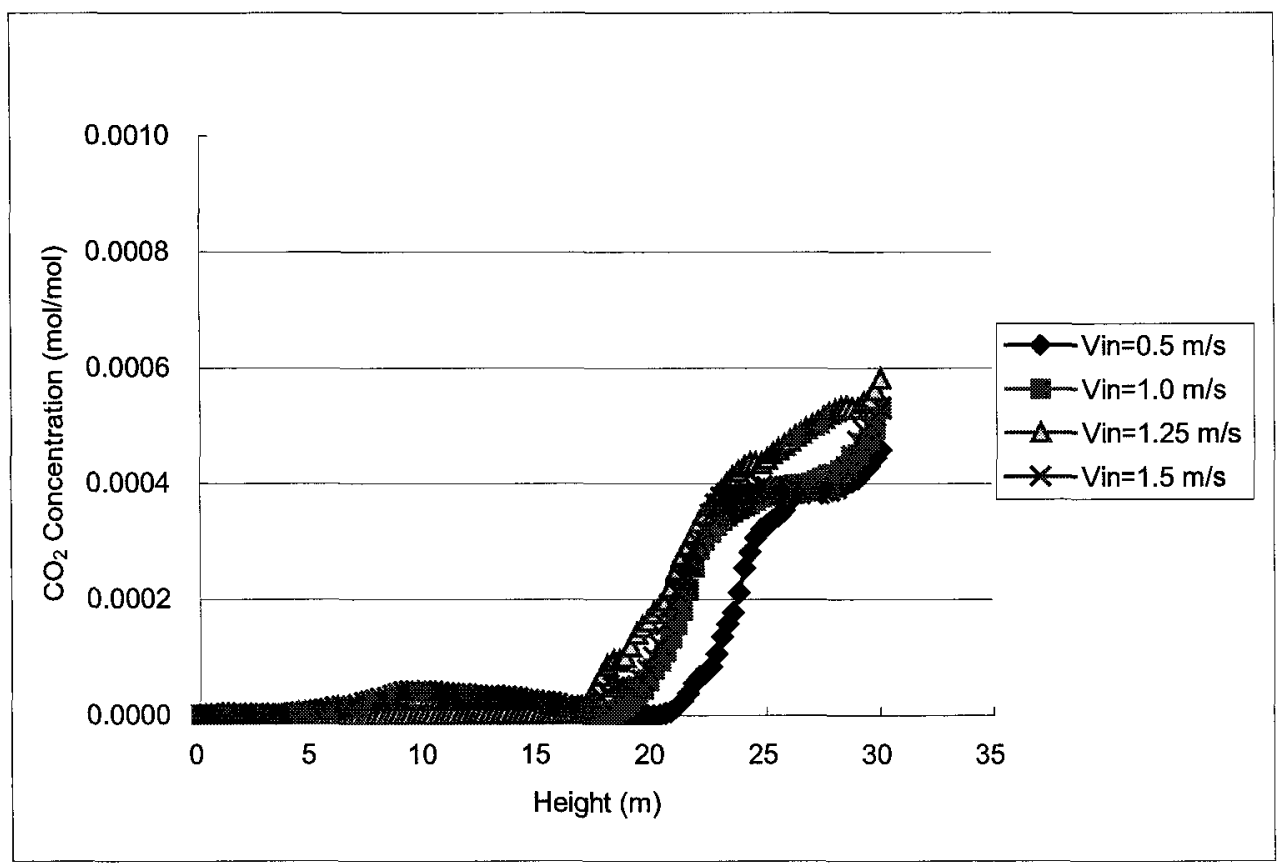

Figure 5.25 $\mathrm{CO}_{2}$ profiles in 30-m tall atrium with 1-MW fire, $5 \mathrm{~m}$ from opening 

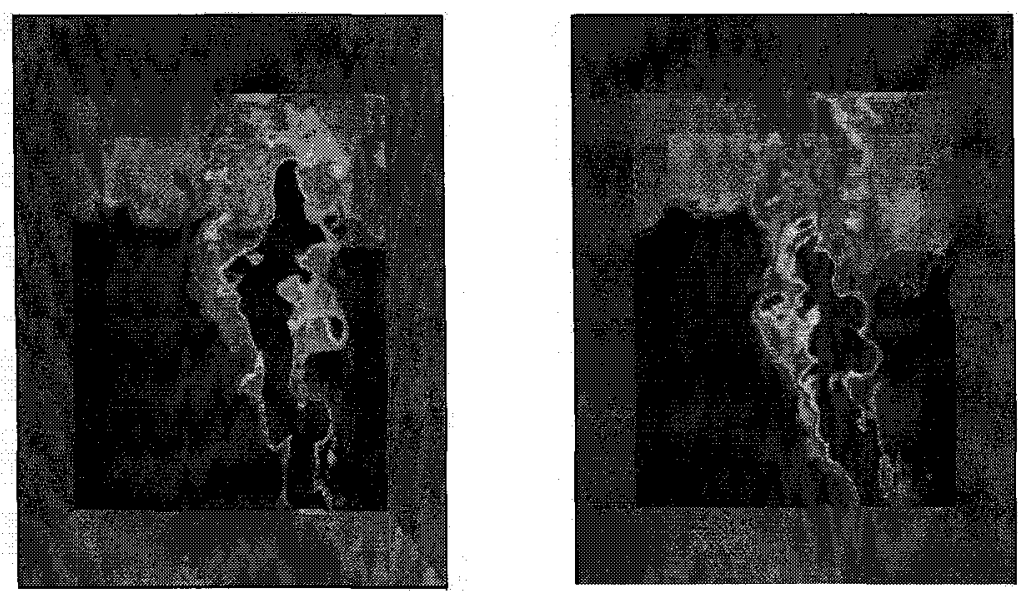

Plot3d

temp

40.0

38.0

36.0

340

32.0

(a) Make-up air velocity $=0.5 \mathrm{~m} / \mathrm{s}$

(b) Make-up air velocity $=1.0 \mathrm{~m} / \mathrm{s}$
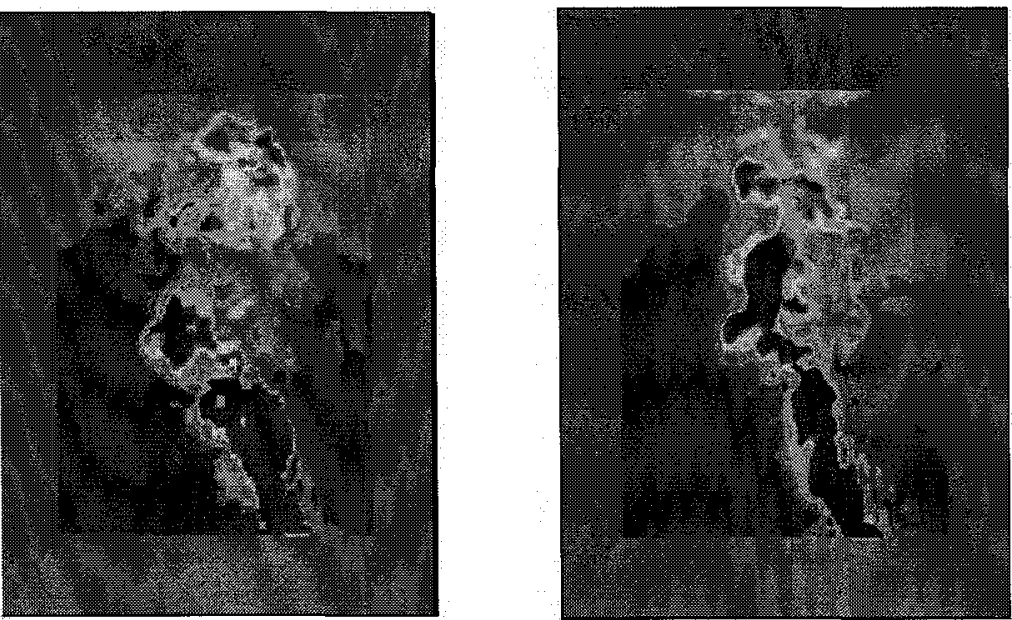

$28: 0$

$26: 0$

24.0

220

2010

(c) Make-up air velocity $=1.25 \mathrm{~m} / \mathrm{s}$

(d) Make-up air velocity $=1.5 \mathrm{~m} / \mathrm{s}$

Figure 5.26 Temperature contours in $30-\mathrm{m}$ tall atrium on a vertical plane through the

fire center, fire size $=2.5 \mathrm{MW}, 5 \mathrm{~m}$ from opening 


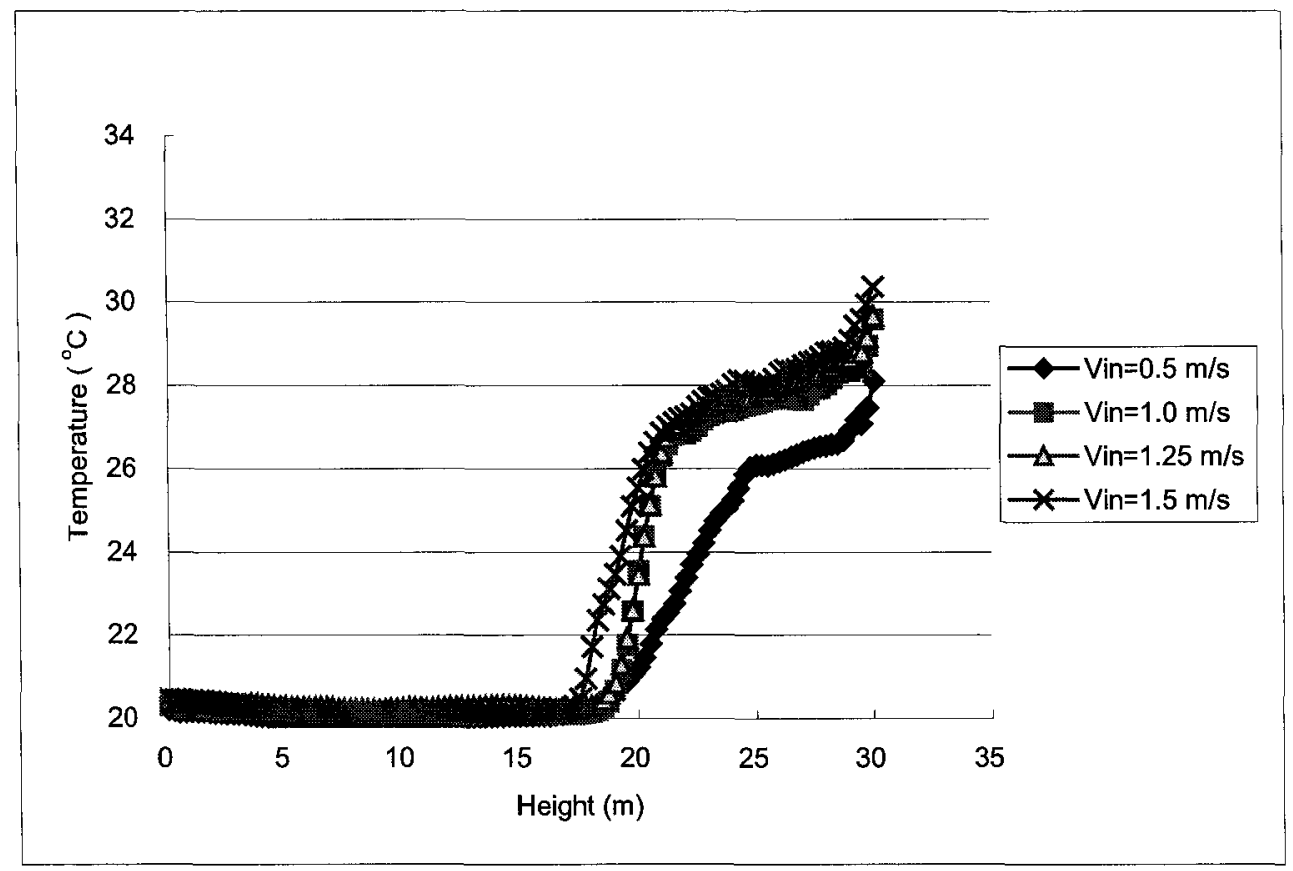

Figure 5.27 Temperature profiles in 30-m tall atrium with $2.5-\mathrm{MW}$ fire, $5 \mathrm{~m}$ from opening

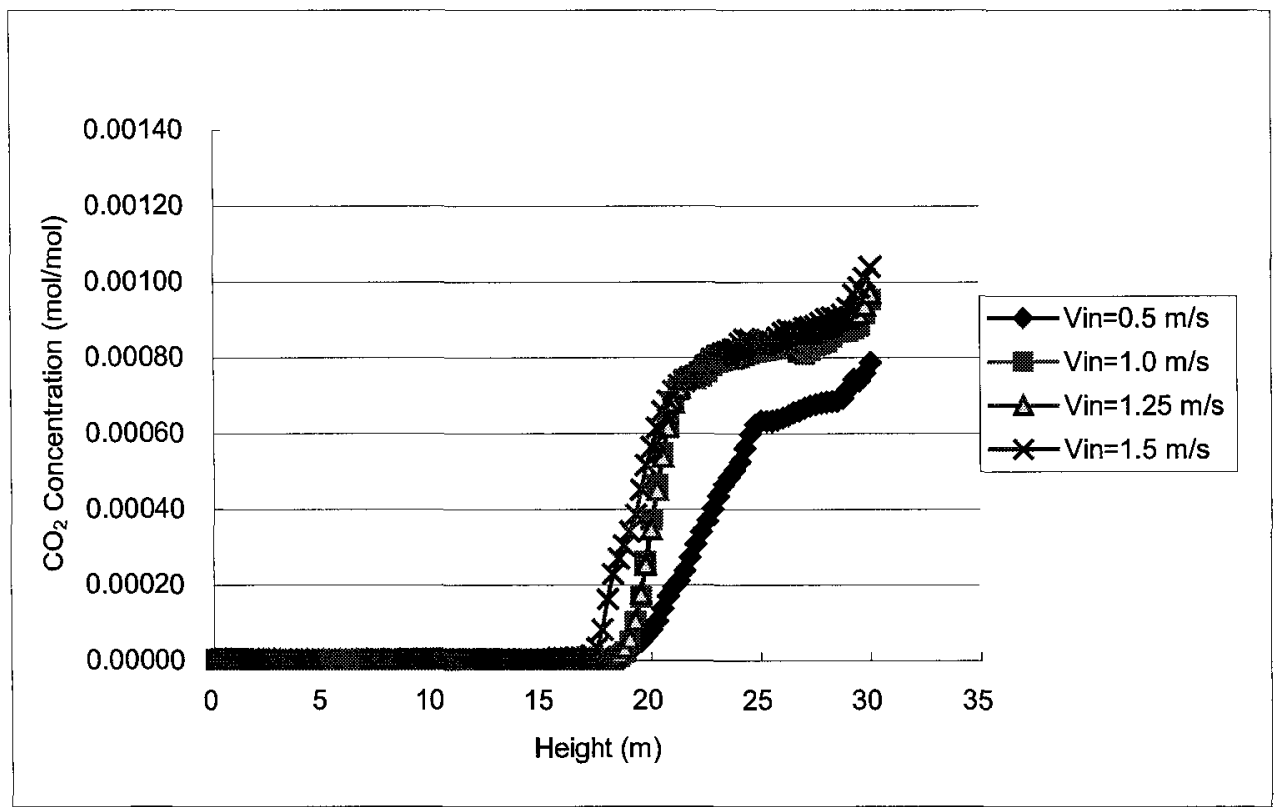

Figure 5.28 $\mathrm{CO}_{2}$ profiles in $30-\mathrm{m}$ tall atrium with $2.5-\mathrm{MW}$ fire, $5 \mathrm{~m}$ from opening 
For the fire size of $5 \mathrm{MW}$, the mass flow rate of the exhaust was set to $215.86 \mathrm{~kg} / \mathrm{s}$, and the areas of the make-up air openings were: $365.94 \mathrm{~m}^{2}, 182.9 \mathrm{~m}^{2}, 146.32 \mathrm{~m}^{2}$ and $121.94 \mathrm{~m}^{2}$. The effect of the make-up air velocity on the fire plume decreases with the increased fire size. This can be seen in Figure 5.29 that shows the temperature contours for the four different make-up air velocities at $300 \mathrm{~s}$. The figure illustrates that the increased velocity does not affect the fire plume significantly.

Figure 5.30 shows temperature profiles for the different velocities at Point 7 of the atrium and Figure 5.31 illustrates the $\mathrm{CO}_{2}$ profiles at the same point. Increasing the make-up air velocity from $0.5 \mathrm{~m} / \mathrm{s}$ to $1.0 \mathrm{~m} / \mathrm{s}$ affects the profiles, however no significant change in the profiles seems to occur when the velocity increases to 1.25 $\mathrm{m} / \mathrm{s}$ and $1.5 \mathrm{~m} / \mathrm{s}$. 


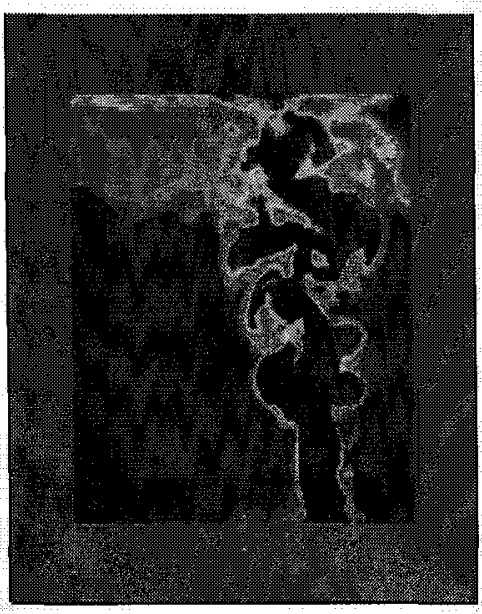

(a) Make-up air velocity $=0.5 \mathrm{~m} / \mathrm{s}$

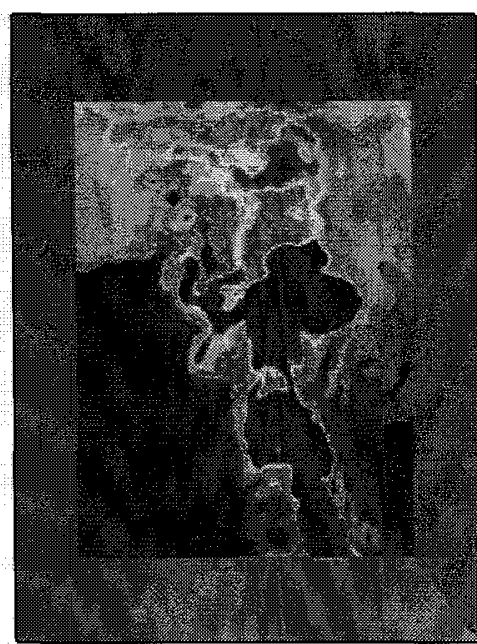

(c) Make-up air velocity $=1.25 \mathrm{~m} / \mathrm{s}$

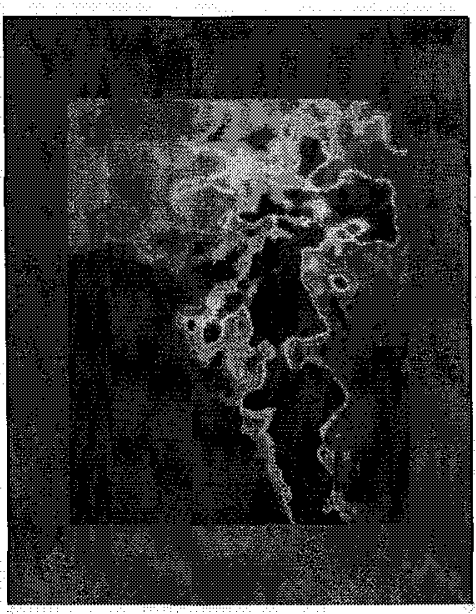

4000 (380

(b) Make-up air velocity $=1.0 \mathrm{~m} / \mathrm{s}$

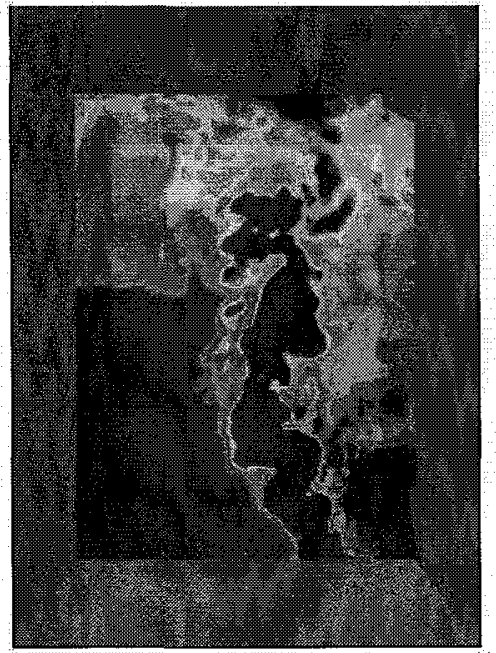

(d) Make-up air velocity $=1.5 \mathrm{~m} / \mathrm{s}$

Figure 5.29 Temperature contours in $30-\mathrm{m}$ tall atrium on a vertical plane through the fire center, fire size $=5 \mathrm{MW}, 5 \mathrm{~m}$ from opening 


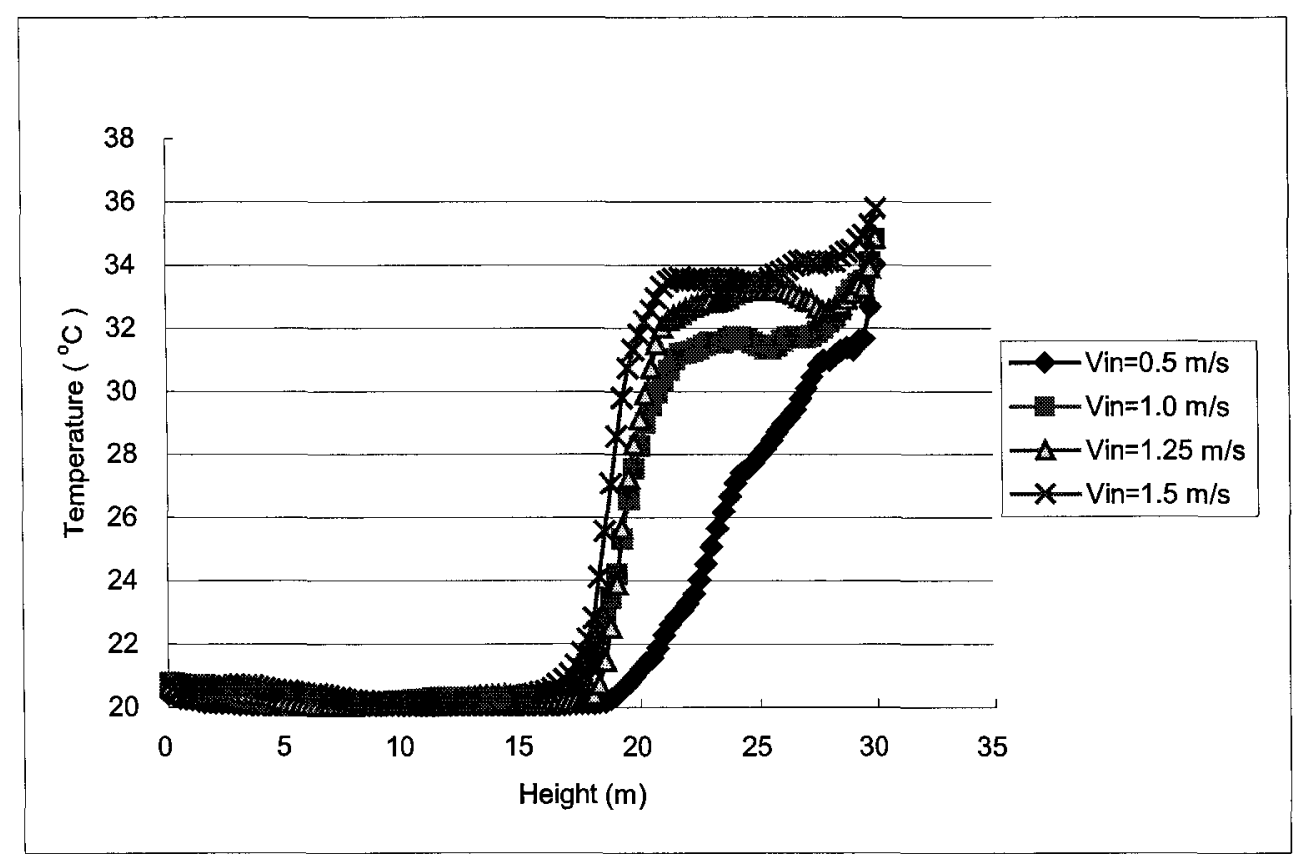

Figure 5.30 Temperature profiles in 30-m tall atrium with 5-MW fire, $5 \mathrm{~m}$ from opening

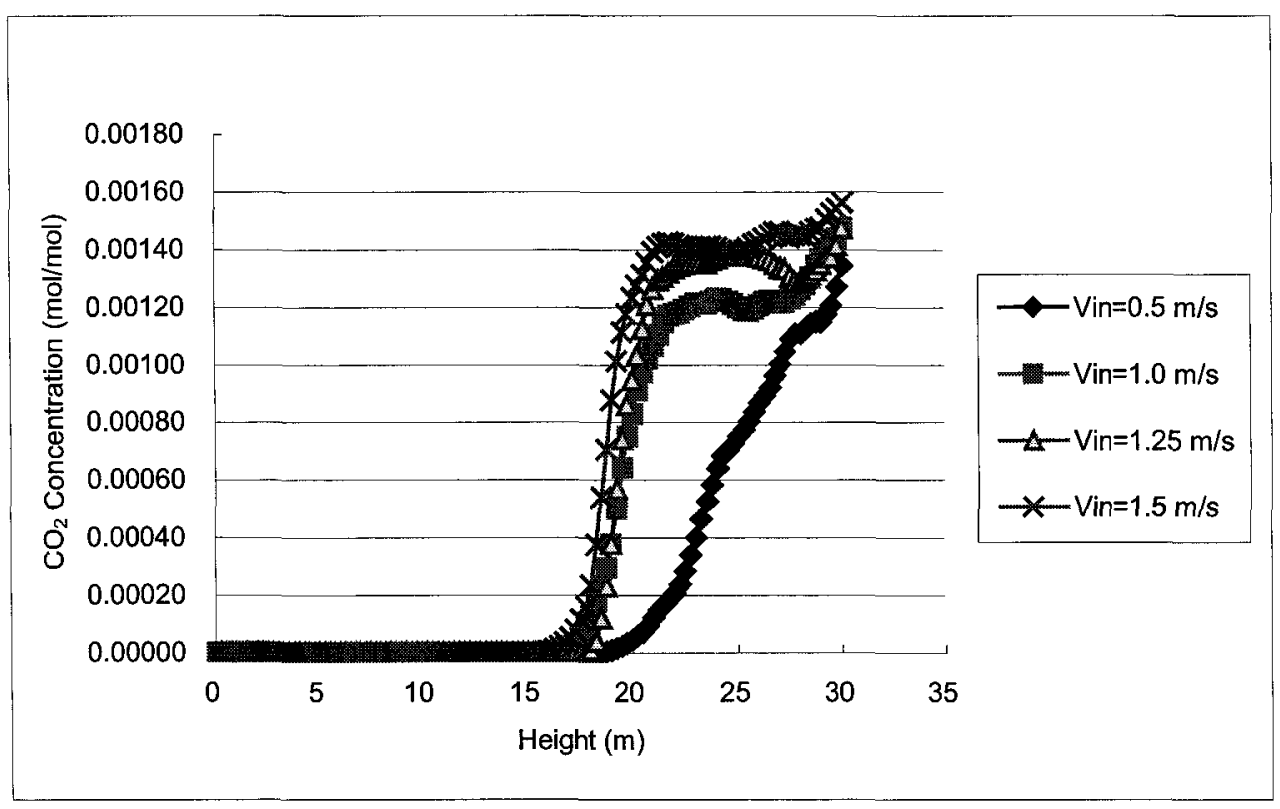

Figure $5.31 \mathrm{CO}_{2}$ profiles in $30-\mathrm{m}$ tall atrium with 5-MW fire, $5 \mathrm{~m}$ from opening The interface heights for the $30-\mathrm{m}$ tall atrium with the fire located $5 \mathrm{~m}$ from the opening are shown in Table 5.4. The table shows that all fire size result in similar interface heights for all make-up air velocities. 
Table 5.4 Interface heights in $30-\mathrm{m}$ tall atrium with fire $5 \mathrm{~m}$ from the opening

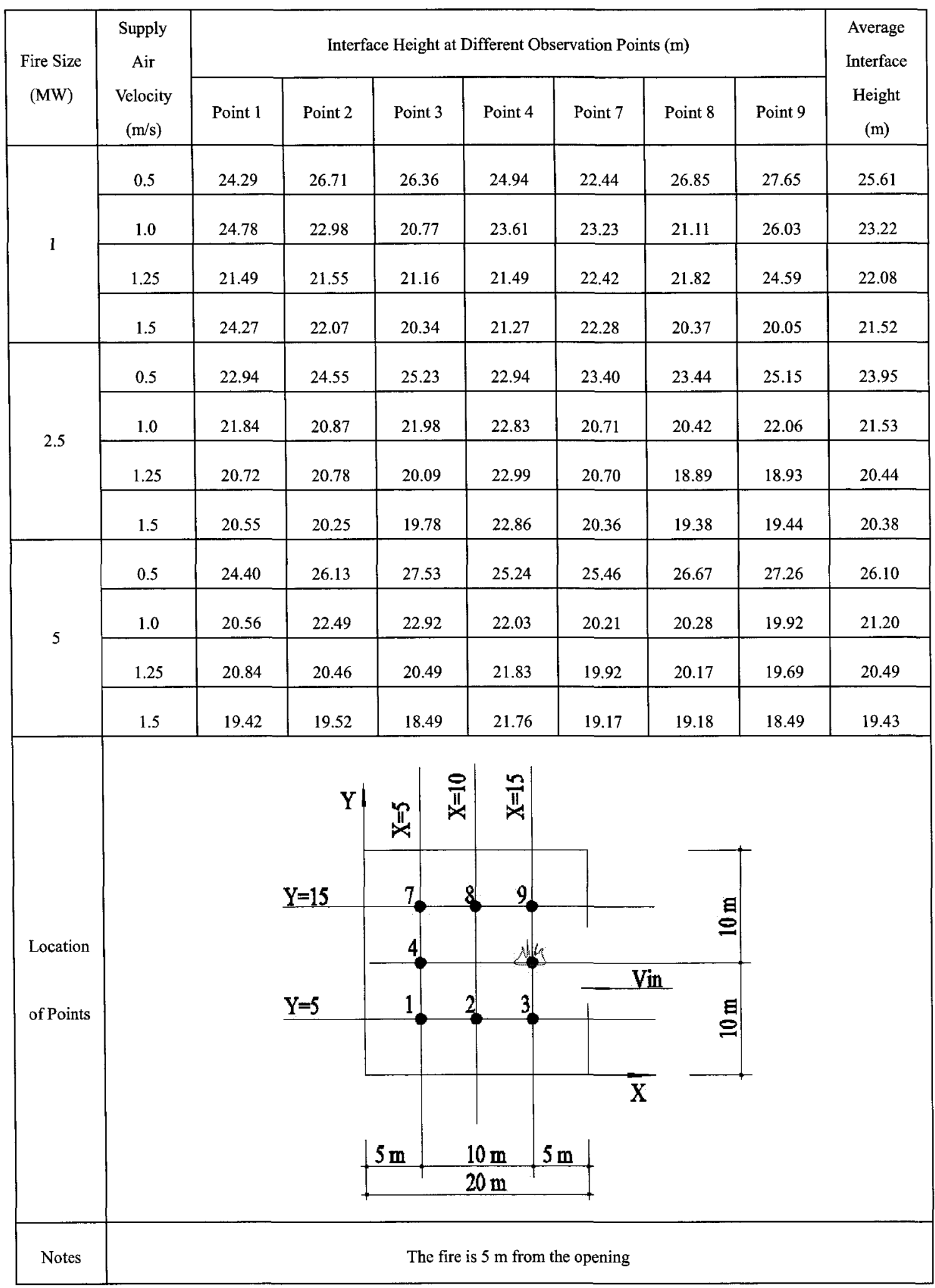




\subsubsection{Fire Location $2.5 \mathrm{~m}$ from the Opening}

The mass flow rate of the exhaust and the areas of the make-up air openings for the 1 MW, 2.5 MW and 5-MW fire simulations had the same values as for the fire placed 5 $\mathrm{m}$ from the opening.

Figure 5.32 shows the temperature contours for the four different make-up air velocities at $300 \mathrm{~s}$. A comparison between Figures 5.23 and 5.32 show that locating the fire at $5 \mathrm{~m}$ from the opening results in similar temperature contours as with the fire at $2.5 \mathrm{~m}$ from the opening. Figures 5.33 and 5.34, that depict temperature and $\mathrm{CO}_{2}$ profiles at Point 7 of the atrium show that the profiles are also quite similar. 


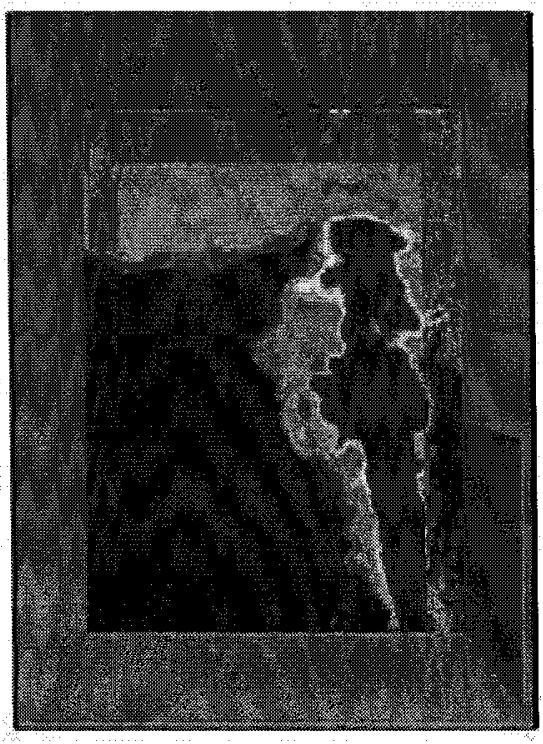

(a) Make-up air velocity $=0.5 \mathrm{~m} / \mathrm{s}$

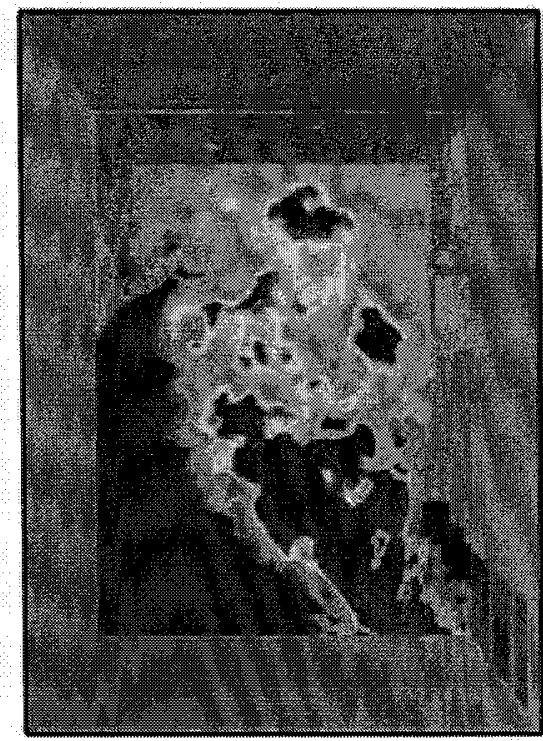

(c) Make-up air velocity $=1.25 \mathrm{~m} / \mathrm{s}$

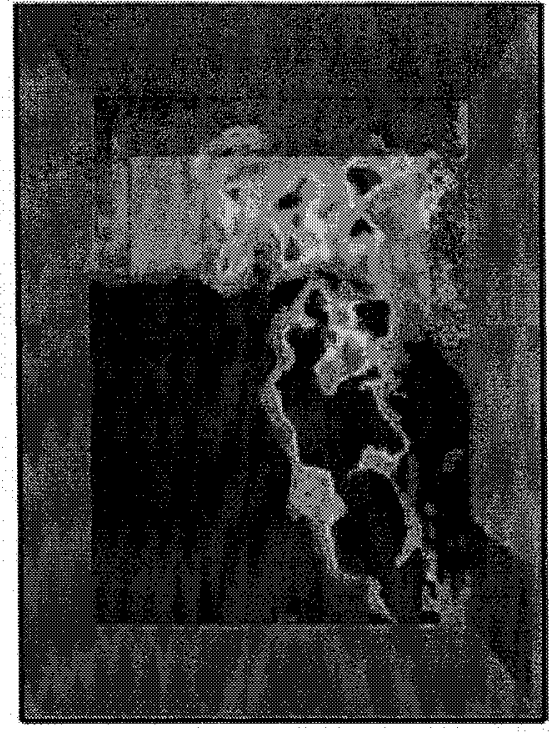

Plot3d

temp

c

30.0

29.0

28.0

27.0

26.0

(b) Make-up air velocity $=1.0 \mathrm{~m} / \mathrm{s}$

25.0

24.0

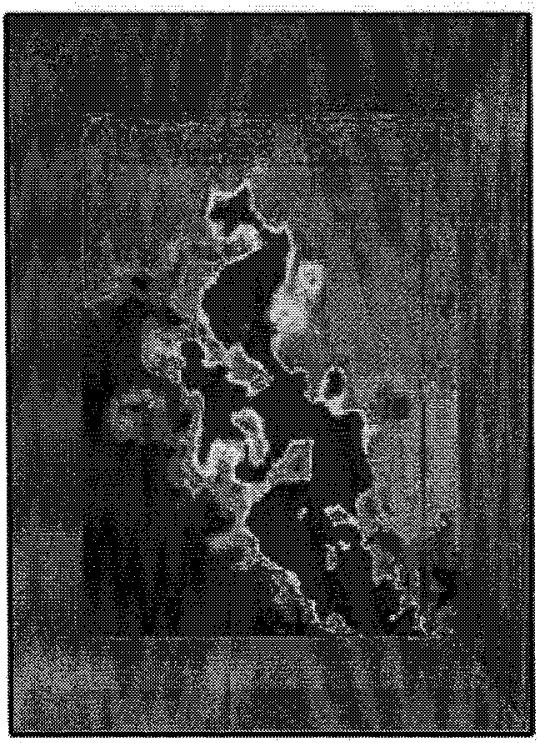

23.0

22.0

21.0

20.0

Figure 5.32 Temperature contours in $30-\mathrm{m}$ tall atrium on a vertical plane through the fire center, fire size $=1 \mathrm{MW}, 2.5 \mathrm{~m}$ from opening 


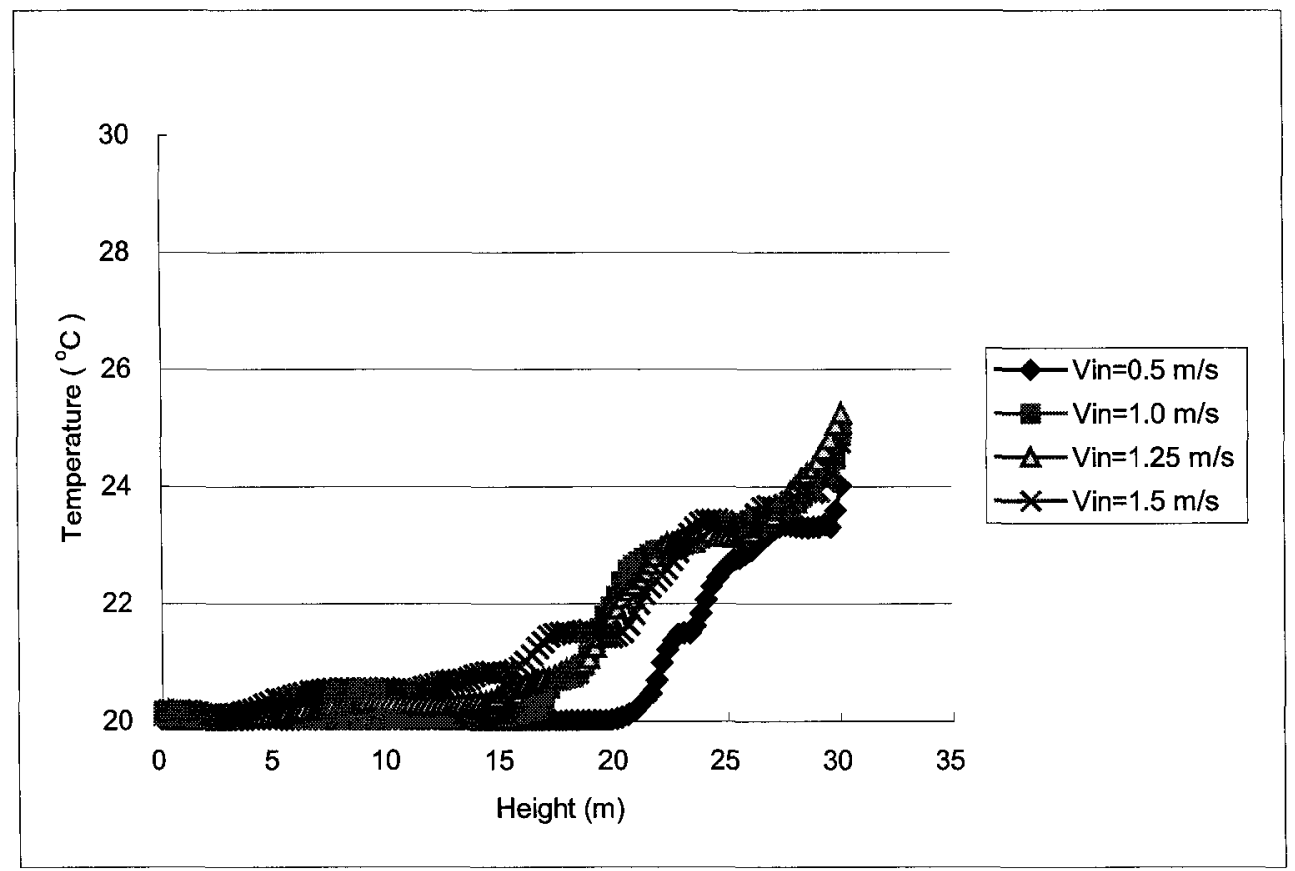

Figure 5.33 Temperature profiles in 30-m tall atrium with 1-MW fire, $2.5 \mathrm{~m}$ from opening

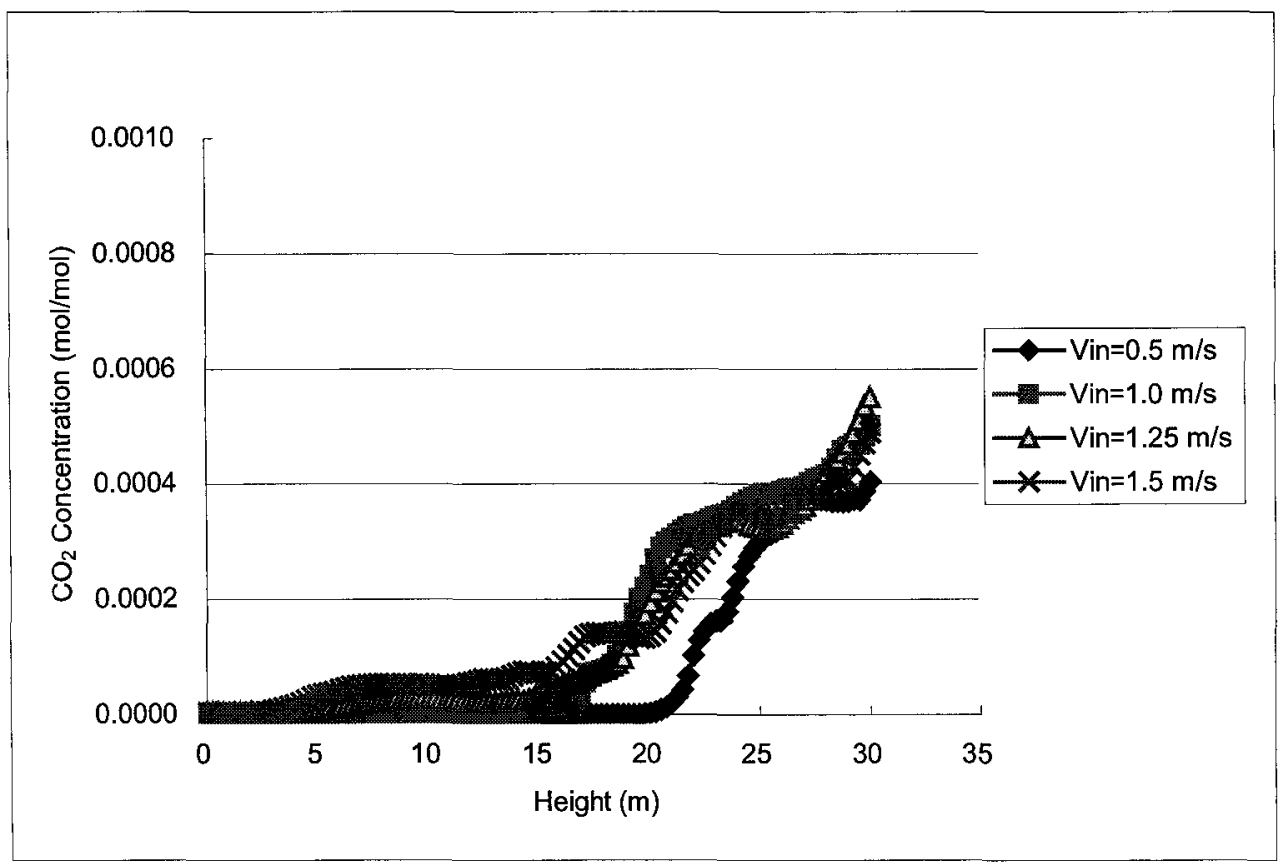

Figure 5.34 $\mathrm{CO}_{2}$ profiles in 30-m tall atrium with 1-MW fire, $2.5 \mathrm{~m}$ from opening

The results for the larger fire sizes, $2.5 \mathrm{MW}$ and $5 \mathrm{MW}$ are very similar as shown in Figures 5.35 - 5.40. The make-up air velocity seems to affect slightly the 
temperature contours in the atrium. There is also a change in the temperature and $\mathrm{CO}_{2}$ concentration profiles when increasing the velocity from $0.5 \mathrm{~m} / \mathrm{s}$ to $1.0 \mathrm{~m} / \mathrm{s}$. The profiles, however, for the $1.25 \mathrm{~m} / \mathrm{s}$ and $1.5 \mathrm{~m} / \mathrm{s}$ velocities are very close to those of the $1 \mathrm{~m} / \mathrm{s}$ velocity.

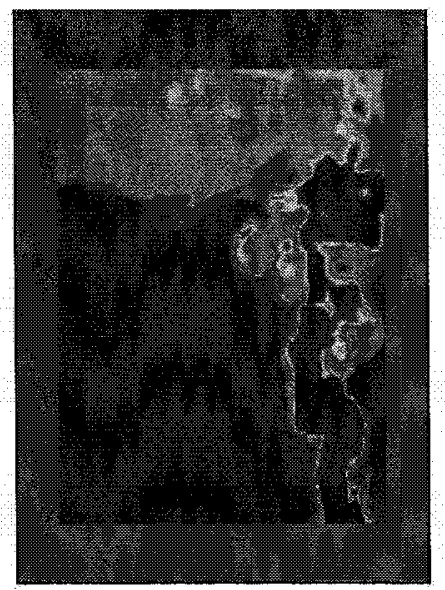

(a) Make-up air velocity $=0.5 \mathrm{~m} / \mathrm{s}$

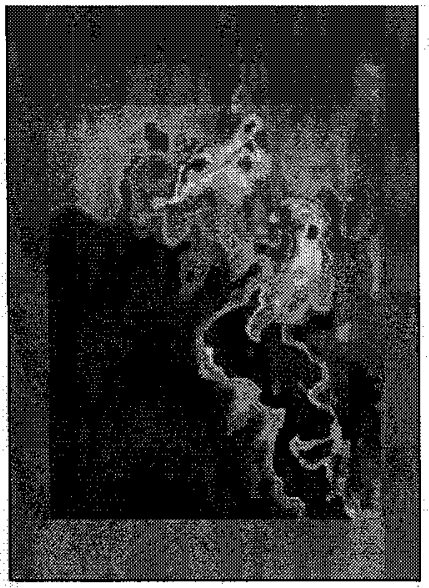

(c) Make-up air velocity $=1.25 \mathrm{~m} / \mathrm{s}$

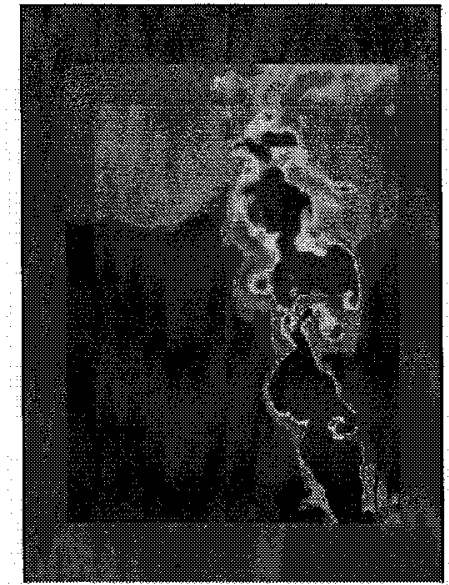

Plot $3 d$

temp

c

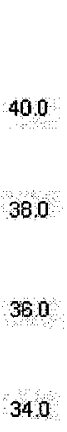

320

(b) Make-up air velocity $=1.0 \mathrm{~m} / \mathrm{s}$

300

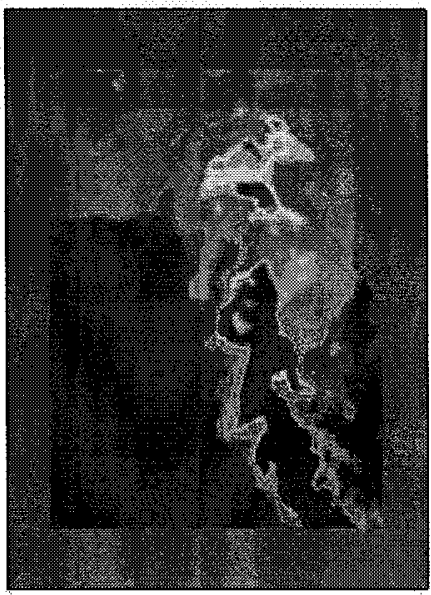

280

260

240

220

200

Figure 5.35 Temperature contours in 30-m tall atrium on a vertical plane through the fire center, fire size $=2.5 \mathrm{MW}, 2.5 \mathrm{~m}$ from opening 


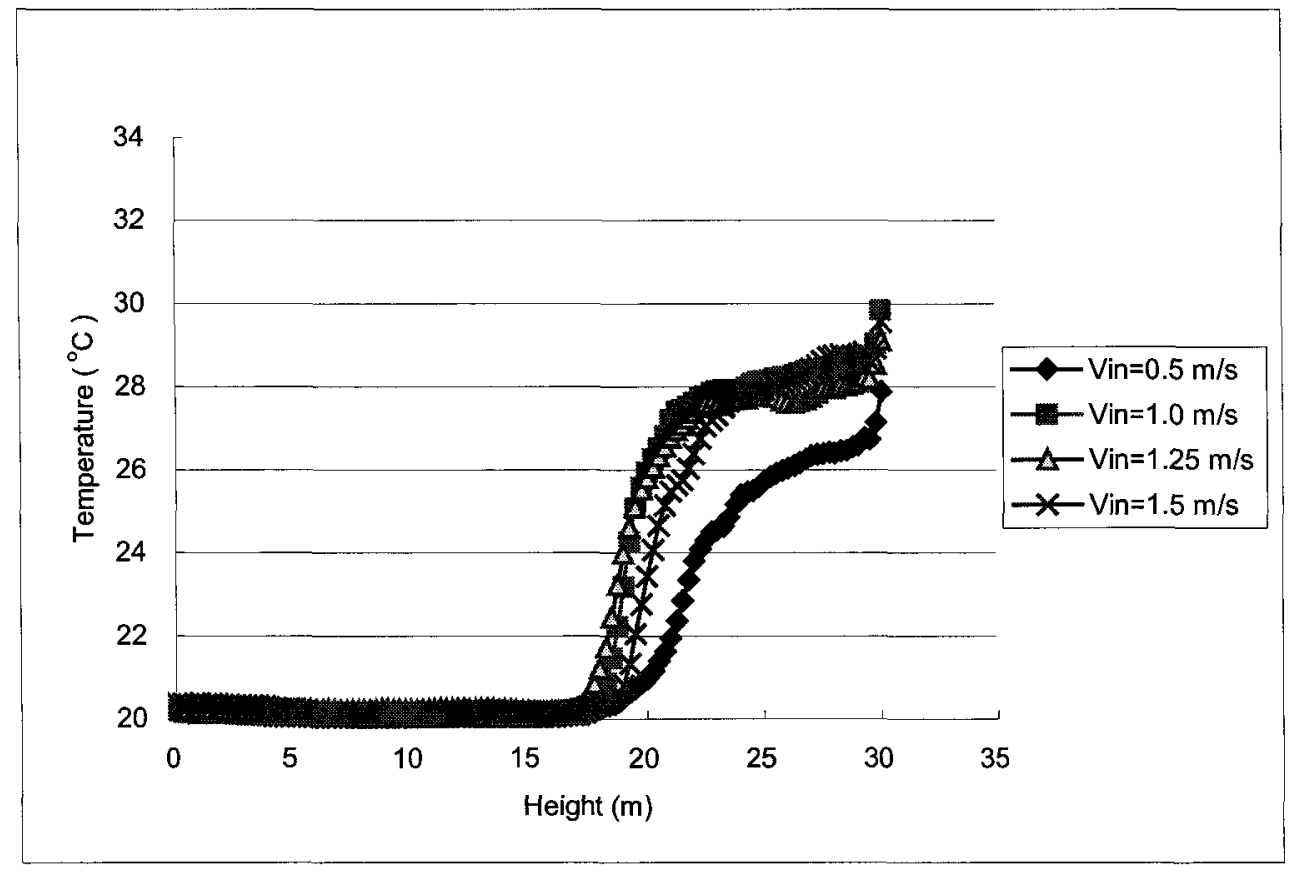

Figure 5.36 Temperature profiles in 30-m tall atrium with $2.5-\mathrm{MW}$ fire, $2.5 \mathrm{~m}$ from opening

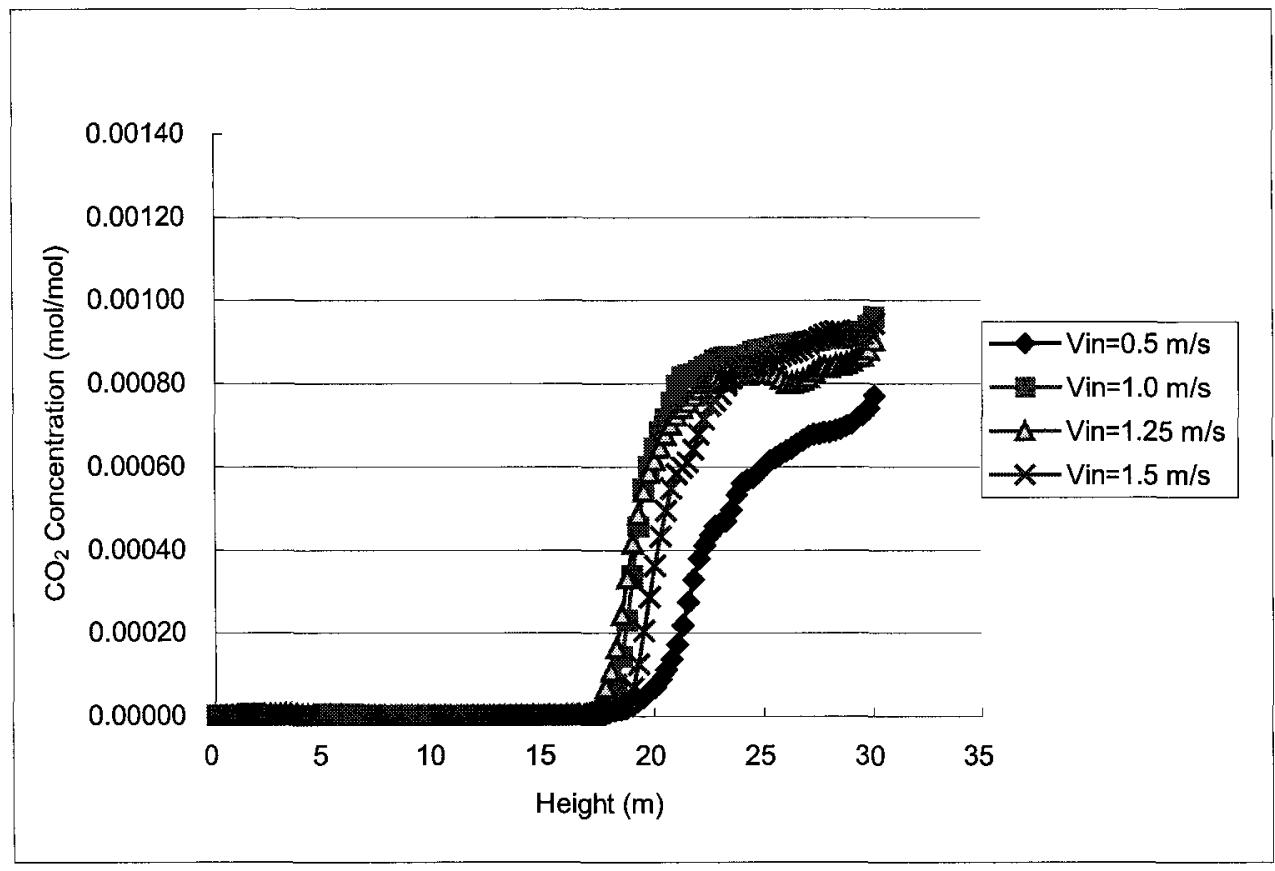

Figure 5.37 $\mathrm{CO}_{2}$ profiles in $30-\mathrm{m}$ tall atrium with $2.5-\mathrm{MW}$ fire, $2.5 \mathrm{~m}$ from opening 


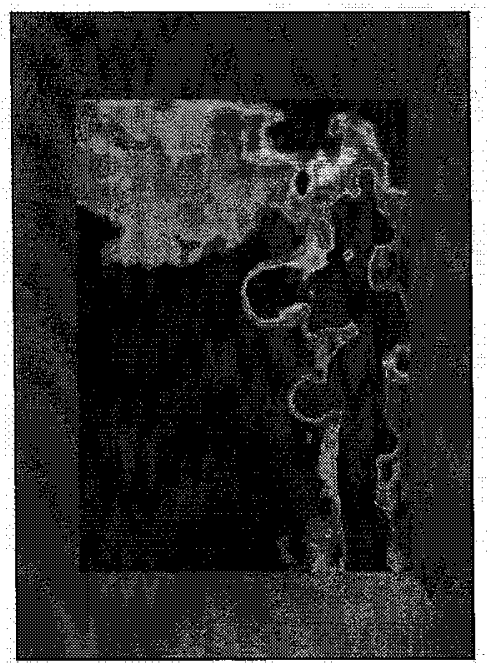

(a) Make-up air velocity $=0.5 \mathrm{~m} / \mathrm{s}$

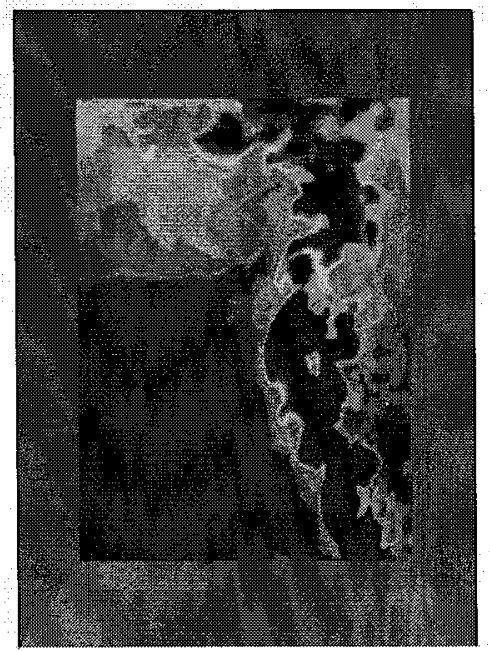

(c) Make-up air velocity $=1.25 \mathrm{~m} / \mathrm{s}$

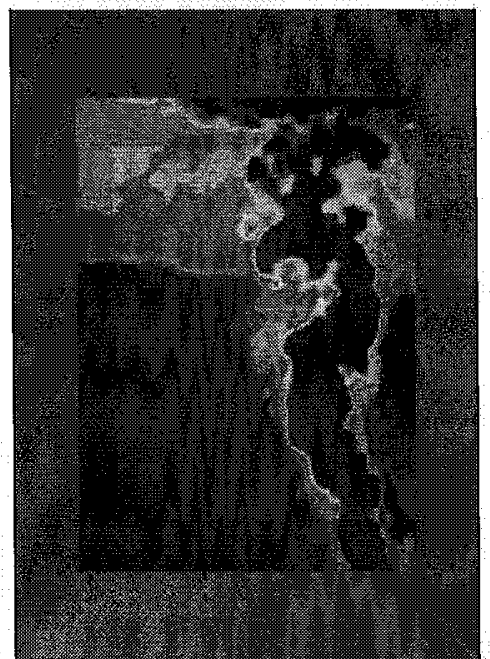

Plot $3 \mathrm{~d}$

temp

400
380
360
340
320

(b) Make-up air velocity $=1.0 \mathrm{~m} / \mathrm{s}$

$30: 0$

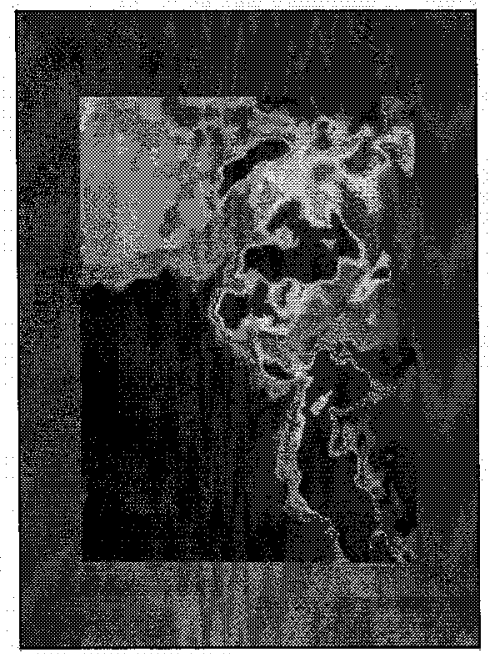

280

260

240

220

200

Figure 5.38 Temperature contours in 30-m tall atrium on a vertical plane through the fire center, fire size $=5 \mathrm{MW}, 2.5 \mathrm{~m}$ from opening 


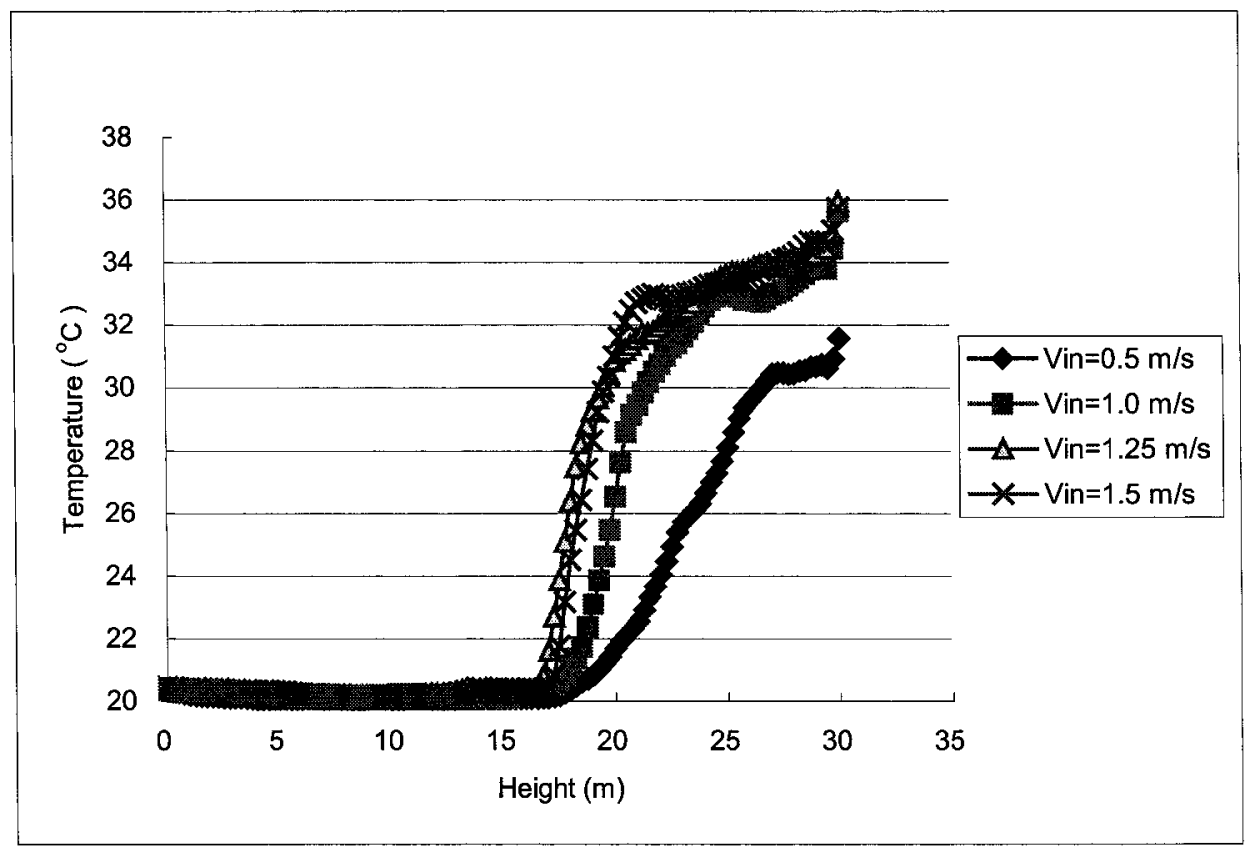

Figure 5.39 Temperature profiles in 30-m tall atrium with 5-MW fire, $2.5 \mathrm{~m}$ from opening

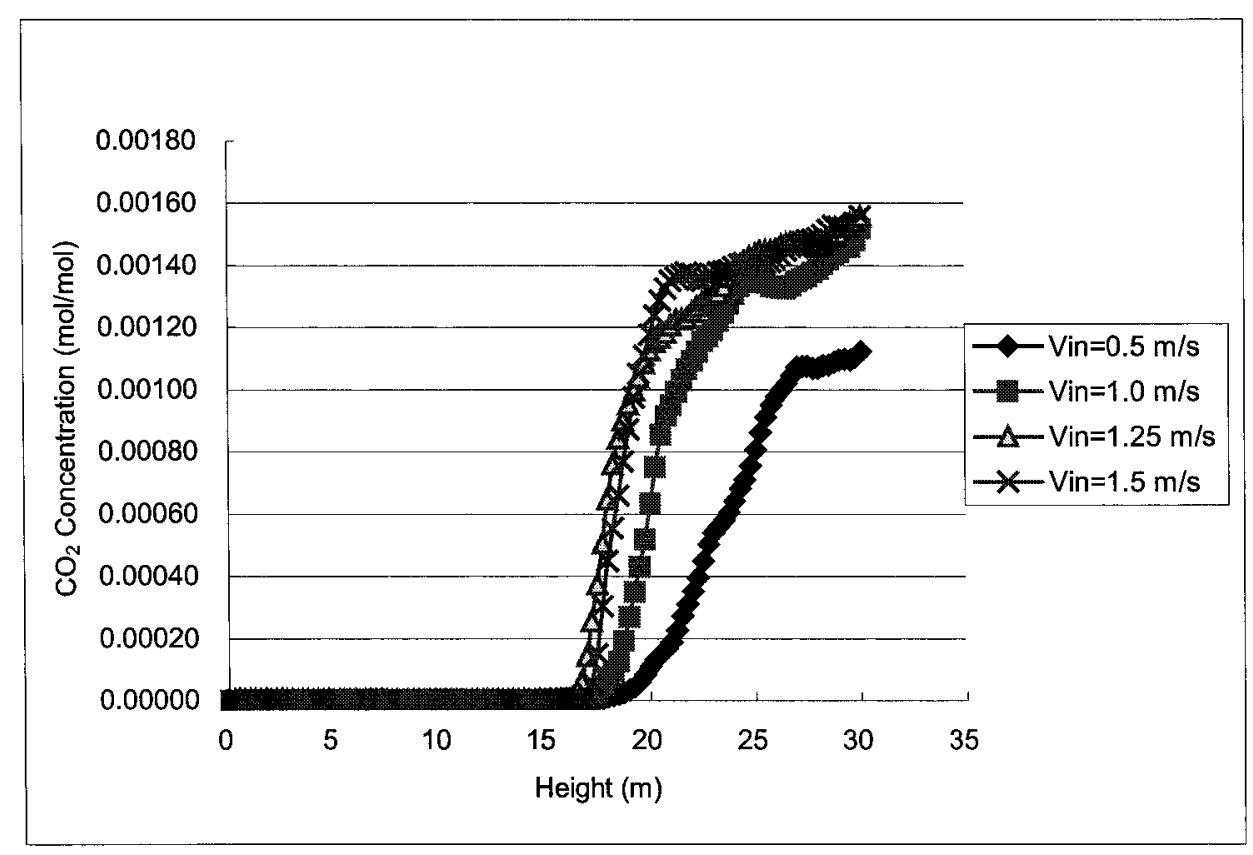

Figure $5.40 \mathrm{CO}_{2}$ profiles in $30-\mathrm{m}$ tall atrium with $5-\mathrm{MW}$ fire, $2.5 \mathrm{~m}$ from opening

The interface heights for the $30-\mathrm{m}$ tall atrium with the fire located $2.5 \mathrm{~m}$ from the opening are presented in Table 5.5. The results are quite similar to those with the fire 
located $5 \mathrm{~m}$ from the opening. Only the $1-\mathrm{MW}$ fire and $1.5 \mathrm{~m} / \mathrm{s}$ velocity result in a lower interface height.

Table 5.5 Interface heights in $30-\mathrm{m}$ tall atrium with fire $2.5 \mathrm{~m}$ from the opening

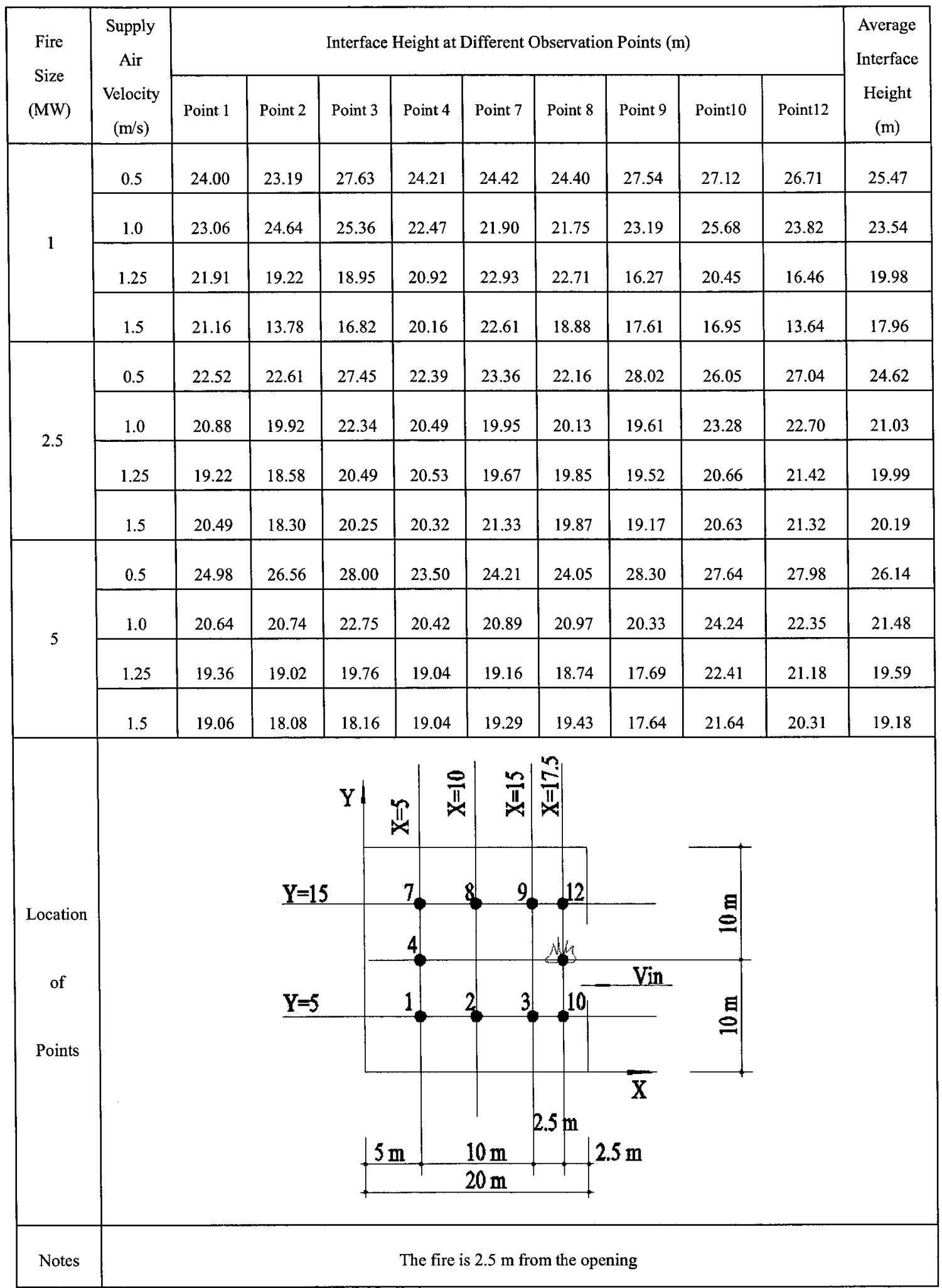




\subsubsection{Results for 50-m Tall Atrium}

The fire for the 50-m tall atrium was placed at two locations: $5 \mathrm{~m}$ and $2.5 \mathrm{~m}$ from the opening. Figure 5.41 which depicts temperature variation with time at different heights in the atrium, shows that steady state conditions were reached at about $200 \mathrm{~s}$ for this atrium. The results of the simulations for the three fire sizes and four make-up air velocities are discussed in the following sections.

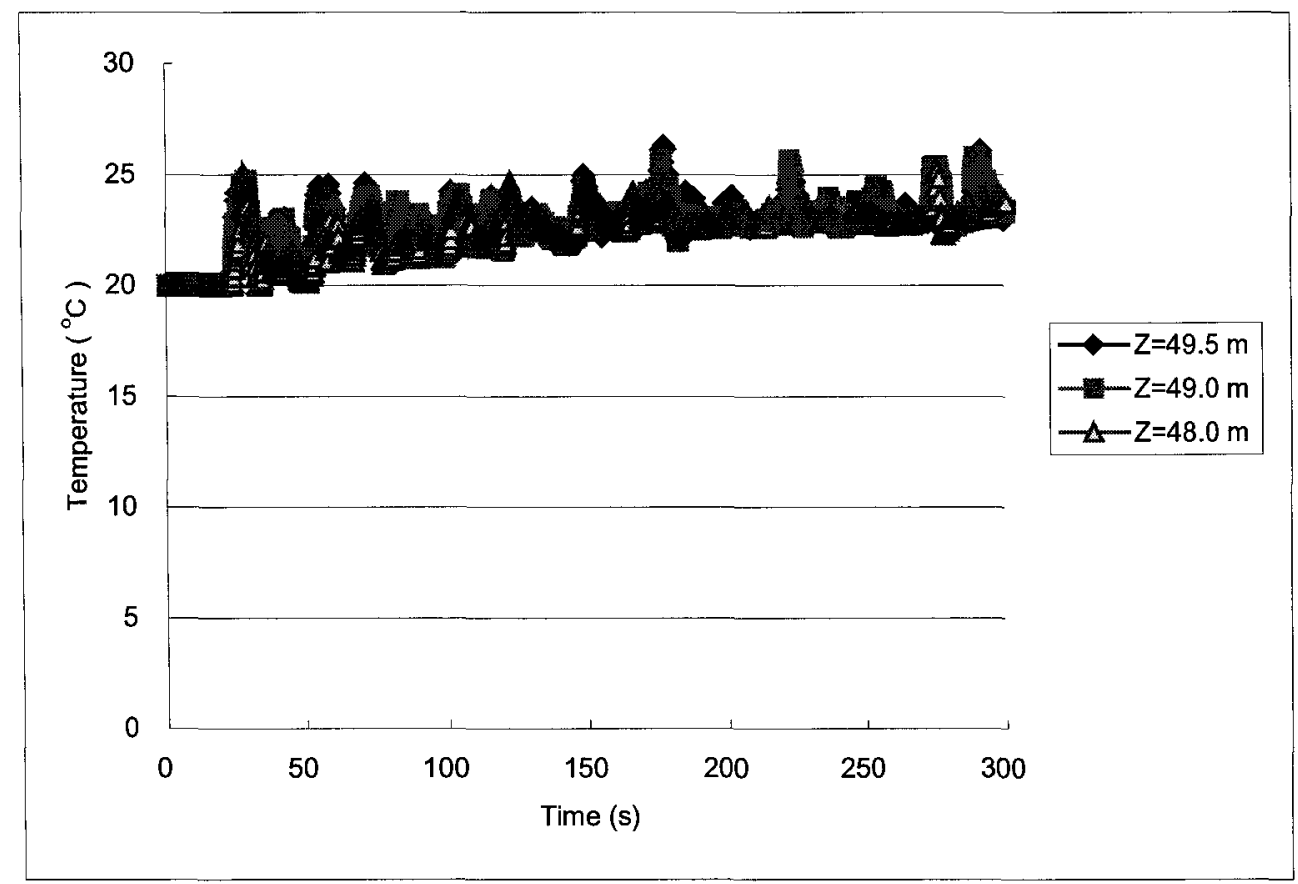

Figure 5.41 Temperature variations with time in 50-m tall atrium

\subsubsection{Fire Location $5 \mathrm{~m}$ from the Opening}

The results for the simulations with the 1-MW fire located $5 \mathrm{~m}$ from the opening are shown in Figures 5.42, 5.43 and 5.44. 
The mass flow rate of the exhaust for the 1-MW fire simulations was set to 288.91 $\mathrm{kg} / \mathrm{s}$, and the areas of the make-up air openings were: $489.6 \mathrm{~m}^{2}, 244.8 \mathrm{~m}^{2}, 195.86 \mathrm{~m}^{2}$ and $163.2 \mathrm{~m}^{2}$. Figure 5.42 shows the temperature contours at $300 \mathrm{~s}$ on a vertical plane passing through the fire centerline and the center of the opening for the $1-\mathrm{MW}$ fire and the four different make-up air velocities. The figure shows that, even at this distance, the fire plume is disturbed by the make-up air especially with the $1.25 \mathrm{~m} / \mathrm{s}$ and $1.5 \mathrm{~m} / \mathrm{s}$ velocities. The temperature rise, however, in the upper layer, as shown in Figure 5.43, which shows temperature profiles in the atrium at point 7 is less than $2^{\circ} \mathrm{C}$. With this temperature rise, the fire plume is sensitive to the flow velocities. The impact, however on the hot layer height is very small. A small effect can also be seen in the profiles of $\mathrm{CO}_{2}$ concentration at point 7 shown in Figure 5.44. Only the $1.5 \mathrm{~m} / \mathrm{s}$ velocity causes a significant change of the profiles. 


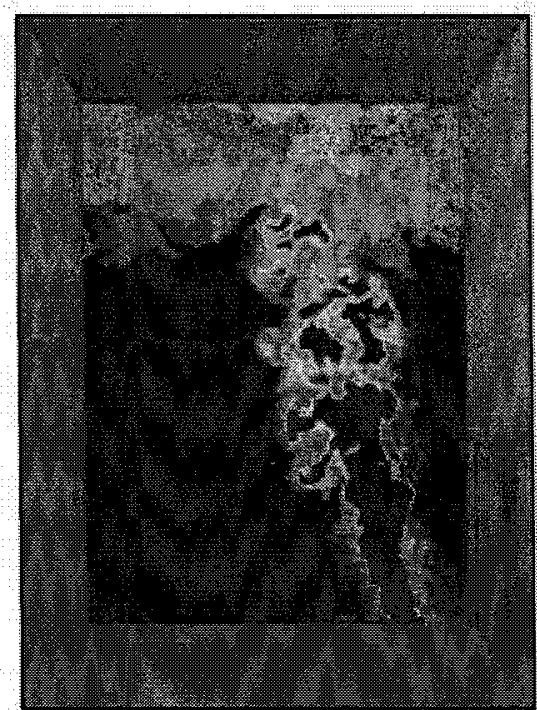

(a) Make-up air velocity $=0.5 \mathrm{~m} / \mathrm{s}$

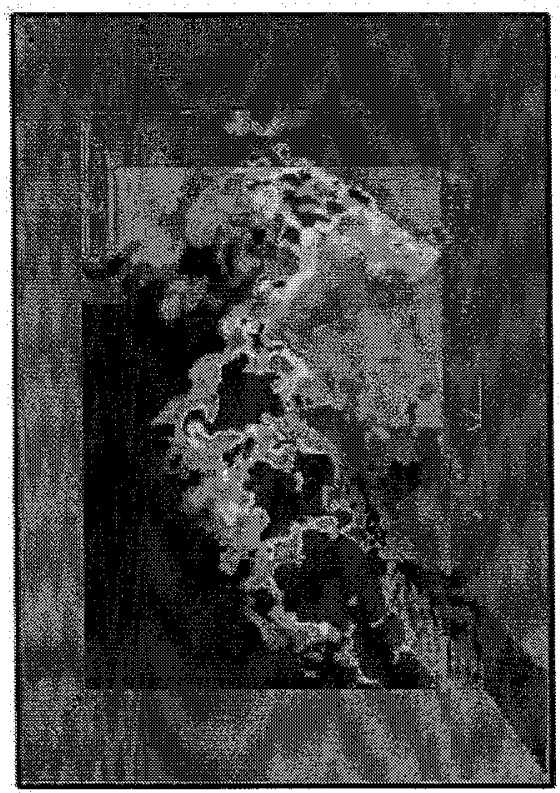

(c) Make-up air velocity $=1.25 \mathrm{~m} / \mathrm{s}$

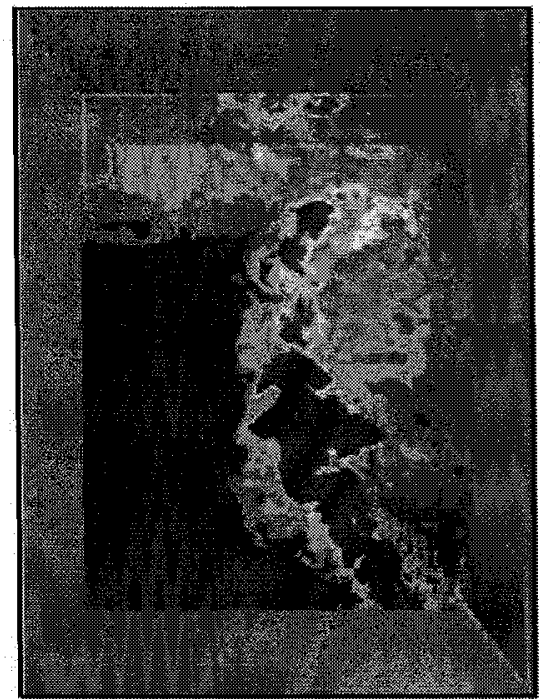

Plot3d

temp

C

24.5

24.0

23.6

23.1

(b) Make-up air velocity $=1.0 \mathrm{~m} / \mathrm{s}$

22.7

22.3

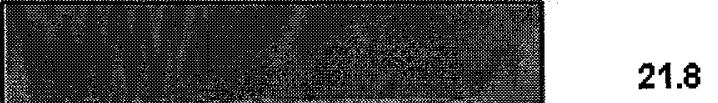

21.4

20.9

20.5

20.0

Figure 5.42Temperature contours in 50-m tall atrium on a vertical plane through the fire center, fire size $=1 \mathrm{MW}, 5 \mathrm{~m}$ from opening 


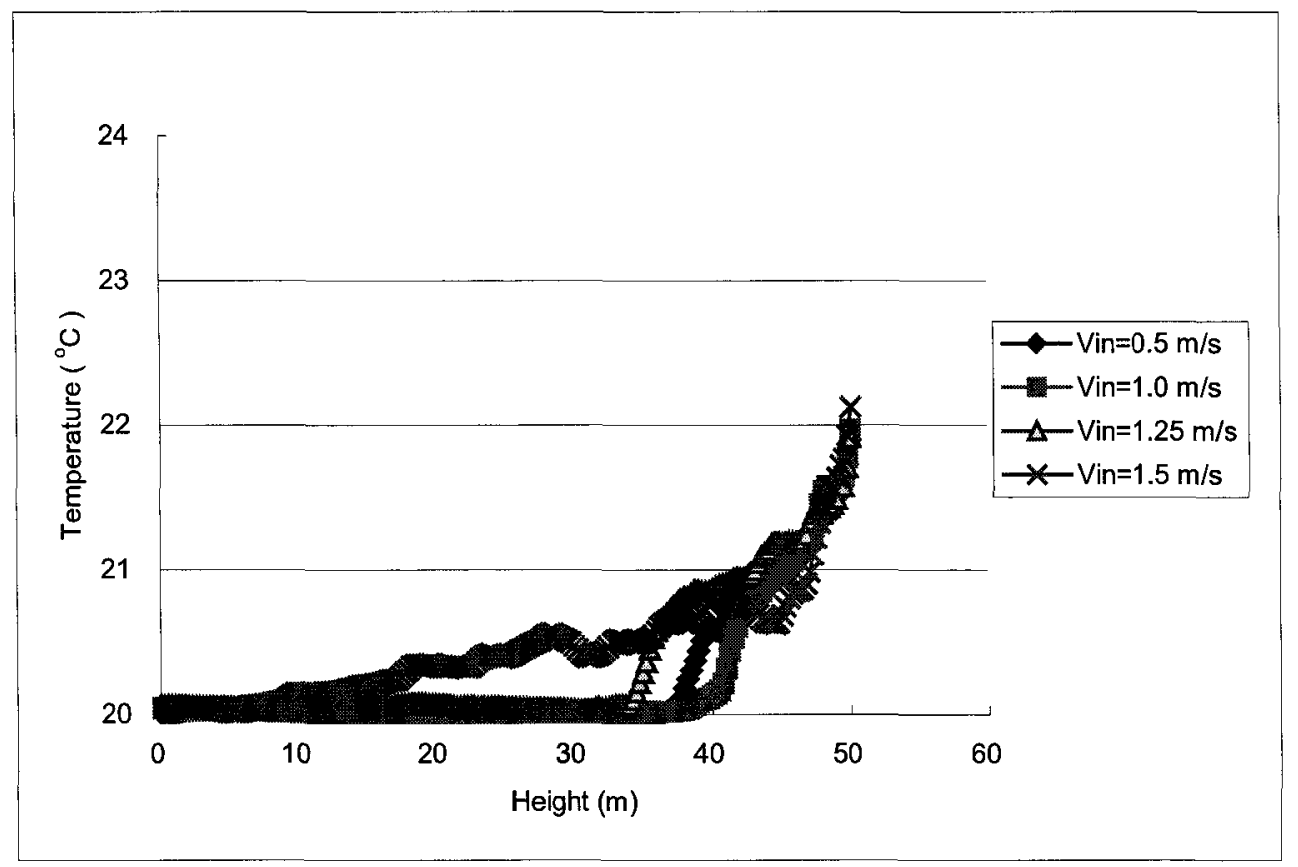

Figure 5.43 Temperature profiles in 50-m tall atrium with 1-MW fire, $5 \mathrm{~m}$ from opening

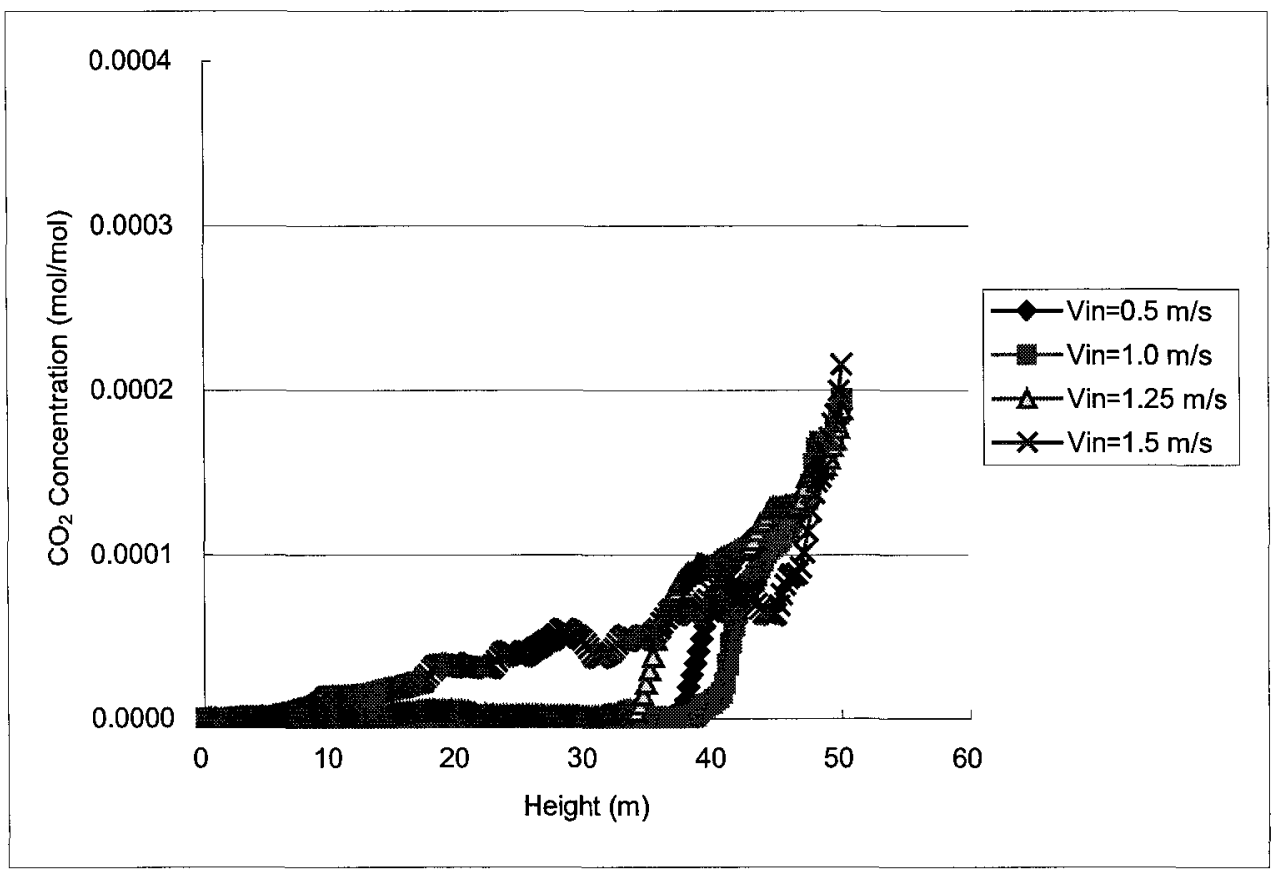

Figure 5.44 $\mathrm{CO}_{2}$ Profiles in 50-m tall atrium with 1-MW fire, $5 \mathrm{~m}$ from opening The mass flow rate of the exhaust for the $2.5-\mathrm{MW}$ fire was set to $393.44 \mathrm{~kg} / \mathrm{s}$, and the areas of the make-up air openings were: $666.77 \mathrm{~m}^{2}, 333.48 \mathrm{~m}^{2}, 266.76 \mathrm{~m}^{2}$ and 222.32 
$\mathrm{m}^{2}$. Figure 5.45 shows the temperature contours with the $2.5 \mathrm{MW}$ fire size at $300 \mathrm{~s}$. The effect of the make-up air velocity on the contours is not as much as that of the 1-MW fire case. Figures 5.46 and 5.47 that depict temperature and $\mathrm{CO}_{2}$ concentration profiles at Point 7 respectively do not show any significant change of the profiles for velocity from $1.0 \mathrm{~m} / \mathrm{s}$ to $1.5 \mathrm{~m} / \mathrm{s}$.

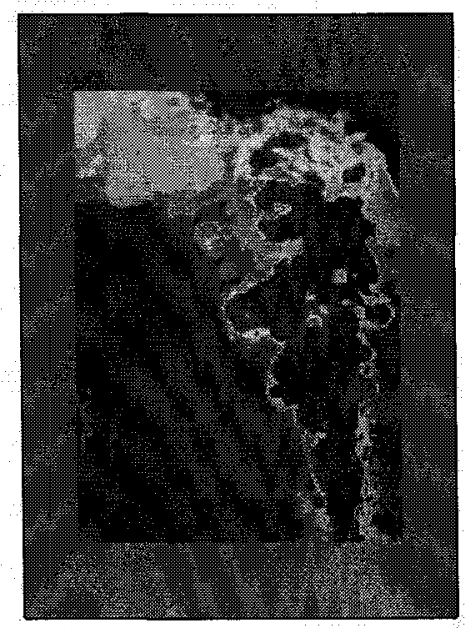

(a) Make-up air velocity $=0.5 \mathrm{~m} / \mathrm{s}$

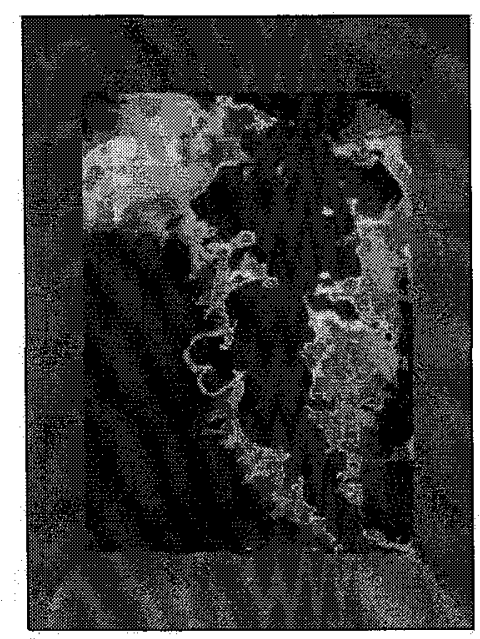

(c) Make-up air velocity $=1.25 \mathrm{~m} / \mathrm{s}$

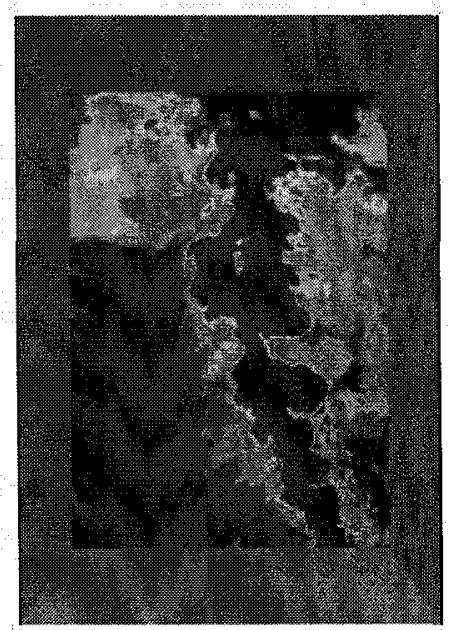

(b) Make-up air velocity $=1.0 \mathrm{~m} / \mathrm{s}$

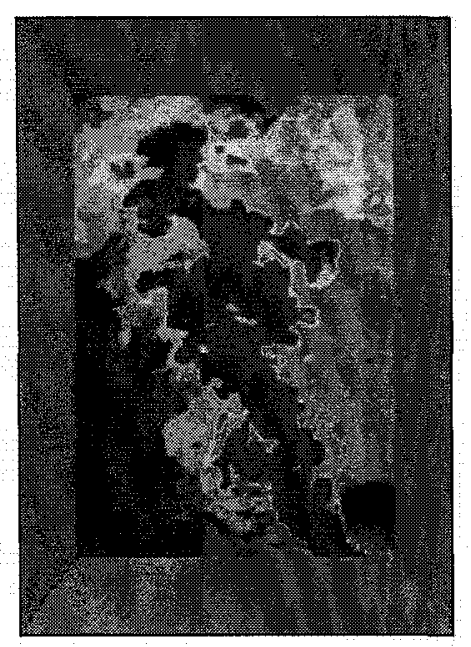

(d) Make-up air velocity $=1.5 \mathrm{~m} / \mathrm{s}$

Figure 5.45 Temperature contours in 50-m tall atrium on a vertical plane through the fire center, fire size $=2.5 \mathrm{MW}, 5 \mathrm{~m}$ from opening 


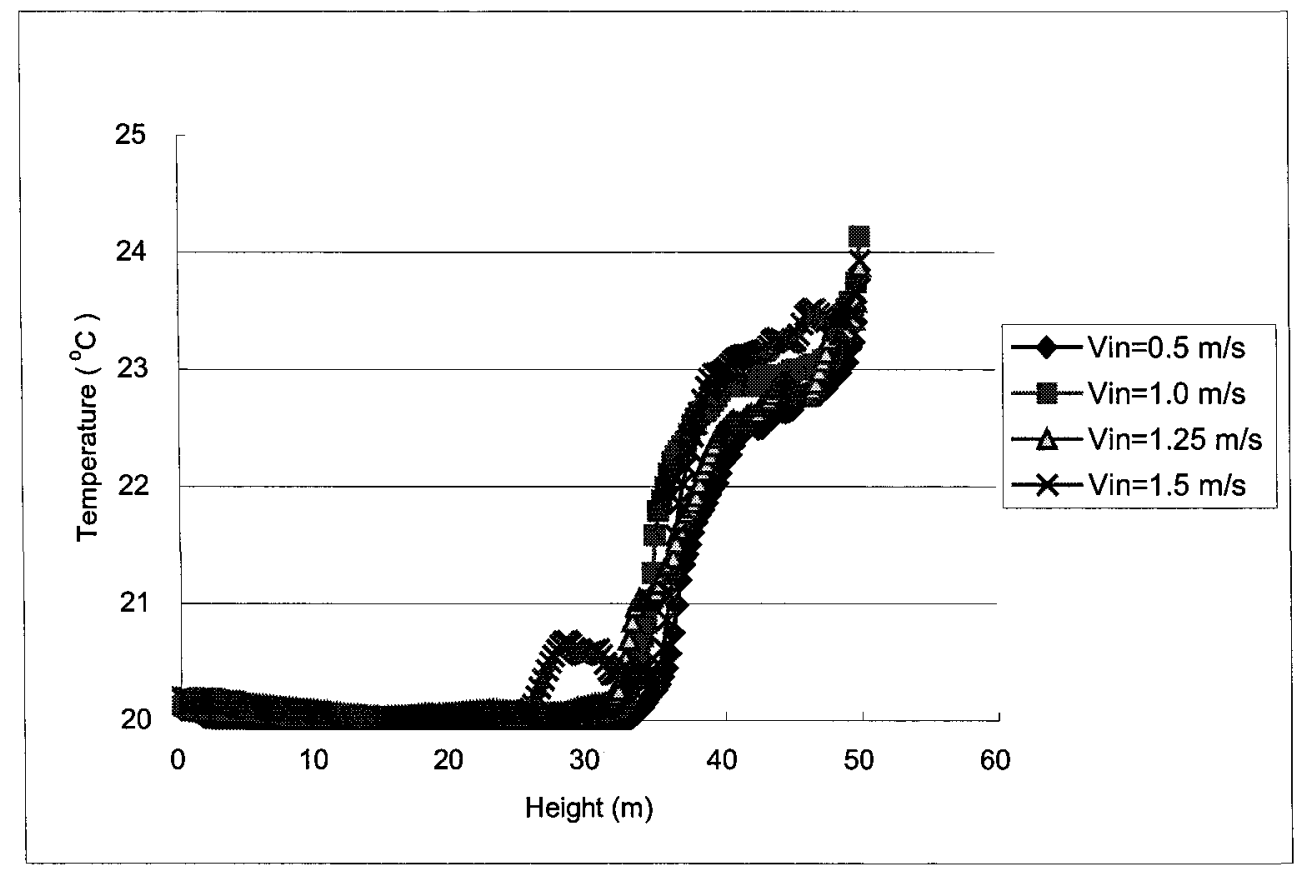

Figure 5.46 Temperature profiles in 50-m tall atrium with $2.5-\mathrm{MW}$ fire, $5 \mathrm{~m}$ from opening

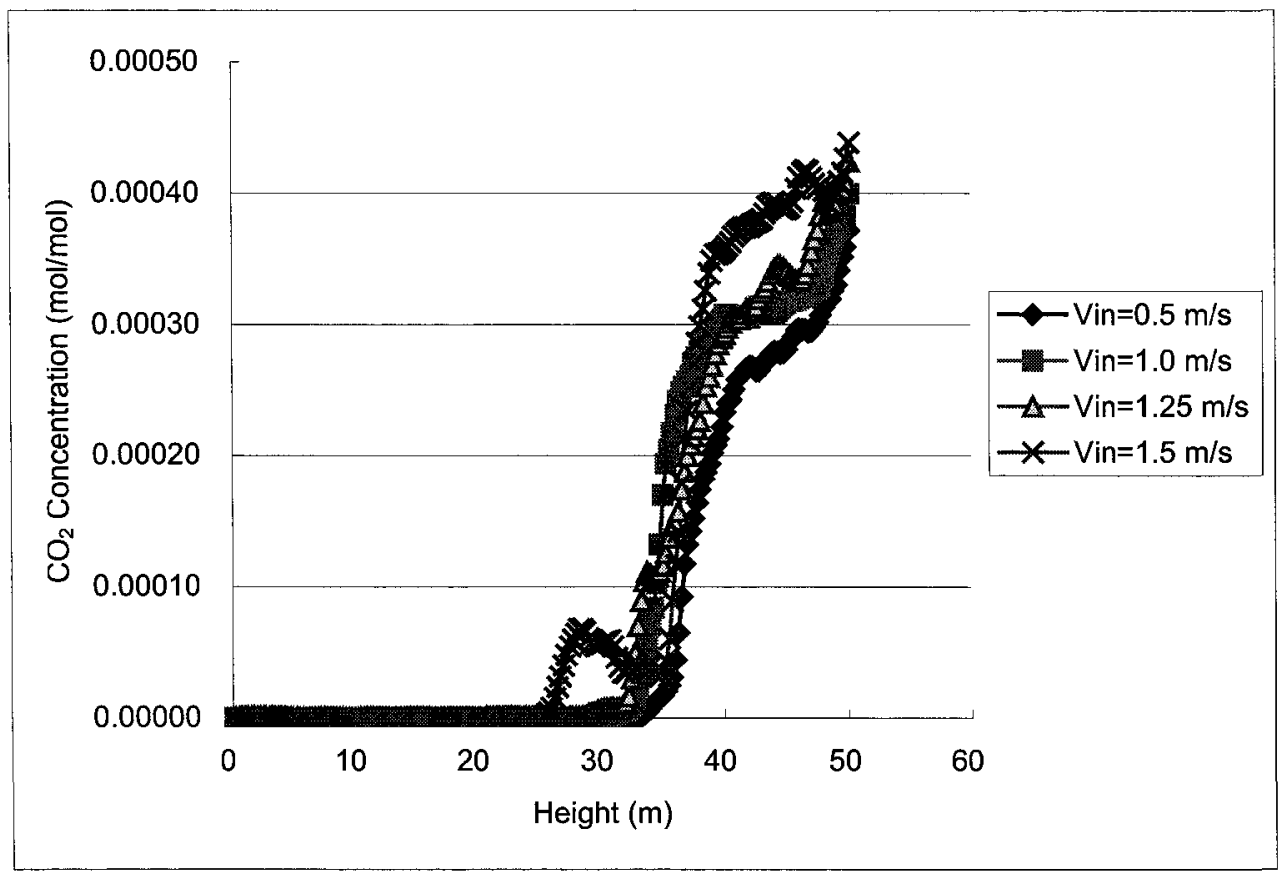

Figure 5.47 $\mathrm{CO}_{2}$ profiles in 50-m tall atrium with 2.5-MW fire, $5 \mathrm{~m}$ from opening

For the fire size of $5 \mathrm{MW}$, the mass flow rate of the exhaust was set to $497.87 \mathrm{~kg} / \mathrm{s}$, and the areas of the make-up air openings were: $843.9 \mathrm{~m}^{2}, 421.95 \mathrm{~m}^{2}, 365.69 \mathrm{~m}^{2}$ and 
$281.3 \mathrm{~m}^{2}$. The results with the 5-MW fire show a stronger plume, which is not influenced as much by the incoming air. The temperature and $\mathrm{CO}_{2}$ concentration profiles at point 7, shown in Figures 5.49 and 5.50 indicate that both profiles are affected by the increased make-up air velocity. The $0.5 \mathrm{~m} / \mathrm{s}$ profile shows a thin hot layer, while the layers of the other velocities are similar with a decreased interface height.

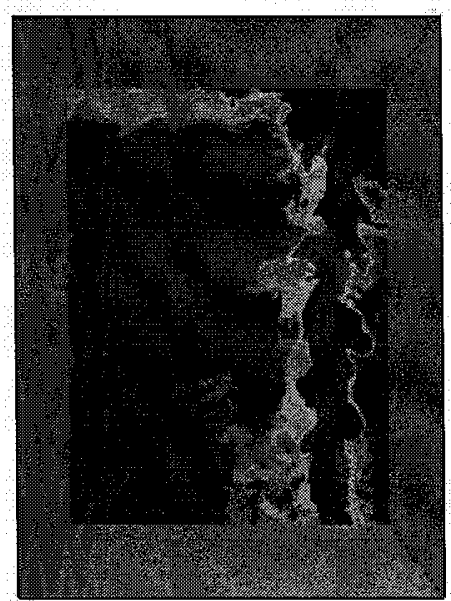

(a) Make-up air velocity $=0.5 \mathrm{~m} / \mathrm{s}$

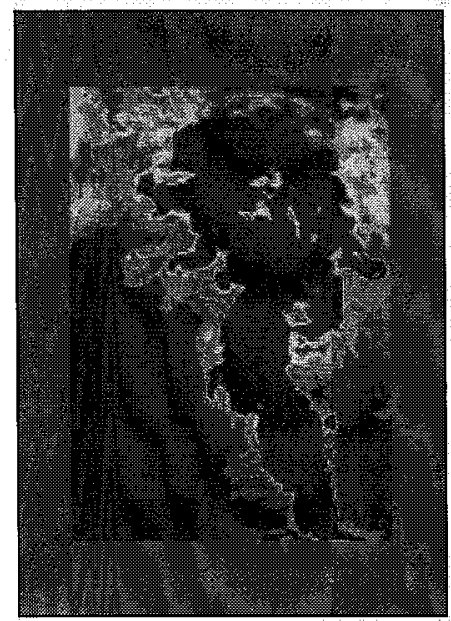

(c) Make-up air velocity $=1.25 \mathrm{~m} / \mathrm{s}$

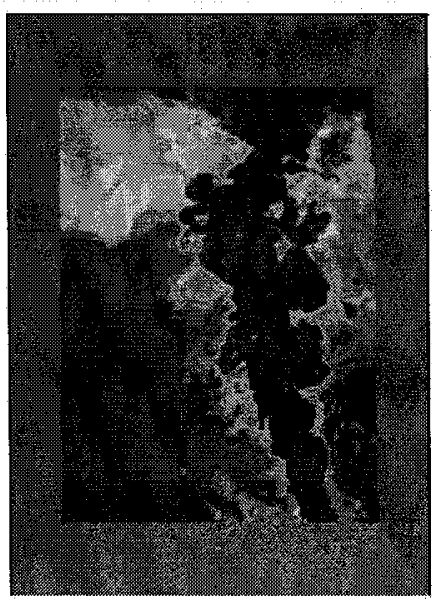

Plotosd

temp

c

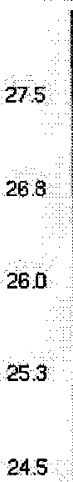

(b) Make-up air velocity $=1.0 \mathrm{~m} / \mathrm{s}$

33.8

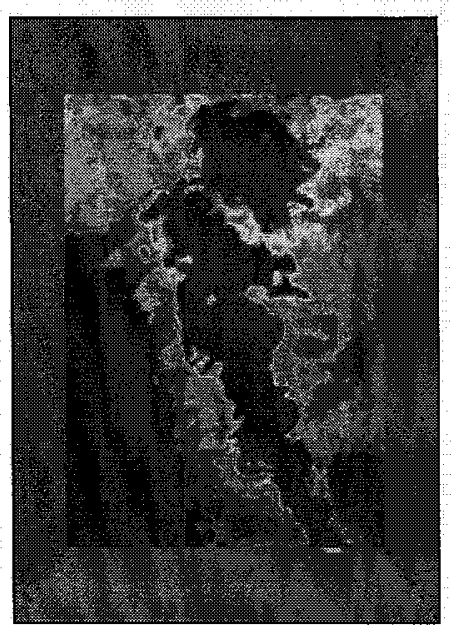

230

22.3

215

208

200

(d) Make-up air velocity $=1.5 \mathrm{~m} / \mathrm{s}$

Figure 5.48 Temperature contours in 50-m tall atrium on a vertical plane through the fire center, fire size $=5 \mathrm{MW}, 5 \mathrm{~m}$ from opening 


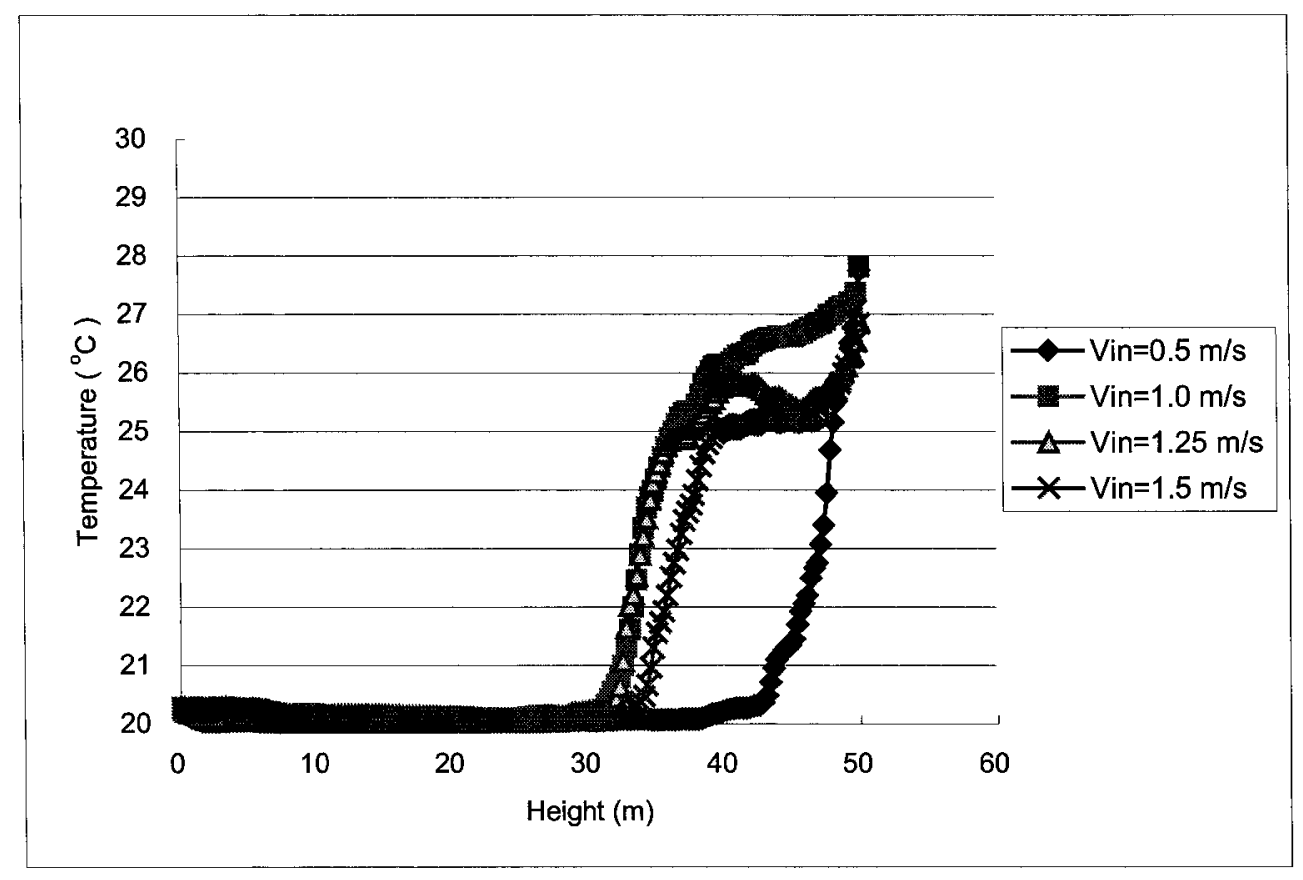

Figure 5.49 Temperature profiles in 50-m tall atrium with 5-MW fire, $5 \mathrm{~m}$ from

opening

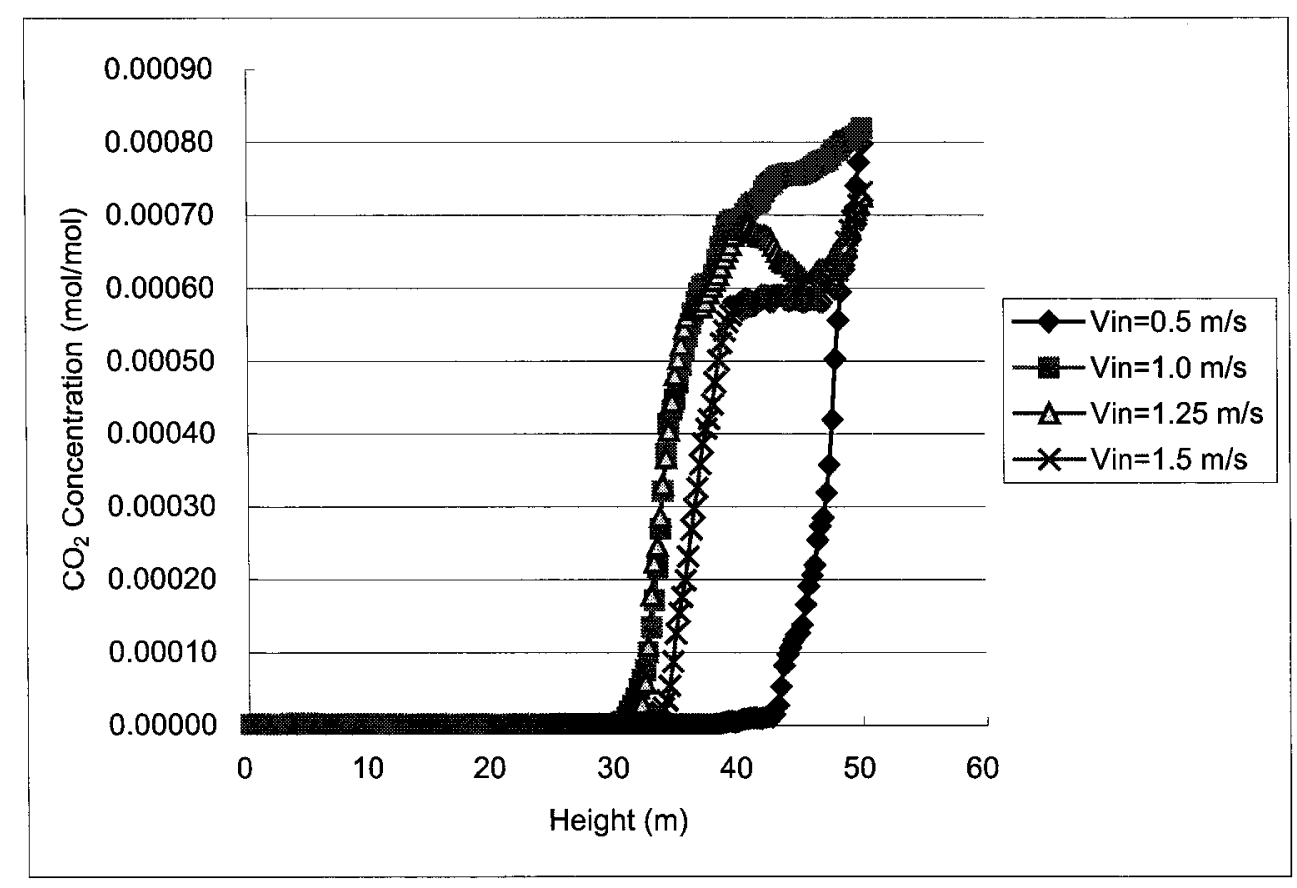

Figure $5.50 \mathrm{CO}_{2}$ profiles in 50-m tall atrium with 5-MW fire, $5 \mathrm{~m}$ from opening 
The interface heights for the $50-\mathrm{m}$ tall atrium and the fire located $5 \mathrm{~m}$ from the opening are shown in Table 5.6. The results show that for the 1-MW case and velocities greater than $1.0 \mathrm{~m} / \mathrm{s}$, the interface heights vary significantly from point to point. This demonstrates that there is a lot of turbulence and mixing caused by the incoming air. Although the average interface height for the 1-MW case and $1.5 \mathrm{~m} / \mathrm{s} \mathrm{s}$ similar to the corresponding interface height with the larger fires, at some points the interface height drop, down to $25 \mathrm{~m}$. 
Table 5.6 Interface heights in 50-m tall atrium with fire $5 \mathrm{~m}$ from the opening

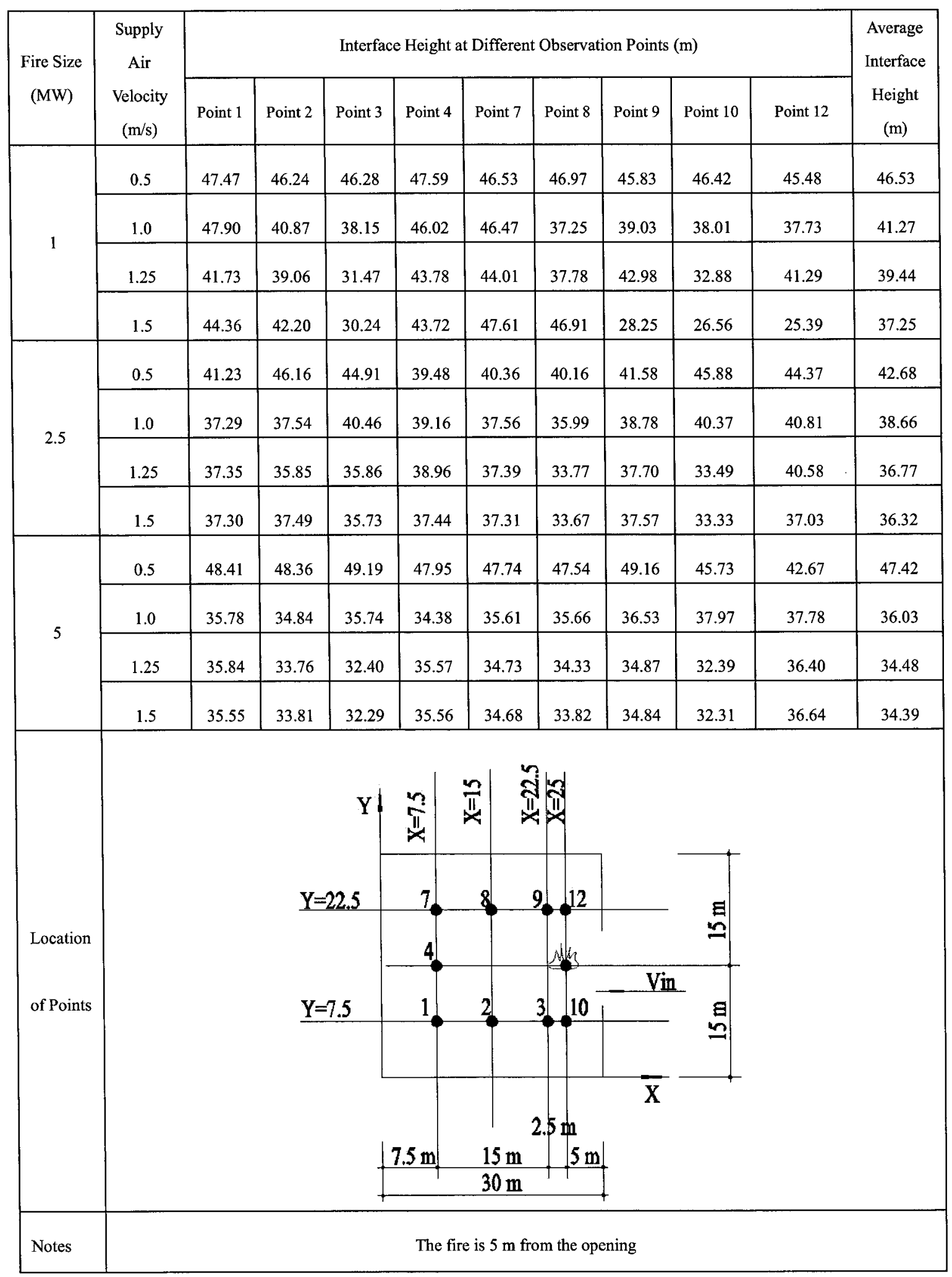




\subsubsection{Fire Location $2.5 \mathrm{~m}$ from the Opening}

The fire for the $50-\mathrm{m}$ atrium simulations was also placed at $2.5 \mathrm{~m}$ from the opening and simulations were done for the three fire sizes and four different make-up air velocities.

The mass flow rate of the exhaust and the areas of the make-up air openings for the 1 MW, 2.5 MW and 5-MW fire simulations had the same values as for the case with the fire placed $5 \mathrm{~m}$ from the opening. Figure 5.51 shows the temperature distributions on a vertical plane passing through the fire centerline and the center of the opening for the 1-MW fire and four different make-up air velocities at $300 \mathrm{~s}$.

The figure shows clearly the impact of the make-up air velocity on fire plume. With the make-up air velocity at $1.0 \mathrm{~m} / \mathrm{s}$, the fire plume is not affected much. A velocity of $1.25 \mathrm{~m} / \mathrm{s}$ causes the plume to tilt, however it quickly rises vertically due to the strong buoyancy effect. The $1.5 \mathrm{~m} / \mathrm{s}$ make-up air velocity causes a significant disturbance of the plume and creates a lot of mixing in the atrium.

Figure 5.52 and Figure 5.53 show the temperature and $\mathrm{CO}_{2}$ profiles with different velocities at Point 7 of the atrium. The figure shows that the interface height is not affected significantly by the make-up air velocities. It also shows a lot of fluctuation due to the low temperature rise and small buoyancy force. 


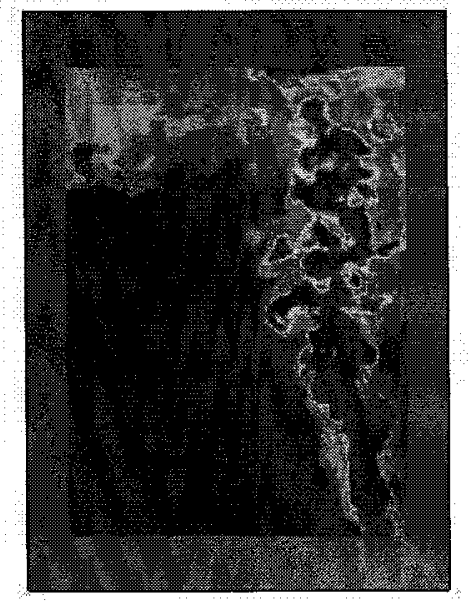

(a) Make-up air velocity $=0.5 \mathrm{~m} / \mathrm{s}$

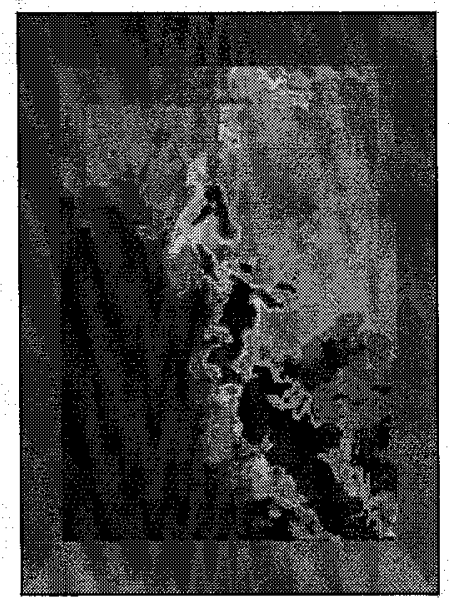

(c) Make-up air velocity $=1.25 \mathrm{~m} / \mathrm{s}$

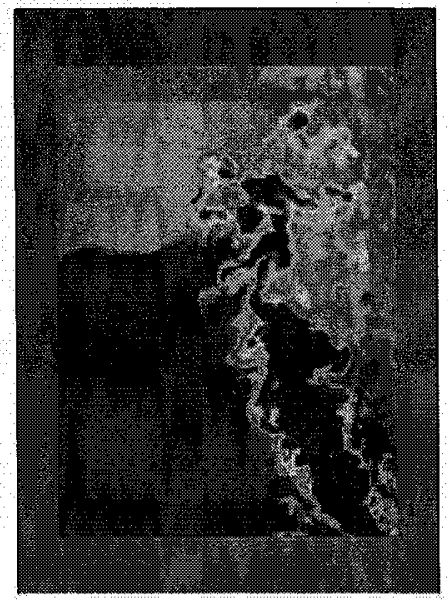

Plot 3 d

temp

c.

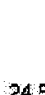

245

$24: 0$

236

231

227

(b) Make-up air velocity $=1.0 \mathrm{~m} / \mathrm{s}$

Figure 5.51 Temperature contours in 50-m tall atrium on a vertical plane through the fire center, fire size $=1 \mathrm{MW}, 2.5 \mathrm{~m}$ from opening 


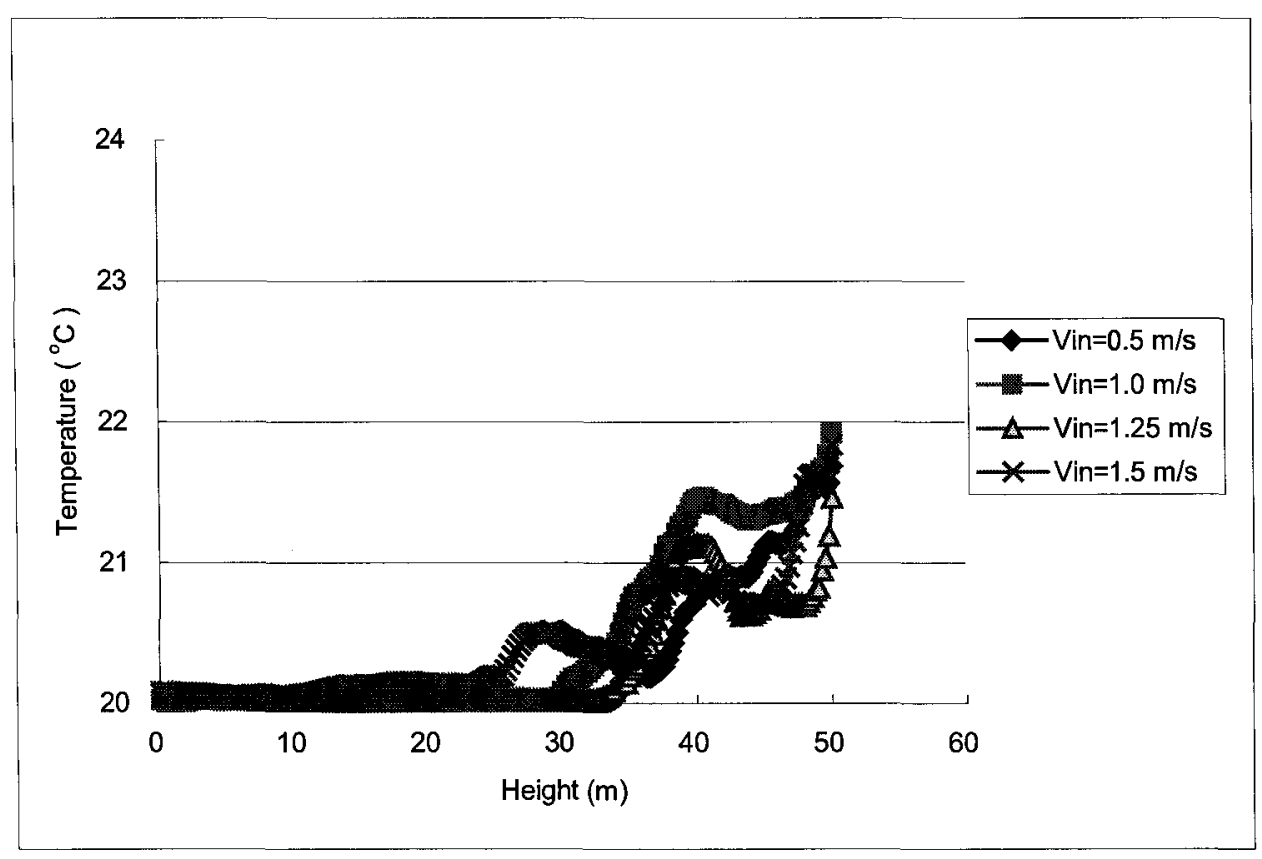

Figure 5.52 Temperature profiles in 50-m tall atrium with 1-MW fire, $2.5 \mathrm{~m}$ from opening

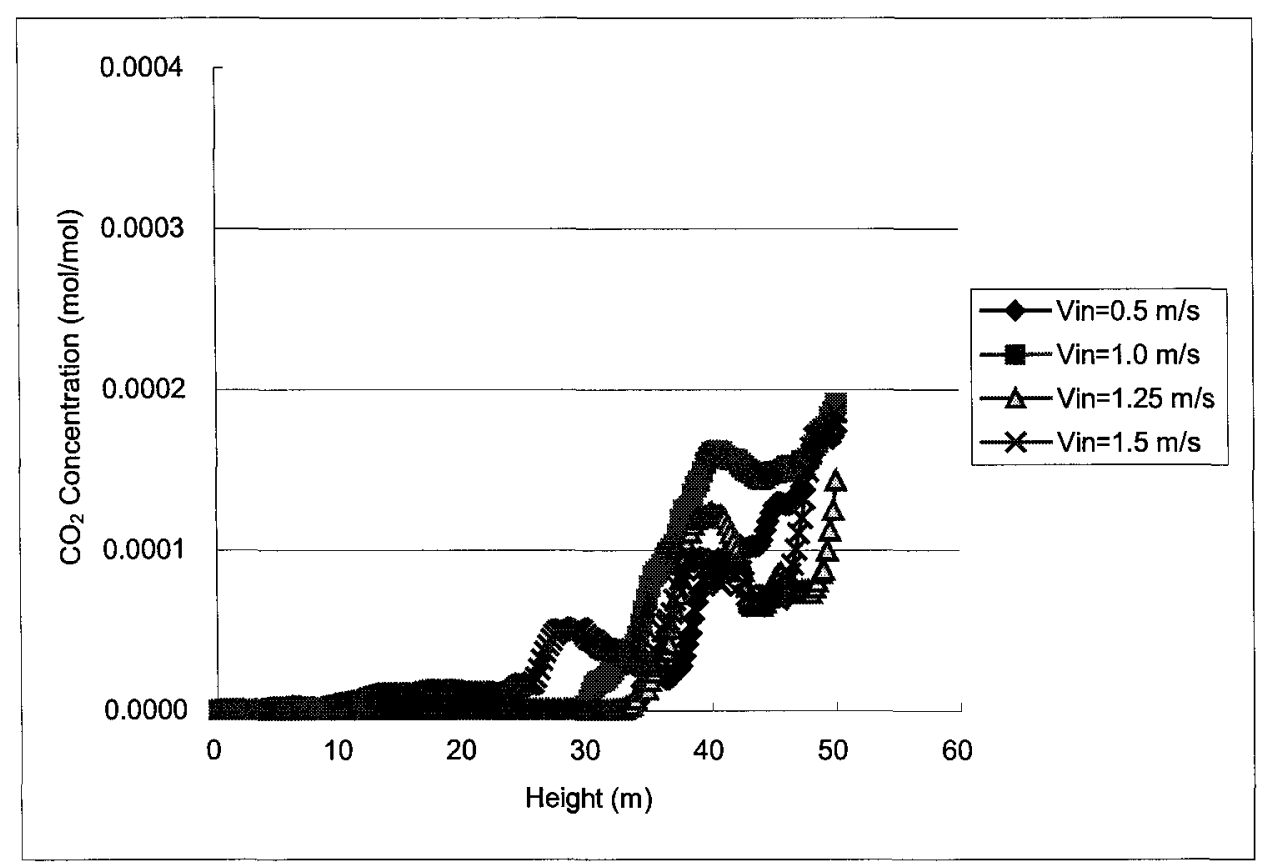

Figure $5.53 \mathrm{CO}_{2}$ profiles in $50-\mathrm{m}$ tall atrium with 1-MW fire, $2.5 \mathrm{~m}$ from opening

The results of the simulations for the 2.5-MW fire are shown in Figures 5.54 - 5.56.

Figure 5.54, which shows the temperature contours on a vertical plane through the 118 
centerline and the center of the opening at $300 \mathrm{~s}$, indicates that the fire plume is now more buoyant and it is not affected much by the make-up air velocities. The temperature and $\mathrm{CO}_{2}$ profiles at Point 7 in the atrium depicted in Figure 5.55 and 5.56 show an increase in the transition zone between the lower and the upper layer for velocities greater than $0.5 \mathrm{~m} / \mathrm{s}$.

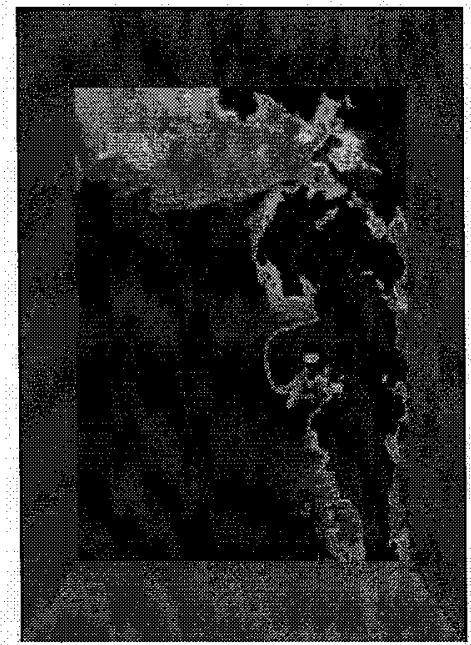

(a) Make-up air velocity $=0.5 \mathrm{~m} / \mathrm{s}$

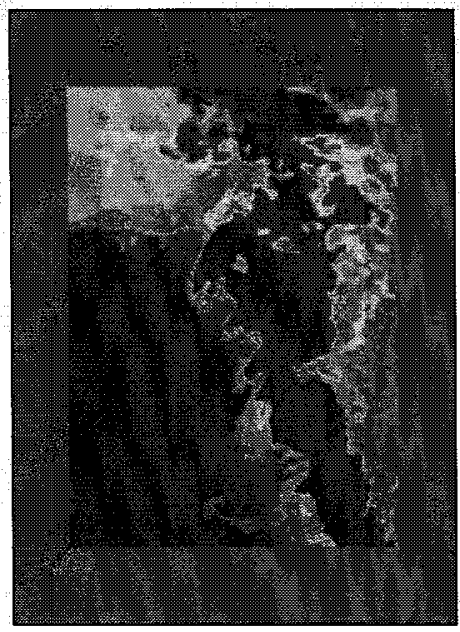

(c) Make-up air velocity $=1.25 \mathrm{~m} / \mathrm{s}$

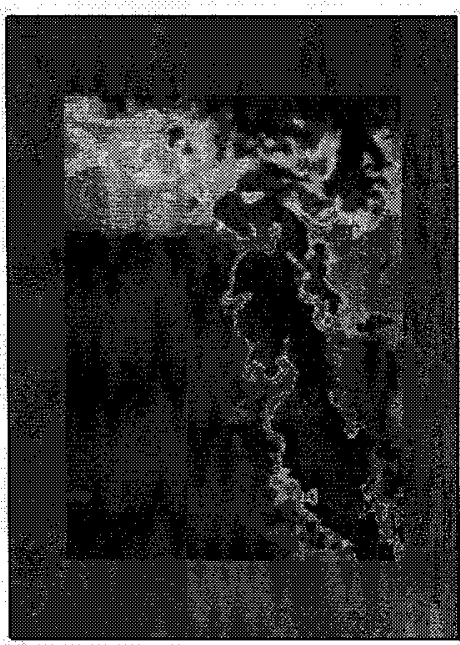

Plot3o

temp

E

240

23.6

232

22.8

22.4

(b) Make-up air velocity $=1.0 \mathrm{~m} / \mathrm{s}$

220

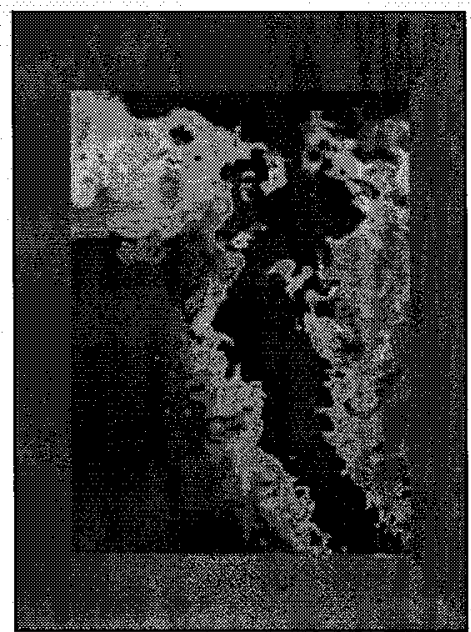

$21: 6$

212

20.8

20.4

200

(d) Make-up air velocity $=1.5 \mathrm{~m} / \mathrm{s}$

Figure 5.54 Temperature contours in 50-m tall atrium on a vertical plane through the fire center, fire size $=2.5 \mathrm{MW}, 2.5 \mathrm{~m}$ from opening 


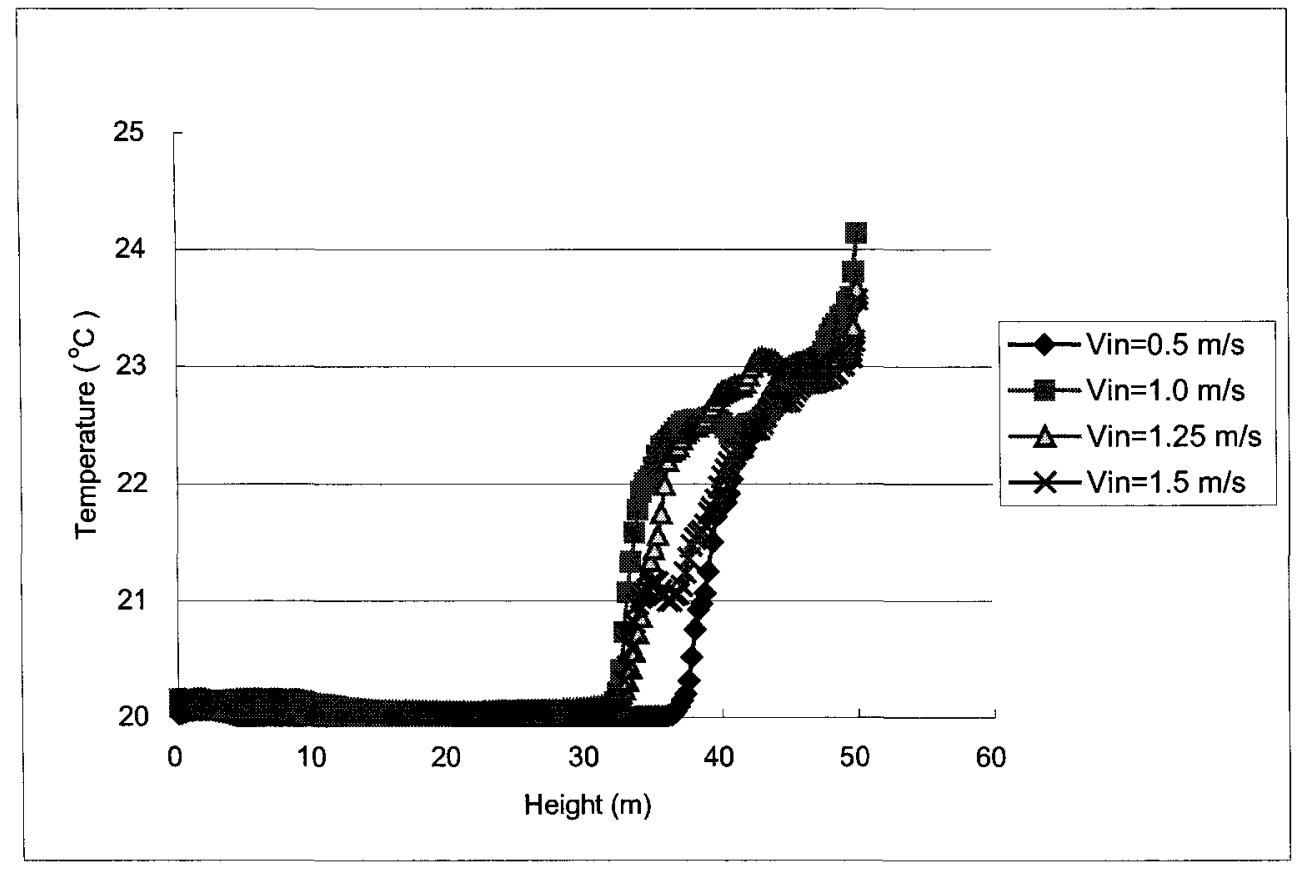

Figure 5.55 Temperature profiles in 50-m tall atrium with $2.5-\mathrm{MW}$ fire, $2.5 \mathrm{~m}$ from opening

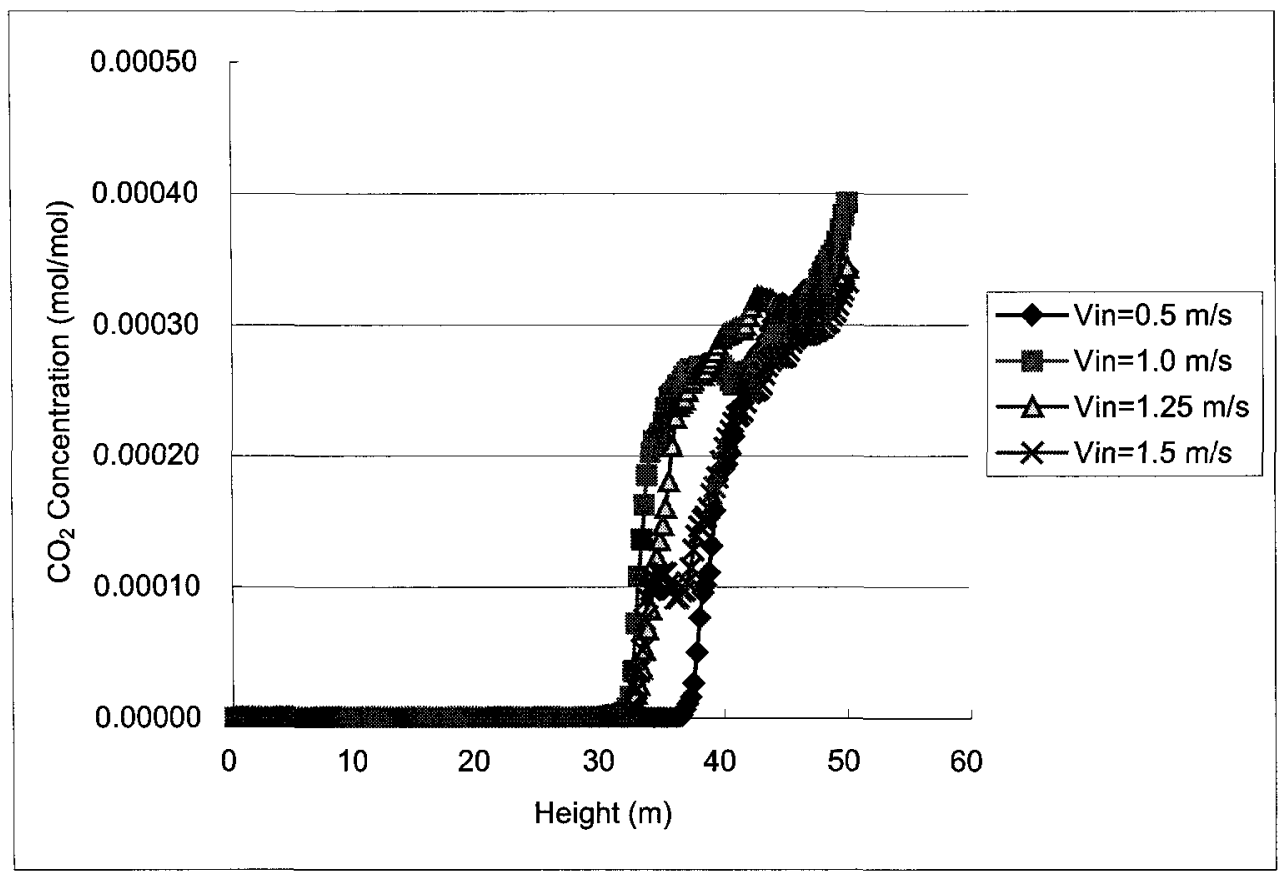

Figure 5.56 $\mathrm{CO}_{2}$ profiles in 50-m tall atrium with $2.5-\mathrm{MW}$ fire, $2.5 \mathrm{~m}$ from opening 
Figure 5.57 shows the temperature contours with $5-\mathrm{MW}$ fire size at $0.5 \mathrm{~m} / \mathrm{s}, 1.0 \mathrm{~m} / \mathrm{s}$, $1.25 \mathrm{~m} / \mathrm{s}$ and $1.5 \mathrm{~m} / \mathrm{s}$ make-up air velocity at $300 \mathrm{~s}$. The figure indicates that the effect of make-up air velocity on the fire plume decreases with increasing the fire size.

Figure 5.58 and Figure 5.59 show the temperature and $\mathrm{CO}_{2}$ profiles with different velocities at Point 7. There is a change in going from $0.5 \mathrm{~m} / \mathrm{s}$ to $1.0 \mathrm{~m} / \mathrm{s}$ in the profiles. The profiles of the higher velocities are similar to the profiles of the $1.0 \mathrm{~m} / \mathrm{s}$. 


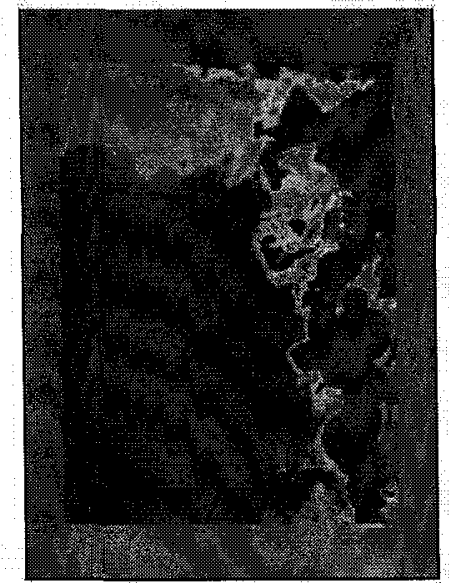

(a) Make-up air velocity $=0.5 \mathrm{~m} / \mathrm{s}$

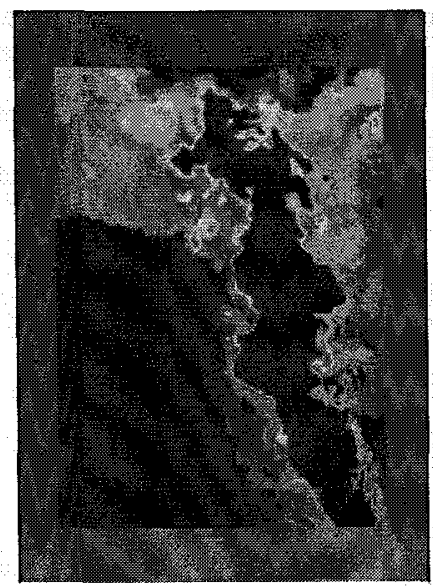

(c) Make-up air velocity $=1.25 \mathrm{~m} / \mathrm{s}$

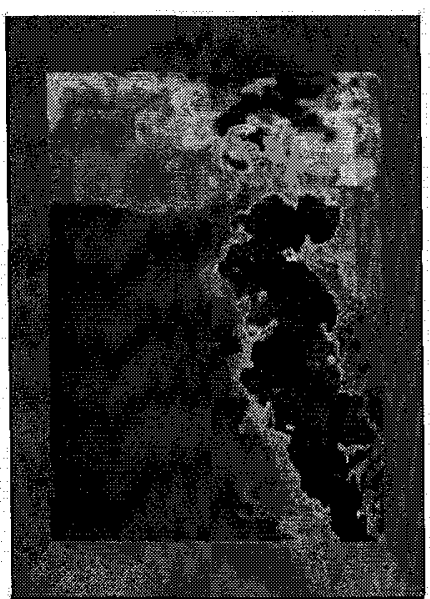

Flot 30

temp

8

275

268

260

253

245

(b) Make-up air velocity $=1.0 \mathrm{~m} / \mathrm{s}$

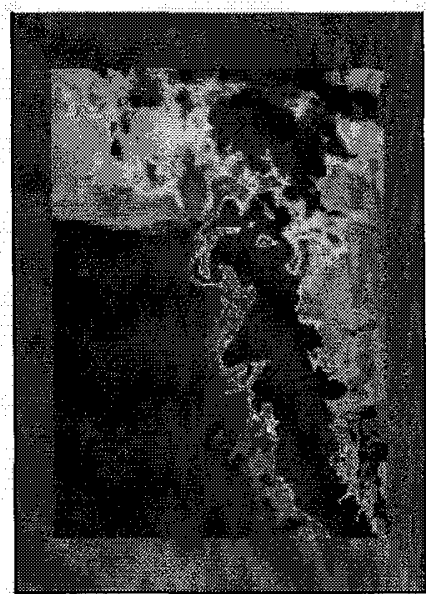

$23:$

223

215

208

200

(d) Make-up air velocity $=1.5 \mathrm{~m} / \mathrm{s}$

Figure 5.57 Temperature contours in 50-m tall atrium on a vertical plane through the fire center, fire size $=5 \mathrm{MW}, 2.5 \mathrm{~m}$ from opening 


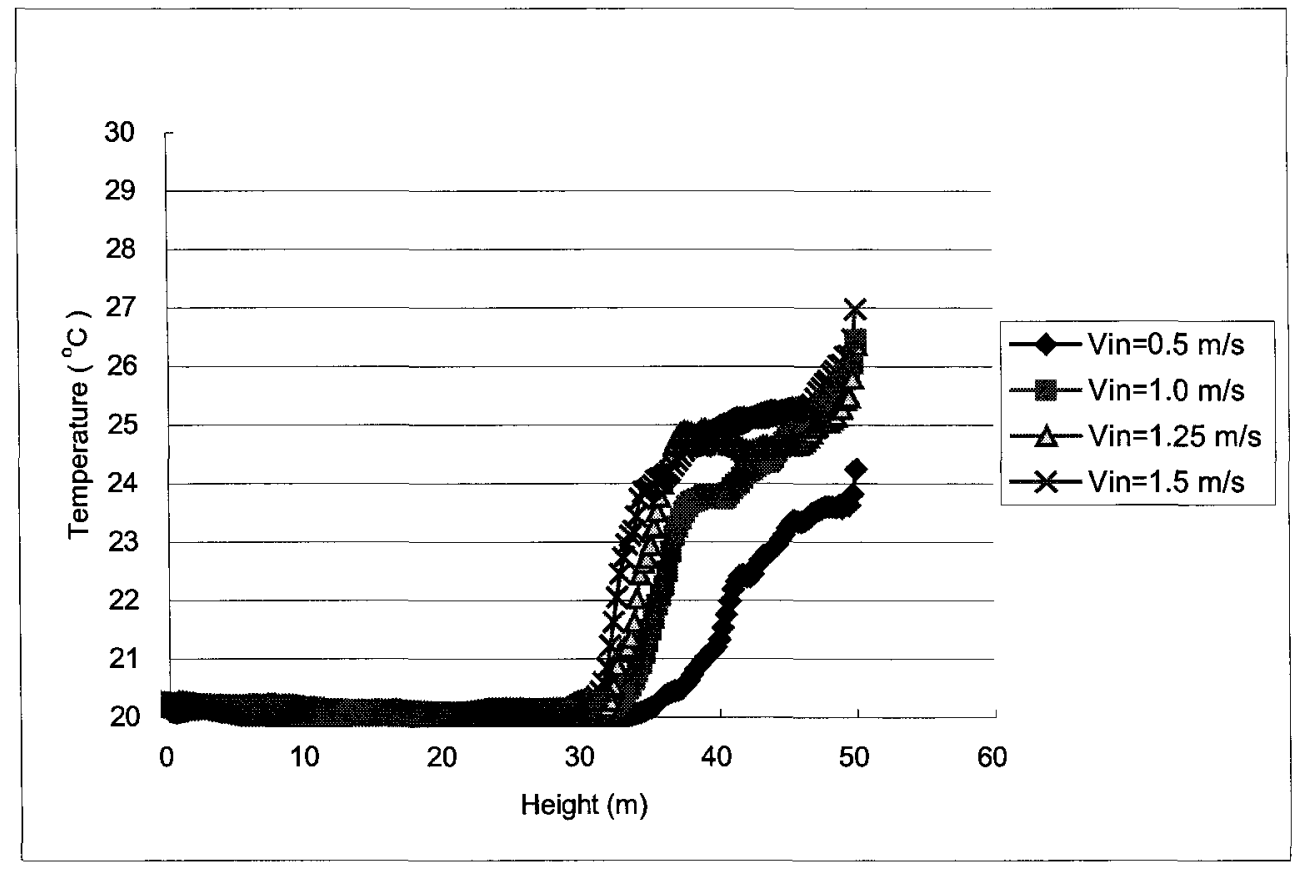

Figure 5.58 Temperature profiles in 50-m tall atrium with 5-MW fire, $2.5 \mathrm{~m}$ from opening

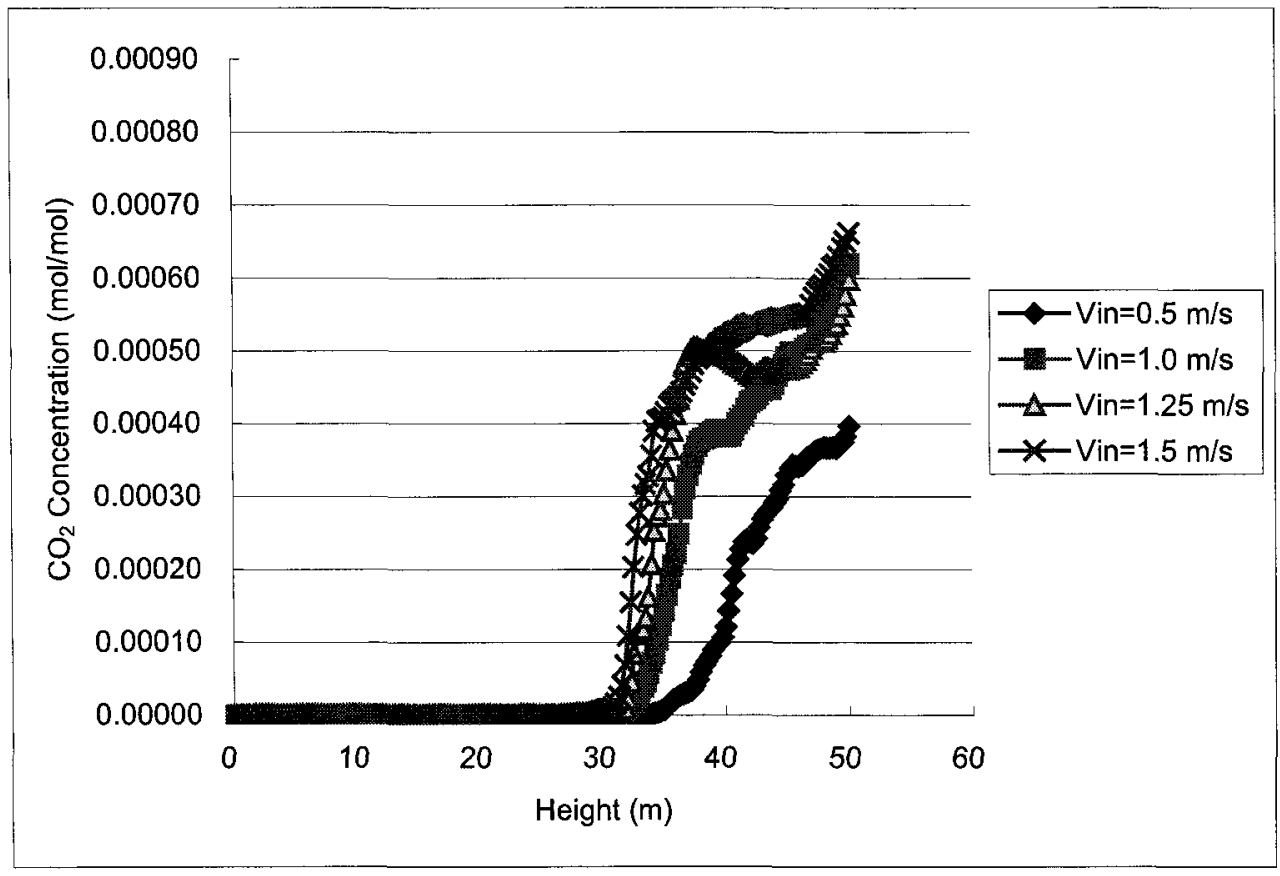

Figure $5.59 \mathrm{CO}_{2}$ profiles in $50-\mathrm{m}$ tall atrium with $5-\mathrm{MW}$ fire, $2.5 \mathrm{~m}$ from opening 
The results of interface heights for the $50-\mathrm{m}$ tall atrium and the fire located $2.5 \mathrm{~m}$ from the opening are presented in Table 5.7. The interface heights are quite similar to those with the fire at $5 \mathrm{~m}$ from the opening. It is a bit surprising to see that some of the interface heights with the 2.5 and 5-MW fire close to the opening are actually a bit higher than with the fire at $5 \mathrm{~m}$. This may be explained by comparing Figure 5.48 (c) and Figure 5.57 (c) which depict the temperature contours in the atrium for the 5-MW fire at $5 \mathrm{~m}$ and $2.5 \mathrm{~m}$ from the opening respectively. As the figures show, when the fire is at $5 \mathrm{~m}$ from the opening the plume is pushed further into the atrium causing more mixing and increased entrainment than when fire is at $2.5 \mathrm{~m}$. 
Table 5.7 Interface heights in 50-m tall atrium with fire $2.5 \mathrm{~m}$ from the opening

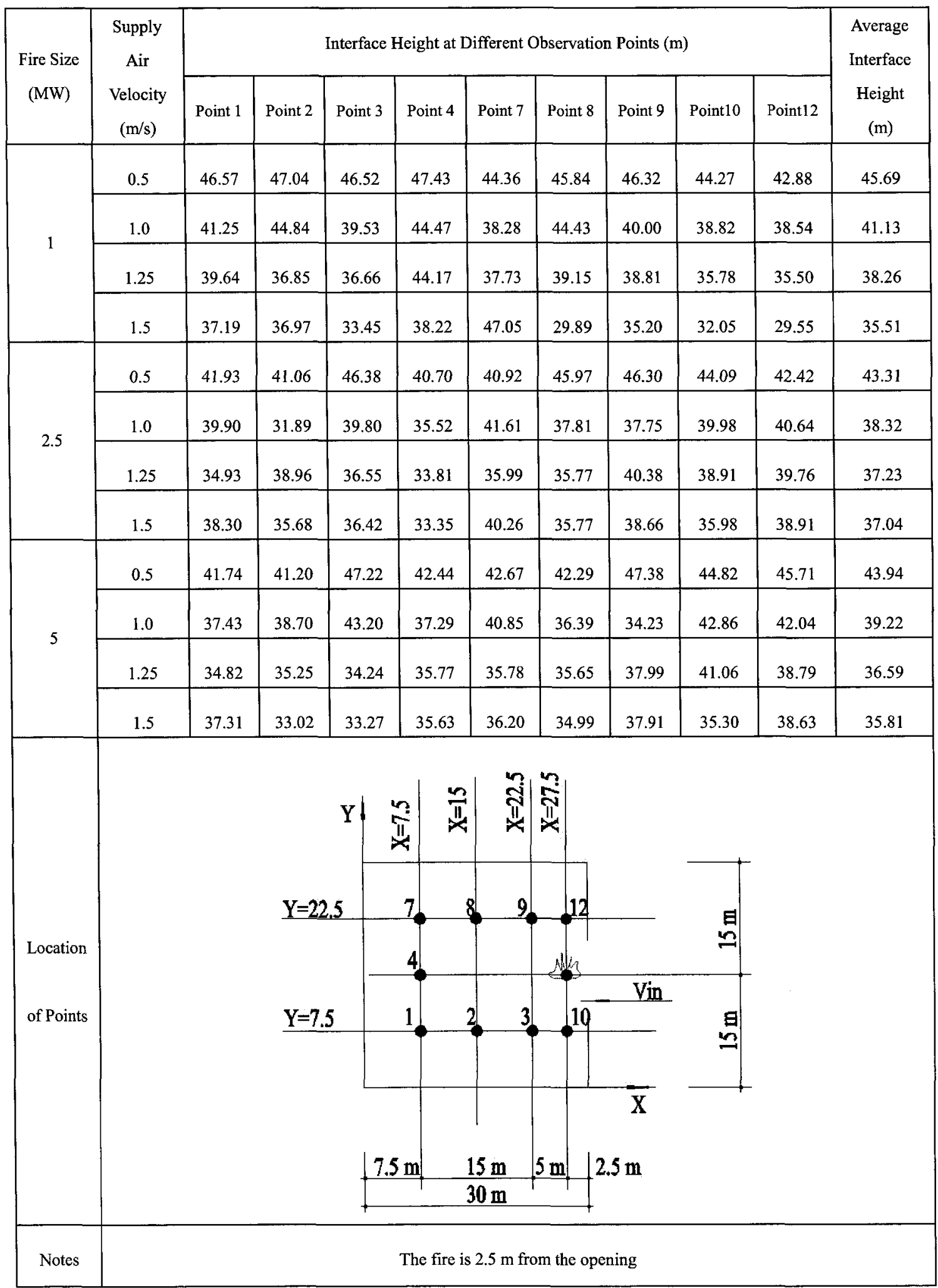




\subsubsection{Results for 60-m Tall Atrium}

The fire for the $60-\mathrm{m}$ tall atrium was placed at two locations: $5 \mathrm{~m}$ and $2.5 \mathrm{~m}$ from the opening. The results of the simulations for the three fire sizes and four make-up air velocities are discussed in the following sections. Figure 5.60 that depicts temperature variations with time at three different heights in the atrium shows that steady state conditions were reached at about $250 \mathrm{~s}$ for this atrium. The interface heights presented in this section have been computed by averaging the computed values over the period from $250 \mathrm{~s}$ to $300 \mathrm{~s}$.

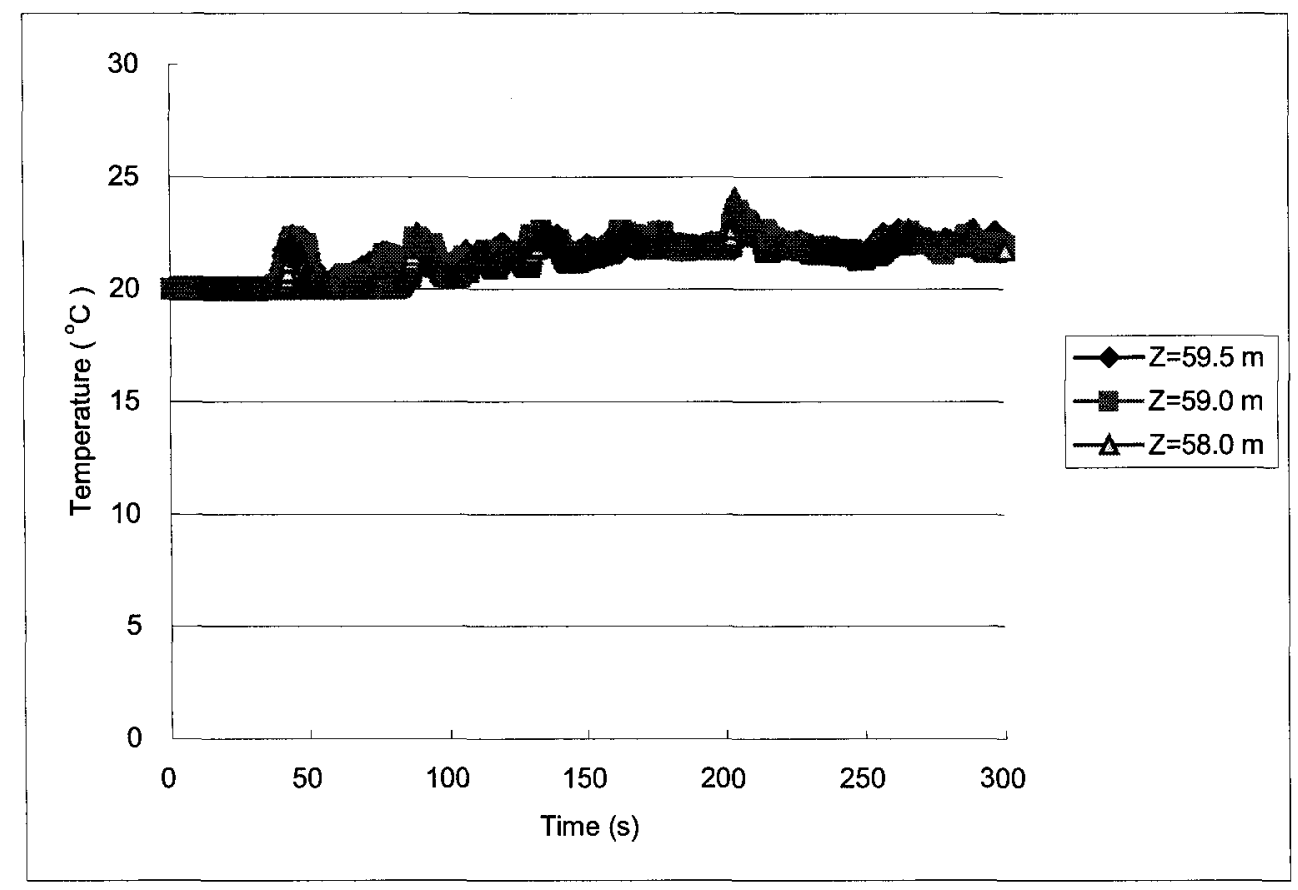

Figure 5.60 Temperature variations with time in $60-\mathrm{m}$ tall atrium

\subsubsection{Fire Location $5 \mathrm{~m}$ from the Opening}

The mass flow rate of the exhaust for the 1-MW fire simulations was set to 391.08 $\mathrm{kg} / \mathrm{s}$, and the areas of the make-up air openings were: $662.76 \mathrm{~m}^{2}, 331.38 \mathrm{~m}^{2}, 265.16$ $\mathrm{m}^{2}$ and $220.92 \mathrm{~m}^{2}$. Figure 5.61 shows the temperature distribution on a vertical plane 
passing through the fire centerline and the center of the opening for the 1-MW fire and the four different make-up air velocities at $300 \mathrm{~s}$.

From the figure, we can see that even the $1.0 \mathrm{~m} / \mathrm{s}$ make-up air velocity causes an inclination of the plume, but not much mixing. The $1.25 \mathrm{~m} / \mathrm{s}$ and $1.5 \mathrm{~m} / \mathrm{s}$ velocities cause a bigger plume disturbance and significant mixing.

Figure 5.62 and Figure 5.63 show the temperature and $\mathrm{CO}_{2}$ profiles with different velocities at point 7 . The profiles show that for velocities up to $1.25 \mathrm{~m} / \mathrm{s}$ the profiles are not affected much by the incoming air flow. The $1.5 \mathrm{~m} / \mathrm{s}$ make-up air velocity however causes a significant change of the profile. 


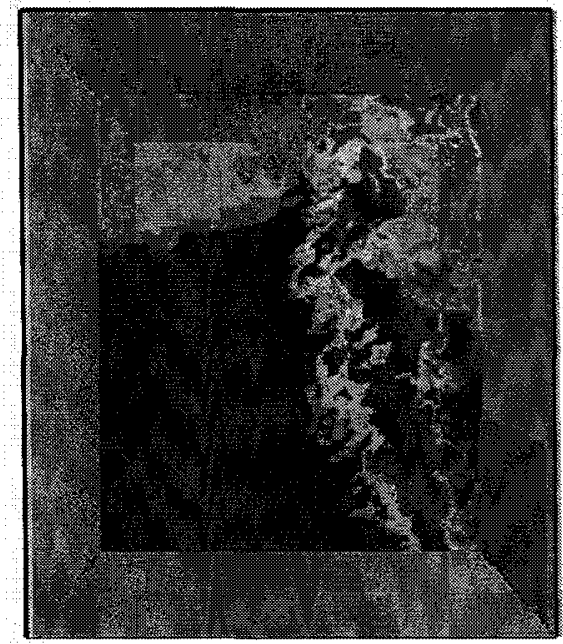

(a) Make-up air velocity $=0.5 \mathrm{~m} / \mathrm{s}$

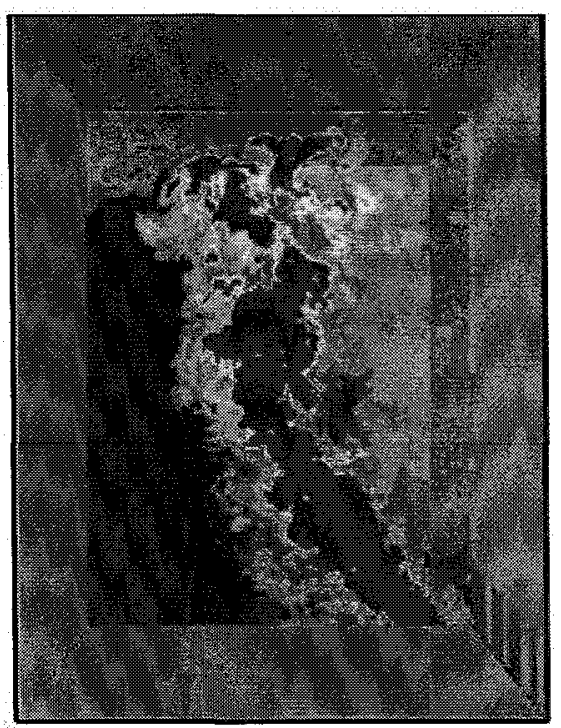

(c) Make-up air velocity $=1.25 \mathrm{~m} / \mathrm{s}$

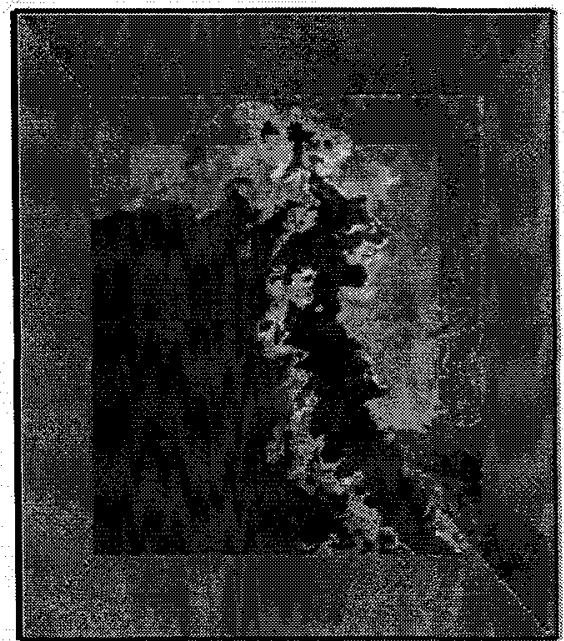

Plot3d

temp

C

22.5

22.3

22.0

21.8

21.5

(b) Make-up air velocity $=1.0 \mathrm{~m} / \mathrm{s}$

21.3

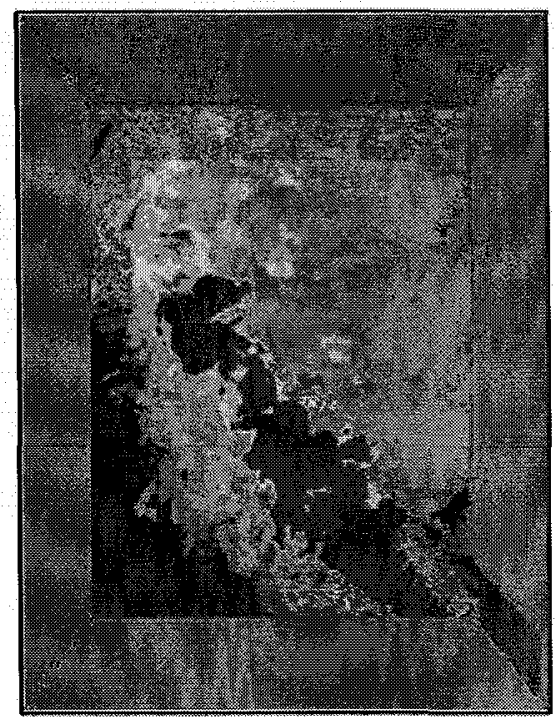

21.0

20.8

20.5

20.3

20.0

Figure 5.61 Temperature contours in $60-\mathrm{m}$ tall atrium on a vertical plane through the

fire center, fire size $=1 \mathrm{MW}, 5 \mathrm{~m}$ from opening 


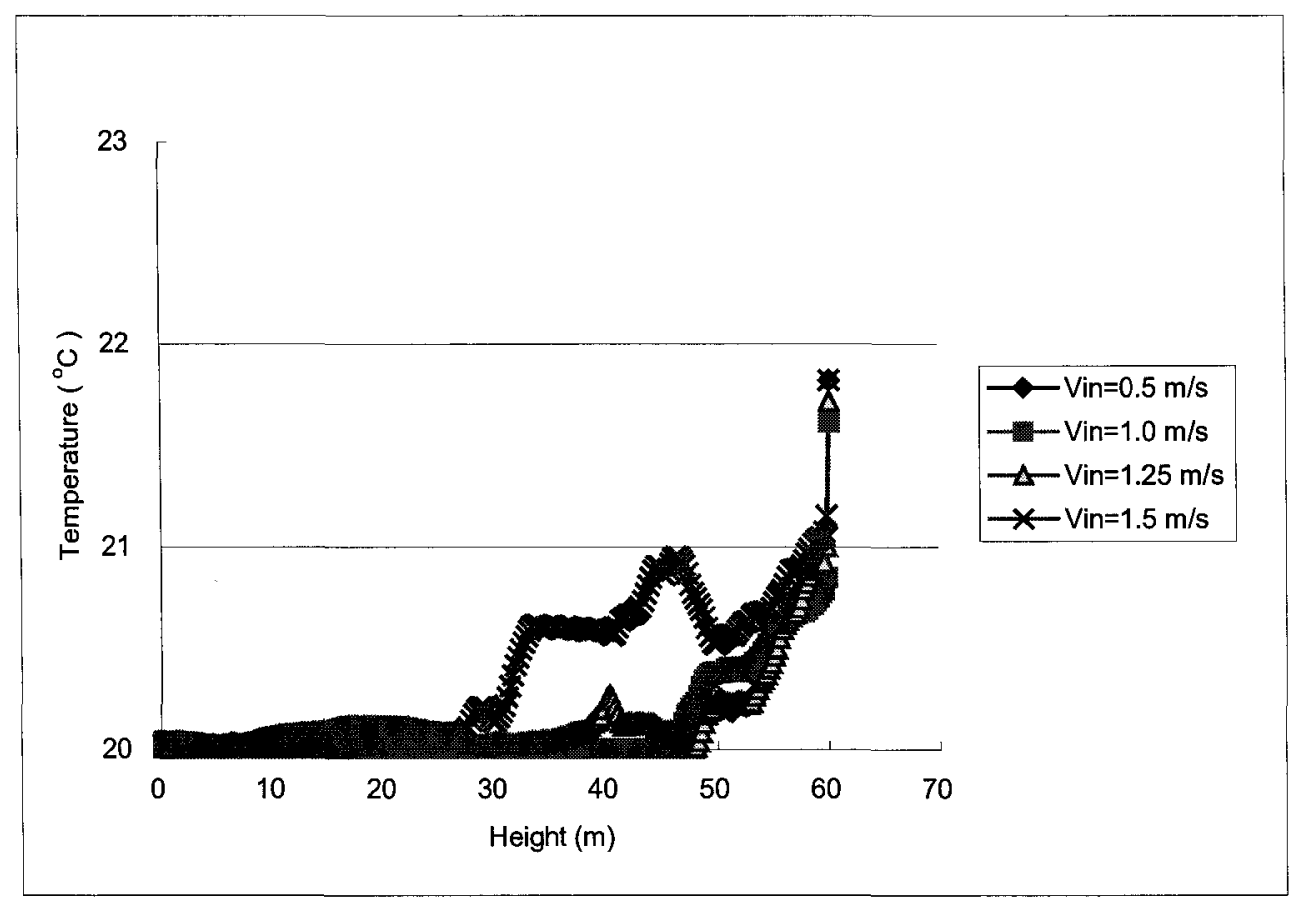

Figure 5.62 Temperature profiles in 60-m tall atrium with 1-MW fire, $5 \mathrm{~m}$ from opening

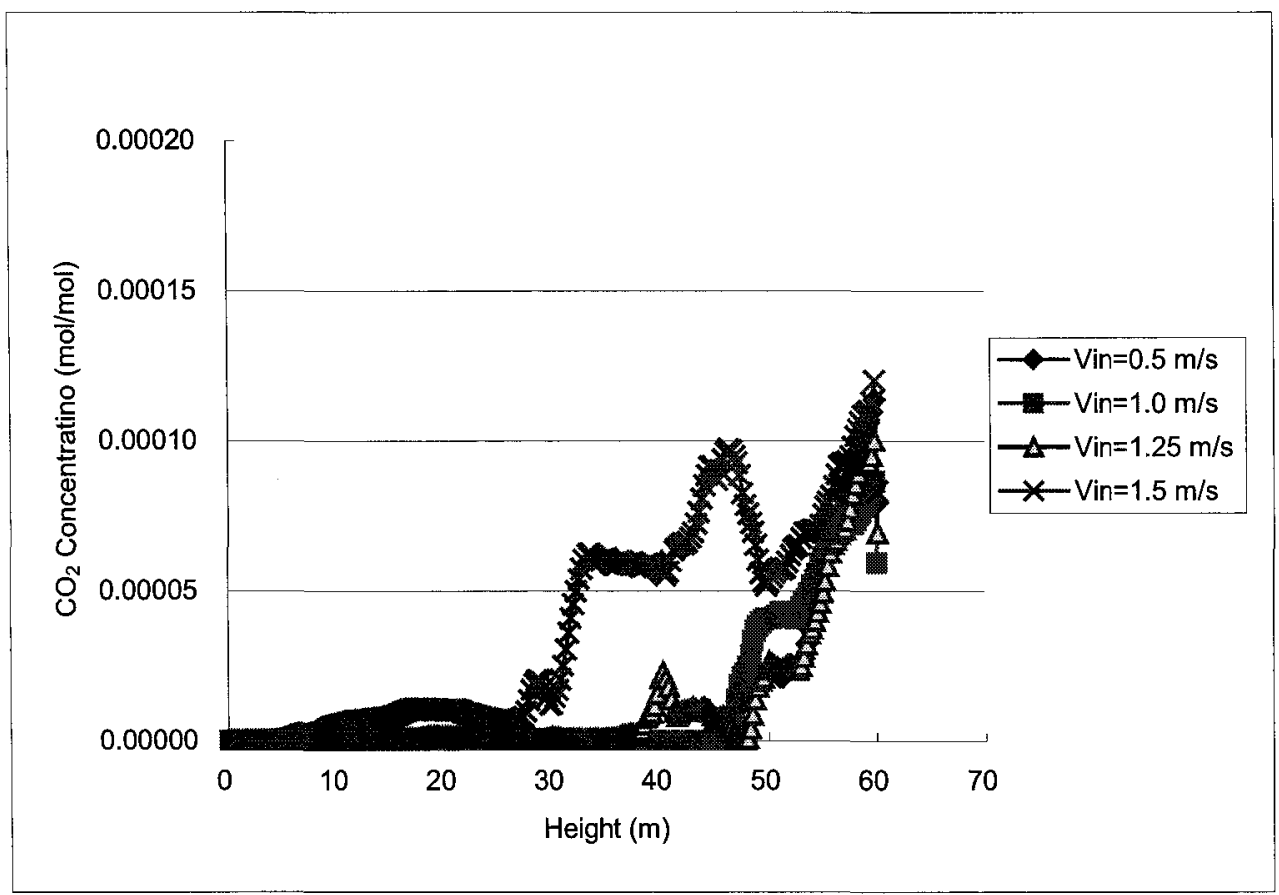

Figure $5.63 \mathrm{CO}_{2}$ profiles in 60 -m tall atrium with 1-MW fire, $5 \mathrm{~m}$ from opening 
The mass flow rate of the exhaust for the $2.5-\mathrm{MW}$ fire was set to $532.11 \mathrm{~kg} / \mathrm{s}$, and the areas of the make-up air openings were: $901.83 \mathrm{~m}^{2}, 450.96 \mathrm{~m}^{2}, 360.8 \mathrm{~m}^{2}$ and 300.64 $\mathrm{m}^{2}$. Figure 5.64 shows the temperature contours at $300 \mathrm{~s}$ of the simulation. As the figure shows, the plume for this fire is not affected as much as the plume of the 1-MW fire by the incoming air. The higher velocities $1.25 \mathrm{~m} / \mathrm{s}$ and $1.5 \mathrm{~m} / \mathrm{s}$ cause the hot layer to decrease. This can also be seen in Figure 5.65 and Figure 5.66 that depict temperature and $\mathrm{CO}_{2}$ profiles at Point 7 of the atrium. These figures show that the 0.5 $\mathrm{m} / \mathrm{s}$ and $1.0 \mathrm{~m} / \mathrm{s}$ velocities have similar profiles. The profiles of the $1.25 \mathrm{~m} / \mathrm{s}$ and 1.5 $\mathrm{m} / \mathrm{s}$ velocities are quite similar, but different than the other two. 


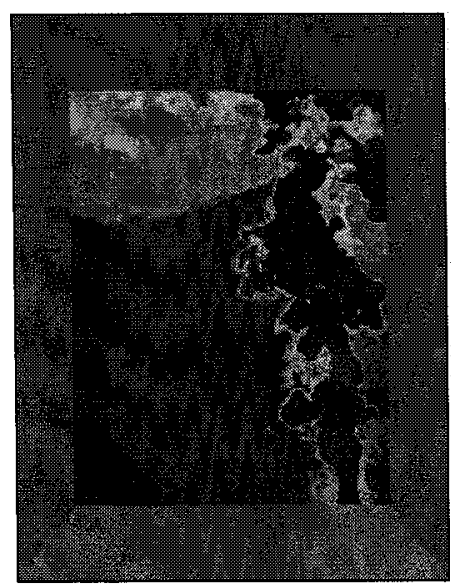

(a) Make-up air velocity $=0.5 \mathrm{~m} / \mathrm{s}$

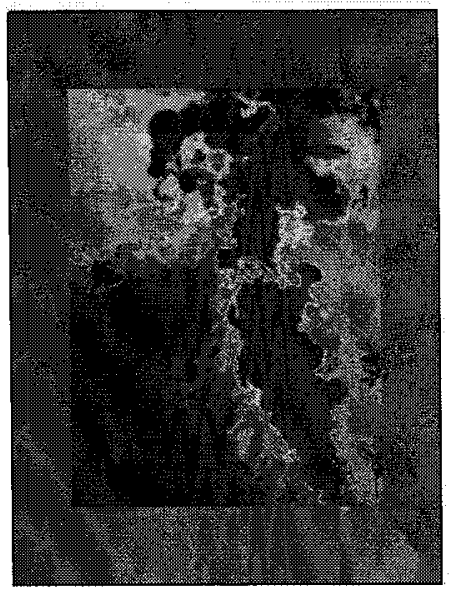

(c) Make-up air velocity $=1.25 \mathrm{~m} / \mathrm{s}$

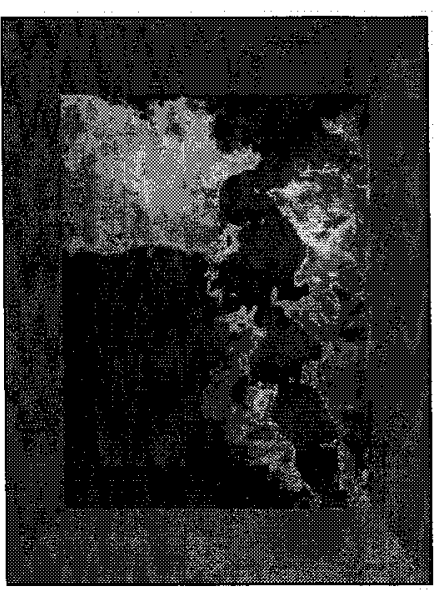

Plot3d

temp

C.

$23.0 \mid$
227
22.4
22.1
218

(b) Make-up air velocity $=1.0 \mathrm{~m} / \mathrm{s}$

21.5 212

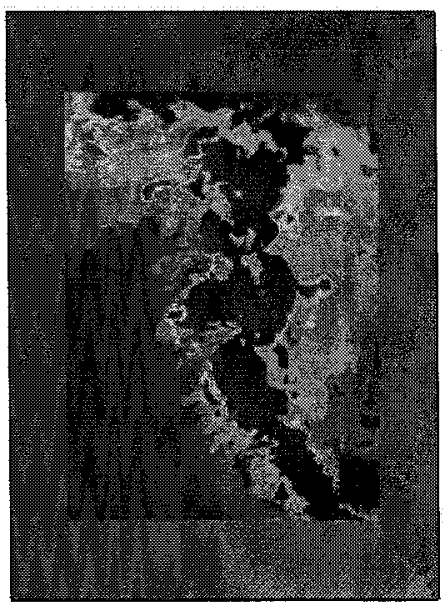

20.9

20.6

203

200

Figure 5.64 Temperature contours in $60-\mathrm{m}$ tall atrium on a vertical plane through the

fire center, fire size $=2.5 \mathrm{MW}, 5 \mathrm{~m}$ from opening 


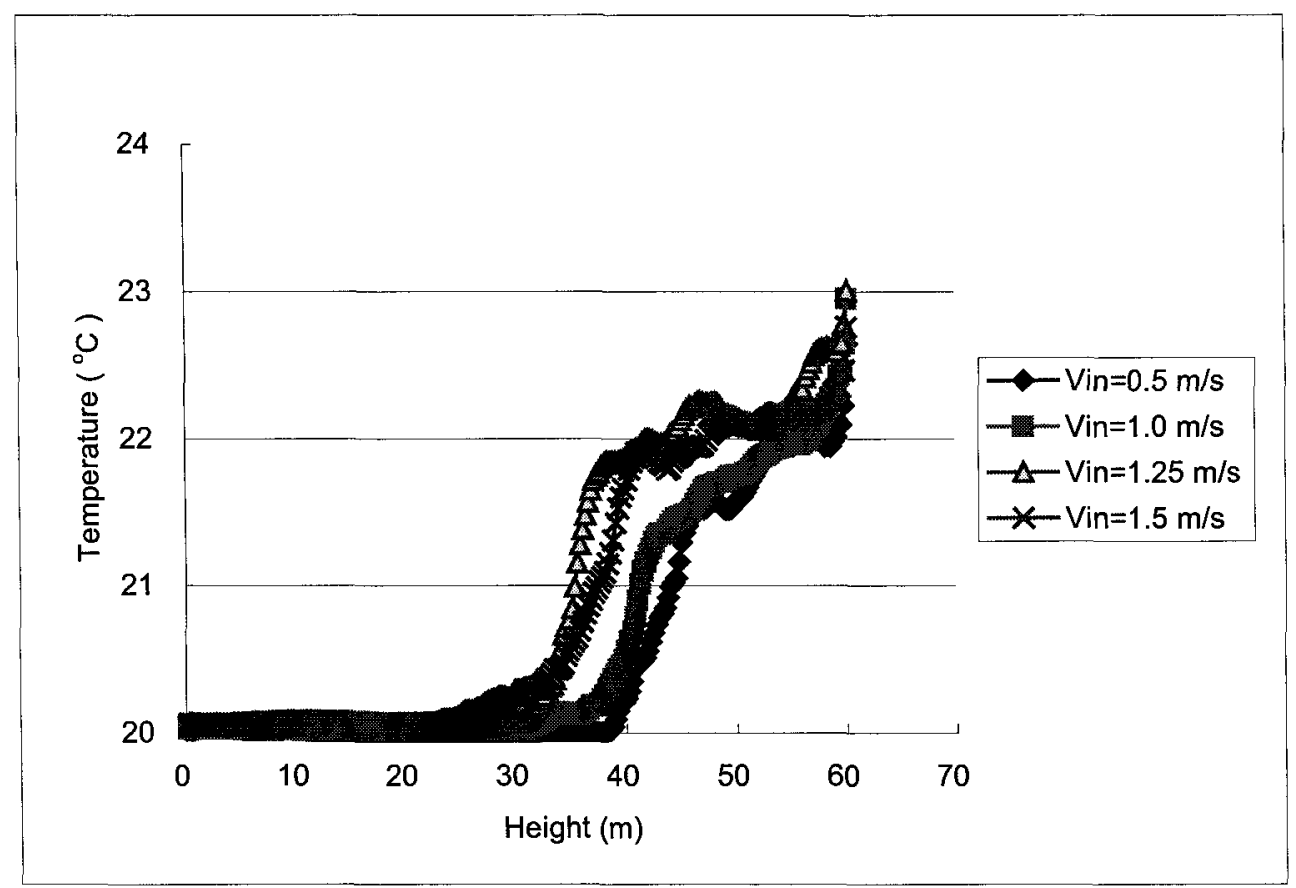

Figure 5.65 Temperature profiles in 60- $\mathrm{m}$ tall atrium with 2.5-MW fire, $5 \mathrm{~m}$ from opening

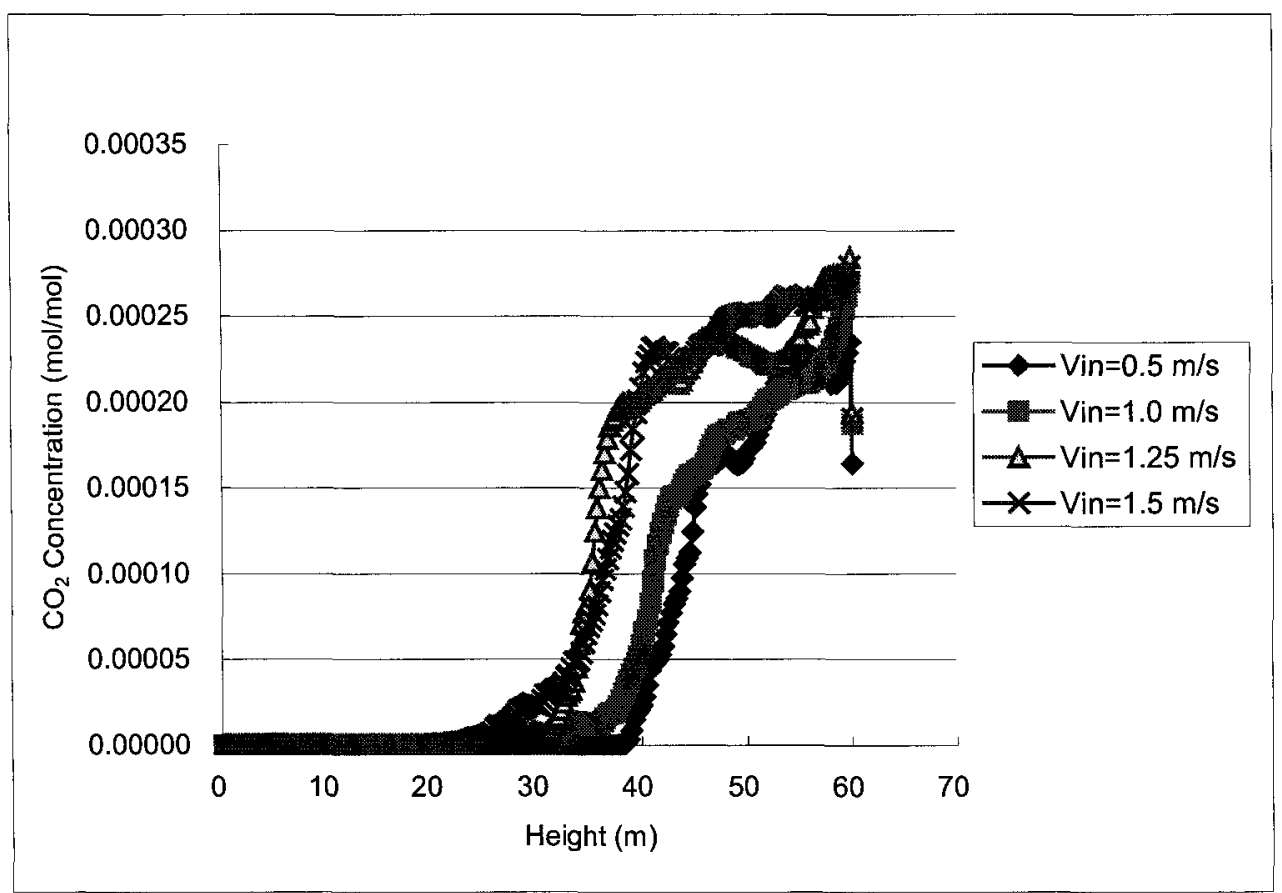

Figure 5.66 $\mathrm{CO}_{2}$ profiles in $60-\mathrm{m}$ tall atrium with 2.5-MW fire, $5 \mathrm{~m}$ from opening 
For the fire size of $5 \mathrm{MW}$, the mass flow rate of the exhaust was set to $672.59 \mathrm{~kg} / \mathrm{s}$, and the areas of the make-up air openings were: $1140 \mathrm{~m}^{2}, 570 \mathrm{~m}^{2}, 456 \mathrm{~m}^{2}$ and $380 \mathrm{~m}^{2}$. The results of the simulation with a 5-MW fire size are shown in Figures 5.67 - 5.69. The temperature contours at $300 \mathrm{~s}$ shown in Figure 5.67 indicate that as with the 2.5-MW fire, the incoming air does not affect the plume significantly. The profiles, however, depicted in Figure 5.68 and Figure 5.69 at Point 7 of the atrium show that the velocities of $1.0 \mathrm{~m} / \mathrm{s}, 1.25 \mathrm{~m} / \mathrm{s}$ and $1.5 \mathrm{~m} / \mathrm{s}$ cause a large change in the profiles, as the temperature starts to increase at about $40 \mathrm{~m}$ as opposed to $50 \mathrm{~m}$ when the velocity is $0.5 \mathrm{~m} / \mathrm{s}$. 


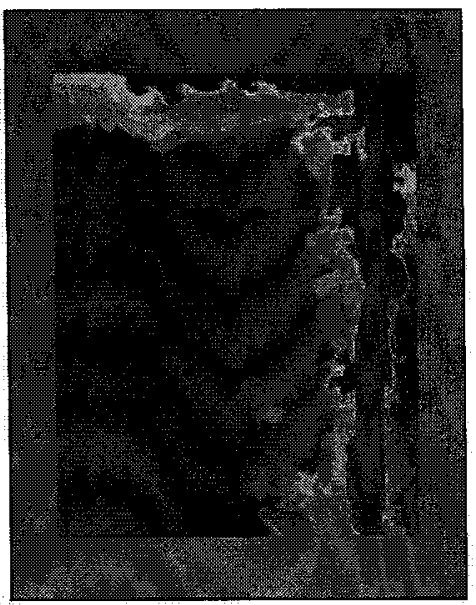

(a) Make-up air velocity $=0.5 \mathrm{~m} / \mathrm{s}$

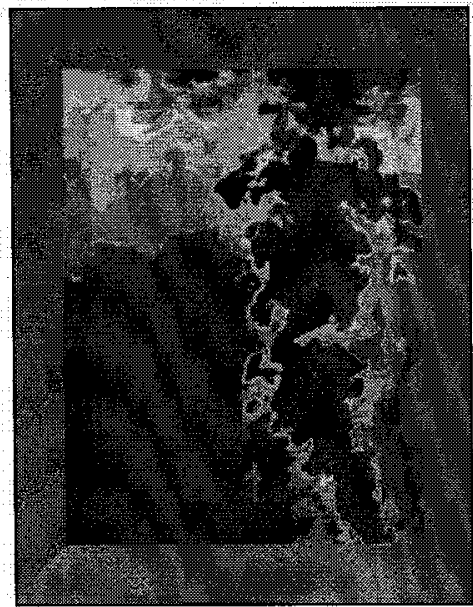

(c) Make-up air velocity $=1.25 \mathrm{~m} / \mathrm{s}$

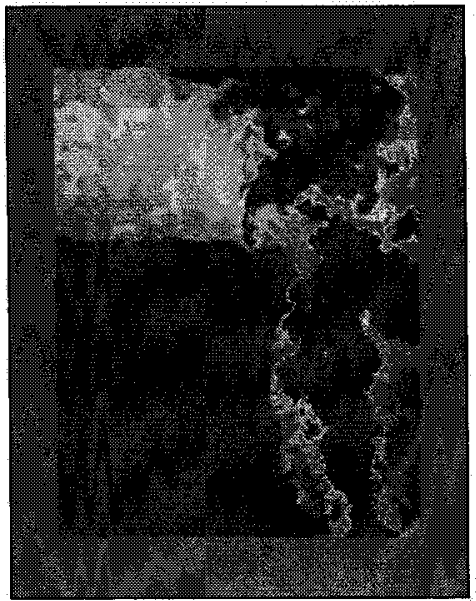

Plot3d

temp:

c

255

250

244

239

293

(b) Make-up air velocity $=1.0 \mathrm{~m} / \mathrm{s}$

(d) Make-up air velocity $=1.5 \mathrm{~m} / \mathrm{s}$

Figure 5.67 Temperature contours in $60-\mathrm{m}$ tall atrium on a vertical plane through the fire center, fire size $=5 \mathrm{MW}, 5 \mathrm{~m}$ from opening 


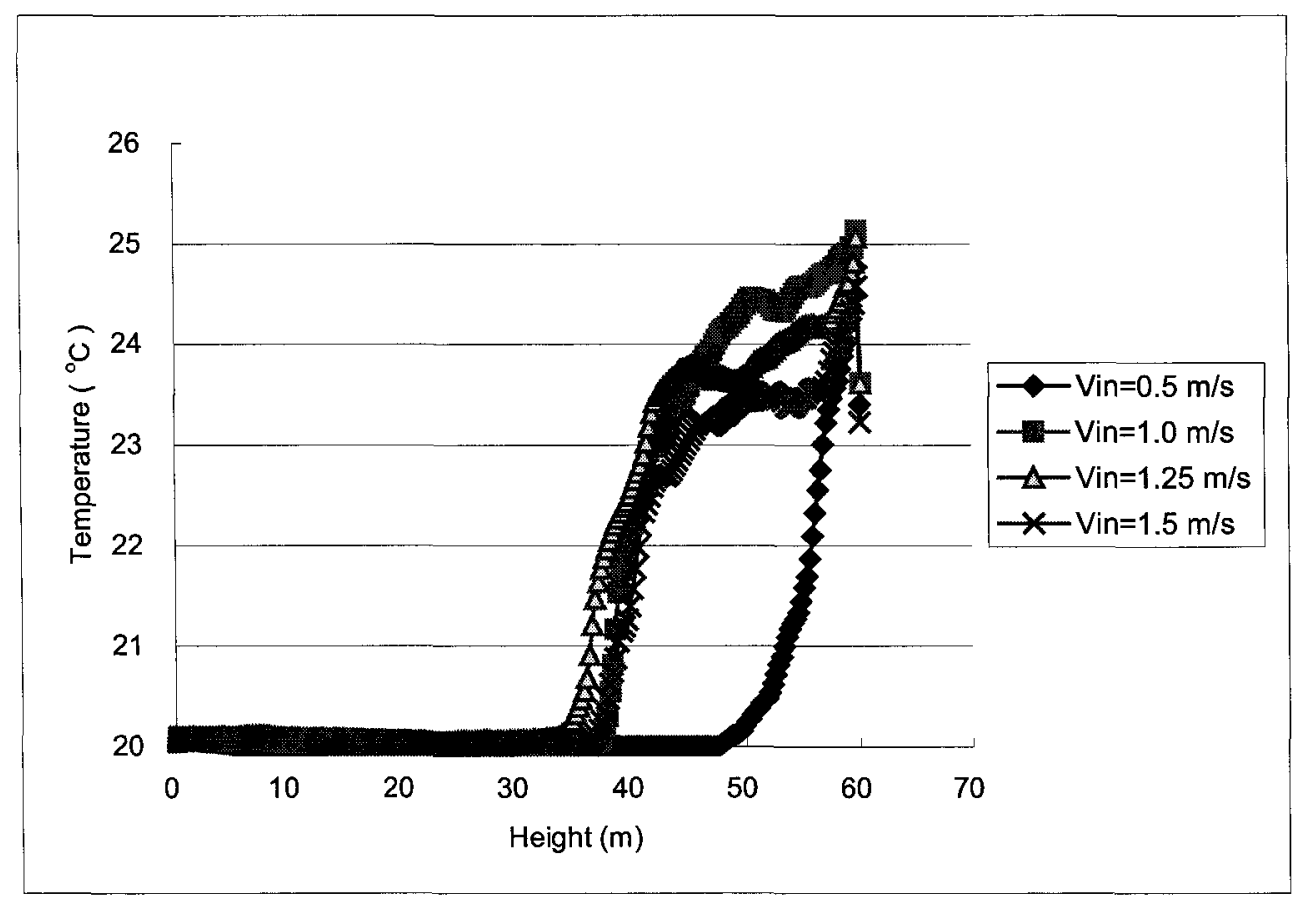

Figure 5.68 Temperature profiles in $60-\mathrm{m}$ tall atrium with 5-MW fire, $5 \mathrm{~m}$ from opening

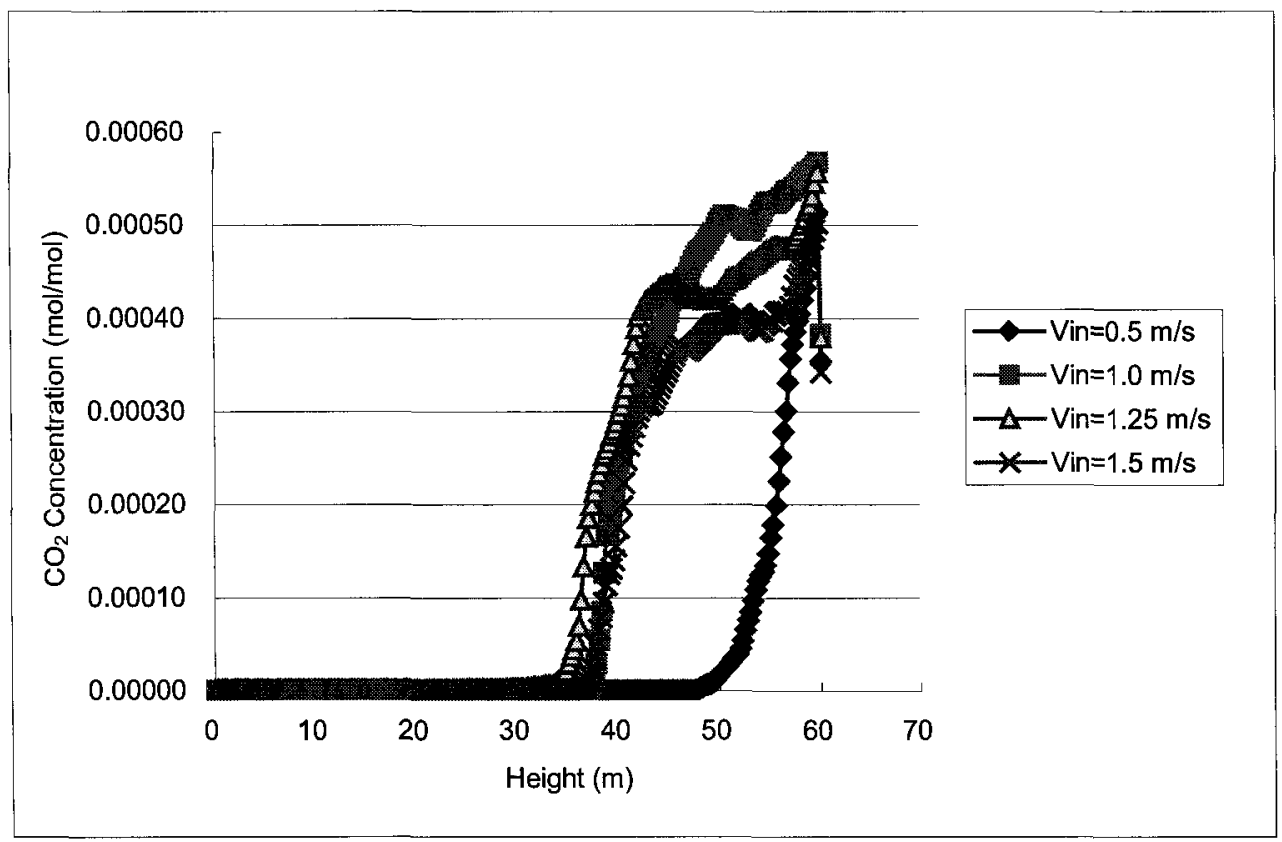

Figure 5.69 $\mathrm{CO}_{2}$ profiles in 60 - $\mathrm{m}$ tall atrium with 5-MW fire, $5 \mathrm{~m}$ from opening 
Table 5.8 shows the interface heights for the $60-\mathrm{m}$ tall atrium and the fire located $5 \mathrm{~m}$ from the opening. The results show that the interface heights for the 1-MW fire and velocities of $1.0,1.25$ and $1.5 \mathrm{~m} / \mathrm{s}$ vary significantly from point to point due to the high turbulence and mixing. The average values however are higher than the average values of the larger fires. For these fires, the velocities of $1.0,1.25$, and $1.5 \mathrm{~m} / \mathrm{s}$ have similar interface heights. 
Table 5.8 Interface heights in $60-\mathrm{m}$ tall atrium with fire $5 \mathrm{~m}$ from the opening

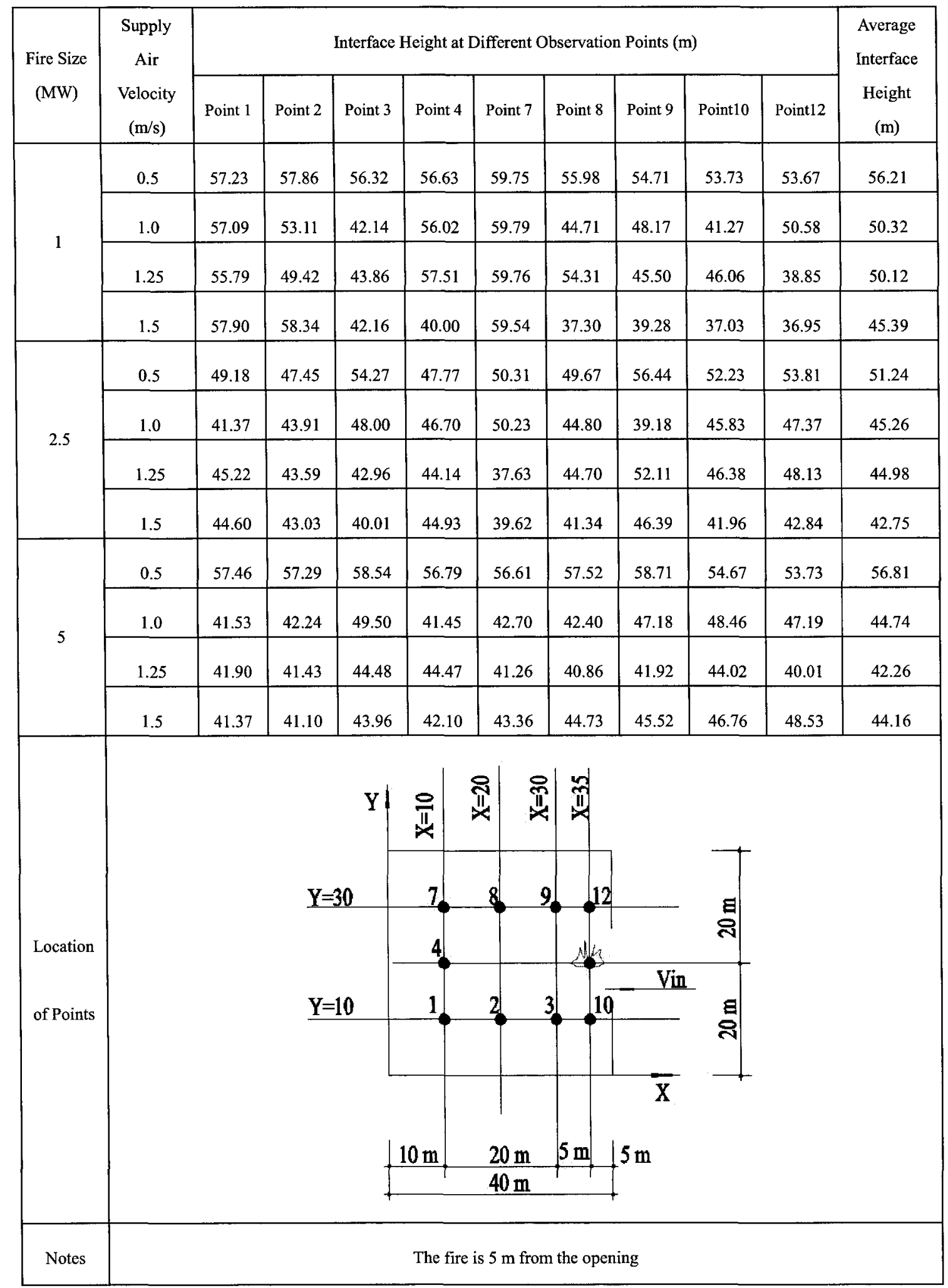




\subsubsection{Fire Location $2.5 \mathrm{~m}$ from the Opening}

The exhaust flow rates for these simulations are similar to those with the fire at $5 \mathrm{~m}$ from the opening. Figure 5.70 shows the temperature distributions on a plane passing through the fire centerline and the center of the opening for the 1-MW fire located 2.5 $\mathrm{m}$ from the opening at $300 \mathrm{~s}$.

The contours are very similar to those with the fire at $5.0 \mathrm{~m}$ from the opening, showing an increased plume inclination and disturbance as the velocity increases.

Temperature and $\mathrm{CO}_{2}$ profiles at Point 7 shown in Figures 5.71 and 5.72 are also similar in that the profiles of velocities $0.5 \mathrm{~m} / \mathrm{s}$ to $1.25 \mathrm{~m} / \mathrm{s}$ are very close. The profile with a velocity of $1.5 \mathrm{~m} / \mathrm{s}$ indicates that this high velocity causes a large disturbance to the plume resulting in higher value at the mid height of the atrium. This may be a result of the plume reaching the quarter point of the atrium. 


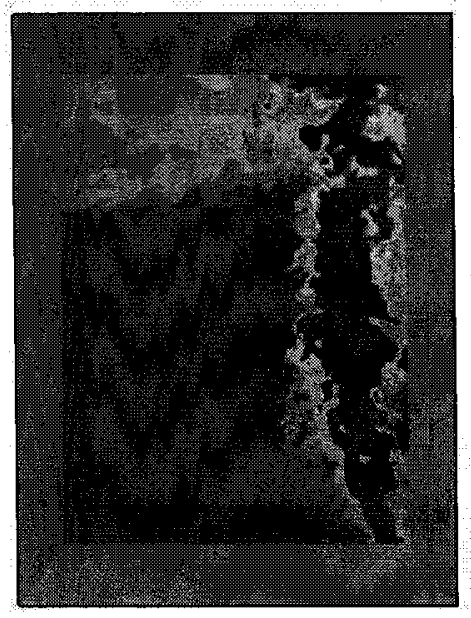

(a) Make-up air velocity $=0.5 \mathrm{~m} / \mathrm{s}$

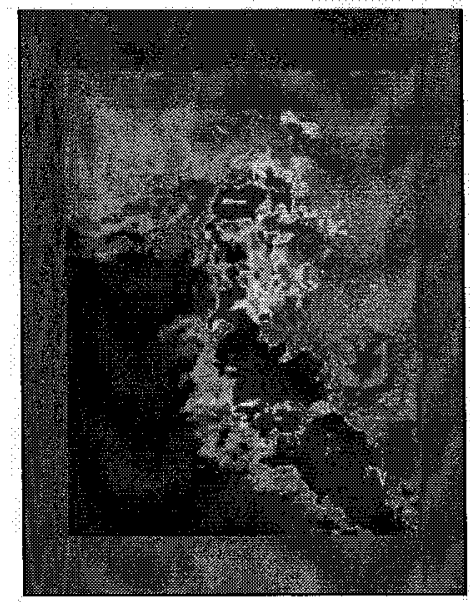

(c) Make-up air velocity $=1.25 \mathrm{~m} / \mathrm{s}$

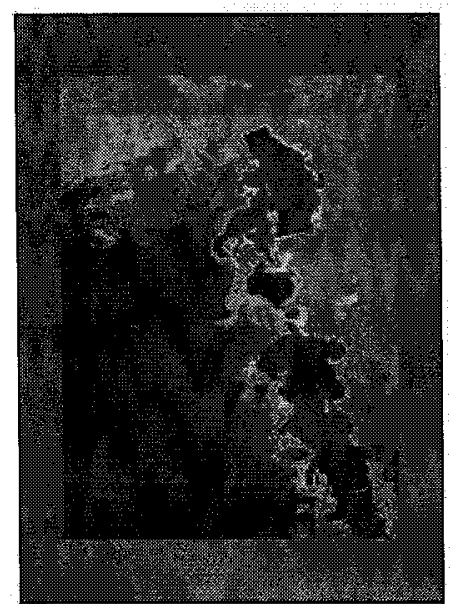

Plot3d

temp

c

225

223

220

218

215

(b) Make-up air velocity $=1.0 \mathrm{~m} / \mathrm{s}$

212

210

207

20.5

202

20

Figure 5.70 Temperature contours in $60-\mathrm{m}$ tall atrium on a vertical plane through the fire center, fire size $=1 \mathrm{MW}, 2.5 \mathrm{~m}$ from opening 


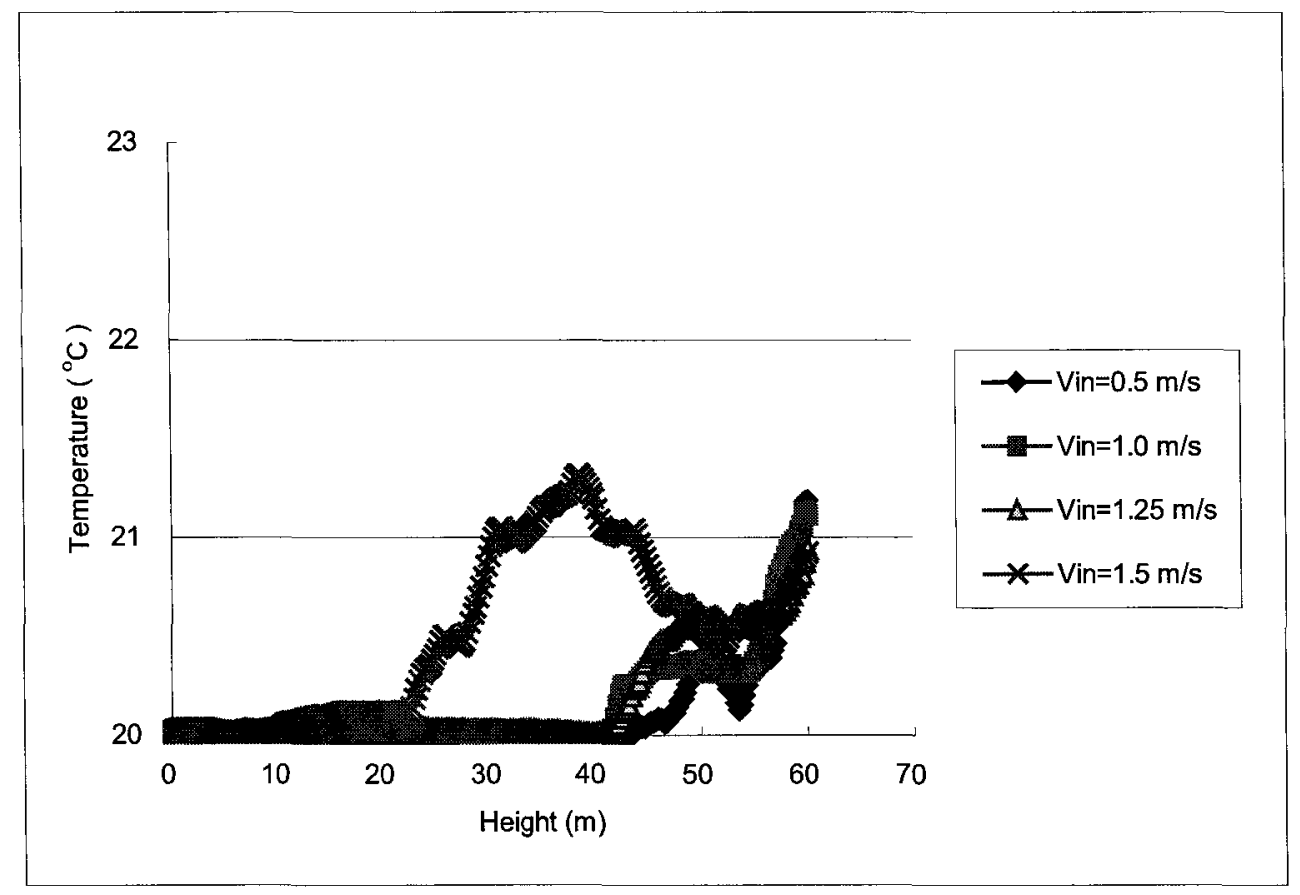

Figure 5.71 Temperature profiles in 60-m tall atrium with 1-MW fire, $2.5 \mathrm{~m}$ from opening

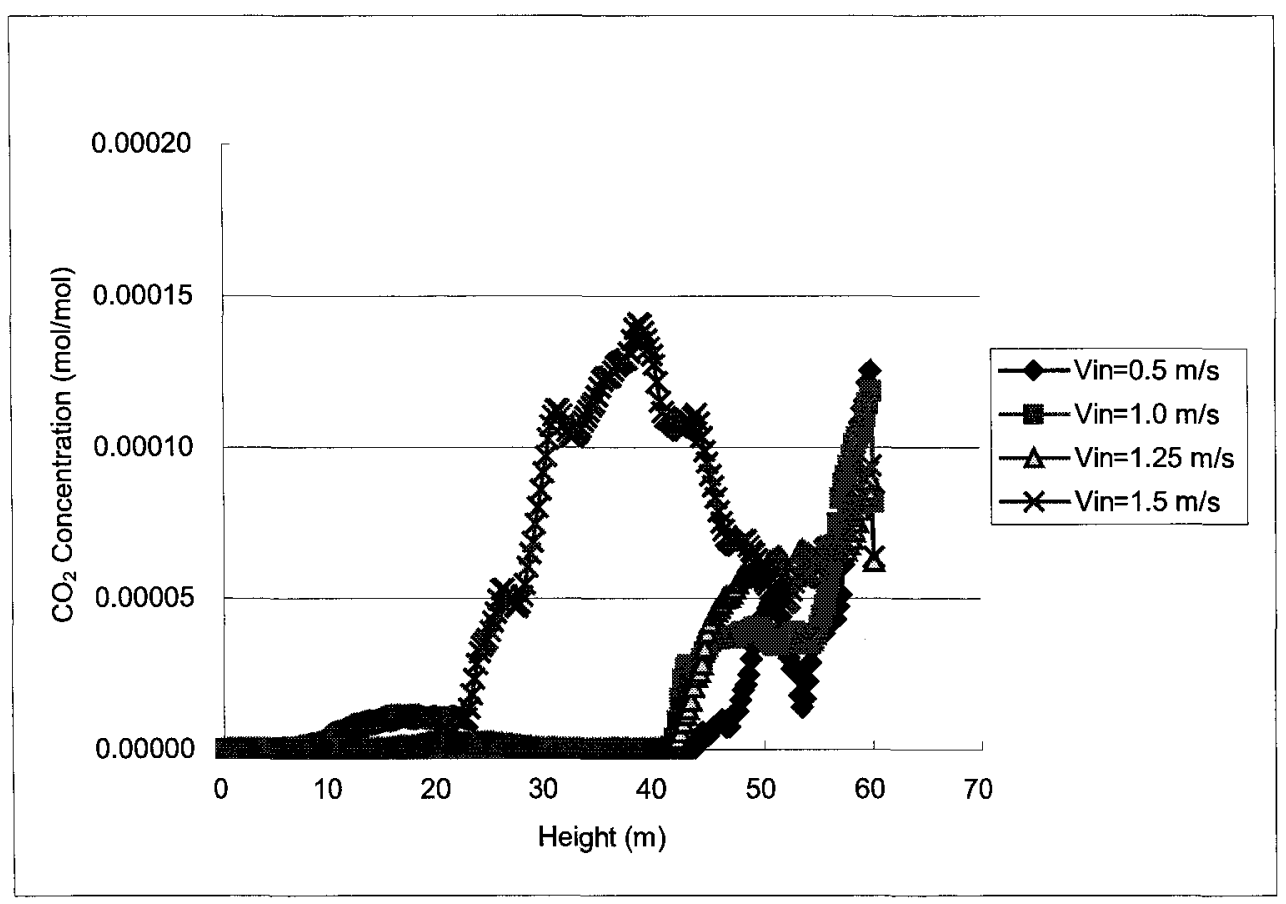

Figure 5.72 $\mathrm{CO}_{2}$ profiles in 60-m tall atrium with 1-MW fire, $2.5 \mathrm{~m}$ from opening 
When the fire size is $2.5 \mathrm{MW}$, the results of the simulations show a similar behaviour as with the results with fire at $5 \mathrm{~m}$ from the opening. This can be seen in Figure 5.73 that depicts temperature contours at $300 \mathrm{~s}$ and Figure 5.74 and Figure 5.75 that illustrate temperature and $\mathrm{CO}_{2}$ profiles with different velocities at point 7 .

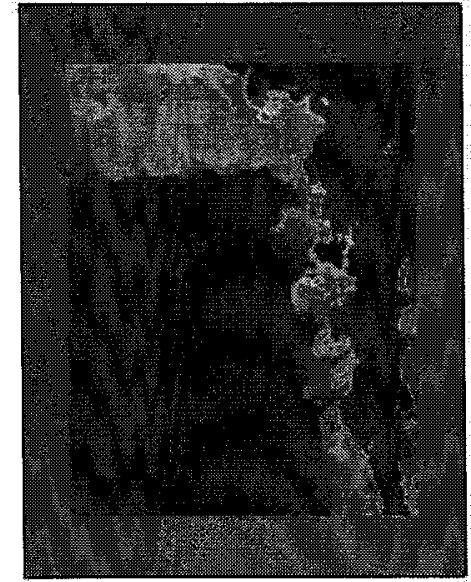

(a) Make-up air velocity $=0.5 \mathrm{~m} / \mathrm{s}$

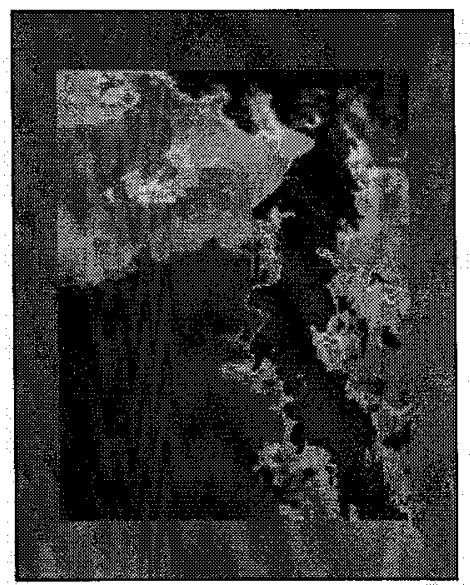

(c) Make-up air velocity $=1.25 \mathrm{~m} / \mathrm{s}$

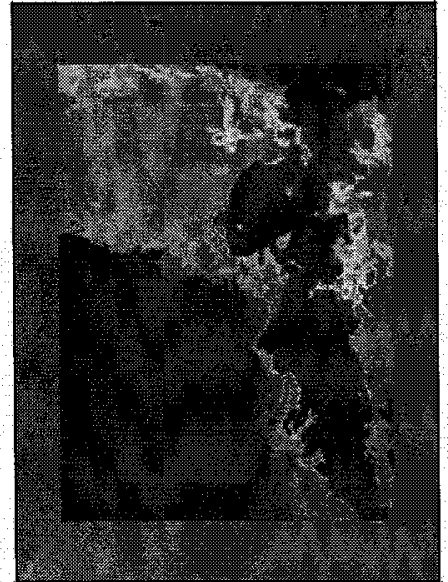

Protod

temp

C.

230

227

224

221

218

(b) Make-up air velocity $=1.0 \mathrm{~m} / \mathrm{s}$

215

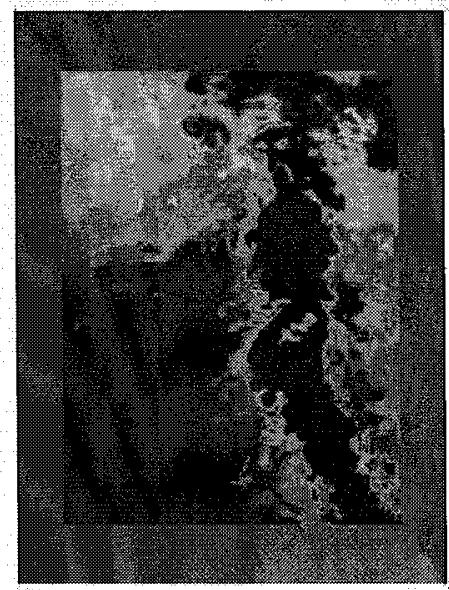

212

20.9

20.6

203

201

Figure 5.73 Temperature contours in $60-\mathrm{m}$ tall atrium on a vertical plane through the fire center, fire size $=2.5 \mathrm{MW}, 2.5 \mathrm{~m}$ from opening 


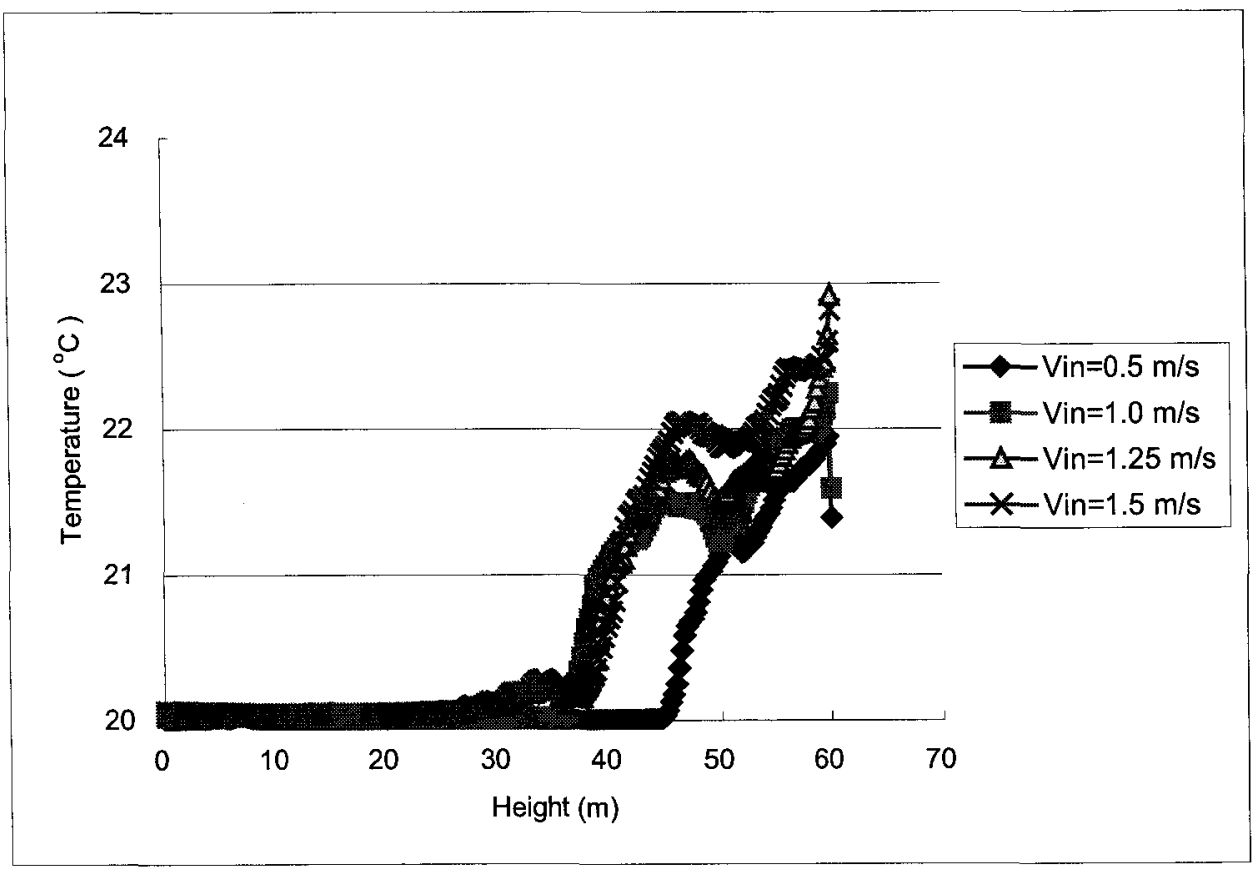

Figure 5.74 Temperature profiles in 60-m tall atrium with $2.5-\mathrm{MW}$ fire, $2.5 \mathrm{~m}$ from opening

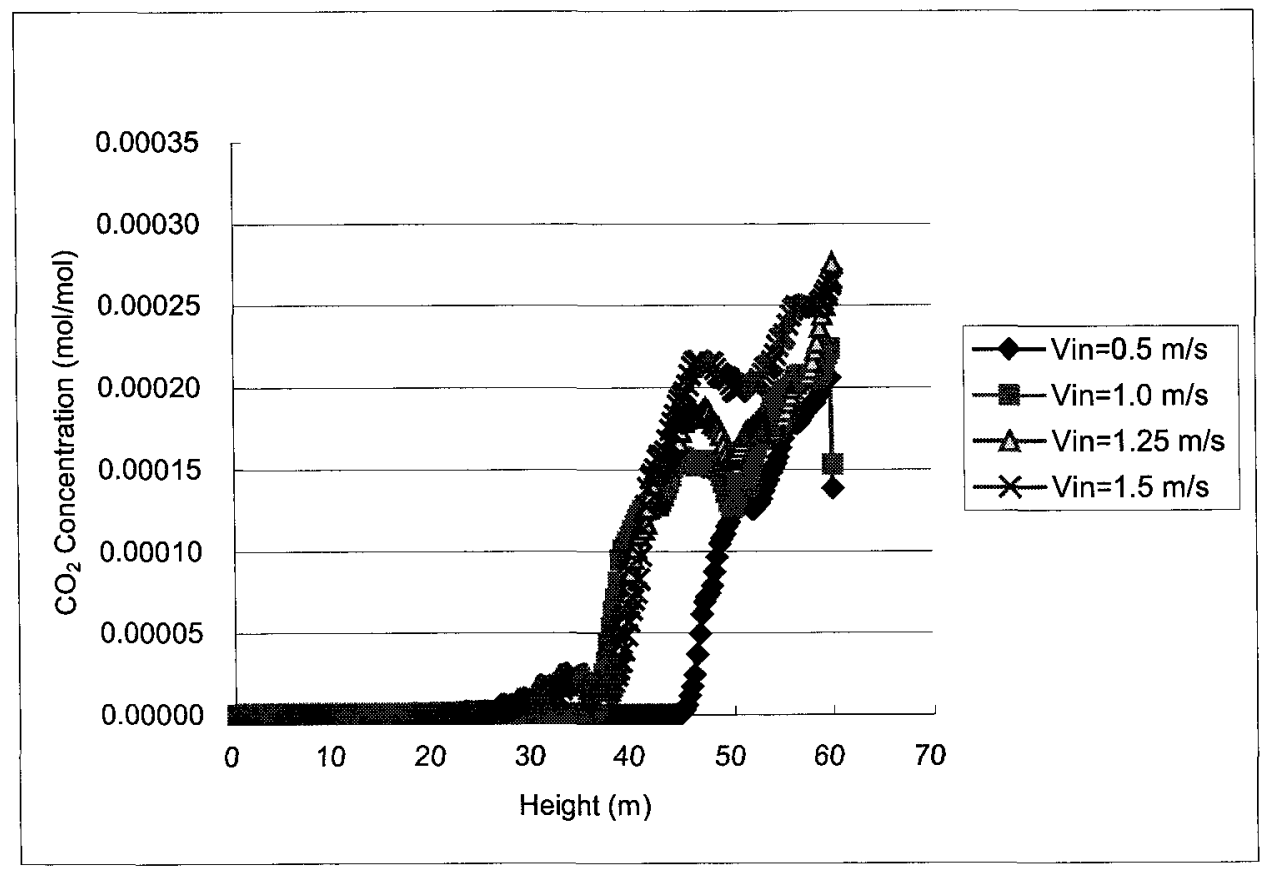

Figure $5.75 \mathrm{CO}_{2}$ profiles in $60-\mathrm{m}$ tall atrium with 2.5-MW fire, $2.5 \mathrm{~m}$ from opening 
The results with the 5-MW fire are shown in Figures 5.76 to 5.78. Figure 5.76 shows that the fire plume at $300 \mathrm{~s}$ is not affected much by the incoming air. The plume remains strong and does not tilt much. The hot layer height however seem to decrease with the increased velocity. This can also be seen in the temperature and $\mathrm{CO}_{2}$ profiles at Point 7 depicted in Figure 5.77 and Figure 5.78.

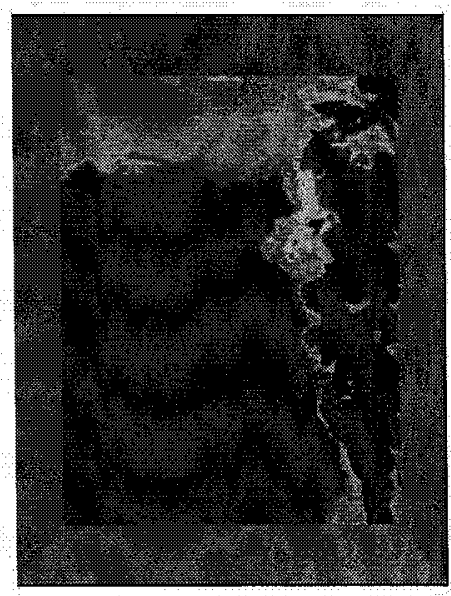

(a) Make-up air velocity $=0.5 \mathrm{~m} / \mathrm{s}$

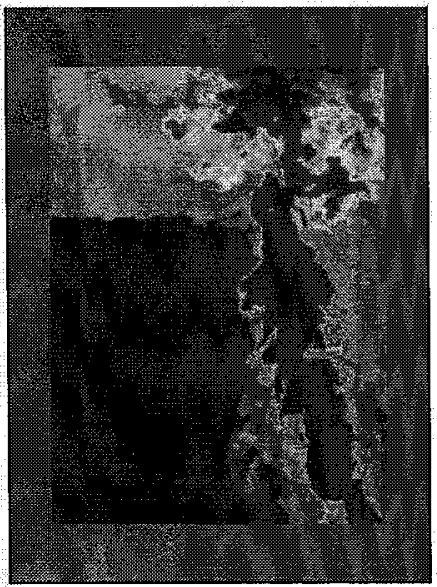

(c) Make-up air velocity $=1.25 \mathrm{~m} / \mathrm{s}$

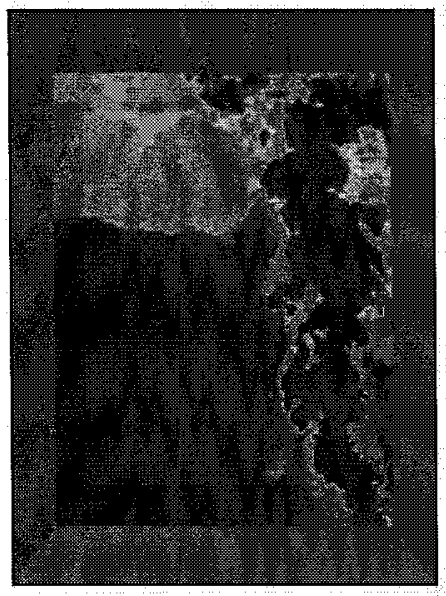

Flot 30

temp

Q

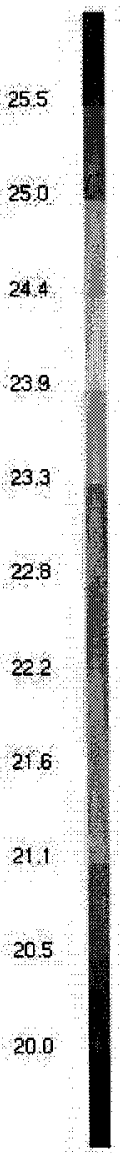

Figure 5.76 Temperature contours in $60-\mathrm{m}$ tall atrium on a vertical plane through the fire center, fire size $=5 \mathrm{MW}, 2.5 \mathrm{~m}$ from opening 


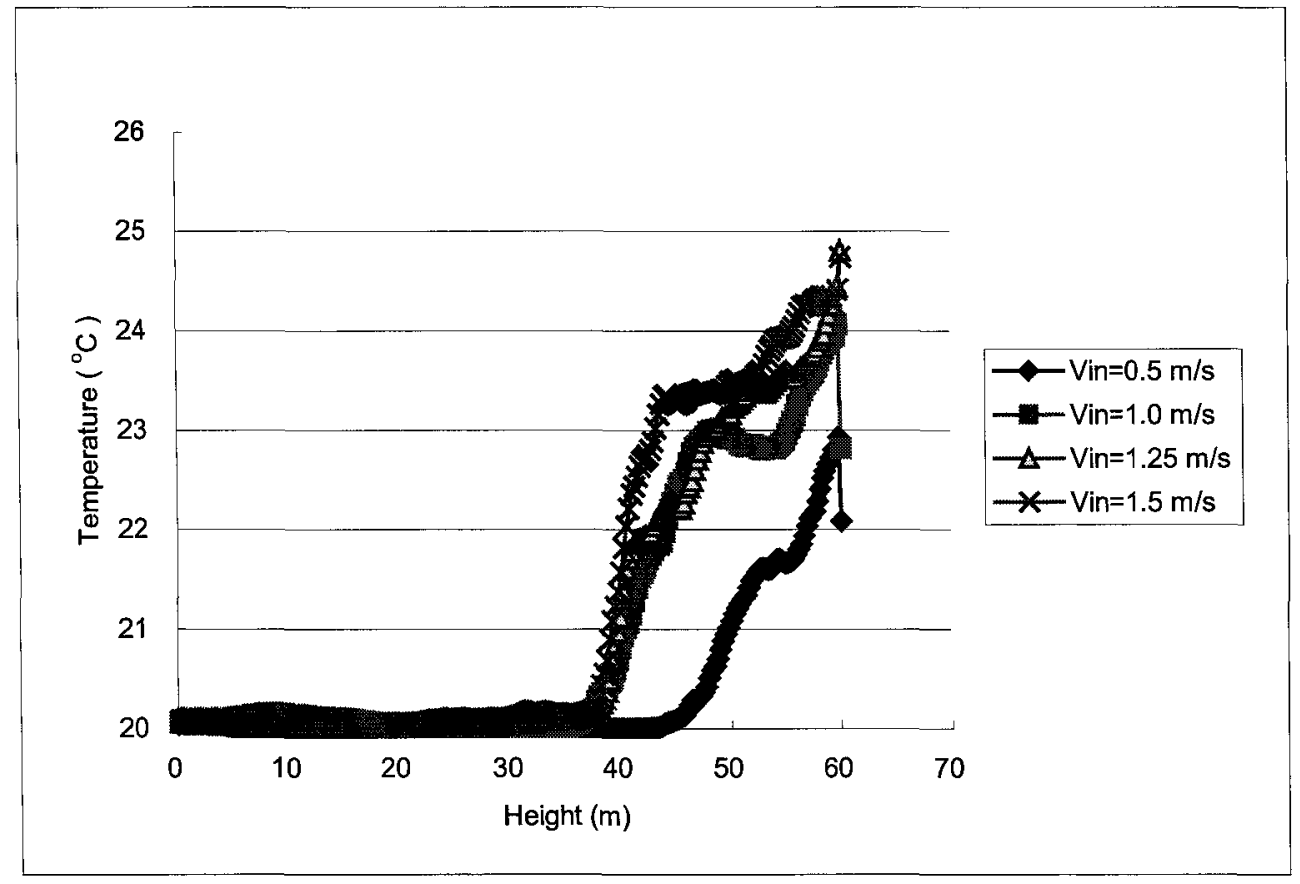

Figure 5.77 Temperature profiles in 60-m tall atrium with 5-MW fire, $2.5 \mathrm{~m}$ from opening

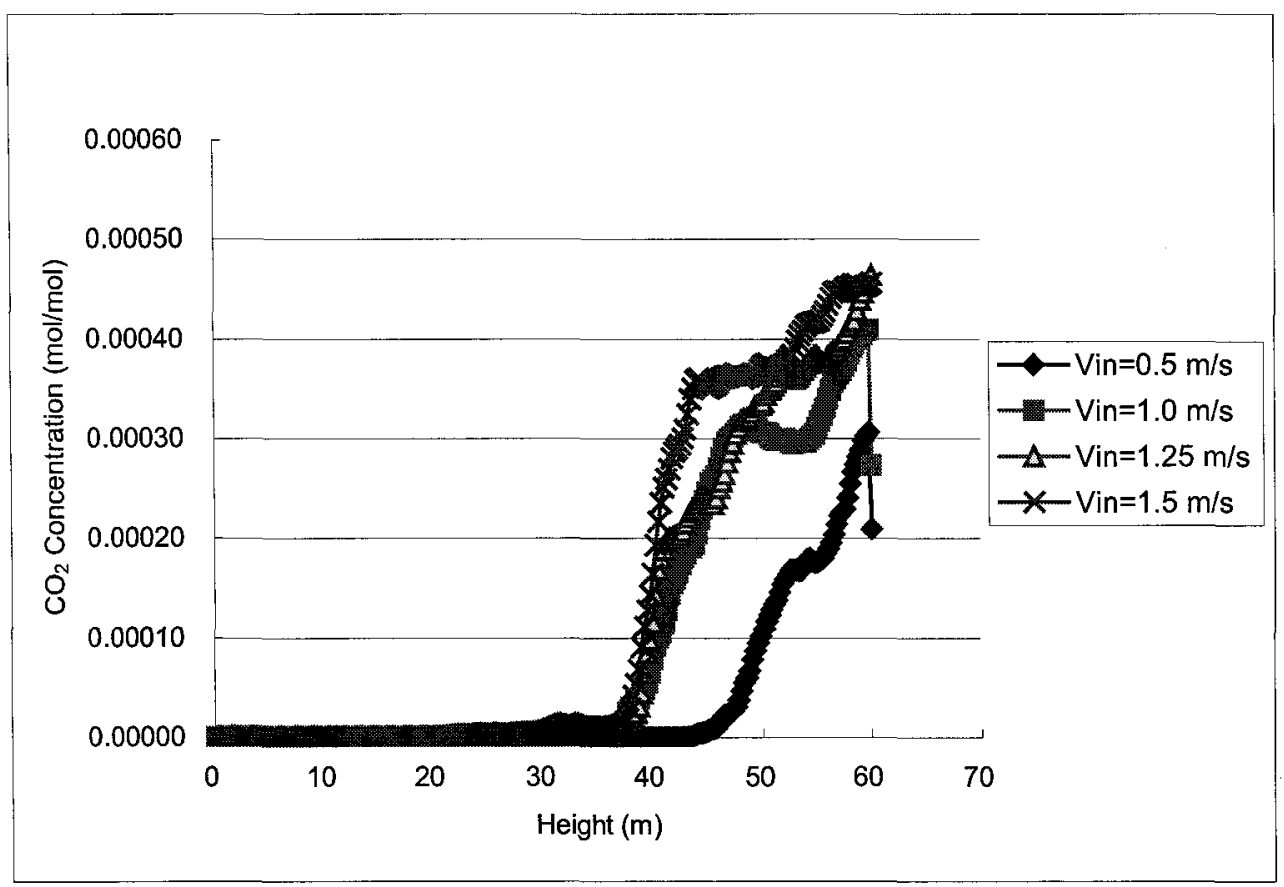

Figure $5.78 \mathrm{CO}_{2}$ profiles in $60-\mathrm{m}$ tall atrium with $5-\mathrm{MW}$ fire, $2.5 \mathrm{~m}$ from opening 
Table 5.9 shows the interface heights for the $60-\mathrm{m}$ tall atrium with the fire located 2.5 $\mathrm{m}$ from the opening. The results show that the interface heights for the 1-MW fire at $2.5 \mathrm{~m}$ from the opening are lower than those with the 1-MW fire at $5 \mathrm{~m}$ from the opening. The interface heights, however for the larger fires and $2.5 \mathrm{~m}$ are higher than those with the fires at $5 \mathrm{~m}$. 
Table 5.9 Interface Heights in 60- $\mathrm{m}$ tall atrium with fire $2.5 \mathrm{~m}$ from the opening

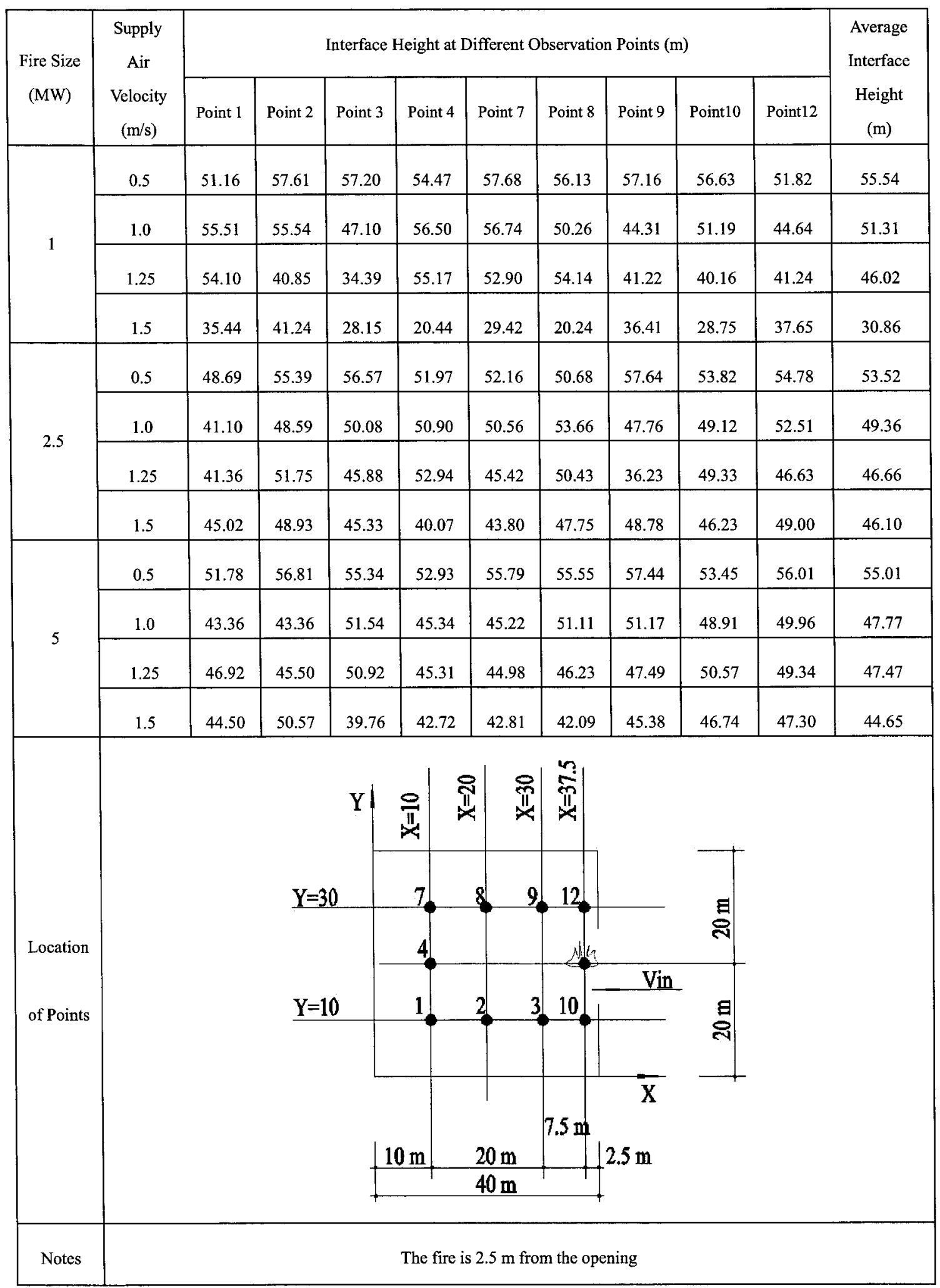




\subsection{Summaries and Discussion of Results}

This section provides an overall assessment of the impact of make-up air velocity on the interface height in the atrium. To facilitate comparison, for each atrium and fire size, the interface heights determined using the predictions of FDS have been normalized using the interface height of the $0.5-\mathrm{m} / \mathrm{s}$ velocity case. This way the relative reduction of interface height by the increasing make-up air velocities can easily be compared.

The interface heights for the $10-\mathrm{m}$ tall atrium for the three heat release rates and make-up air velocities are shown in Table 5.10. The last row presents the values obtained by dividing the interface height for each case by the interface height of the $0.5-\mathrm{m} / \mathrm{s}$ case. These values are also shown in Figure 5.79.

Table 5.10 The effect of make-up air velocity on interface height for the $10-\mathrm{m}$ tall atrium

\begin{tabular}{|l|c|c|c|c|c|c|c|c|c|c|c|c|}
\hline Fire Load & \multicolumn{3}{|c|}{$1 \mathrm{MW}$} & \multicolumn{3}{c|}{$2.5 \mathrm{MW}$} & \multicolumn{3}{c|}{$5 \mathrm{MW}$} \\
\hline $\begin{array}{l}\text { Entry Air } \\
\text { Velocity (m/s) }\end{array}$ & 0.5 & 1.0 & 1.25 & 1.5 & 0.5 & 1.0 & 1.25 & 1.5 & 0.5 & 1.0 & 1.25 & 1.5 \\
\hline $\begin{array}{l}\text { FDS predicted } \\
\text { Interface } \\
\text { Height (m) }\end{array}$ & 7.74 & 6.74 & 6.12 & 4.43 & 7.78 & 6.90 & 6.23 & 5.39 & 9.26 & 7.95 & 6.84 & 6.61 \\
\hline $\begin{array}{l}\text { Normalized } \\
\text { Interface } \\
\text { Height }\end{array}$ & 1.00 & 0.87 & 0.80 & 0.72 & 1.00 & 0.89 & 0.80 & 0.69 & 1.00 & 0.86 & 0.74 & 0.71 \\
\hline
\end{tabular}




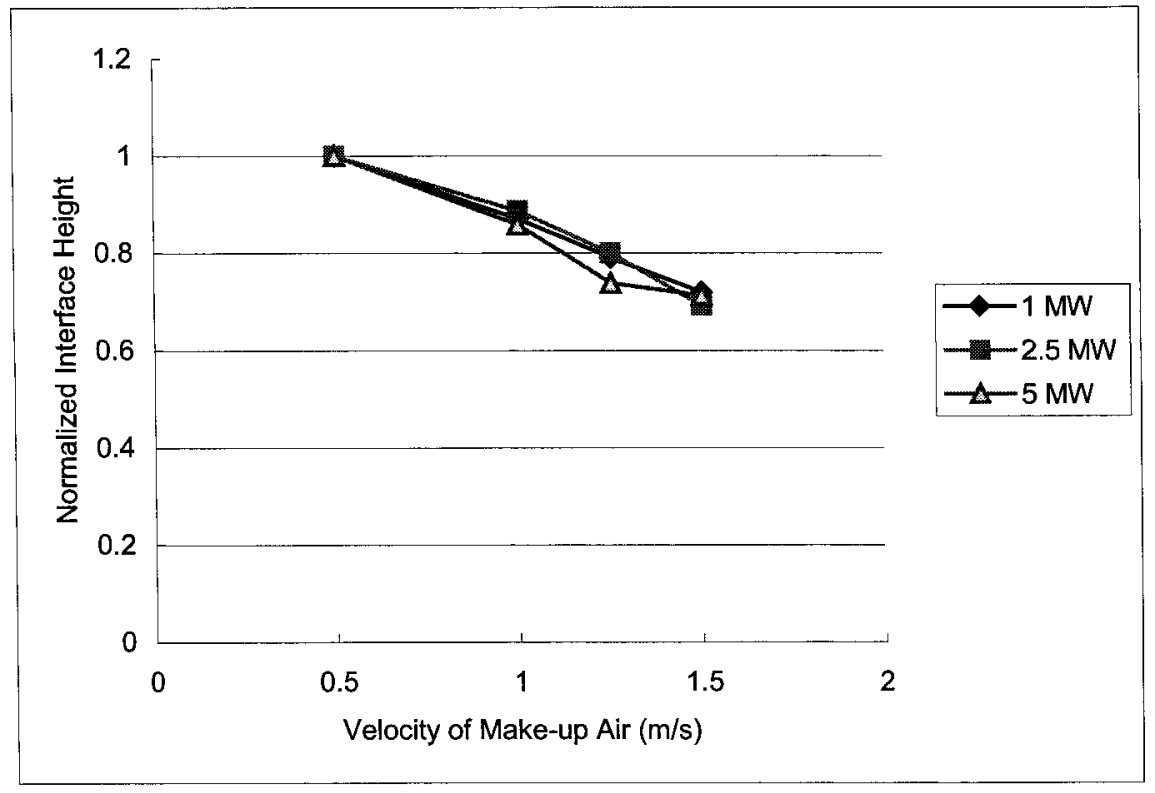

Figure 5.79 Normalized interface height of the $10-\mathrm{m}$ tall atrium

It is clear from the figure that by increasing the make-up air velocity the interface height decreases. This reduction is similar for the all fire sizes. When the velocity is $1.5 \mathrm{~m} / \mathrm{s}$, the interface height for the 1-MW fire is much lower than the other fire sizes, with a reduction of about $45 \%$.

The results for the $20-\mathrm{m}$ tall atrium are shown in Table 5.11 and plotted in Figure 5.80.

Table 5.11 The effect of make-up air velocity on interface height for the 20-m tall atrium

\begin{tabular}{|l|c|c|c|c|c|c|c|c|c|c|c|c|}
\hline Fire Load & \multicolumn{3}{|c|}{$1 \mathrm{MW}$} & \multicolumn{3}{c|}{$2.5 \mathrm{MW}$} & \multicolumn{3}{c|}{$5 \mathrm{MW}$} \\
\hline $\begin{array}{l}\text { Entry Air } \\
\text { Velocity (m/s) }\end{array}$ & 0.5 & 1.0 & 1.25 & 1.5 & 0.5 & 1.0 & 1.25 & 1.5 & 0.5 & 1.0 & 1.25 & 1.5 \\
\hline $\begin{array}{l}\text { FDS predicted } \\
\text { Interface } \\
\text { Height (m) }\end{array}$ & 17.05 & 15.03 & 12.70 & 11.31 & 16.77 & 14.21 & 13.75 & 13.35 & 19.18 & 15.24 & 13.64 & 12.73 \\
\hline \multicolumn{1}{|c|}{ Normalized } & 1.00 & 0.86 & 0.73 & 0.65 & 1.00 & 0.85 & 0.82 & 0.80 & 1.00 & 0.79 & 0.71 & 0.66 \\
\hline
\end{tabular}




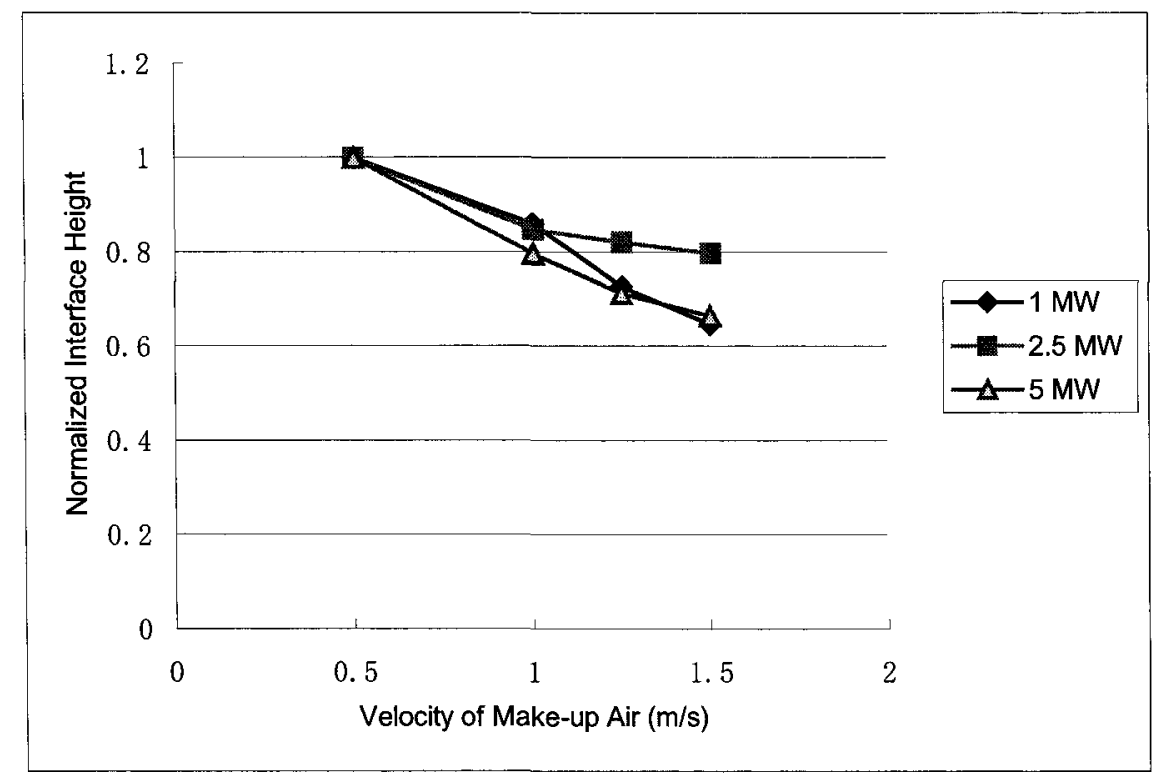

Figure 5.80 Normalized interface height of the $20-\mathrm{m}$ tall atrium

As with the 10-m tall atrium, for all fire sizes, the increased make-up air velocities decrease the interface heights. It is interesting to see that the $2.5-\mathrm{MW}$ fire produces the least decrease in the interface height when the make-up air velocity is $1.25 \mathrm{~m} / \mathrm{s}$ and $1.5 \mathrm{~m} / \mathrm{s}$.

Table 5.12 shows the results for the $30-\mathrm{m}$ tall atrium with the fire located $5 \mathrm{~m}$ from the opening and Table 5.13 with the fire located $2.5 \mathrm{~m}$ from the opening. The normalized heights for these cases are plotted in Figures 5.81 and 5.82 respectively. The relative decrease of the interface height for this atrium is less than the decrease of the smaller atria. When the fire is $5-\mathrm{m}$ from the opening the reduction of the interface height for the 1-MW fire and $1.5 \mathrm{~m} / \mathrm{s}$ make-up air velocity is only $15 \%$. The other fire sizes yield similar reductions, with a maximum of $25 \%$ decrease when the velocity is 
$1.5 \mathrm{~m} / \mathrm{s}$. When the fire is $2.5 \mathrm{~m}$ from the opening the reductions are larger except for the $2.5-\mathrm{MW}$ fire which has a reduction of less than $20 \%$.

Table 5.12 The effect of make-up air velocity on interface height for the 30-m tall atrium (1)

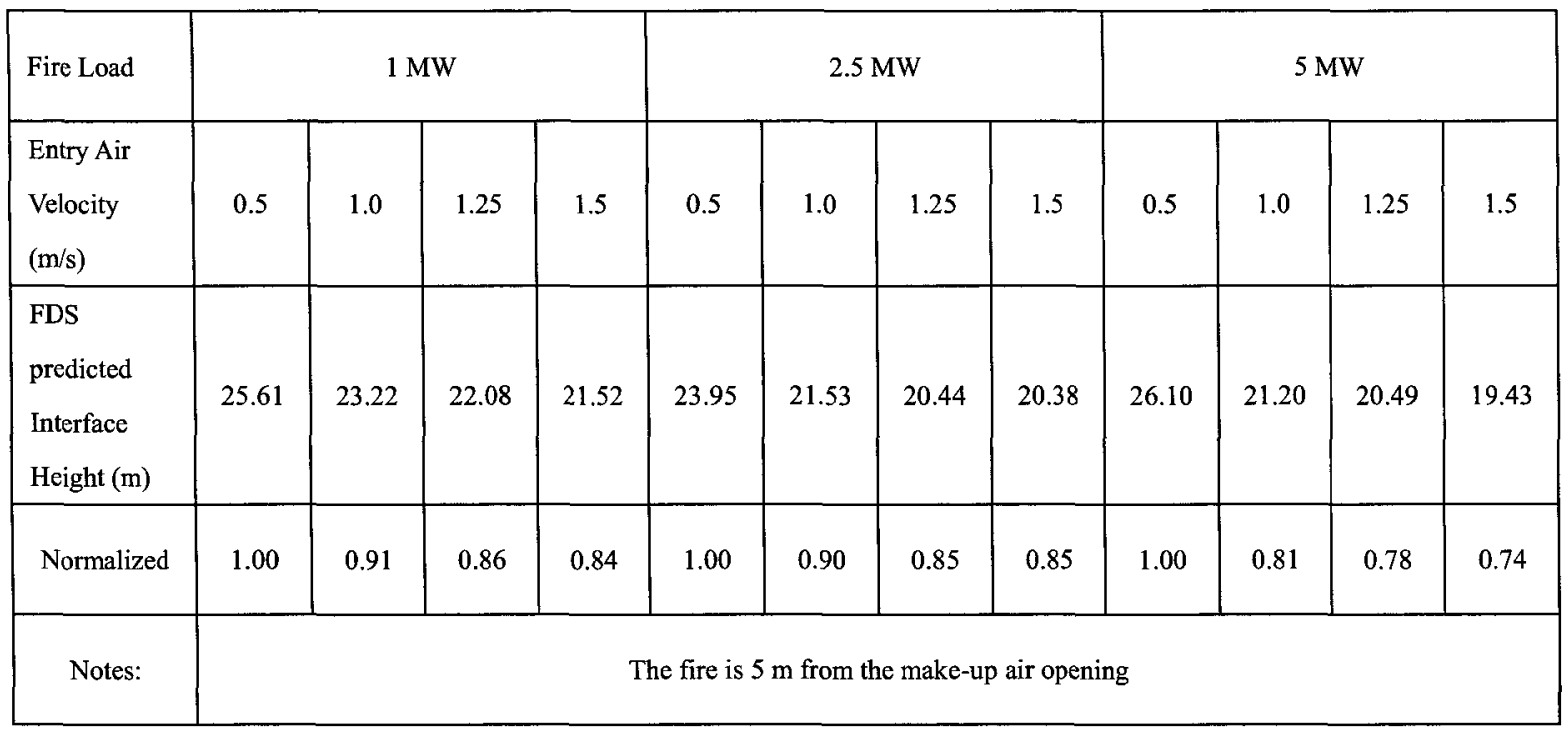

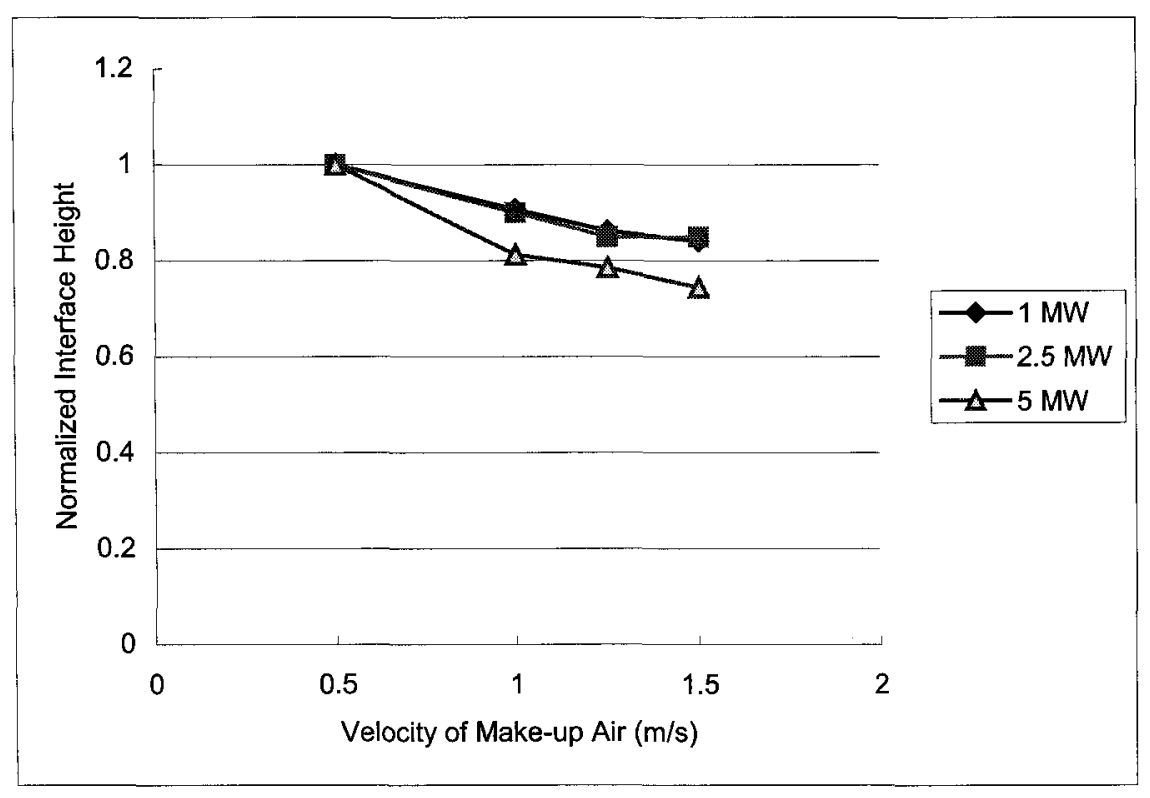

Figure 5.81 Normalized interface height of $30-\mathrm{m}$ tall atrium with fire $5 \mathrm{~m}$ from the opening 
Table 5.13 The effect of make-up air velocity on interface height for the 30-m tall atrium (2)

\begin{tabular}{|c|c|c|c|c|c|c|c|c|c|c|c|c|}
\hline Fire Load & \multicolumn{4}{|c|}{$1 \mathrm{MW}$} & \multicolumn{4}{|c|}{$2.5 \mathrm{MW}$} & \multicolumn{4}{|c|}{$5 \mathrm{MW}$} \\
\hline $\begin{array}{l}\text { Entry Air } \\
\text { Velocity } \\
(\mathrm{m} / \mathrm{s})\end{array}$ & 0.5 & 1.0 & 1.25 & 1.5 & 0.5 & 1.0 & 1.25 & 1.5 & 0.5 & 1.0 & 1.25 & 1.5 \\
\hline $\begin{array}{l}\text { FDS } \\
\text { predicted } \\
\text { Interface } \\
\text { Height (m) }\end{array}$ & 25.47 & 23.54 & 19.98 & 17.96 & 24.62 & 21.03 & 19.99 & 20.19 & 26.14 & 21.48 & 19.59 & 19.18 \\
\hline Normalized & 1.00 & 0.92 & 0.78 & 0.71 & 1.00 & 0.85 & 0.81 & 0.82 & 1.00 & 0.82 & 0.75 & 0.73 \\
\hline Notes: & & & & & & $f$ & $\mathrm{ma}$ & Sir & & & & \\
\hline
\end{tabular}

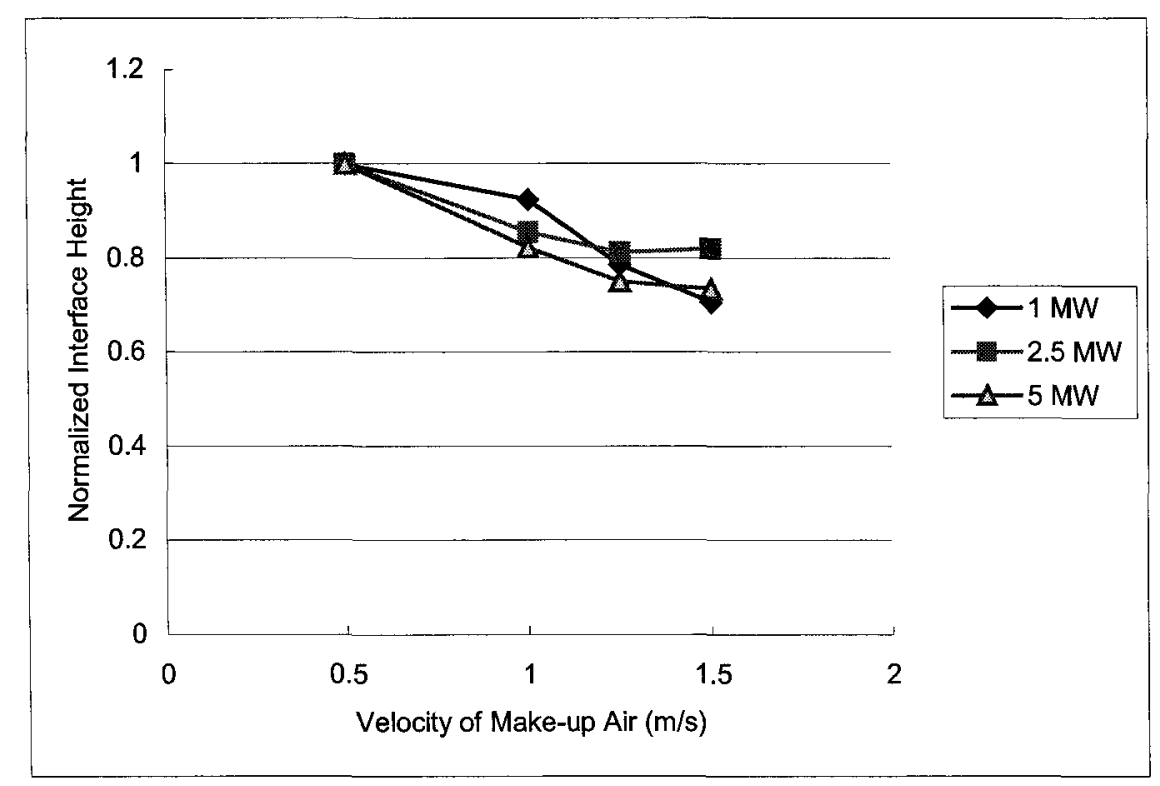

Figure 5.82 Normalized interface height of $30-\mathrm{m}$ tall atrium with fire $2.5 \mathrm{~m}$ from the opening

The results for the 50-m tall atrium shown in Table 5.14 and Figure 5.83 for the cases with the fire located $5 \mathrm{~m}$ from the opening and Table 5.15 and Figure 5.84 for the cases with the fire $2.5 \mathrm{~m}$ are quite interesting. The reduction of the interface is about the same for the two fire locations except for the $5 \mathrm{MW}$ fire cases, which show that 
the fire close to the opening yields a smaller reduction than the fire at $5 \mathrm{~m}$ from the opening.

Table 5.14 The effect of make-up air velocity on interface height for the 50-m tall atrium (1)

\begin{tabular}{|c|c|c|c|c|c|c|c|c|c|c|c|c|}
\hline Fire Load & \multicolumn{4}{|c|}{$1 \mathrm{MW}$} & \multicolumn{4}{|c|}{$2.5 \mathrm{MW}$} & \multicolumn{4}{|c|}{$5 \mathrm{MW}$} \\
\hline $\begin{array}{l}\text { Entry Air } \\
\text { Velocity } \\
(\mathrm{m} / \mathrm{s})\end{array}$ & 0.5 & 1.0 & 1.25 & 1.5 & 0.5 & 1.0 & 1.25 & 1.5 & 0.5 & 1.0 & 1.25 & 1.5 \\
\hline $\begin{array}{l}\text { FDS } \\
\text { predicted } \\
\text { Interface } \\
\text { Height (m) }\end{array}$ & 46.53 & 41.27 & 39.44 & 37.25 & 42.68 & 38.66 & 36.77 & 36.32 & 47.42 & 36.03 & 34.48 & 34.39 \\
\hline Normalized & 1.00 & 0.89 & 0.85 & 0.80 & 1.00 & 0.91 & 0.86 & 0.85 & 1.00 & 0.76 & 0.73 & 0.73 \\
\hline Notes: & \multicolumn{12}{|c|}{ The fire is $5 \mathrm{~m}$ from the make-up air opening } \\
\hline
\end{tabular}

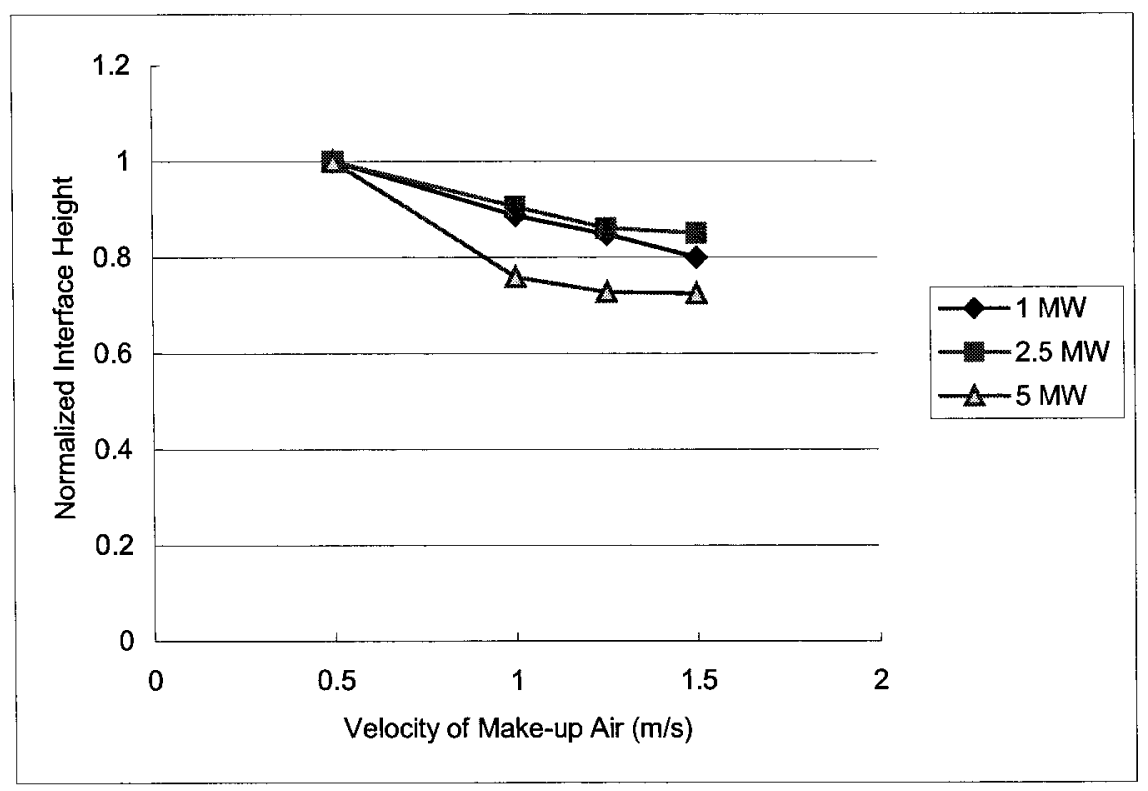

Figure 5.83 Normalized interface height of $50-\mathrm{m}$ tall atrium with fire $5 \mathrm{~m}$ from the opening 
Table 5.15 The effect of make-up air velocity on interface height for the 50-m tall atrium (2)

\begin{tabular}{|c|c|c|c|c|c|c|c|c|c|c|c|c|}
\hline Fire Load & \multicolumn{4}{|c|}{$1 \mathrm{MW}$} & \multicolumn{4}{|c|}{$2.5 \mathrm{MW}$} & \multicolumn{4}{|c|}{$5 \mathrm{MW}$} \\
\hline $\begin{array}{l}\text { Entry Air } \\
\text { Velocity } \\
(\mathrm{m} / \mathrm{s})\end{array}$ & 0.5 & 1.0 & 1.25 & 1.5 & 0.5 & 1.0 & 1.25 & 1.5 & 0.5 & 1.0 & 1.25 & 1.5 \\
\hline $\begin{array}{l}\text { FDS } \\
\text { predicted } \\
\text { Interface } \\
\text { Height (m) }\end{array}$ & 45.69 & 41.13 & 38.26 & 35.51 & 43.31 & 38.32 & 37.23 & 37.04 & 43.94 & 39.22 & 36.59 & 35.81 \\
\hline Normalized & 1.00 & 0.90 & 0.84 & 0.78 & 1.00 & 0.88 & 0.86 & 0.86 & 1.00 & 0.89 & 0.83 & 0.81 \\
\hline Notes: & & & & & & fro & & & & & & \\
\hline
\end{tabular}

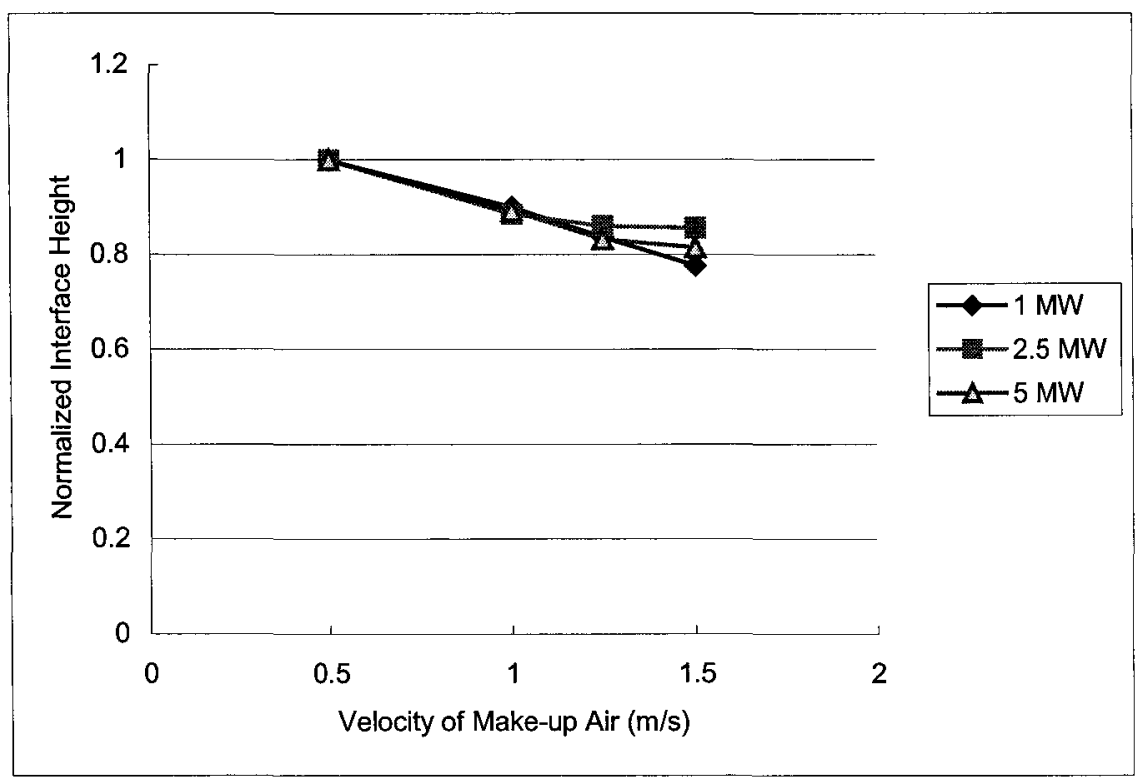

Figure 5.84 Normalized interface height of $50-\mathrm{m}$ tall atrium with fire $2.5 \mathrm{~m}$ from the opening

The results of the $60-\mathrm{m}$ tall atrium shown in Tables 5.16 and 5.17 for the two fire locations and plotted in Figures 5.85 and 5.86. The results are similar to the results of the 50-m tall atrium. The main difference is the result of the 1-MW fire located $2.5 \mathrm{~m}$ from the opening and a make-up air velocity of $1.5 \mathrm{~m} / \mathrm{s}$, which cause a $45 \%$ reduction 
of the interface height. This may be due to the fact that increase of the temperatures and $\mathrm{CO}_{2}$ concentrations for this case are quite small; hence the calculation of the interface height is very sensitive to small variations of these variables.

Table 5.16 The effect of make-up air velocity on interface height for the 60-m tall atrium (1)

\begin{tabular}{|c|c|c|c|c|c|c|c|c|c|c|c|c|}
\hline Fire Load & \multicolumn{4}{|c|}{$1 \mathrm{MW}$} & \multicolumn{4}{|c|}{$2.5 \mathrm{MW}$} & \multicolumn{4}{|c|}{$5 \mathrm{MW}$} \\
\hline $\begin{array}{l}\text { Velocity } \\
(\mathrm{m} / \mathrm{s})\end{array}$ & 0.5 & 1.0 & 1.25 & 1.5 & 0.5 & 1.0 & 1.25 & 1.5 & 0.5 & 1.0 & 1.25 & 1.5 \\
\hline $\begin{array}{l}\text { FDS } \\
\text { predicted } \\
\text { Interface } \\
\text { Height (m) }\end{array}$ & 56.2 & 50.32 & 50.12 & 45.39 & 51.24 & 45.26 & 44.98 & 42.75 & 56.81 & 44.74 & 42.26 & 44.16 \\
\hline Normalized & 1.00 & 0.90 & 0.89 & 0.81 & 1.00 & 0.88 & 0.88 & 0.83 & 1.00 & 0.79 & 0.74 & 0.78 \\
\hline Notes: & & & & & re & from & nake & r op & & & & \\
\hline
\end{tabular}

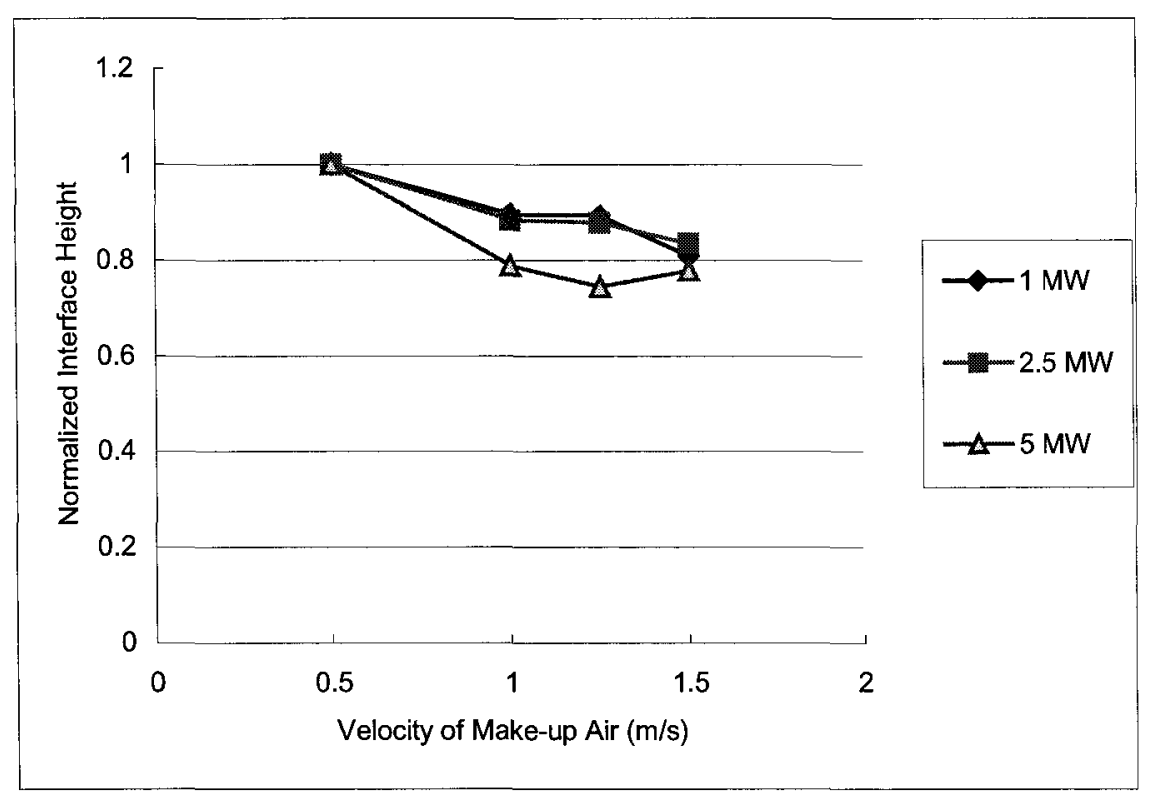

Figure 5.85 Normalized interface height of $60-\mathrm{m}$ tall atrium with fire $5 \mathrm{~m}$ from the opening 
Table 5.17 The effect of make-up air velocity on interface height for the 60-m tall atrium (2)

\begin{tabular}{|c|c|c|c|c|c|c|c|c|c|c|c|c|}
\hline Fire Load & \multicolumn{4}{|c|}{$1 \mathrm{MW}$} & \multicolumn{4}{|c|}{$2.5 \mathrm{MW}$} & \multicolumn{4}{|c|}{$5 \mathrm{MW}$} \\
\hline $\begin{array}{l}\text { Velocity } \\
(\mathrm{m} / \mathrm{s})\end{array}$ & 0.5 & 1.0 & 1.25 & 1.5 & 0.5 & 1.0 & 1.25 & 1.5 & 0.5 & 1.0 & 1.25 & 1.5 \\
\hline $\begin{array}{l}\text { FDS } \\
\text { predicted } \\
\text { Interface } \\
\text { Height (m) }\end{array}$ & 55.54 & 51.31 & 46.02 & 30.86 & 53.52 & 49.36 & 46.66 & 46.10 & 55.01 & 47.77 & 47.47 & 44.65 \\
\hline Normalized & 1.00 & 0.92 & 0.83 & 0.56 & 1.00 & 0.92 & 0.87 & 0.86 & 1.00 & 0.87 & 0.86 & 0.81 \\
\hline Notes: & & & & & & & & & & & & \\
\hline
\end{tabular}

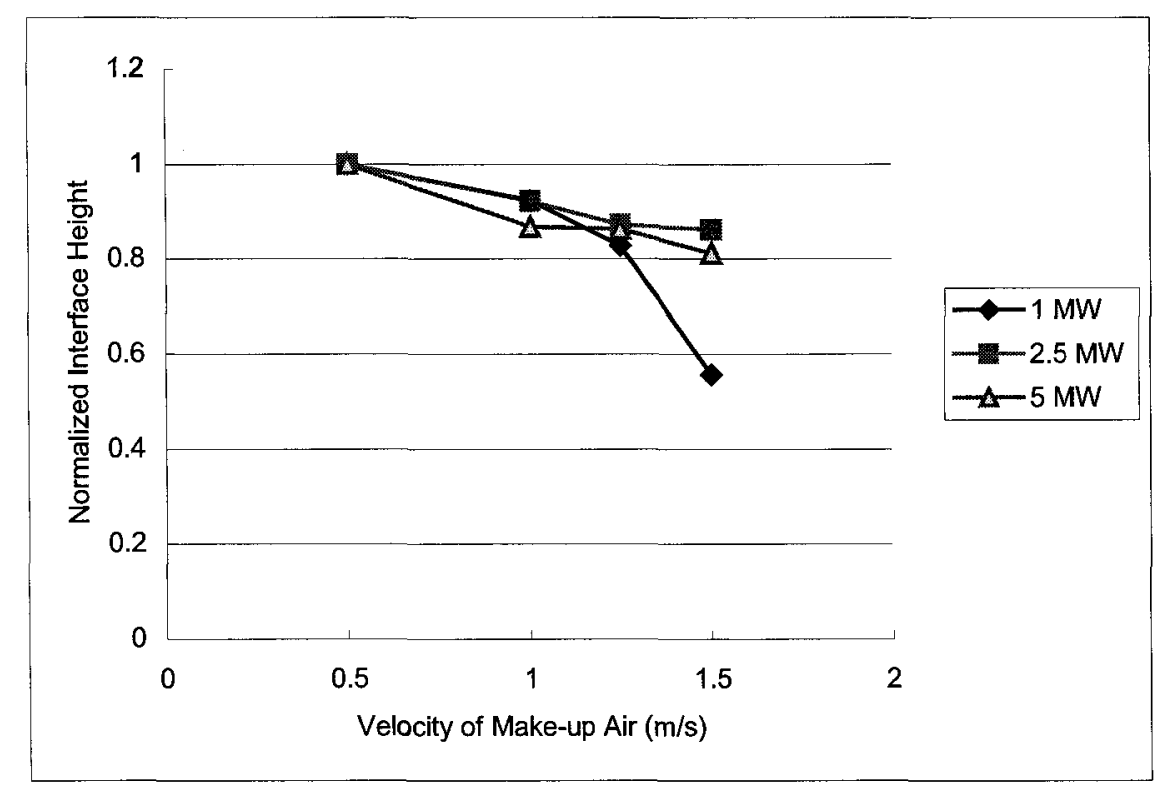

Figure 5.86 Normalized interface height of $60-\mathrm{m}$ tall atrium with fire $2.5 \mathrm{~m}$ from the opening 


\subsection{Summary.}

This section presented the relative reductions of the interface height due to the increased make-up air velocities for all cases studied. The following observations can be made from this analysis.

- For all cases studied, the increased make-up air velocity decreases the interface height in the atrium.

- The interface height is affected more by the increased velocities when the atrium height is less than $20 \mathrm{~m}$, in which case the decrease is as high as $45 \%$. The maximum decrease for the larger atria is about $20 \%$ except for the case of the 1-MW fire and velocity of $1.5 \mathrm{~m} / \mathrm{s}$ and the fire located at $2.5 \mathrm{~m}$ from the opening. 


\section{Chapter 6}

\section{Conclusions and Recommendations}

The objective of this research was to study the impact of the make-up air velocity on the smoke layer height in an atrium in order to determine whether the $1 \mathrm{~m} / \mathrm{s}$ criterion for make-up air velocity is too restrictive. The computer model Fire Dynamics Simulator (FDS) has been used to model the fire, the exhaust system and to predict the conditions in the atrium.

Preliminary results indicated that FDS is sensitive to grid size, especially in the region near the fire. In regions away from the fire it was found that a grid size of $0.25 \mathrm{~m}$ resulted in results that were similar to those with a $0.125 \mathrm{~m}$ grid.

FDS was used to study the impact of wind speed on flames and to compare the results with other studies. This exercise showed that FDS is capable of modeling the impact of wind speed on the fire plume. The results also indicated that a velocity of up to 1.0 $\mathrm{m} / \mathrm{s}$ causes minimal flame tilt for all size of fires simulated. The air velocity affects the plume of small size fires considerably more than the plume of large fires. Higher velocities cause significantly disruptions to the plume.

This study also considered the impact of different locations of wall openings on the fire plume in an atrium and found that placing openings at the bottom and the top of 
the atrium causes the least disruption to the plume. The largest plume disturbance occurred when the opening was at the mid-height of the wall.

The investigation of the impact of the make-up air velocity on the fire plume and interface height for different fire locations and fire sizes concluded the following:

The make-up air velocity restriction of $1.0 \mathrm{~m} / \mathrm{s}$ is not conservative as it causes plume disturbance that result in lower interface heights.

$>$ If, however the $1.0 \mathrm{~m} / \mathrm{s}$ criterion is acceptable then the $1.25 \mathrm{~m} / \mathrm{s}$ may also be considered as this increase produces results similar to the $1.0 \mathrm{~m} / \mathrm{s}$ velocity.

$>$ The impact of the make-up air velocity is more pronounced in atria with height less than $20 \mathrm{~m}$.

\section{Recommendations for future work}

Although the results of this research showed that the make-up air velocity affects the interface height in an atrium and that the $1 \mathrm{~m} / \mathrm{s}$ criterion is not too restrictive, before this topic can be laid to rests more work should be done. The following are recommendations for future work.

Perform simulations with openings on multiple walls.

$>$ Conduct additional simulations with fire located in different locations.

Perform experiments to verify the results of the computer simulations.

$>$ Perform simulations with different arrangements for the smoke exhaust locations. 


\section{Chapter 7}

\section{References}

1. NFPA 92B, Guide for smoke management systems in malls, atria, and large areas, NFPA, 2005.

2. Klote, J.K., and Milke, J.A., Design of smoke management systems. Atlanta: American Society of Heating, Refrigerating and Air-Conditioning Engineers, Inc, 1992.

3. Klote, J.H., and Milke, J.A., Principles of smoke management, ASHRAE, Atlanta, GA, pp. 206, 2002.

4. Mudan, K.S., and Croce, P. A., Fire hazard calculations for large open hydrocarbon fires. SFPE Handbook of Fire Protection Engineering, NFPA, Quincy, MA, 1998.

5. Mudan, K.S., and Croce, P.A., Fire hazard calculations for large open hydrocarbon fires. SFPE Handbook of Fire Protection Engineering, NFPA, Quincy, MA, pp. 3-271, 2002.

6. Hansell, G.O., and Morgan, H.P., Design approaches for smoke control in atrium building, BR-258, Building Research Establishment, Garston, UK, 1994.

7. Hinckley, P.L., Smoke and heat venting, SFPE Handbook of Fire Protection Engineering, National Fire Protection Association, Quincy, MA, pp. 3-160 to 3-173, 1995.

8. McGrattan, K., and Forney, G., Fire dynamics simulator (version 3) user's guide. National institute of Standards and Technology, 2002. 
9. McGrattan, K., and Forney, G., Fire dynamics simulator (version 4) user's guide. National institute of Standards and Technology, 2004.

10. Hadjisophocleous, G.V., and McCartney, C.J., Guidelines for the use of CFD simulations for fire and smoke modeling. ASHRAE symposium paper 2005 Summer ASHRAE meeting, Denver.

11. Souza, V.T.D., and Milke, J.A., Modeling smoke layer interface height as a function of make-up air supply velocity for atrium design. Fire Safety Journal 6, 2004.

12. Heskestad, G., Engineering relations for fire plumes, Fire Safety Journal, Vol. 7, pp. 25-32, 1984.

13. Zukoski, E.E., Properties of fire plumes. Combustion Fundamentals of Fire, Cox, G., Ed., Academic Press, London, 1995.

14. Heskestad, G., Fire plume air entrainment according to two competing assumptions, Twenty-first Symposium (International) on Combustion, Combustion Institute, Pittsburgh, Pa., pp. 111-120, 1986.

15. Thomas, P.H., The size of flame from natural fires. $9^{\text {th }}$ Symposium (International) on Combustion, The Combustion Institute, Pittsburgh, pp. 844-859, 1962.

16. LNG safety research program, Report IS 3-1, American Gas Association, 1974.

17. Chow, W.K., Smoke development and engineering aspects of smoke-extraction systems for atria in Hong Kong. Fire and Materials, Vol.17, pp.71-77, 1993

18. Wong, L.T, Scale modeling studies of smoke filling. International Journal on Engineering Performance-Based Fire Codes, No. 3, Vol.3, pp.118-127, 2001. 
19. Cooper, L.Y., Harkleroad, M., Quintiere, J., and Rinkinen, W., An experimental study of upper hot layer stratification in full-scale multi-room fire scenarios. Journal of Hear Transfer, Vol. 104, pp. 741-749, 1982.

20. Lougheed, G.D., Hadjisophocleous, G.V., and Cao, S., Numerical study of the effectiveness of atrium smoke exhaust systems. ASHRAE Transactions, Vol. 105, pt. 1, pp. 1-17, 1999.

21. Lougheed, G.D., Hadjisophocleous, G.V., McCartney, C., and Taber, B.C., Large-scale physical model studies for an atrium smoke exhaust system. ASHRAE Transactions, Vol. 105, pt. 1, pp.1-23, 1999.

22. Bukowski, R.W., Fire models, the future is now. NFPA Journal, No. 85, Vol. 2, pp. 60-69, 1991.

23. Jones, W.W., A review of compartment fire models. Nat. Bur. Of Stand. (US.), NBSIR 83-2684, 1983.

24. Nowler, S.P., Enclosure environment characterization testing for the baseline validation of computer fire simulation codes. Sandia National Laboratories, 1987.

25. Mulholland, G., et al., Smoking filling in an enclosure. New York: American Society of Mechanical Engineers, pp. 81 - HT - 8, 1981.

26. Cooper, L.Y., et al., An experimental study of upper hot layer stratification in full scale multiroom fire scenarios. American Society of Mechanical Engineers, pp. $81-\mathrm{HT}-9,1981$.

27. Hagglund, B., et al., Smoking filling experiments in a $6 \times 6 \times 6$ meter enclosure. National Defense Research Institute of Sweden, 1985. 
28. Hadjisophocleous, G.V., and Fu, Z. Experimental study and zone modeling of smoke movement in a model atrium. ASHRAE Presented in Hawaii.

29. Mudan, K.S., and Croce, P.A., Fire hazard calculations for large open hydrocarbon fires, The SFPE Handbook of Fire Protection Engineering $\left(2^{\text {nd }} e d\right)$, P.J. DiNenno (ed.), National Fire Protection Association, Quincy, MA02269, Vol.3, pp. 197-240, 1995.

30. Yi, L., Chow, W.K., Li, Y.Z., and Huo, R. A simple two-layer zone model on mechanical exhaust in an atrium. Building and Environment, Vol.8, 2004.

31. McGrattan, K., Fire dynamics simulator (version 4) technical reference guide. National institute of Standards and Technology, 2004.

32. Design approach for atrium exhaust effectiveness (899-RP). NRC, Client Report, A-4414.11, 1999. 